LIVE LARGE IN SMALL SPACES

DANAE BLOXHAM 


\section{LIVE LARGE IN SMALL SPACES}

\section{Danae Siobhan Bloxham}

A 120 point thesis submitted to the School of Architecture \& Design, Victoria University of Wellington, in fulfillment of the requirements for the degree of Masters in Architecture (Prof)

Victoria University of Wellington

2017 


\section{ACKNOWLEDGEMENTS}

I would like to thank the support of my supervisor Mark Southcombe, for his continuous motivation and guidance throughout this past year, the support has been invaluable.

Mum and Dad, thank you for your continual encouragement and support over the last 5 years.

To my friends, you have made my time in Wellington the most enjoyable.

And finally, to Russell, I could not have done this without you. Your support has been incredible.

${ }^{*}$ All work marked with an * has been previously examined for the visual presentation assessment 


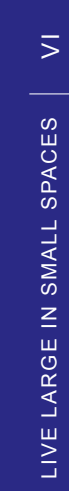


"Can greater access to desirable housing occur through interrelated well designed small homes?" 
"Is life better lived wanting less, and, if so, how can this be achieved without sacrificing aesthetics, light, space, flow and other fundamentals of good architecture?"

(Foster, 2015) 


\section{ABSTRACT}

The 'kiwi dream' of home ownership has become less attainable because of increases in housing costs. Unaffordability is linked with the house price to income ratio, especially within urban environments where incomes have fallen to $50 \%$ below property prices. This not only affects access to affordable housing, but also access to quality housing. A home should be dry, warm and safe - these are the key fundamentals of quality housing and people of all ages should have access to a home in which these qualities are not compromised by their personal income. A home that is well insulated, heated, structurally sound and located close to transport nodes should be affordable for all New Zealanders.

Home ownership in New Zealand plays a central role in our national identity. The design research will cater for the younger generation that are most affected by the housing crisis - first home buyers ranging between the ages of 25 and 30 , wanting to get their foot on the property ladder and realise the 'kiwi dream' of home ownership.

A key issue of New Zealand's high house prices is the influence of land costs. An intensification strategy to reduce the amount of land per dwelling is one solution to combat house prices. Intensification of New Zealand's cities should also be targeted at an increase in urban housing along railway corridors, transport hubs and in town centres, improving both housing affordability and transport costs - two main factors of household expenditure. When these two strategies are combined with careful design and space efficient techniques, solutions can be created within a small footprint, without compromising comfort and functionality.

This thesis proposition is tested in Khandallah, one of Wellington's wealthiest suburbs, with high access to public amenities, transport and services. The suburb already has the infrastructure needed to accommodate intensification. It's comparatively low density housing holds great opportunity for medium density and infill development. The suburb has a large range of community facilities, schools and open spaces and dwellings are typically of low density with large sites - developed through meandering roads and col-desacs of single houses on single sections. With Wellingtons housing needs changing, a greater need for diverse housing throughout all of Wellington's suburbs is necessary to cater for the growing population. Khandallah has the infrastructure to support intensification and young families should have the option of buying into a suburb of their choice.

The aim of this research is to develop a model for affordable, high quality suburban housing that is responsive to New Zealand's housing preferences, providing a solution for greater access to desirable housing that occurs through interrelated well designed small homes. This thesis argues that doubling suburban density while retaining site coverage will make housing more affordable. This is tested through planning and spatial design strategies of a range of small homes less than $80 \mathrm{~m} 2$. These homes will be developed through examining the design of internal spaces; the limits of the small home and relationship with external spaces and the limits of the suburb. The relationship between homes will allow a development of private and common utilities, optimising open space and shared amenities within an intensification strategy for the suburb. The design research produces an argument for clusters of small homes as future housing that will have a positive impact on New Zealand's housing affordability as 'starter homes' and 'downsize homes'. 


\section{PREFACE}

Inspiration for this research topic came from the Japanese 9 Tsubo house originally designed by architect Makoto Masuzawa. A tsubo is a square the size of two tatami mats and 9 of these make a square of only $49 \mathrm{~m} 2$. Also known as the absolute minimum house, the design catered to Japanese families, for more affordable housing following the destruction of WWII and despite the small foot print, this compact design is incredibly efficient.

We can learn a lot from Japanese architecture and their solutions for compact living - the variety in unity, their conformity to a mode of living, simplicty in design, functionality and connection with nature (Harada, 2011). Doing away with the notion that 'big is better' altering our lifestyle choices and by utilising our space and belongings, we can learn to live more sustainably with better, affordable, smaller homes. 
9TSUBO HOUSE
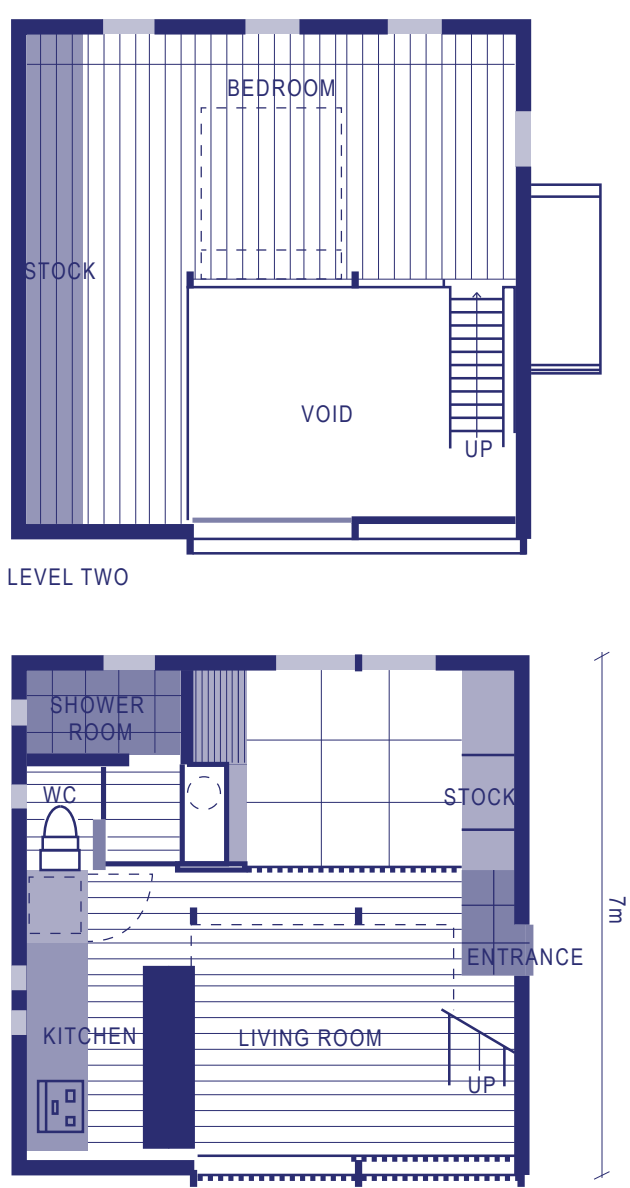

LEVEL ONE

$7 \mathrm{~m}$ 


\section{CONTENTS}

$\begin{array}{ll}\text { ACKNOWLEDGEMENTS } & \mathrm{v} \\ \text { ABSTRACT } & \text { vii } \\ \text { PREFACE } & \mathrm{x} \\ \text { CONTENTS } & \mathrm{xii}\end{array}$

01 INTRODUCTION

Methodology 08

02 CONTEXT 10

Efficient small spaces $\quad 14$

Successful inner city small spaces 18

Ineficient existing small spaces 19

Space efficient design principles + Guidelines $\quad 20$

03 EXPERIMENTAL DESIGN / THE SMALL HOME 22

Implementing the design guidelines 24

Who am I housing / generation rent $\quad 26$

Site $\quad 28$

Massing on site $\quad 36$

Experimental Design 38

Affordability Design $\quad 40$

Affordability Analysis $\quad 44$

04 INITIAL DESIGN / LIMITS OF A SINGLE SITE

Common space vs private space $\quad 52$

Density + Parking $\quad 54$

Design development $\quad 56$

Initial design $\quad 58$

Where to next / findings and reflection 64

05 CONCEPT DESIGN / SMALL HOMES WITHIN A SUBURB 66

Wellington DPH $\quad 68$

$\begin{array}{ll}\text { Intensification zoning } & 70\end{array}$

Khandallah housing models $\quad 72$

$\begin{array}{ll}\text { Traumhaus Funari } & 76\end{array}$

Hagen Island $\quad 77$

Infill opportunities $\quad 78$

Site 1 redevelopment $\quad 80$

Where to next / findings and reflection 104

06 DEVELOPED DESIGN / SMALL HOMES + TEST SITES 106

Site $2+3$ Test $\quad 113$

Affordability revisited $\quad 120$

Where to next / findings and reflection 124

07 CONCLUSIONS / A CLUSTERED HOUSING TYPOLOGY 126

Refinement of Design 130

District Plan / Rules and regulations $\quad 136$

Implications of the suburb 138

Live Large In Small Spaces / Conclusion $\quad 142$

A clustered housing typology 144

BIBLIOGRAPHY 148

LIST OF FIGURES $\quad 152$ 


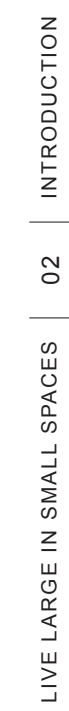




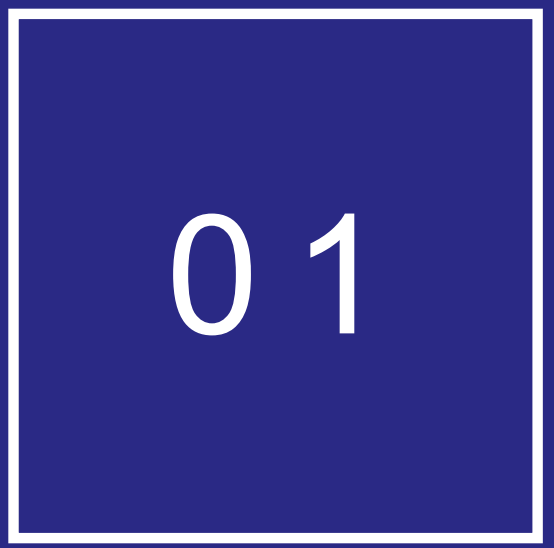

INTRODUCTION 


\section{INTRODUCTION}

Owning your own home in New Zealand is something generations of Kiwis have aspired. Home ownership provides a sense of social security and community belonging. It is common that homeowners are more involved with their community, as they tend to live there longer and therefore have more of an interest to invest in a positive environment. It is also proven that, residents living in their own home are more satisfied than those renting - particularly renters with children who are least happy (Equab \&Equab, 2015).

Not only does home ownership benefit a person's quality of life and increases their stake in the community, it offers financial security. In recent years New Zealand's house prices have risen 7 percent a year, allowing homeowners to reap the rewards - their house sometimes earning more than they do - while those left renting, find it increasingly difficult to reach the bottom rung on the property ladder (Equab \& Equab, 2015).

Research shows that in the 1950s, the average house cost 2.1 times the annual salary and by 2010 that ratio was around 8.37 times (Bruce, 2014) - this outlines how unaffordable New Zealand's houses have become, topping the list of house price-to-incomes globally (fig 1.01).

As Philipa Howden-Chapman discusses, it is people who don't own a house that are significantly impacted. With access to affordable, quality housing declining, a larger percentage of people are left living in unregulated and often poor quality rental homes (Howden-Chapman, 2015). It is the younger generation who are missing out on the accumulation of wealth that a home provides.

"unable to realise the Kiwi dream of home ownership; not being able to save enough for retirement or a rainy day; and being forced to rent, which remains significantly inferior to ownership in terms of stability and comfort."

(Equab \& Equab, 2015)

The younger generation are left behind while a massive inequality in wealth develops between those in and out of the property market (Equab \& Equab, 2015).

Proven links between housing and land cost put rising land prices at the top of the list of factors affecting housing unaffordability. Intensification is one option to combat the issue and aim to get first home buyers into their own homes. What is currently seen is a move towards townhouses and apartments, away from the stand alone dwelling.

New Zealand's suburban housing has long been defined by the 'Quarter acre Pavlova Paradise' - single detached dwellings on large parcels of land at relatively low density, characterise suburban lifestyle (Laxon, 2016). However, the growth of our cities has resulted in an urban sprawl that makes this lifestyle increasingly unattainable and with house prices continuing to rise, a solution for more affordable and efficient homes is needed. To reduce the cost of housing there is a need to reduce the amount of land that is consumed and alter the perception of small house living. 


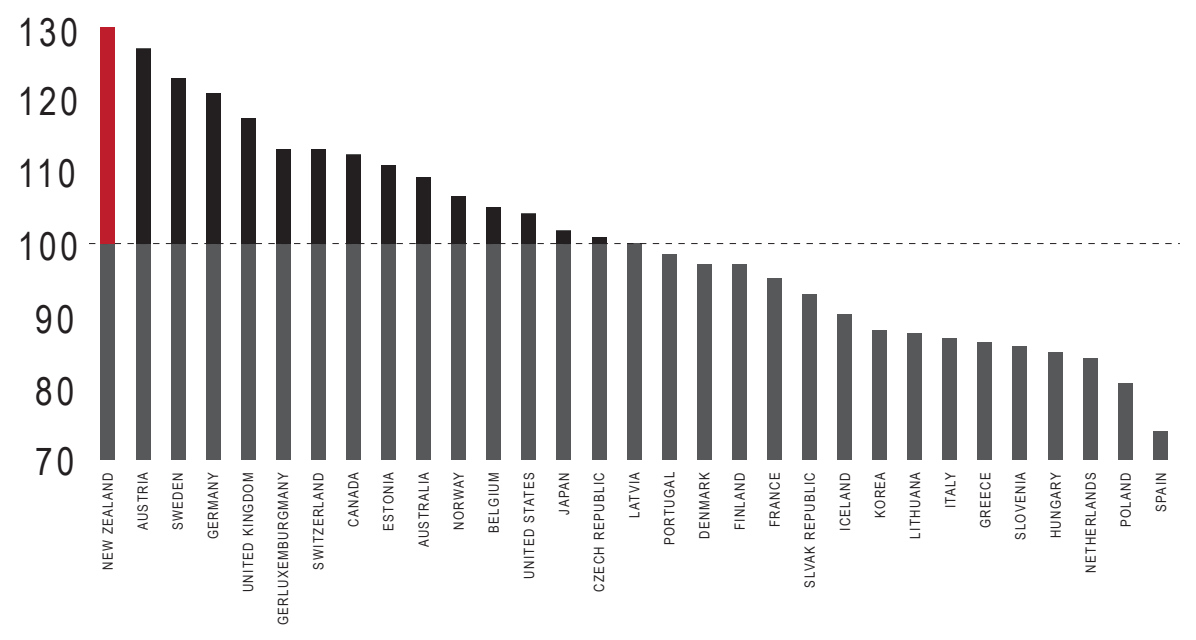

HOUSE PRICE-TO-INCOME RATIO AROUND THE WORLD

'NZ TOPS IMF'S HOUSING UNAFFORDABILITY LIST'

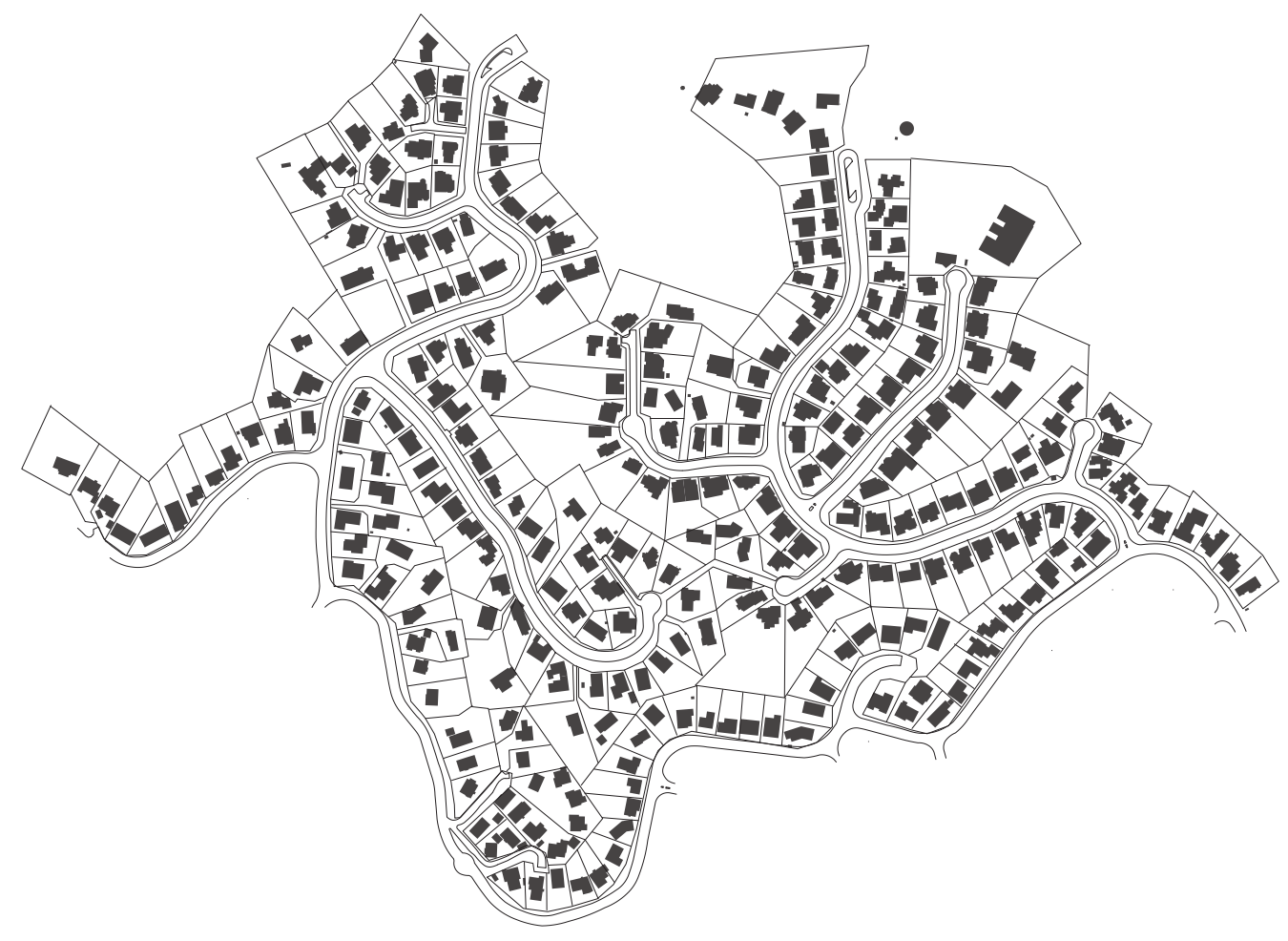



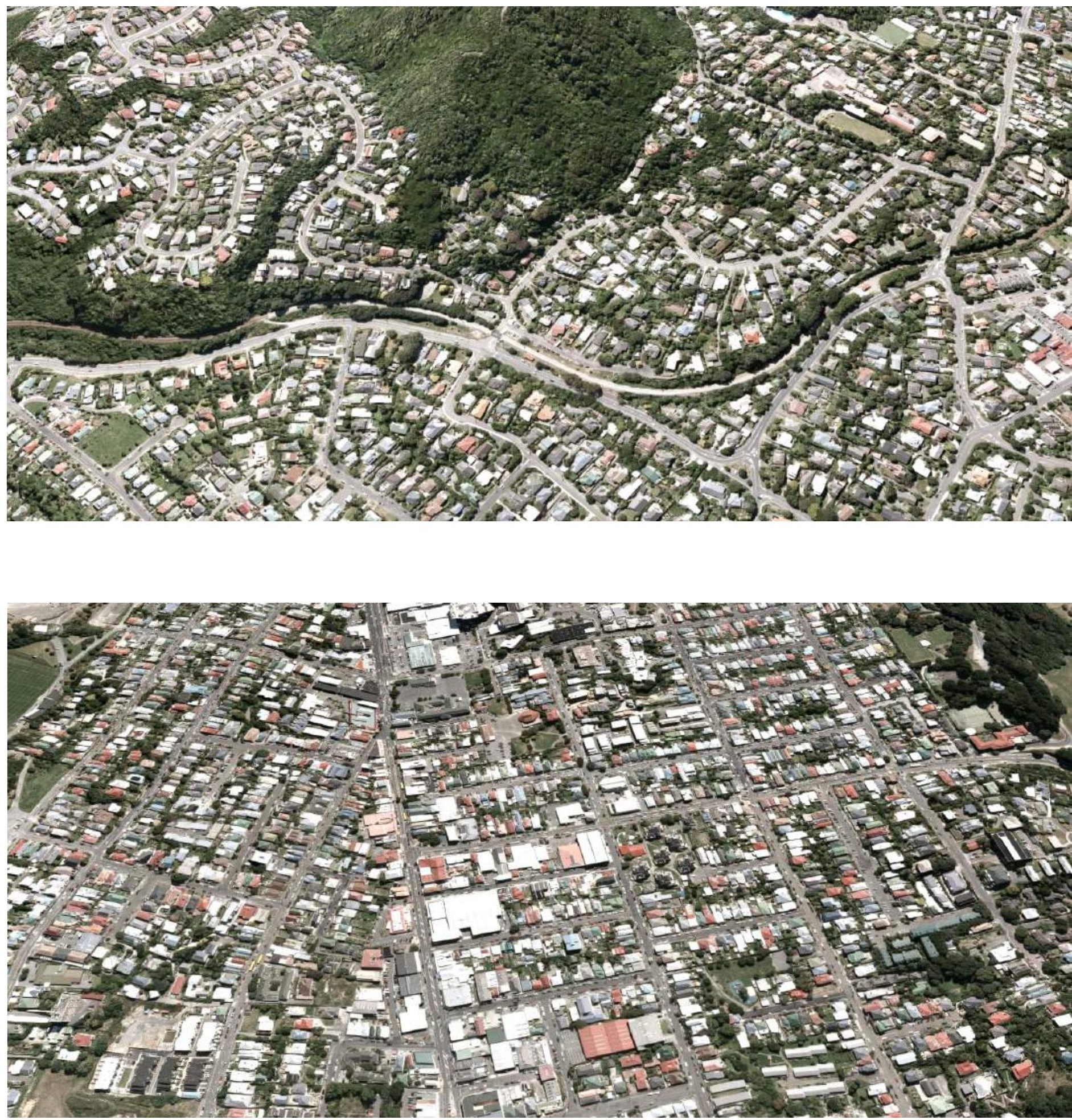
In a context of New Zealand's preferences of independent houses on their own land, how can we design more efficiently and effectively whilst also providing affordable housing? Can a solution for greater access to desirable housing occur through interrelated well designed small homes? Making small houses more desirable will create affordable options through efficient use of land, space and materials.

"A General misconception exists concerning small spaces and quality. To some people, small connotes cheap or less desirable."

(Kenneth R. Tremblay, 1997)

With carefully considered design and space efficient techniques, solutions can be created within a small footprint, without compromising comfort and functionality.

The aim of this thesis is to develop a new model for affordable, high quality suburban housing that is responsive to New Zealanders housing preferences, providing a solution for greater access to desirable housing through clusters of interrelated well designed small homes. The research will test a series of small homes that range between 40 and $80 \mathrm{~m} 2$. Efficient design principles will be implemented through an iterative process to understand the detail required to live within a small footprint and reach a level of resolution that ensures a high quality of space design.

The site will be located in Khandallah, Wellington. As the city's population is growing, and while the average household size will decrease, the number of dwellings in Kaiwharawhara, Khandallah and Broadmeadows is forecast to grow to 4,200 by 2028 from 3,990 in 2013 (Wellington City Council, 2016). Khandallah is one of the city's wealthiest suburbs, making the area desirable for residents of all ages, it already has the infrastructure to support medium density development. The suburb is a perfect location to test the research and how well the suburb will cater for intensification.

Multiple sites of varying size, orientation and gradient will be considered to allow the research to investigate the effects of the changed housing patterns on the suburb and to test the site specific implications of living in small homes. The relationship each house will have to each other and the levels of density required to achieve an appropriate balance of intensification and infill development for the suburb will be determined.

The thesis argues that doubling suburban occupation density while retaining similar site coverage will make housing more affordable. An analysis of affordability at site development concept design is essential to demonstrate how downsizing the average New Zealand home can assist to combat our housing crisis within our existing suburban context.

Fig 1.03. (Top left)

Low density suburb Khandallah

Fig 1.04. (Bottom Left)

Medium density suburb Newtown 


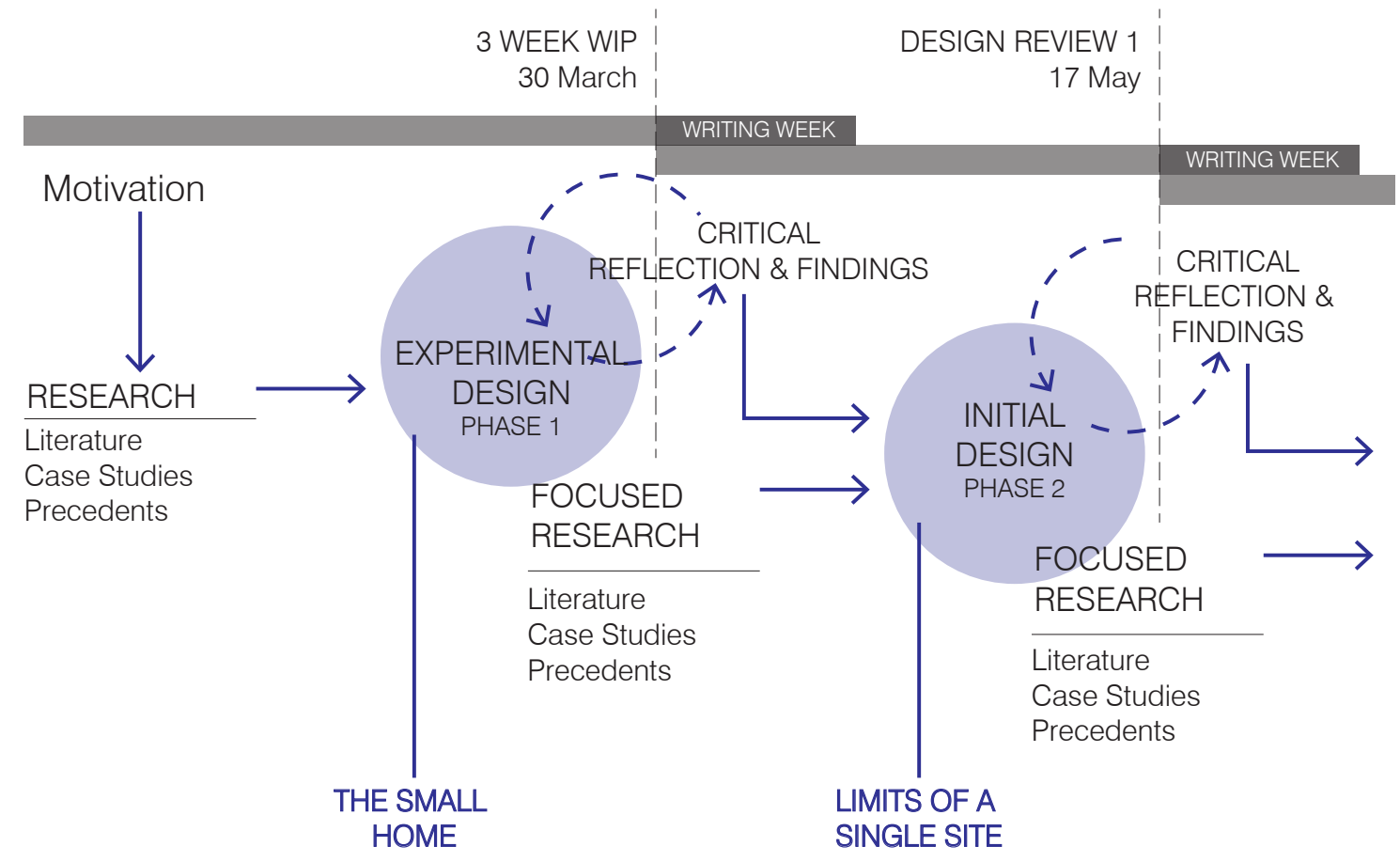

\section{METHODOLOGY}

This design-led research project has occurred through multiple iterations resulting in a rigorous developed design. The final concept design has been refined through 5 phases of design, described as;

- The small home

- Limits of a single site

- Small homes and test sites

- Small homes within a suburb

- A clustered housing typology

The design research also addresses Wellingtons District plan and the potential guidelines and zone changes needed for the proposed intensification strategy will be recommended. The final design illustrates an ideal pattern for development of infill housing and intensification of Khandallah that is currently restricted by the district plan. This project has tested sites specific to Wellington but the research findings will be relevant to other outer residential and inner residential zones throughout New Zealand. 


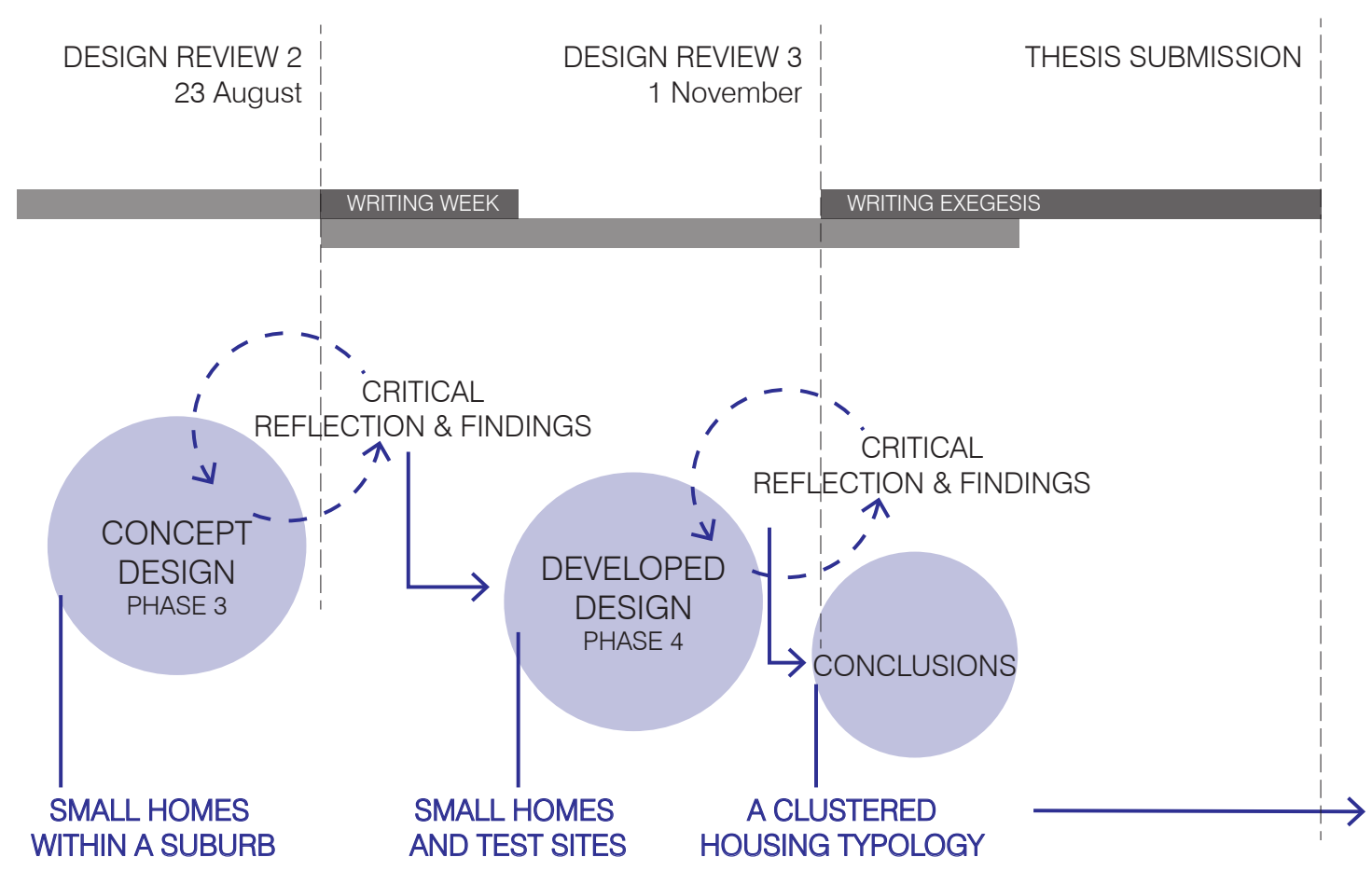




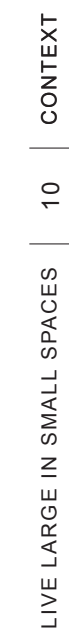




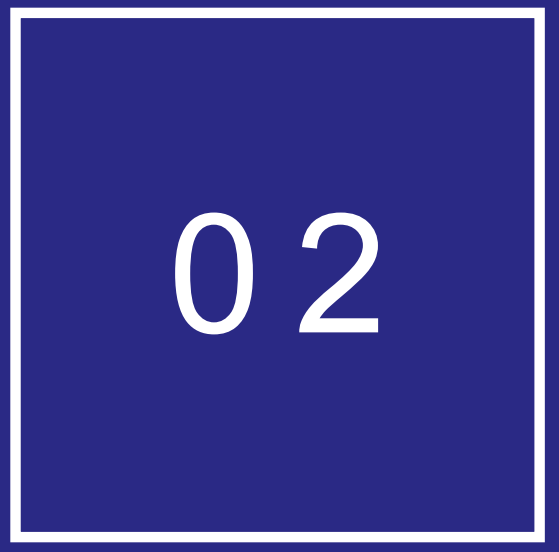

CONTEXT 


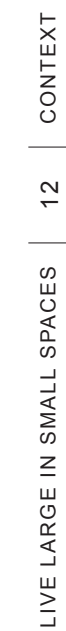


The next section investigates precedents of small homes and apartments to establish a set of guidelines and design requirements for small space architecture 


\section{EFFICIENT SMALL SPACES \\ LESS THAN $100 \mathrm{M} 2$}

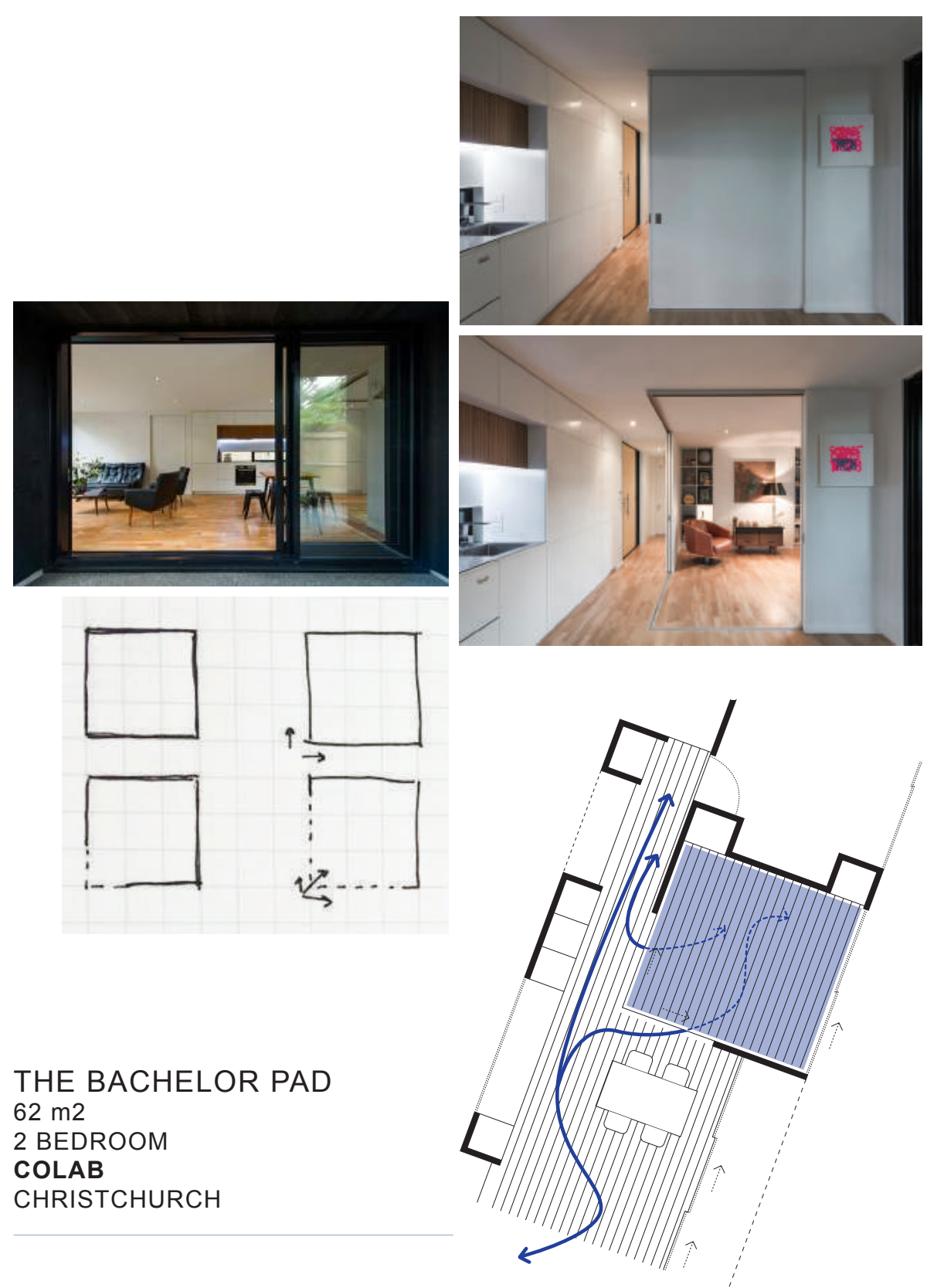

The bachelor pad implemented multifunctional rooms by separating two spaces with large recessing doors, allowing a study to convert into a spare bedroom when needed. However, when the spare bedroom is not required the Living room is extended, allowing flow through the hallway, kitchen and into the dining area. 

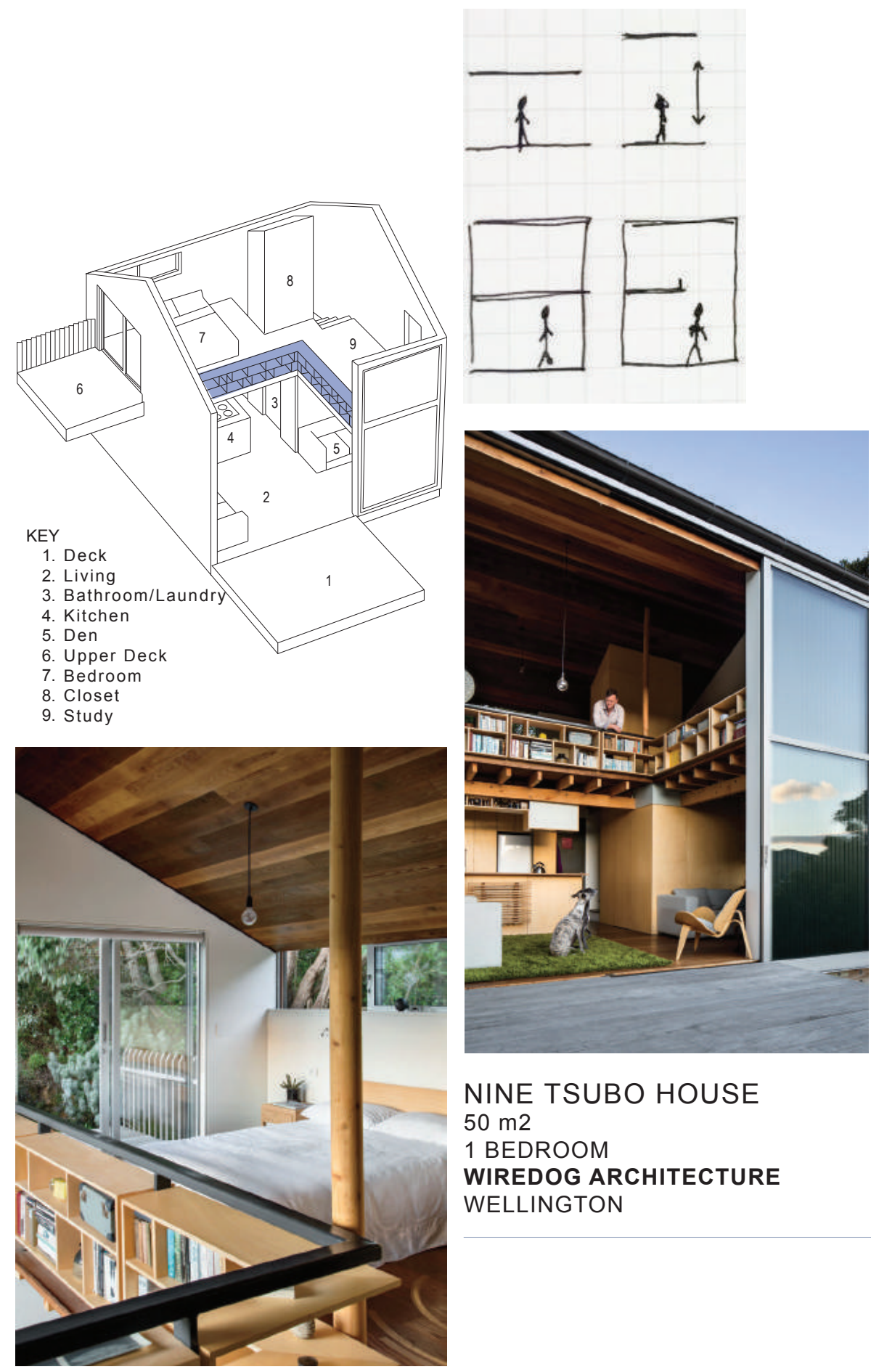

NINE TSUBO HOUSE

$50 \mathrm{~m} 2$

1 BEDROOM

WIREDOG ARCHITECTURE

WELLINGTON

The Nine Tsubo House was developed from a Japanese precedent, measuring only $50 \mathrm{~m} 2$ the home optimises storage in every available use of space, through hidden drawers and open shelves. The large double height space and open flow between interior and exterior expands its small footprint, 'blurring' the interior boundary, creating a much larger feel within the space. 


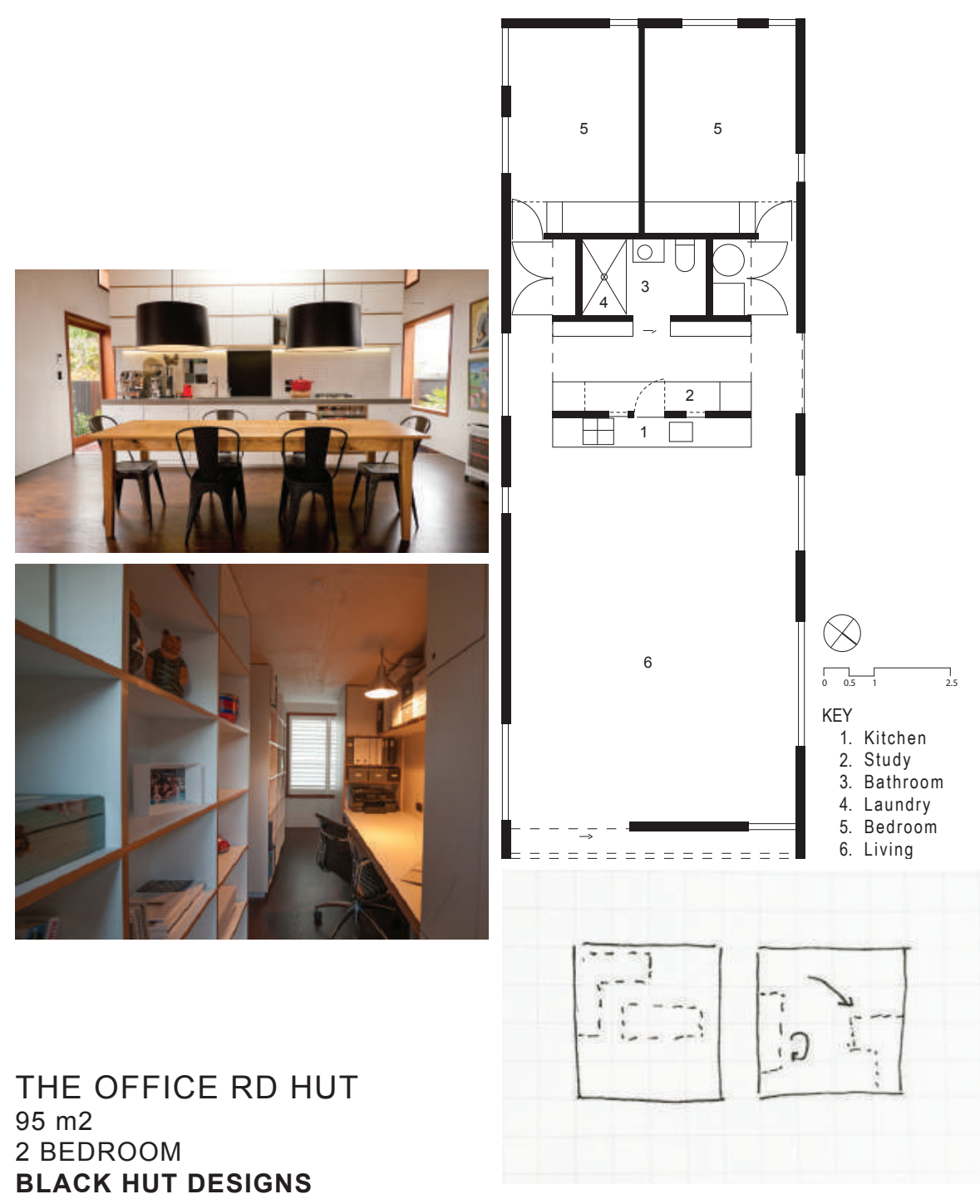

Fig 2.03.

*Combination of The Office Rd Hut photos and Authors diagrams

The Office Rd Huts pre-set designs come altered to the client's preferences. The open plan design allows occupants to change the interior configuration to suit their living arrangements. The large dining table doubles as a kitchen bench, providing extra space when needed and saving space in the kitchen. The planning has been articulated very successfully, neatly tucking the study within the circulation space between the kitchen and bathroom. This ensures there is no 'sole circulation' space, utilising every available inch efficiently. 

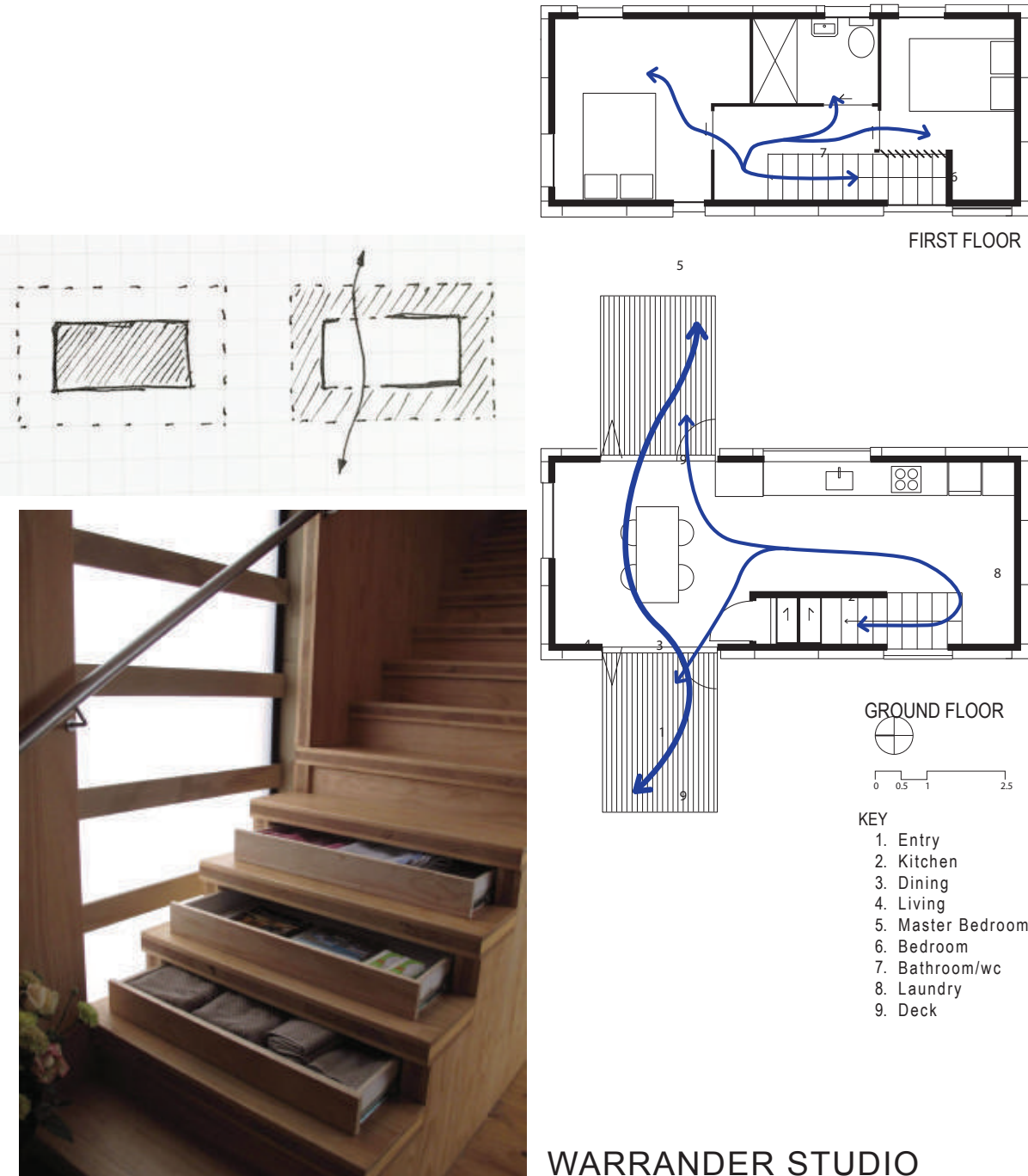

WARRANDER STUDIO

$65 \mathrm{~m} 2$

\section{BEDROOM}

MAKERS OF ARCHITECTURE CHRISTCHURCH

The Warrander studio minimises clutter, utilising all available space and providing storage within the stairs. The open flow between interior and exterior push the buildings footprint, enlargening the living spaces and optimising views and sunlight which allows the small space to feel more generous. The use of natural materials and soft palettes visually enhance the illusion of space. The filtered light through the stairway complement these, and add visual interest. 


\section{SUCCESSFUL INNER CITY SMALL SPACES}
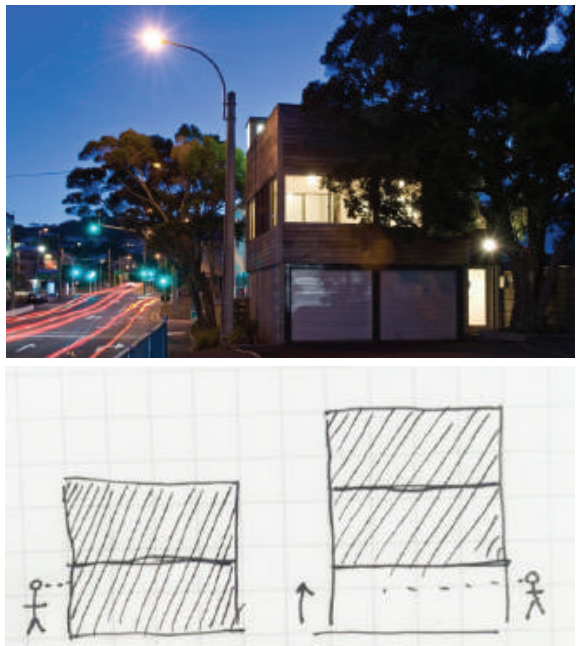

CITY BACH

$42 \mathrm{~m} 2$

1 BEDROOM

MELLING ARCHITECTS

CENTRAL WELLINGTON
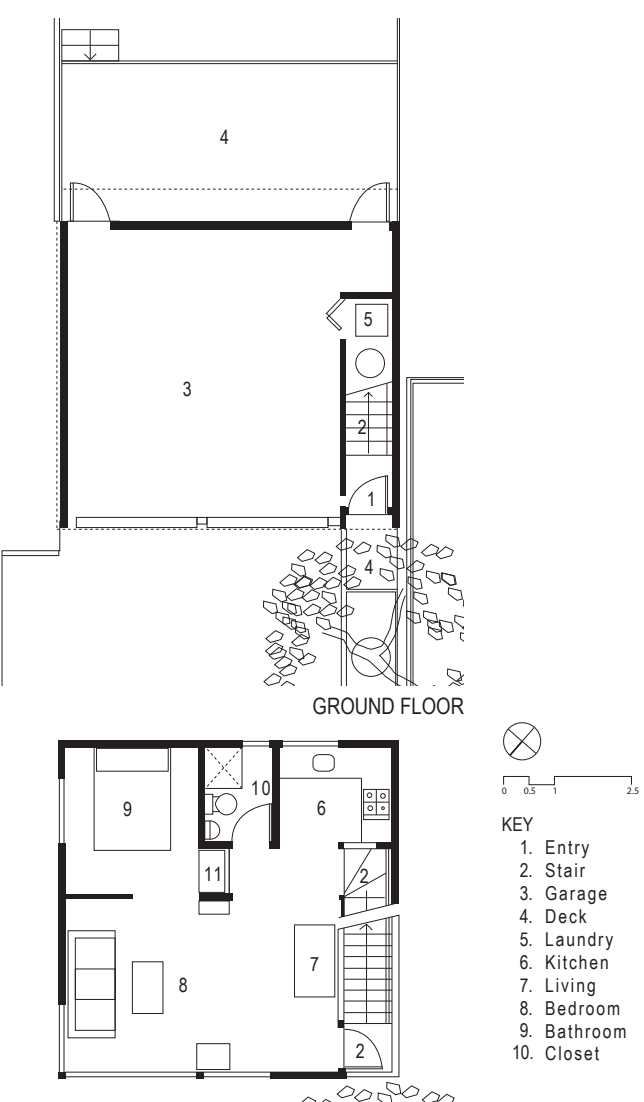

KEY

1. Entry

2. Stair

3. Garage

4. Deck

5. Laundry

6. Kitchen

7. Living

8. Bedroom

9. Bathroom

10. Closet

Fig 2.05.

*Combination of The City Bach photos and Authors diagrams and floor plans 


\section{INEFFICIENT EXISTING \\ SMALL SPACES}

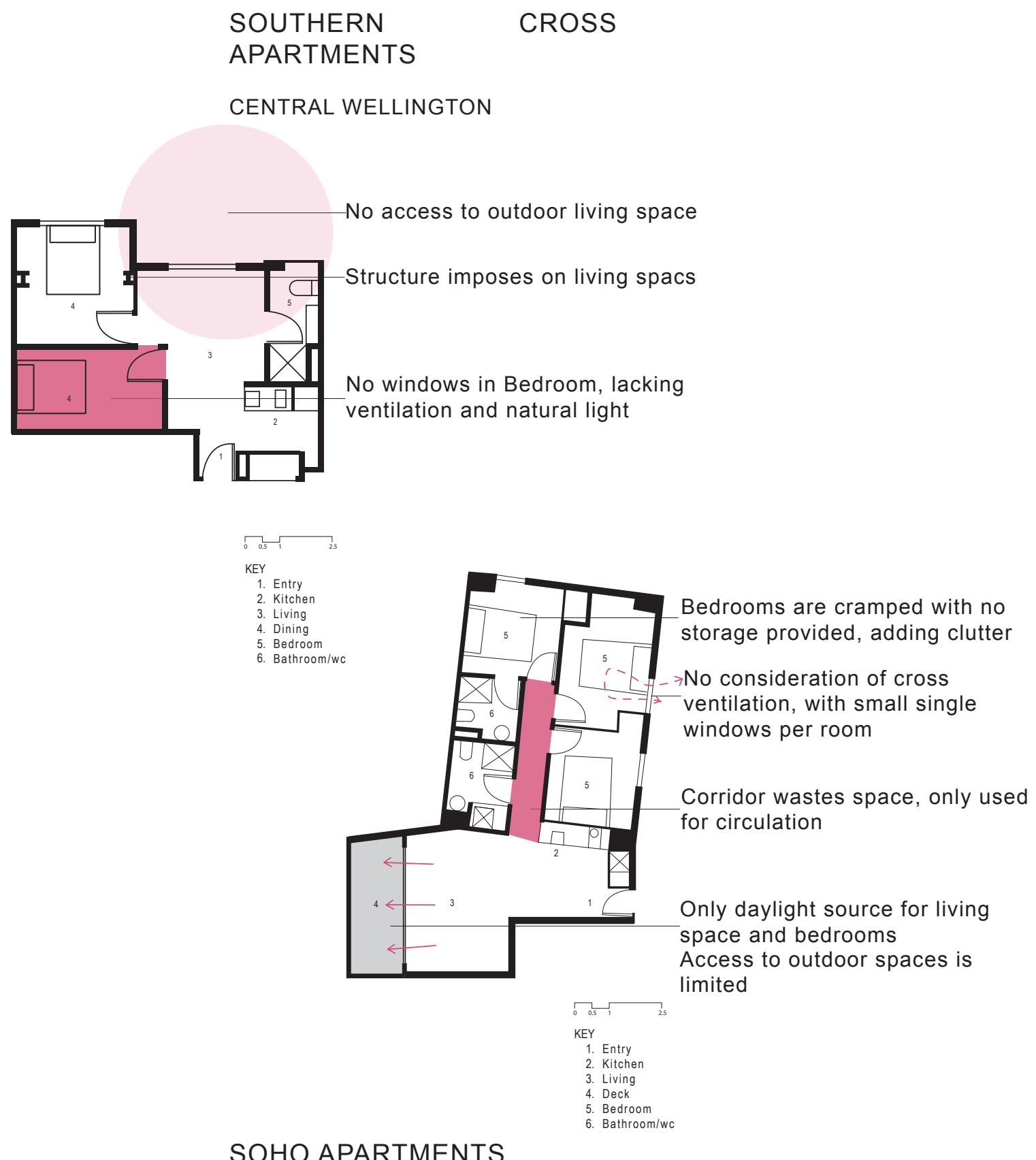

CENTRAL WELLINGTON 


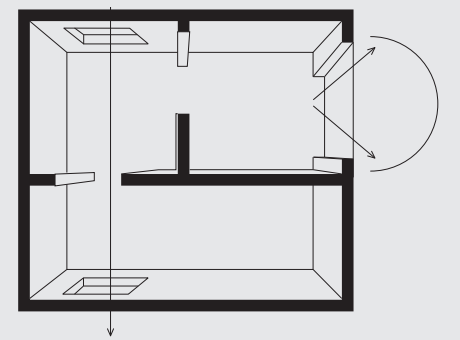

OUTLOOK AND LIGHTING 1

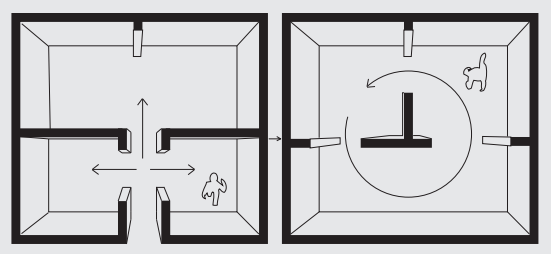

$$
\underset{4}{\text { CIRCULATION }}
$$
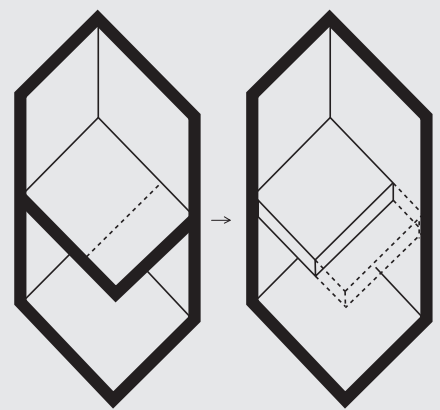

DOUBLE HEIGHT SPACE

7

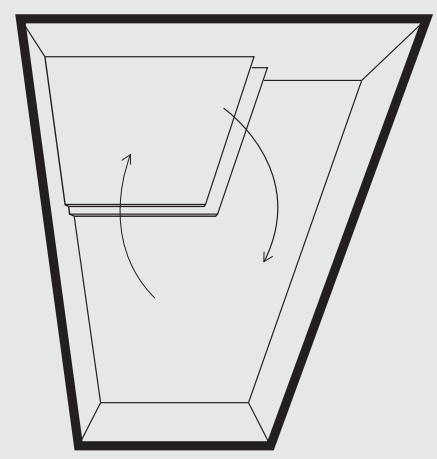

FLOW AND PLANNING

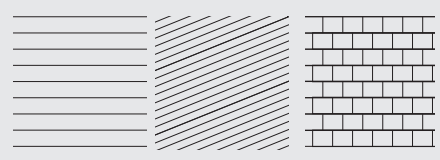

MATERIALS AND COLOUR PALLETTES 5

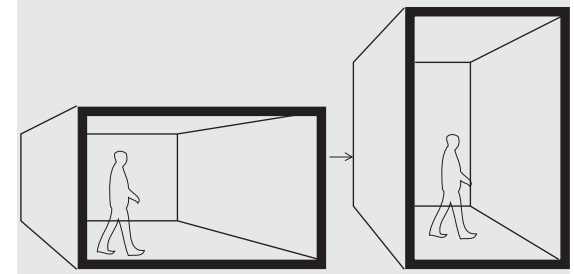

FLOOR TO CEILING RATIO 8

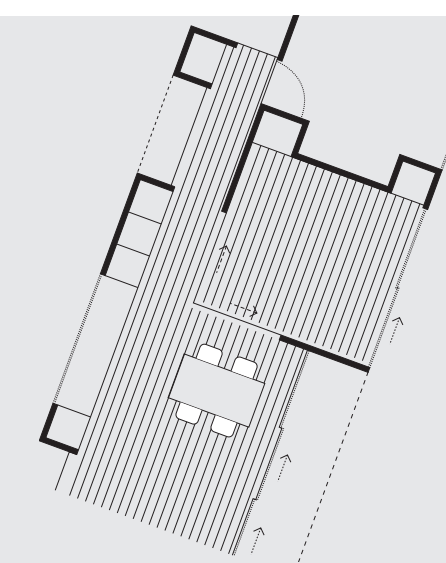

MULTIFUNCTIONAL AREAS

3

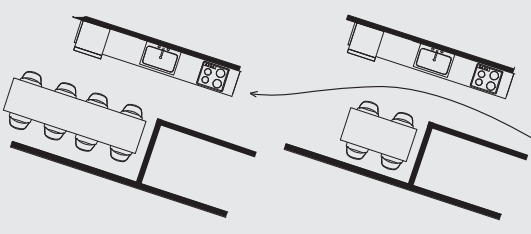

FURNITURE

6

\section{STORAGE}

INTERIOR LIGHTING

9

\section{SPACE EFFICIENT DESIGN PRINCIPLES + GUIDE LINES}

From the analysis of small homes and Catherine Fosters 'Small House Living', a set of guidelines and principles have been outlined for the design of small homes. 
Exterior views will open a small space and feel less enclosing

If sunlight is not available, use mirrors to bounce light in, introduce skylights if possible

1

Corridors waste space and add to expense

Reduce circulation with open plan design and make spaces multifunctional

4

Mezzanines and high ceilings will make a small space appear larger than it is
Cavity sliding doors within walls save space for privacy when required

Uninterrupted flow between interior and exterior living spaces increases apparent size of available indoor space

Introducing vertical circulation or split levels

Small spaces can feel cluttered or crowded, a minimal colour palette and natural materials create a more open feel

Restricting the material palette visually enhances the illusion of space

Textured materials or various shades of timber will visually enhance spaces without creating a clutte Fed feel

Where possible, extra height creates a perception of more space and feels less enclosing
Changing interior configurations, insert concealed doors into walls to form another room when required

Create rooms from nowhere or allow a study to be used as a second living space and spare bedroom

3

Small spaces work best with built in furniture, i.e functional walls or cores, or items built custom to size and requirement

Make furniture multi-functional, use every wall space

Make use of underused space.

Can storage be introduced in stair treads or under stair cases

Manipulate light and shadow, avoiding central downlights for low ceilinged rooms as these do nothing to create atmosphere 


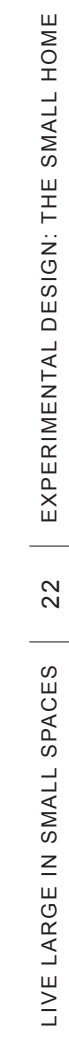




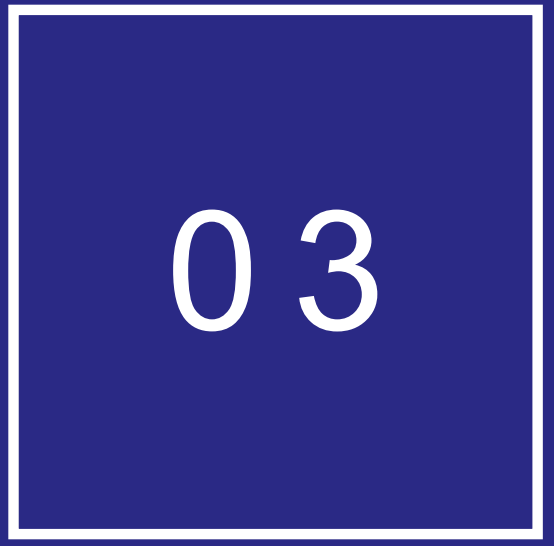

EXPERIMENTAL DESIGN

THE SMALL HOME 


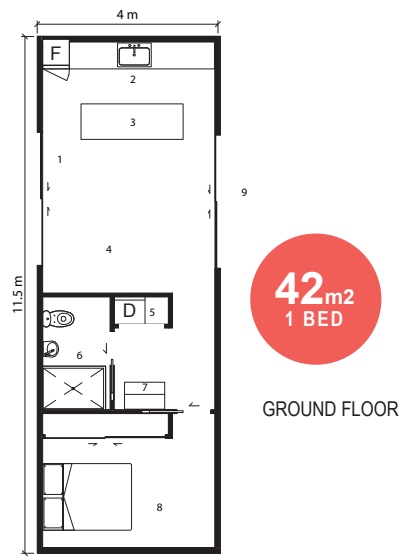

\section{IMPLEMENTING THE DESIGN GUIDELINES}

To begin the design process, a series of 8 houses were developed. Ranging between $42 \mathrm{~m} 2$ and $80 \mathrm{~m} 2$. Each of these tested planning of minimum design requirements, ensuring to provide all amenities necessary. Each house contains a standard sized kitchen and bathroom, 1 or 2 bedrooms + wardrobes, living and dining, study and laundry space. The design guidelines and principles were implemented through the planning process, ensuring optimal indoor/outdoor flow, reducing sole circulation space and providing spaces that allow for change.

The range of 8 houses were to test flexibility in design and allow a sense of individuality leading into the next design phase.

Fig 3.01.

*Small house iterations 


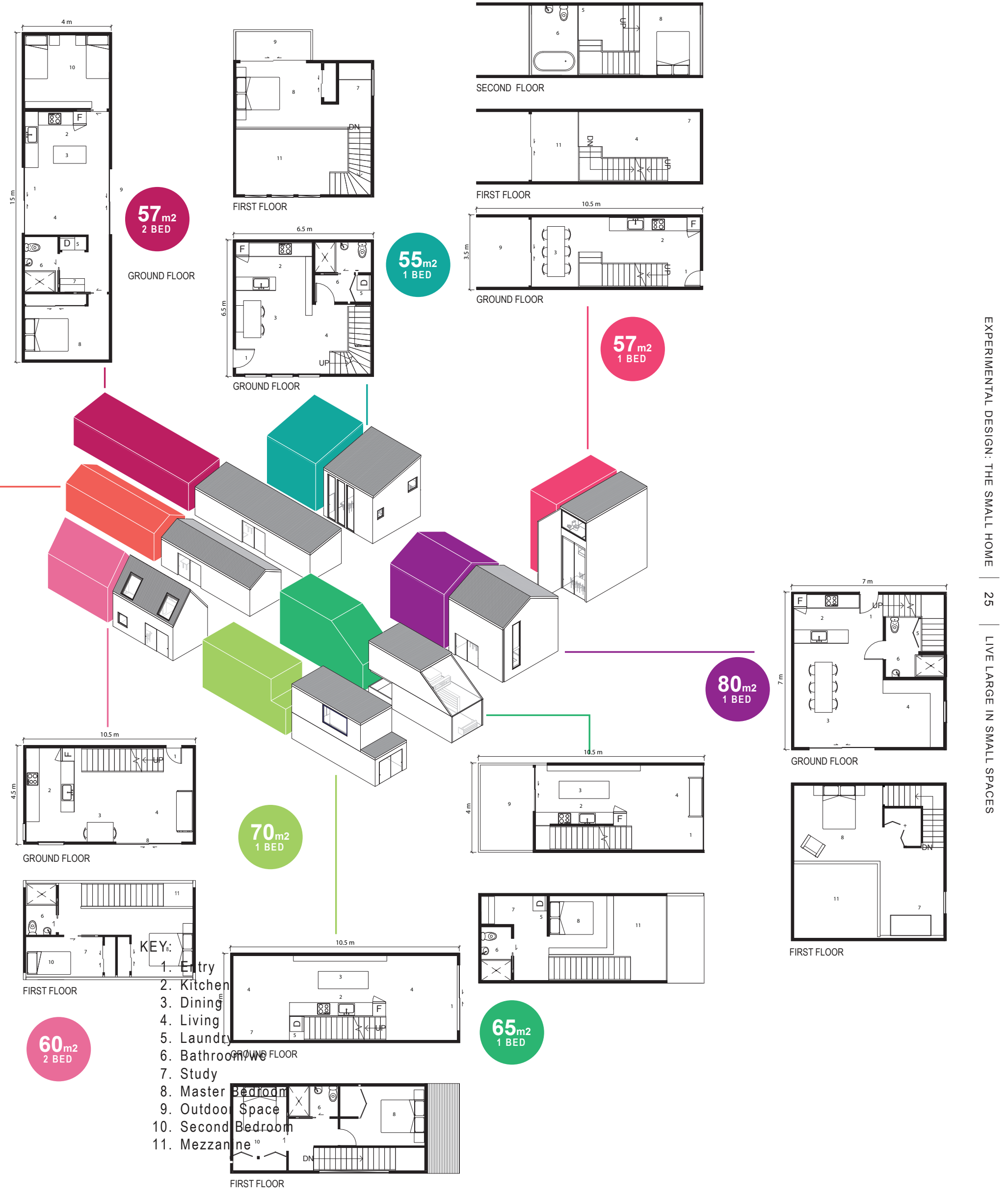




\section{WHO AM I HOUSING? GENERATION RENT}

Home ownership is a rite of passage for generations of New Zealanders, offering financial security and playing a central role in our national identity. In this sense, owning one's home has become a cultural expectation. In New Zealand today, a house costs almost 8 times the annual salary and housing affordability has become a large issue across the world (Eaqub \& Eaqub, 2015).

In 'Small House Designs' Kenneth Tremblay and Lawrence von Bamford point out that for young families, smaller houses make sense. When done right, the advantages of small house living are numerous; less cleaning, painting, routine maintenance, more energy efficient and "may allow owners to pursue recreational or other personal activities." (Kenneth R. Tremblay, 1997). Young couples and small families (Couple with one child), will easily adapt to living small and when families get to the point of outgrowing they can move on. The sense that people do change houses fairly frequently, and because getting started is the hard thing, then this design research will make an easy first step.

The design research will aim to house first home buyers, implementing more affordable design and catering to the widespread issue of housing affordability. First home buyers or 'starter homes' will cater for young families, young couples and singles ageing between 25 and 35 . 


\section{M}

YOUNG COUPLE + CHILD

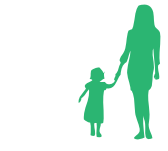

SOLE PARENT +CHILD

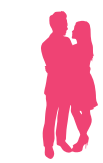

YOUNG COUPLE

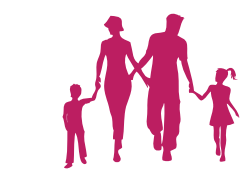

YOUNG COUPLE + 2 CHILDREN

"The stresses felt by generation rent are many and various: a feeling of disenfranchisement and desperation at being unable to realise the Kiwi dream of home ownership; not being able to save enough for retirement or a rainy day; and being forced to rent, which remains significantly inferior to ownership in terms of stability and comfort"

(Eaqub \& Eaqub, 2015)

2X YOUNG PROFESSIONALS

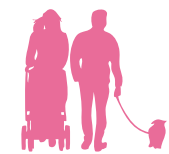

YOUNG COUPLE + BABY 

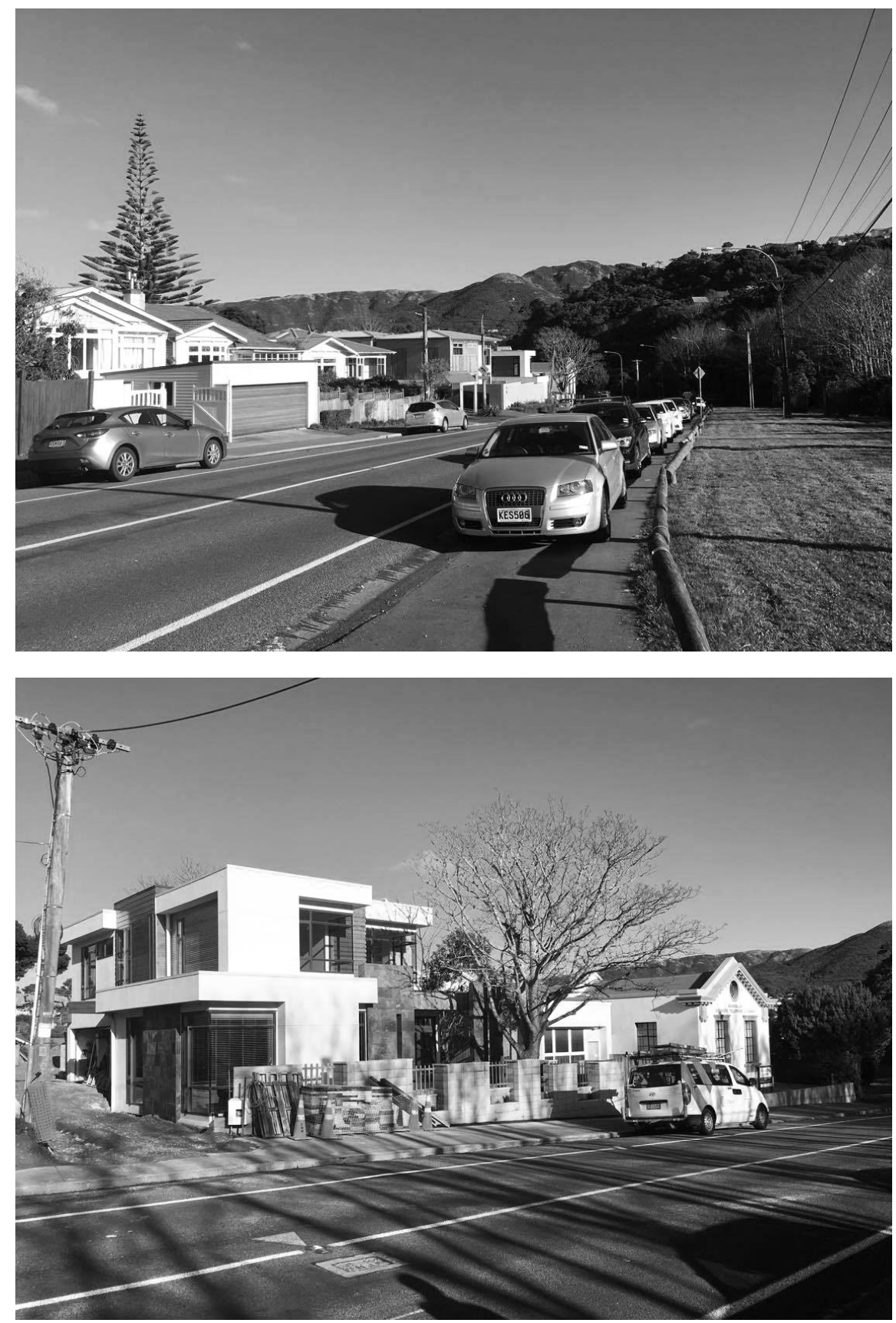

90 KHANDALLAH RD 
The next section of Design

Phase 1 investigated small

homes on a compact site,

generating a concept design

for a site in Khandallah. 
"The Council has a responsibility to give the community what it needs and to make it possible for a variety of housing types to be developed. To achieve this, we are now planning to encourage more medium-density housing to be built in Khandallah."

(Wellington City Council, 2016)

Fig 3.02 .

TOP: Khandallah Rd looking towards site

BOTTOM: Site view from street

Fig 3.03 .

(Right)

Lush greenery surrounds the suburb 


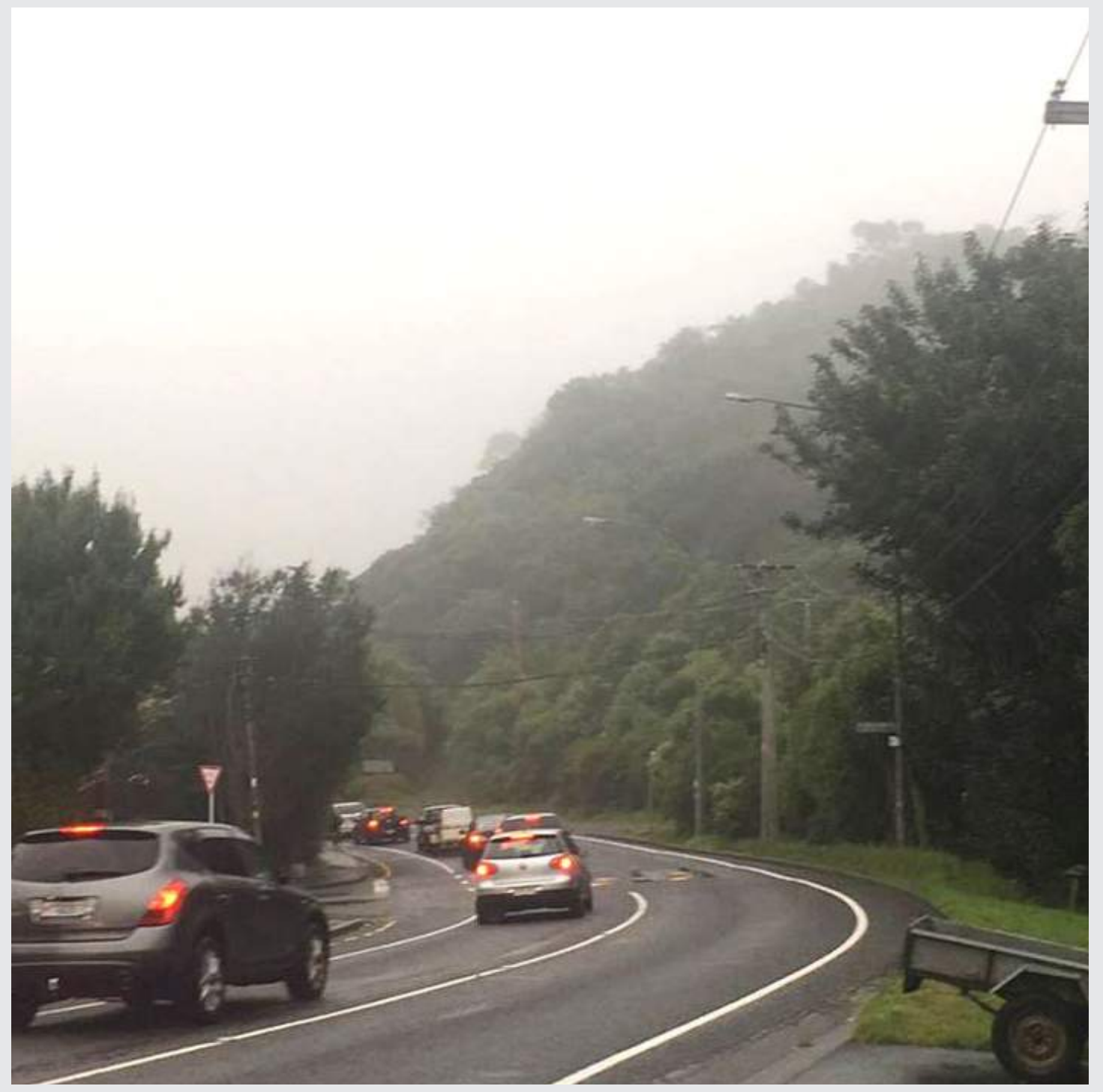

KHANDALLAH RD 


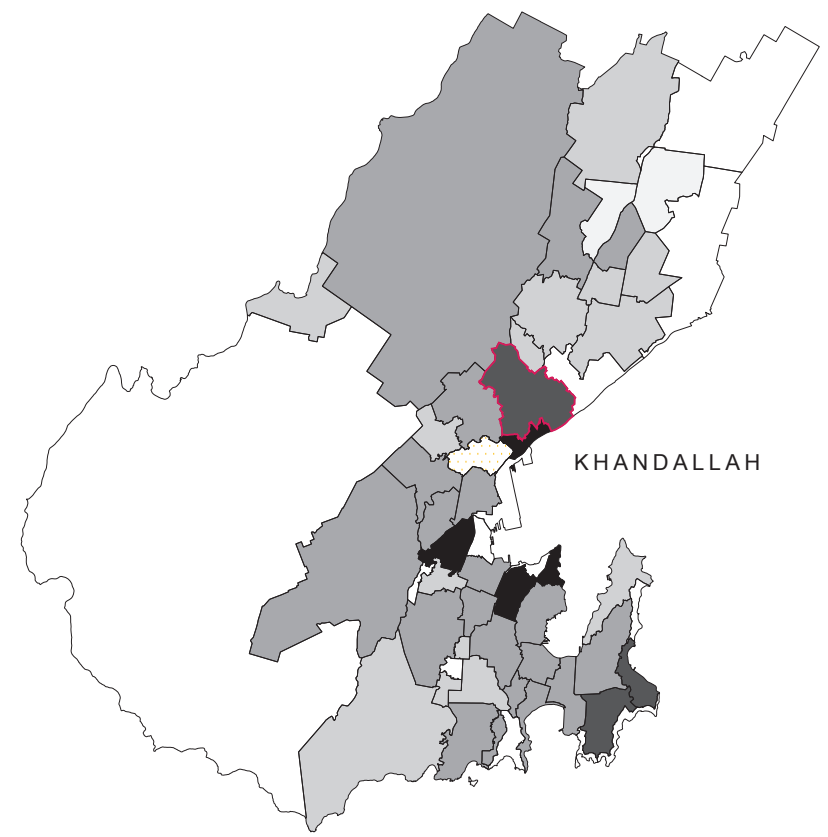

MEDIAN PRICE (\$)

200,000

$1,000,000$

\section{KHANDALLAH, WELLINGTON}

With Wellingtons population growing, more diverse housing is needed. The average number of persons per household will fall from 2.69 to 2.58 by 2028 , while the number of dwellings is expected to increase by 290 (.id, 2013). With our housing needs changing, there is a greater demand for one and two person households and a trend for people wanting to move into different housing types within their own suburb (Wellington City Council, 2016). Khandallah has a strong infrastructure to support medium density housing and a need for more practical, good-quality affordable homes.

And with just a ten minute drive to central Wellington, the site is an optimal location for the proposed scheme. The site is situated on the outskirts of Khandallah, 10 minutes walking distance from the suburbs town centre. One minutes walk from the railway station, the site holds potential for intensification

Fig 3.04 .

(Above)

*Wellington house prices by suburb

Fig 3.05 .

(Top right)

${ }^{*}$ Areas within 5 and 10 minutes walk from Khandallah's centre

Fig 3.06. (Mid right)

${ }^{*}$ Aerial view of site

Fig 3.07. (Bottom right)

${ }^{*}$ Aerial view of site and development of more affordable homes.

Khandallahs town centre provides shopping, services and local employment with great access to public transport networks. The suburb is typically low density and large houses and hosts a range of community facilities, schools and open spaces. 

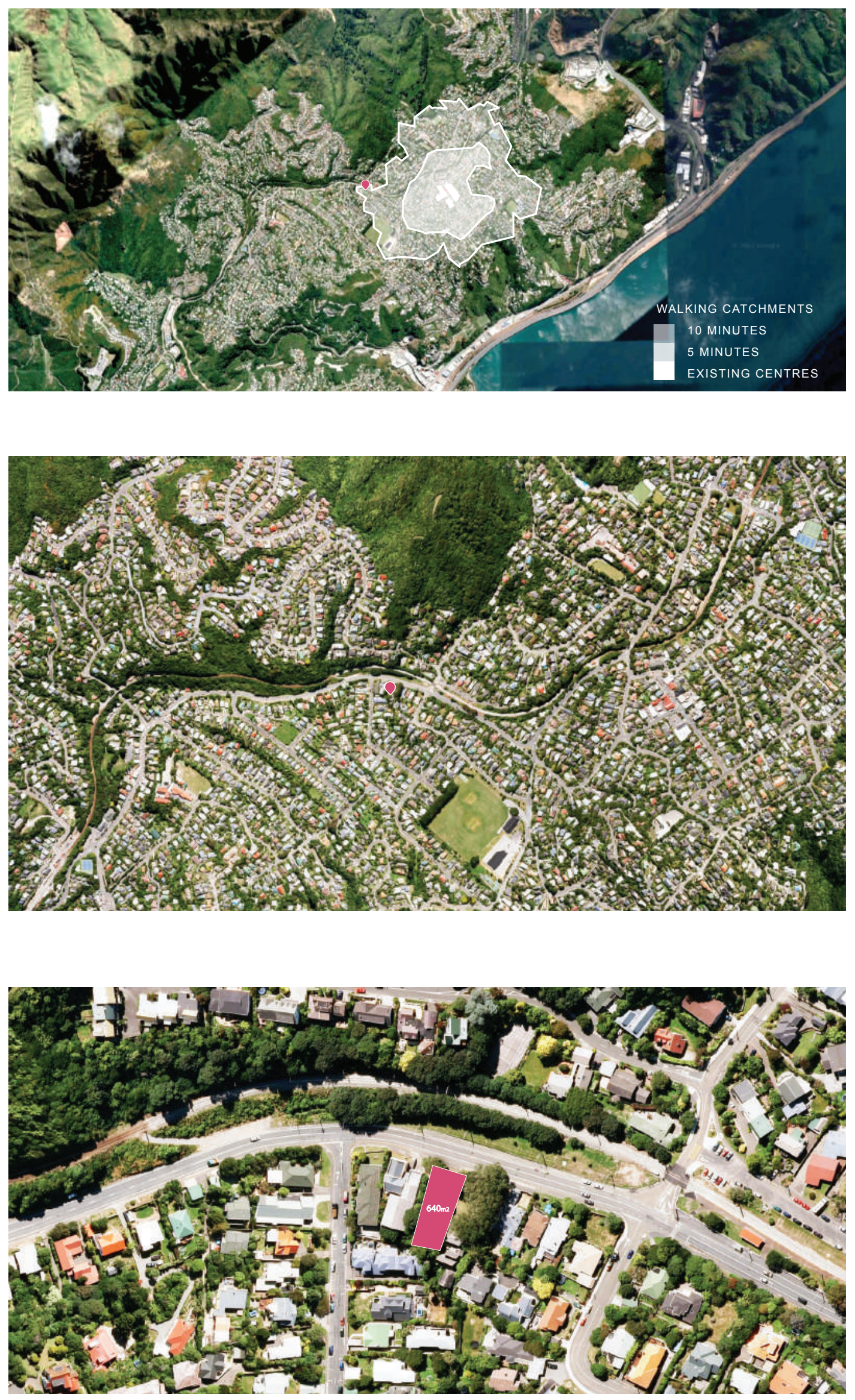


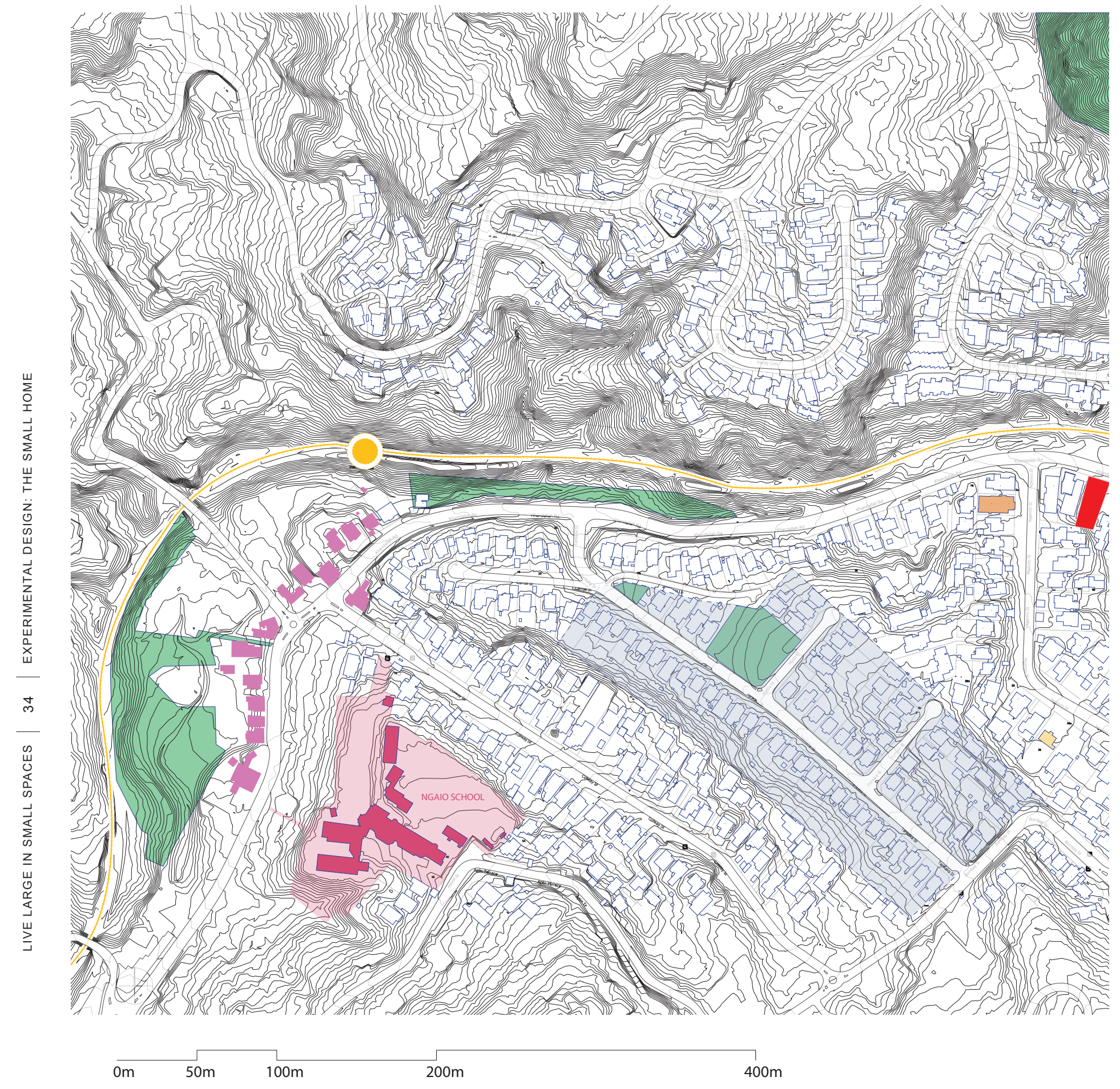




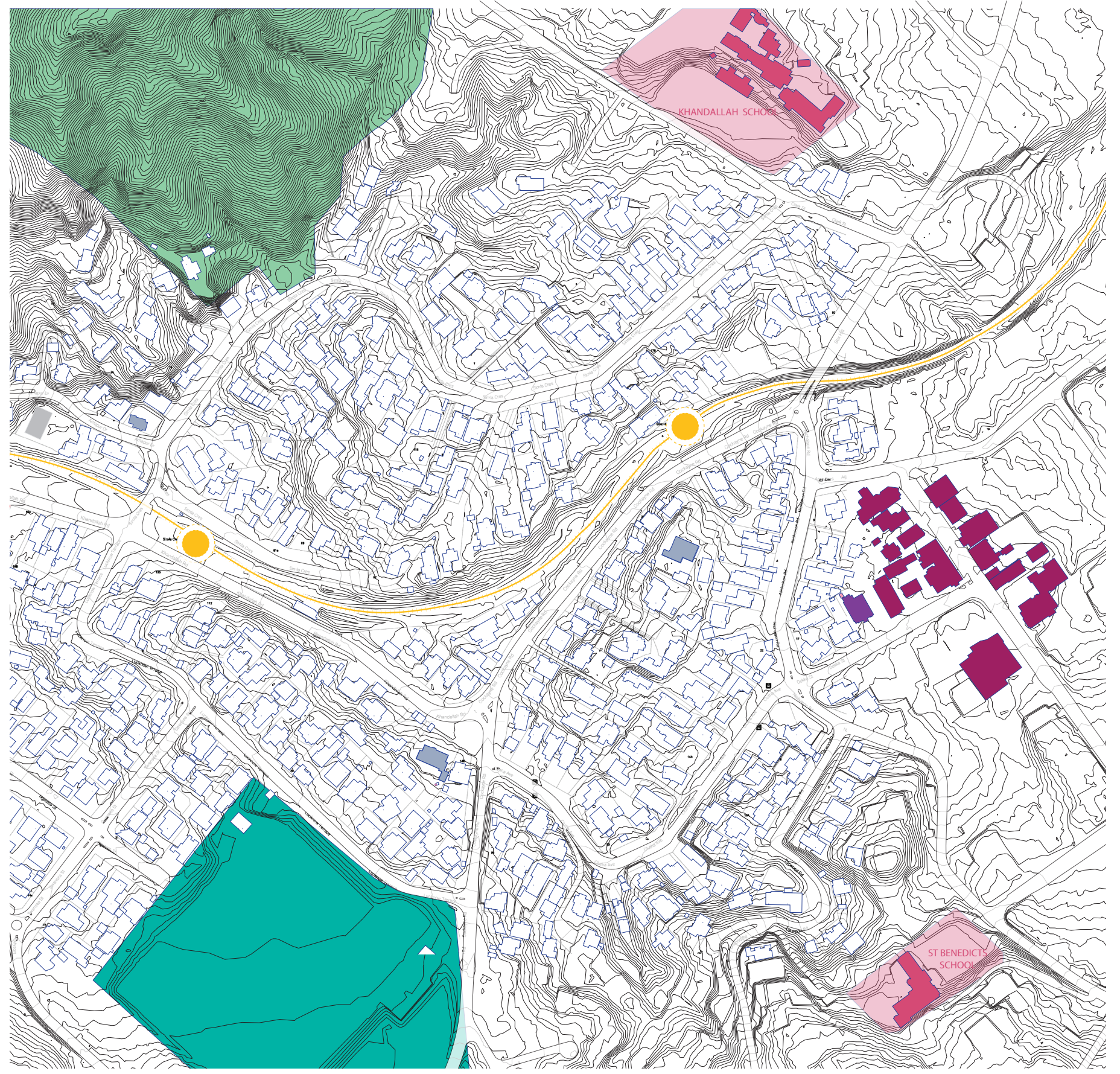

- NGAIO CENTRE

- HERITAGE BUILDINGS

HERITAGE AREA

- CATHOLIC CHURCH ST JOHNS

- PRIMARY SCHOOLS

TRAIN STATION + RAILWAY LINE

- ONSLOW COMMUNITY CHURCH

- KHANDALLAH MEDICAL CENTRE

- KHANDALLAH CENTRE

- PARKS + RESERVES

- NAIRNVILLE SPORTS GROUND, REC

CENTRE + PLAYGROUND 


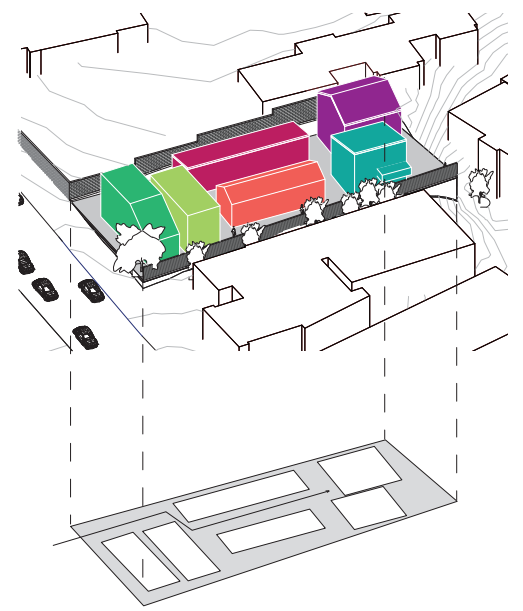

-AWKWARD SITE ACCESS

-LIMITED PRIVATE SPACE
-SPACE FOR TURNING AND PARKED CARS REDUCES SITE FOOTPRINT
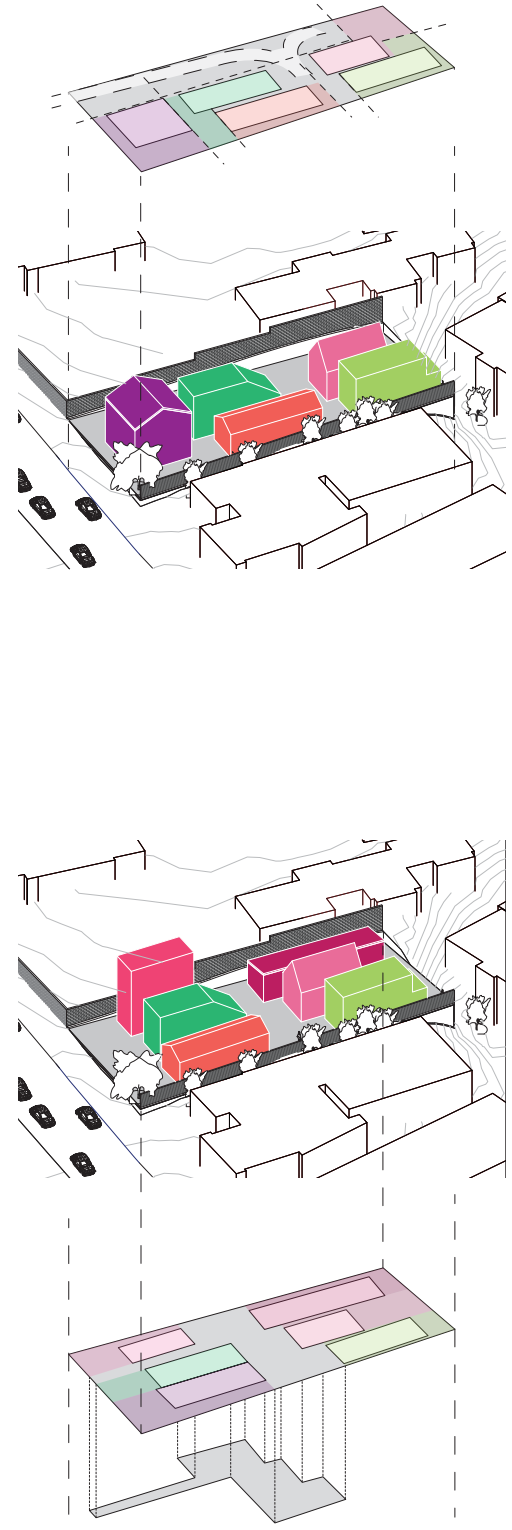

-COMMUNAL SPACE CENTRAL TO SITE ALLOWS OPPORTUNITY FOR RESIDENTS TO INTERACT

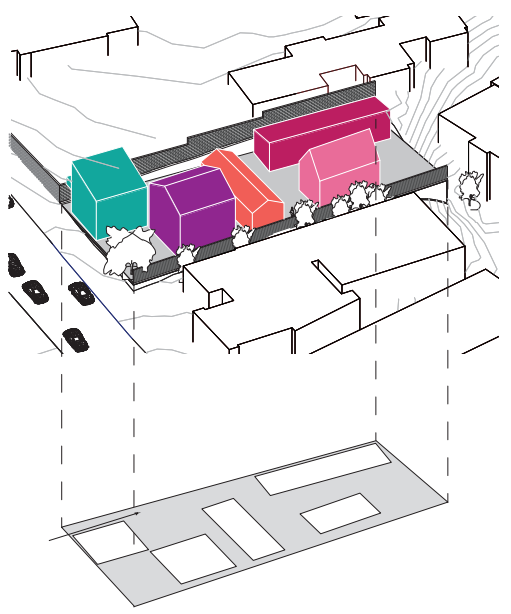

-MAXIMUM PRIVATE SPACE -PEDESTRIAN ONLY ACCESS

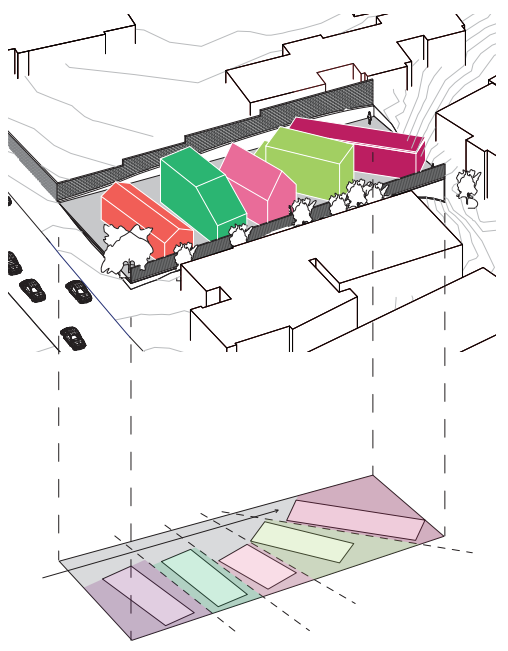

-SPACED DWELLINGS TO PROVIDE A SPECIFIC BOUNDARY FOR EACH DWELLING

\section{MASSING ON SITE}

The following iterations were developed from the initial house designs and the arrangement of these on site has been explored. Issues that were analysed iteratively include:

- Site access, pedestrian or vehicular

- Private and Public space

- Car parking, on site, on site boundary, turning radius of a car

- Landscaping options

- Relationship between houses

- Orientation on site

- Communal and shared space

- Density on site 
-PARKING AT FRONT OF SITE AND CLEAR ACCESS TO EACH DWELLING

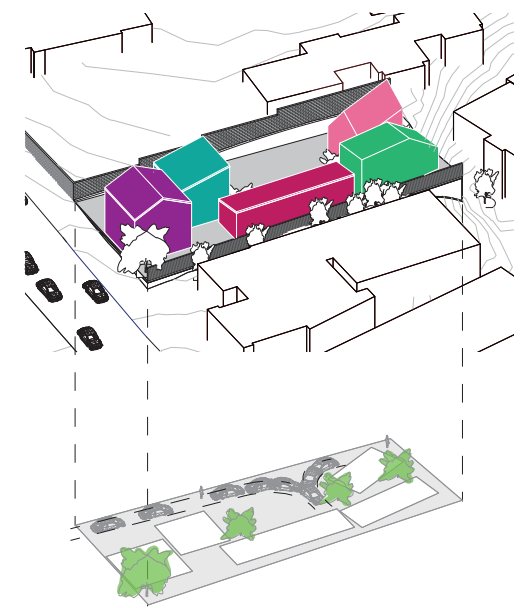

-LANDSCAPING SEPARATES PUBLIC AND PRIVATE SPACE WHILE ALLOWING FLOW BETWEEN EACH DWELLING AND NEIGHBOURS TO INTERACT

-DWELLING PACKED TIGHTLY ONSITE ALLOWS EFFICIENT USE OF SPACE AND PARKING AT FRONT OF SITE

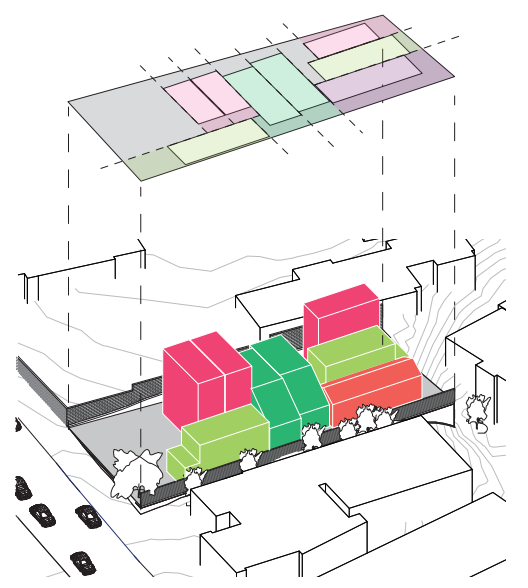

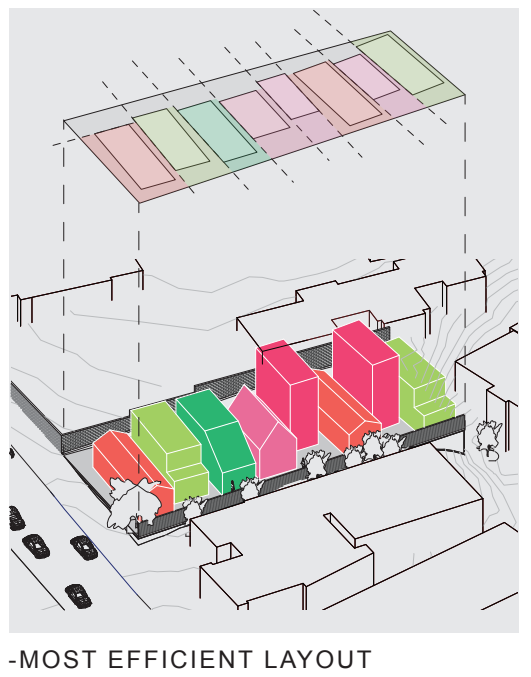
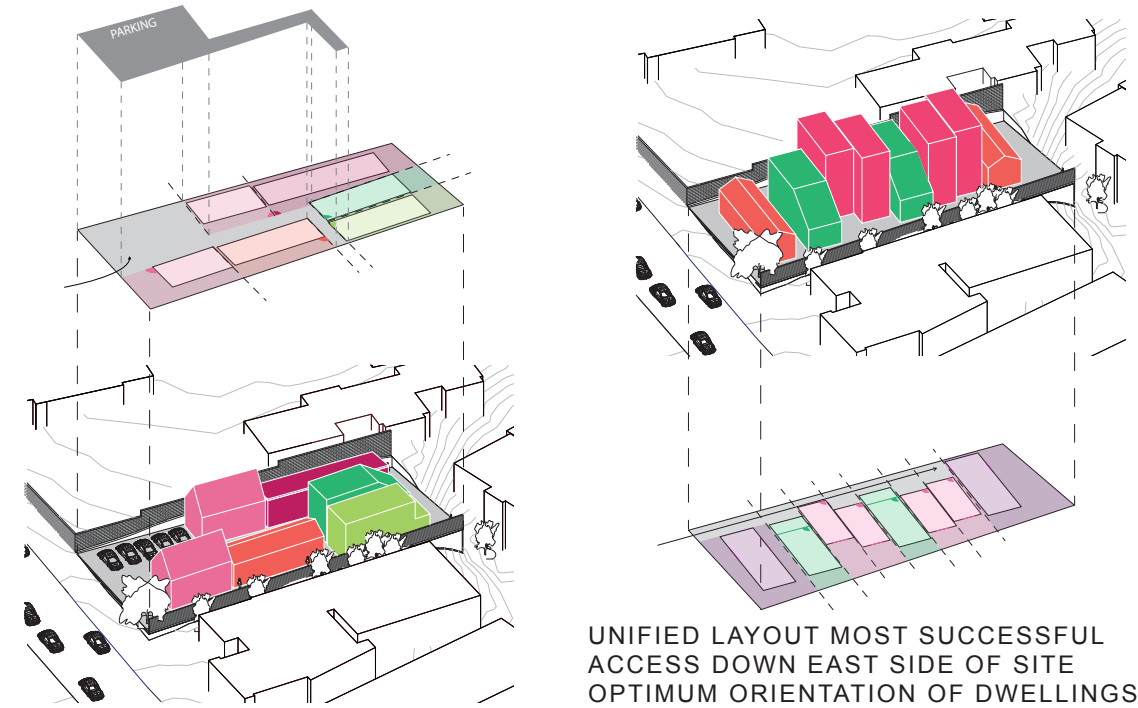

NNIFIED LAYOUT MOST SUCCESSFUL ACCESS DOWN EAST SIDE OF SITE OPTIMUM ORIENTATION OF DWELLINGS 


\section{EXPERIMENTAL DESIGN}

The experimental design was developed from the massing study, which concluded that the most efficient combination and layout of houses was by providing a common access route along the east boundary. This allowed clear and direct access to each dwelling and all private outdoor spaces were well defined. The concept also provided potential for parking below ground.

Eight houses fit on the one site, exploring maximum density. The relationship between the houses, how to address privacy and allow light in were the main issues developed within this scheme. Window placement was very specific to ensure that other residents walking past were not invading the occupant's privacy. Entranceways were pushed and pulled so that from the street view, no one could look directly into an occupant's home. 


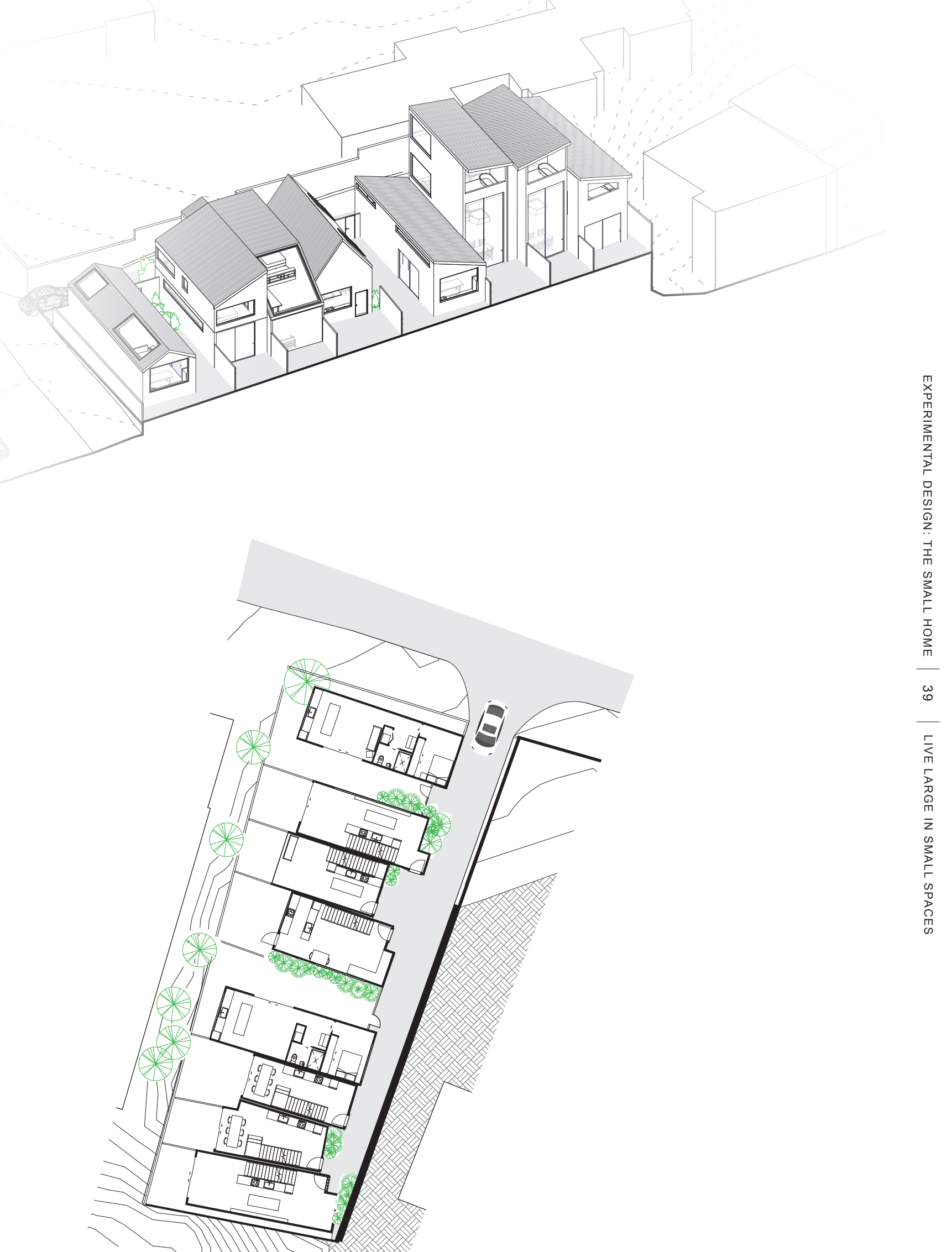


KHANDALLAH SITE: $640 \mathrm{~m} 2$

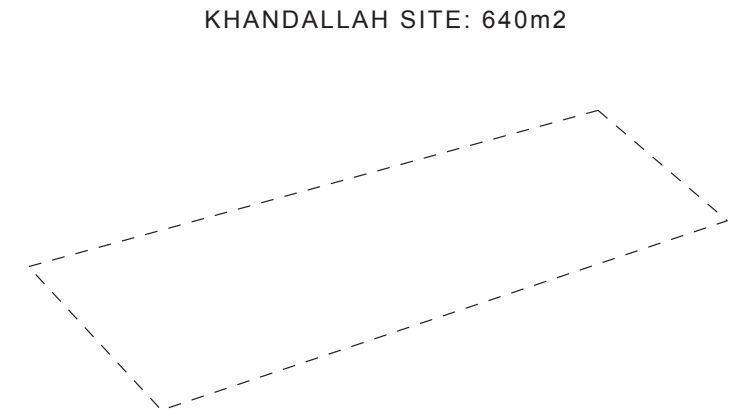

AVERAGE NZ HOUSE 2016: 210m2

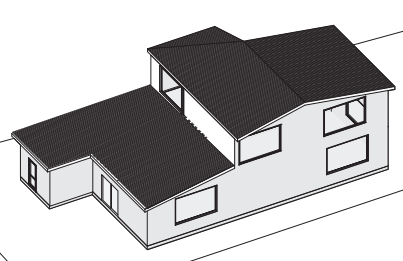

PROPOSAL:

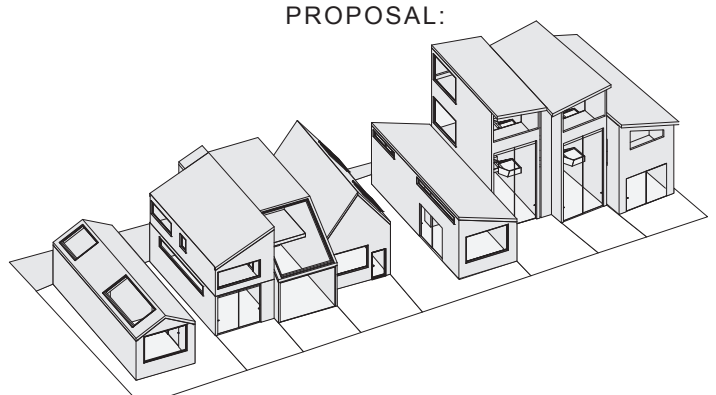

Fig 3.12

*Proposal for an affordable project 
The next section of Design

Phase 1 investigated the

feasibility of the project.

How affordable the proposal

could be and the flexibility

of design in regards to its affordability.

AFFORDABILITY DESIGN 


\section{AFFORDABILITY}

The first concept design explores intensification on one site of $640 \mathrm{~m} 2$ (fig 3.12). A site this size will fit 1 or 2 Average sized New Zealand homes at $210 \mathrm{~m} 2$ each. From this, an analysis on affordability of the proposal was examined. The analysis aimed to provide a rough average which would indicate if the proposal could be made affordable for first home buyers.

Housing affordability is dependent on a combination of 3 factors, house prices, household incomes and mortgage interest rates. The affordability index (fig 3.13) shows housing affordability from 1999 until 2015. From mid-2013, house prices have risen and affordability has declined. Ian Page predicts that the index will reach an all-time low, as already, in Auckland the median house price is more than 8 times the median household income. Housing is considered affordable at a ratio of 3 for the median household (Page, 2015).

Housing affordability significantly affects first home buyers and as the issue continues to grow, the younger generation see themselves excluded from the dream of home ownership. First home buyers with a two income -aged 2529 , are needing to spend more than $50 \%$ of their joint income on mortgage repayments for a lower quartile home, while roughly $30 \%$ would be considered affordable (Page, 2015).

"Tracking the rise of housing costs, both for new dwellings and already existing properties, shows the major influence rising land costs are having on affordability."

BRANZ 2009 findings on house price index's show that 20 years ago, a section of a new house/section package cost an average of $28 \%$. By 2009 a section was an average of $44 \%$ of the total package (Page, 2009) (fig 3.15). If the trend in affordability continues to decline, we risk seeing an intergenerational issue with a massive inequality in wealth (Eaqub \& Eaqub, 2015).

BRANZ findings point to Land costs as the main factor behind rising house prices (fig 3.14). Other factors influencing house prices such as construction costs, regulations and more complete documentation are minor in comparison to land prices which have risen an average of $7 \%$ per year.

Fig 3.13. (Top right))

Existing house affordability - the higher the index, the more affordable Source: Massey University House Affordability Index

Fig 3.14. (Middle right)

New house cost components "Land costs are leading the other components, and this is a major reason why affordability is becoming a major problem". So how do we tackle land costs? The encouragement of medium density, infill housing and smaller builds is definitely a solution. Ian Page highlights intensification as an answer, where "land as a proportion of total cost is reduced compared to detached housing" (Page, 2014).

Fig 3.15.

(Bottom right)

House price index 

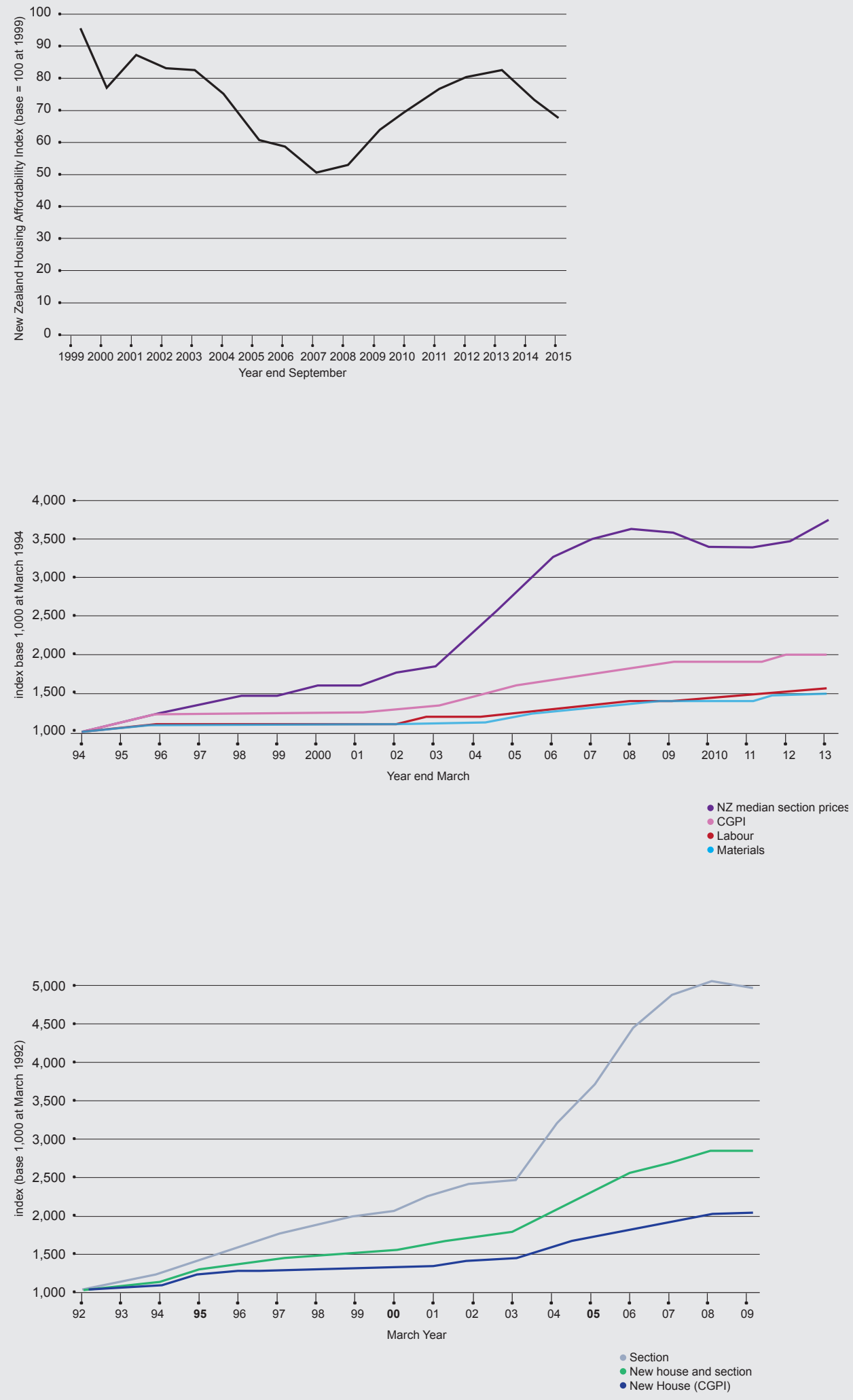


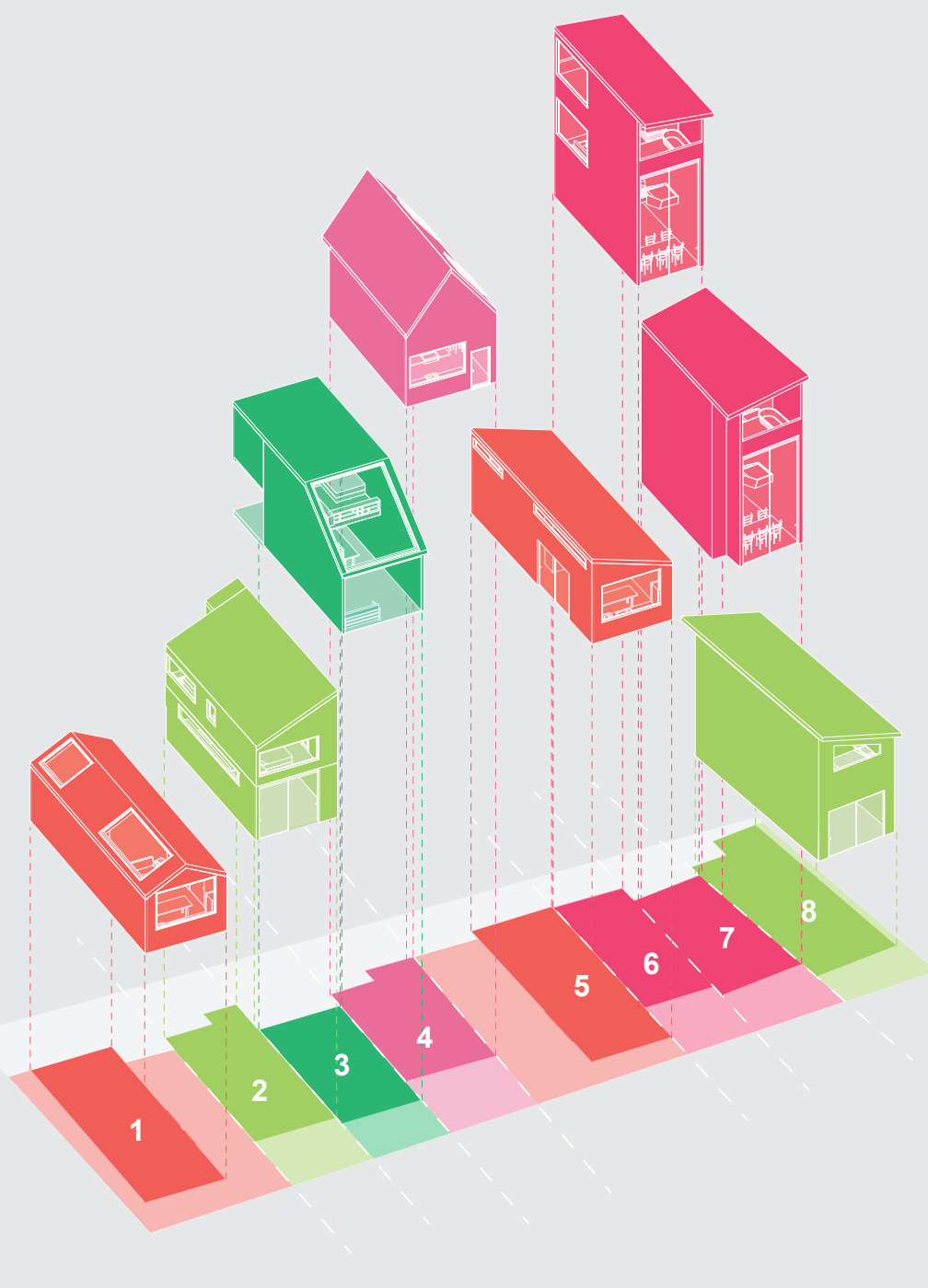

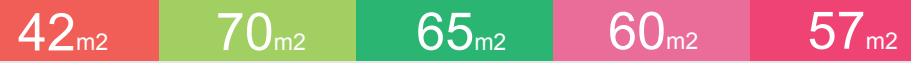

TOTAL SITE VALUE $=\$ 595,000$

SITE COST PER HOUSE $=\$ 75,000$

(Divided by number of houses per site) 


\section{AFFORDABILITY ANALYSIS}

The first design phase addressed this issue by intensifying a site and splitting the total land cost by the number of dwellings. It was found that the land cost could be significantly decreased.

An affordability by income analysis was calculated from assumptions taken from The interest.co.nz Home Loan Affordability series.

First home buyers were classified by the following categories:

-Couple, aged 25-29, both full time workers

-Single, aged 25-29, full time worker

-Couple and child, aged 30-34, one full-timer, one part-timer

(Ninnes, 2017)

A lower quartile house price in Wellington is $\$ 465,300$, which is deemed unaffordable for a single first home buyer. (Ninnes, 2017).
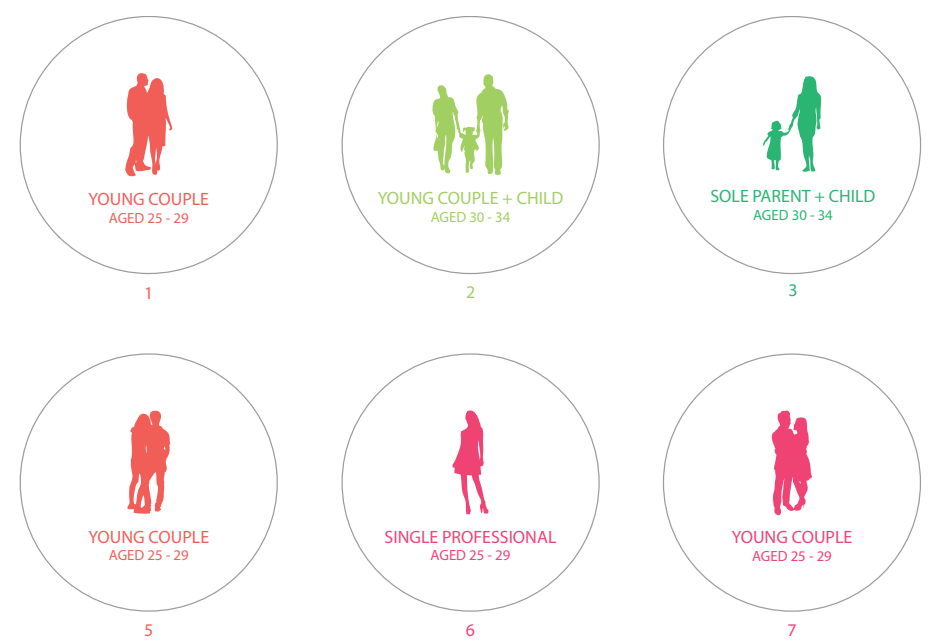

An affordability by house cost analysis was calculated from assumptions taken from Rawlinsons. The average cost of building a standard single storey, $150 \mathrm{~m} 2$, in Wellington is $\$ 3,000$ per $\mathrm{m} 2$ (excl GST). A smaller home will have a more intense unit rate as it still requires 1 kitchen and 1 bathroom. Therefore the assumption that these houses would cost $\$ 4,000$ per $\mathrm{m} 2$, including council fees, preliminaries and architects fees gave a rough estimate to calculate their cost, including land value.

The affordability analysis showed that the intensification of one site with smaller homes significantly increased their affordability.
Fig 3.16.

(Left)

${ }^{*}$ Concept design house sizing

Fig 3.17.

(Above)

*Demographic diagram 

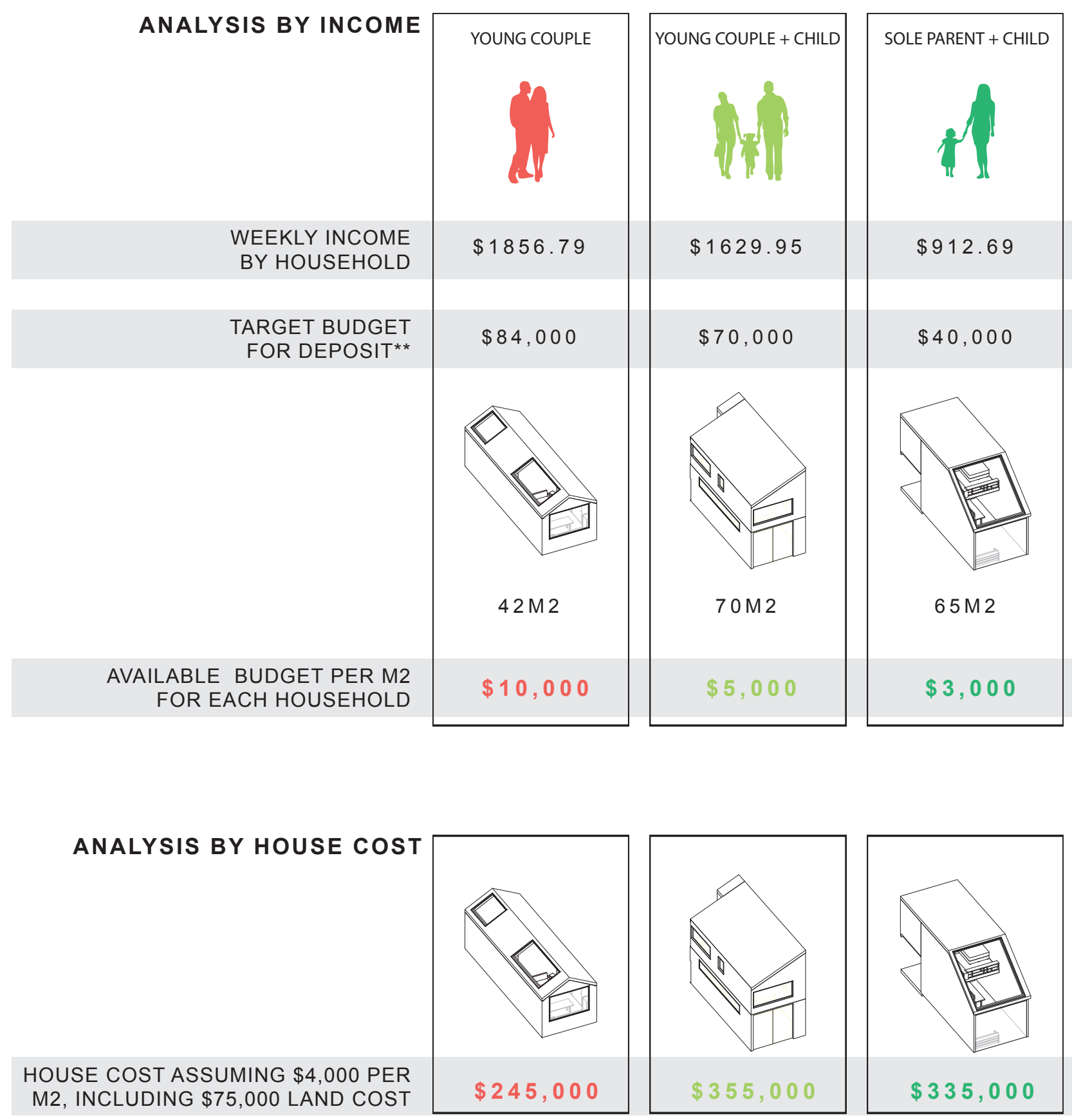

\footnotetext{
**Target budget for deposit assumes occupants have saved for 4 years
}

Fig 3.18.

*Affordability analysis by income and house cost 

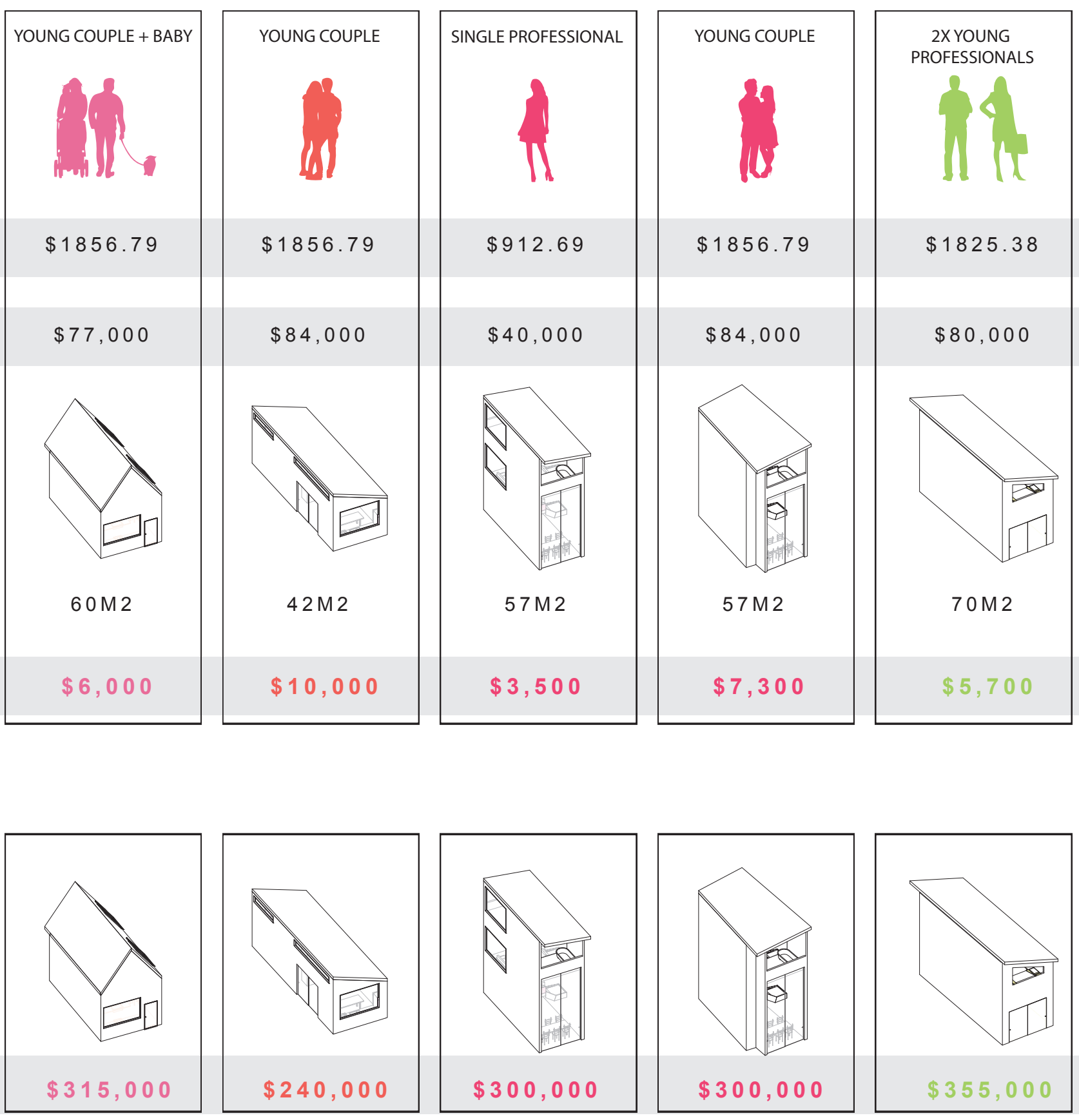
MEDIAN HOUSE PRICES IN WELLINGTON $\$ 583,700$

\section{LOWER QUARTILE HOUSE PRICES IN WELLINGTON \\ $\$ 465,300$}




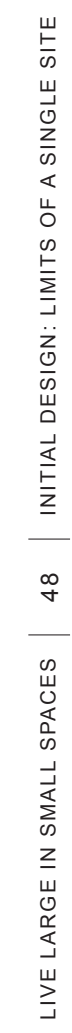




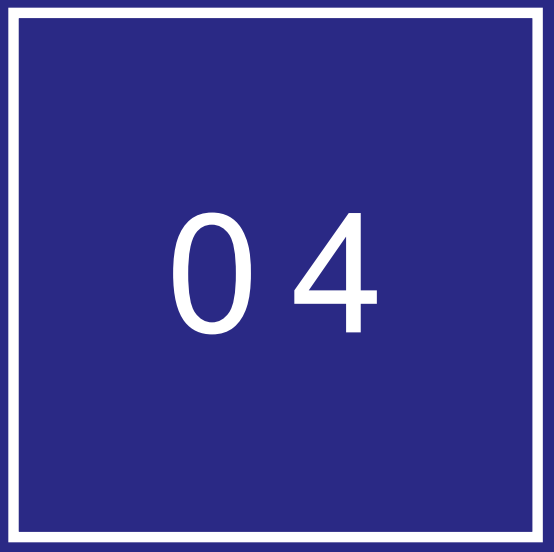

INITIAL DESIGN

LIMITS OF A SINGLE SITE 

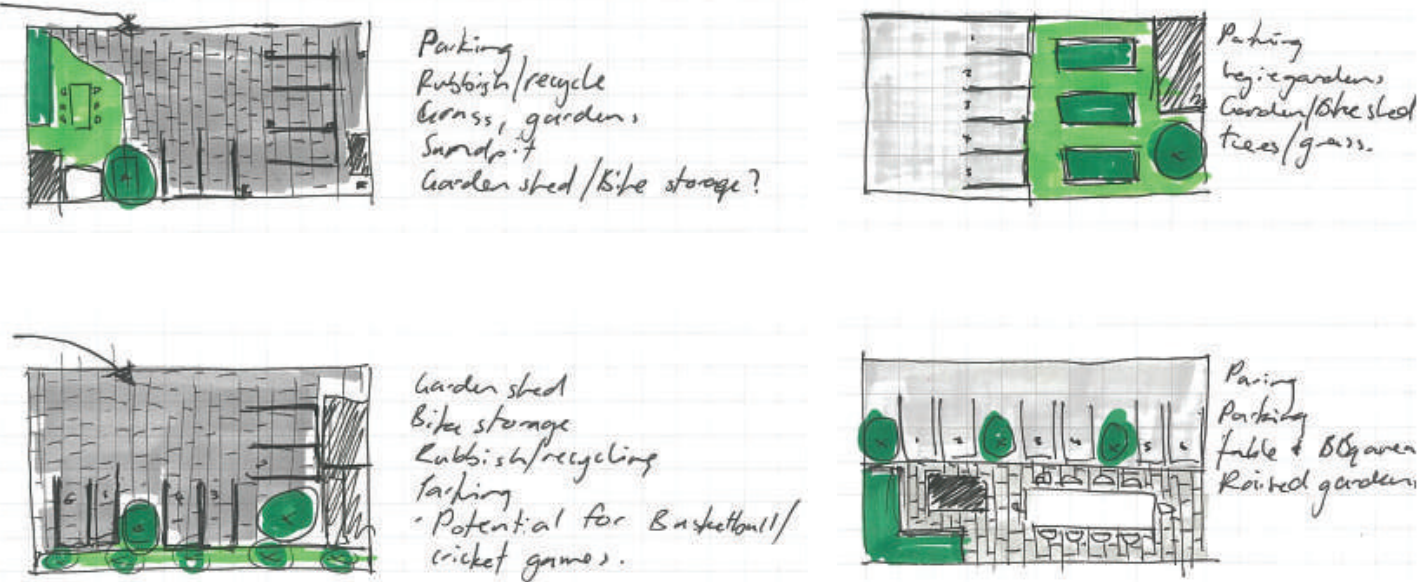

Garden sted

Bite stomere

Eubbish/recycling

- Potential for Bustuctoarl

(ricket games.
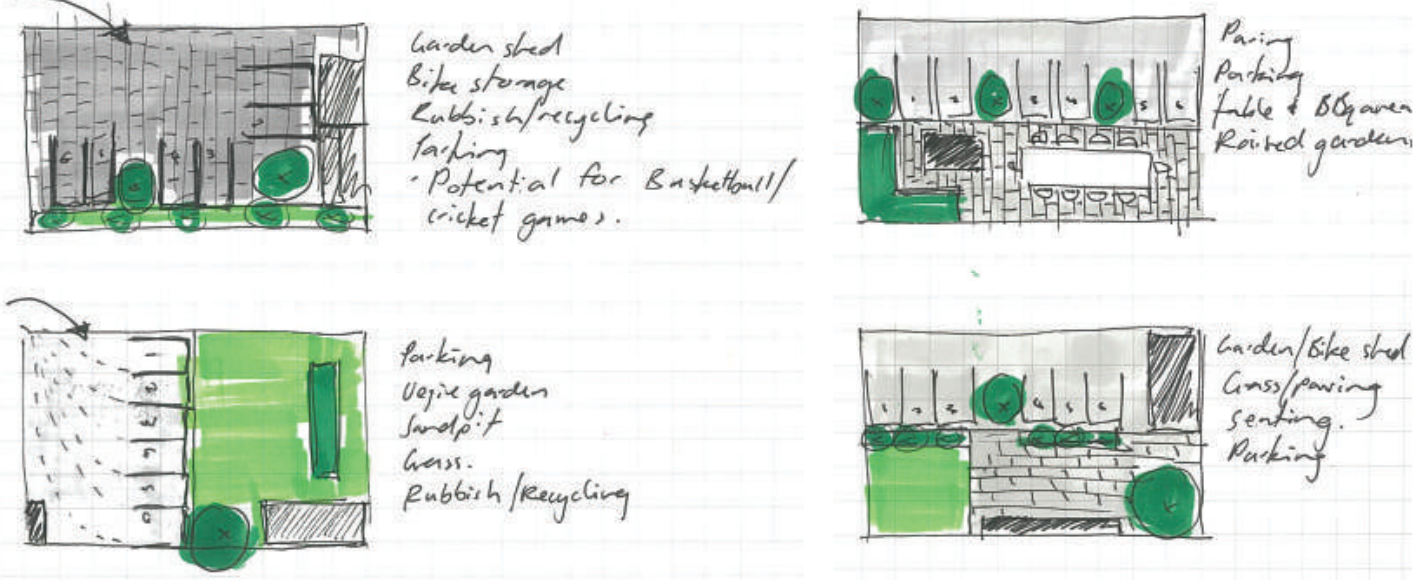

Gaiden/bike stod Guss/paving Paking
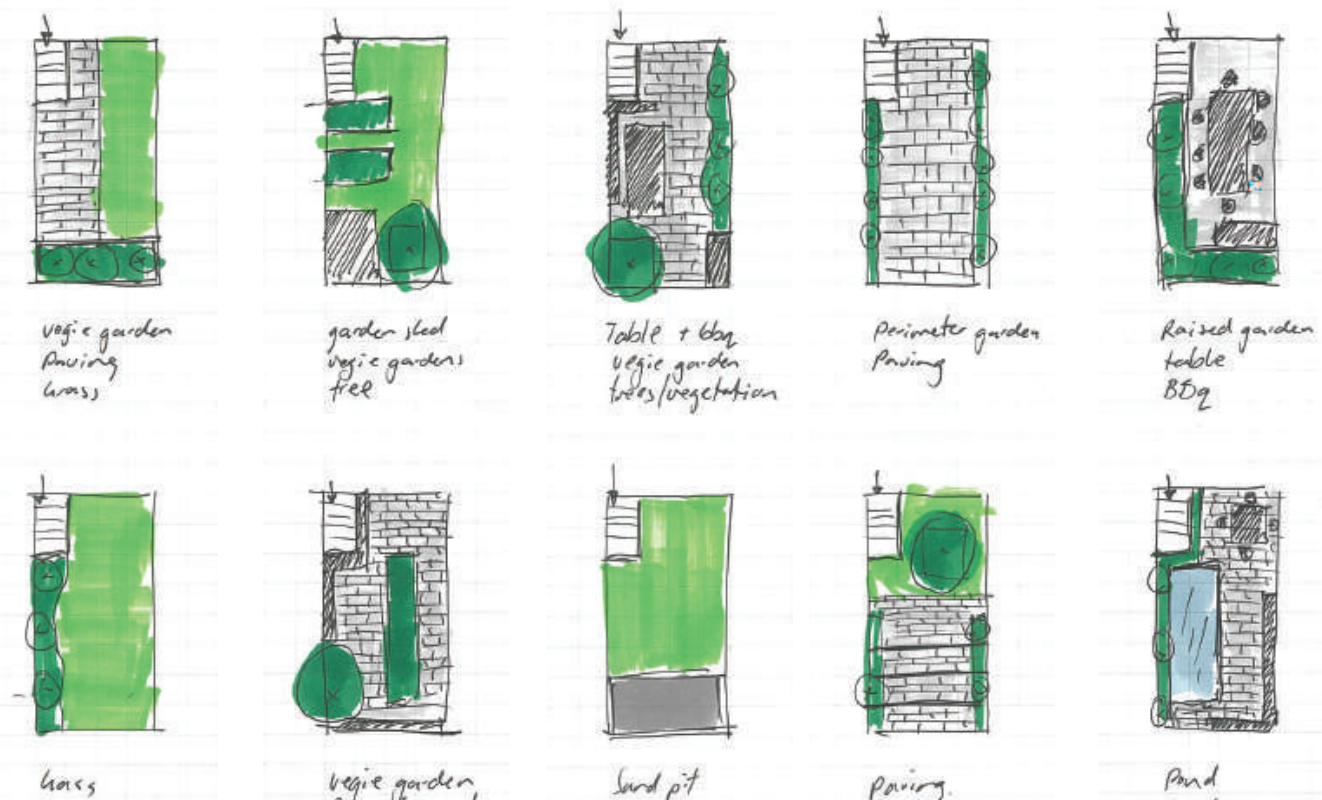

regie garden
perimter seating

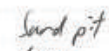

Paring.
Washing fine
trees s garden

pond

Gerdens Table 
The next section critically analysed the experimental design, further testing the scale of intensification and relationship between the dwellings. 


\section{COMMON SPACE Vs PRIVATE SPACE HOW DENSE DO WE GO?}

The experimental design explored intensification of a single site and the maximum density possible. For the next phase of the design, the ratio of common space vs private space was developed - how the design might establish private and common space, between individual and collective, and the relationship between each dwelling and the neighbourhood. Living large in small spaces is about creating qualitative space that appears larger than it is. One way to develop this is by addressing the 'lost' space, i.e quality open spaces, storage, privacy, and how this might be utilised for shared use within the common spaces.

The following options of how to facilitate interaction between residents and provide quality open shared spaces within the development were explored -Rubbish Recycling

- Letterboxes

-Parking

-Court/Paving - area for ball games

- Bike storage

- Garden shed

- Vegie garden

- Barbeque

- Table/eating area

-Playground

- Sandpit

Fig 4.02. (Top right)

*Exploration between private and -Washing line

- Grass area

Fig 4.03.

(Bottom right)

*How the common space might be utilised 

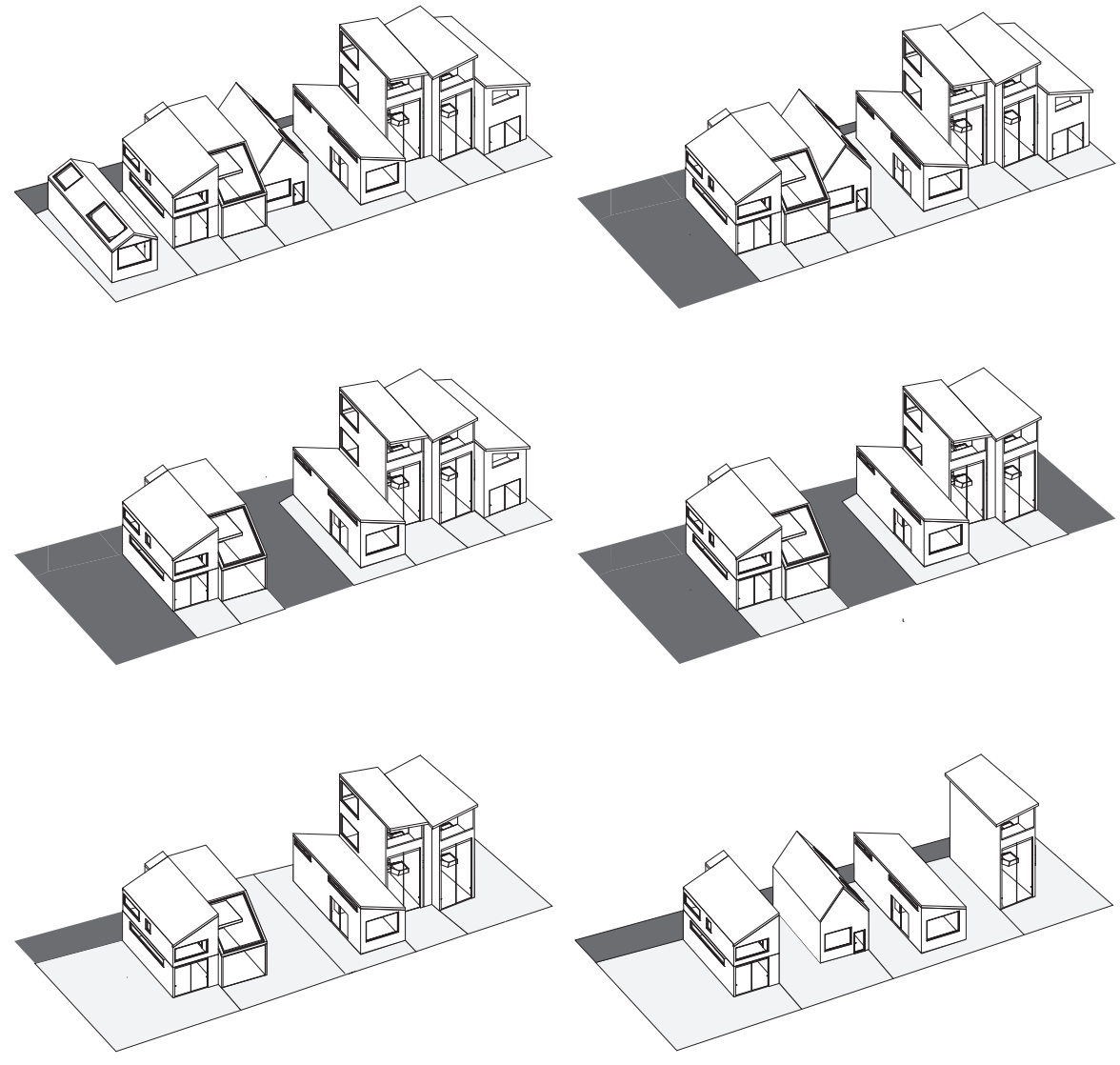

Testing how the common space could be developed through a series of iterations testing size and scale of the areas and location to the dwellings
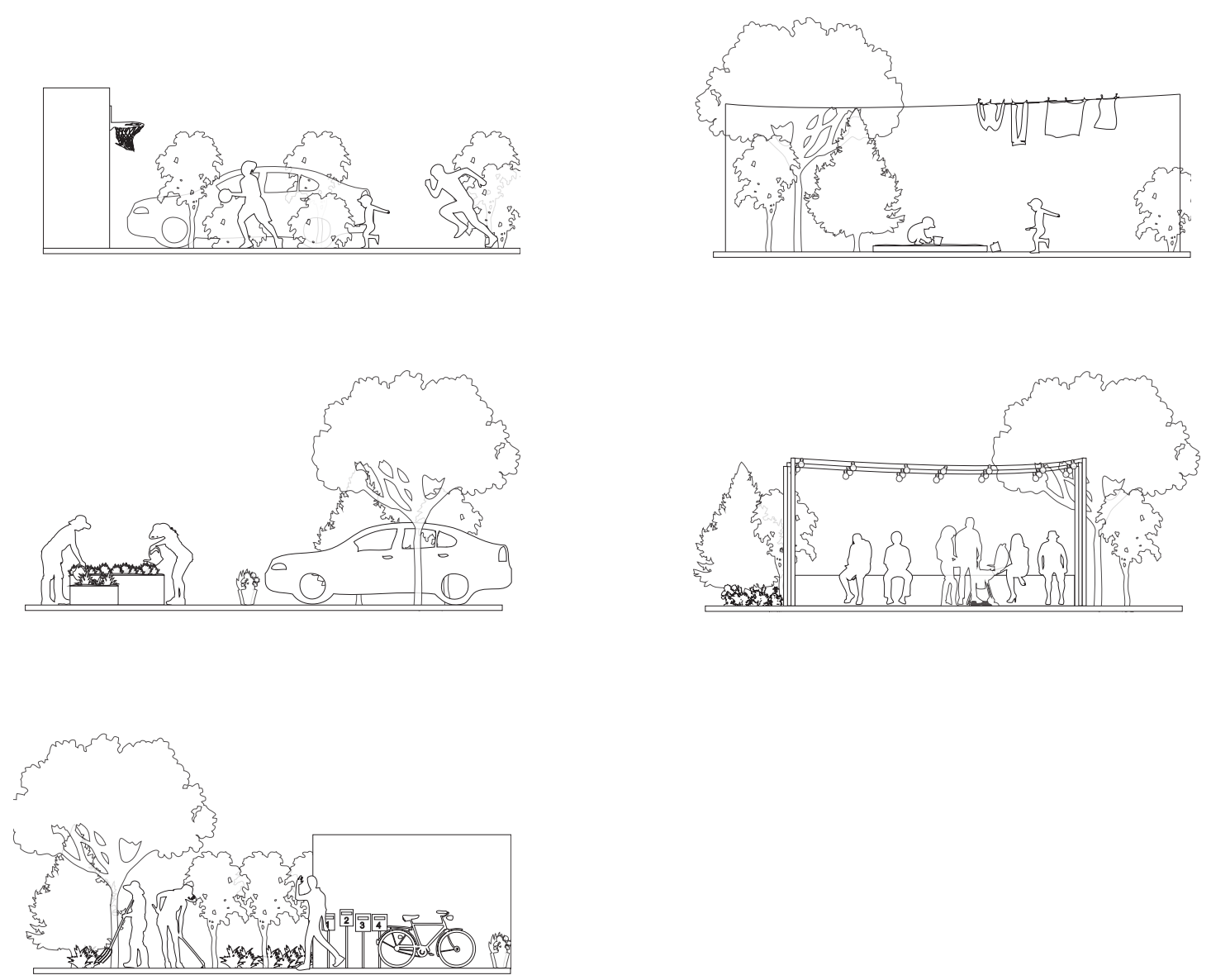


\section{DENSITY + PARKING}

Onsite parking requirements set out by the Wellington District Plan are as follows:

- minimum 1 space per household

- visitor parking for multi unit developments: a minimum 1 dedicated space for every four household units for any proposal that results in 7 or more units

(Wellington City Council, 2017)

With these requirements, a substantial portion of site area is lost to vehicle access. The following set of iterations explored options to minimise site area dedicated solely for vehicle use, and maximise the number of dwellings to fit on site.

With an anticipated decrease in car ownership due to rising fuel prices, it seems unreasonable to dedicate such a large portion of site to parking. Enjoyable open space is essential for the success of medium density housing developments and the loss of amenity due to sole vehicle access is quite significant at this scale of density (Monash University, 2011).

In the short term, vehicle access is a priority but with the site located close to transport amenities it is safe to assume that in future, parking will not be as necessary and some areas dedicated for vehicle access could be adapted for other use. 

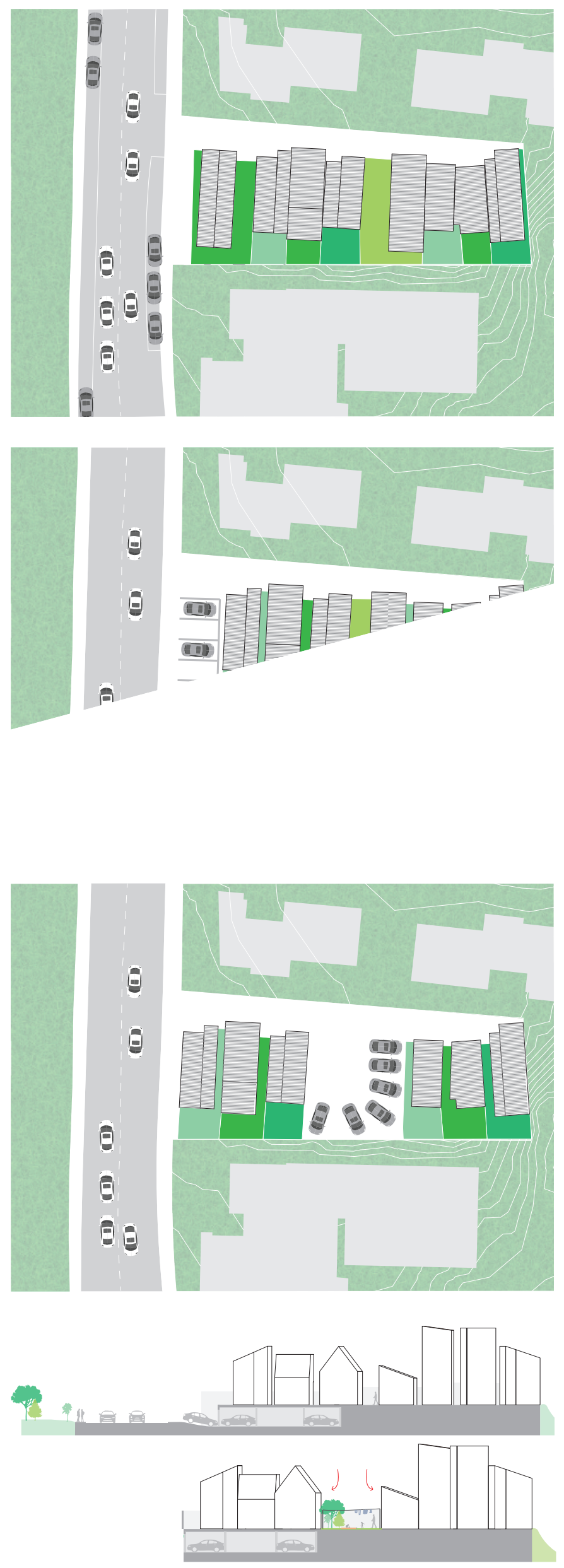

\section{ON STREET}

- 8 Houses

- Max density

- 0 Communal amenities

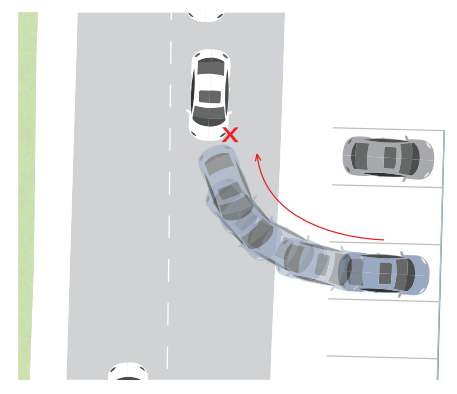

ON SITE EDGE

-7 Houses

- High Density

- 0 Communal amenities

- Less desirable as cars are backing out onto busy street

\section{SITE CENTRE}

- 6 Houses

- Med density

- Potential for communal amenities with extra space

\section{UNDERGROUND PARKING}

\section{- 7 Houses}

- High density

- Pedestrian friendly

- Potential for communal amenities and extra space 


\section{DESIGN DEVELOPMENT}

ITERATION 1: INTERNAL SITE PARKING

This development allowed 6 houses on the site, with central parking. The arrangement was very limited in terms of vehicular access, allowing the space to become vehicle dominated while the area dedicated for shared use became wasted and too small to be utilised effectively.

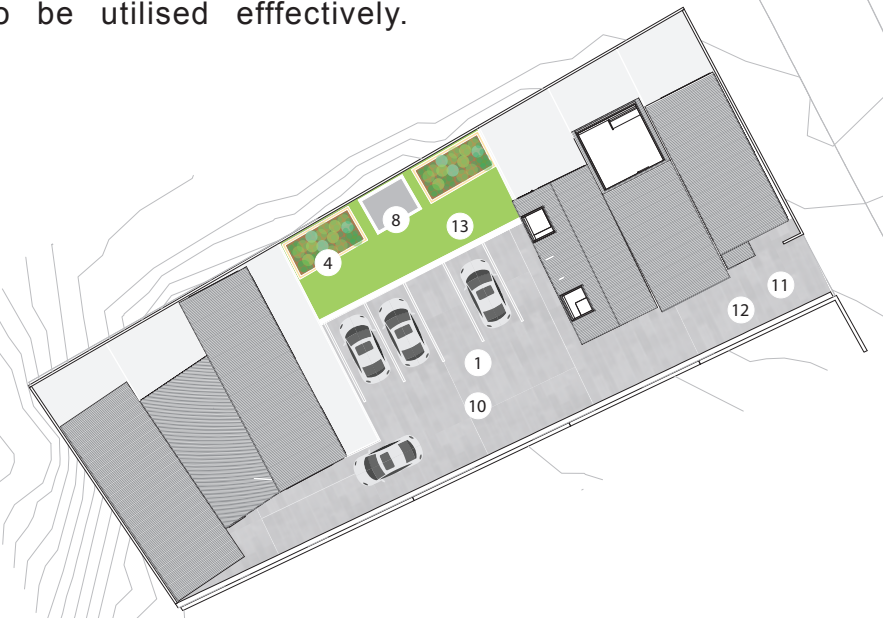

ITERATION 2: UNDERGROUND PARKING

The sites slope allows the ground plane to be elevated without disturbing the existing dwellings or blocking sun on neighbouring properties. Elevating the ground plane allows room for an underground car park with ample storage and covered parking. The common space can be utilised as an access point for residents to the car park and provides an area for interaction and socialising for the residents of 7 dwellings. This also creates a pedestrian friendly zone with added safety for any young children.
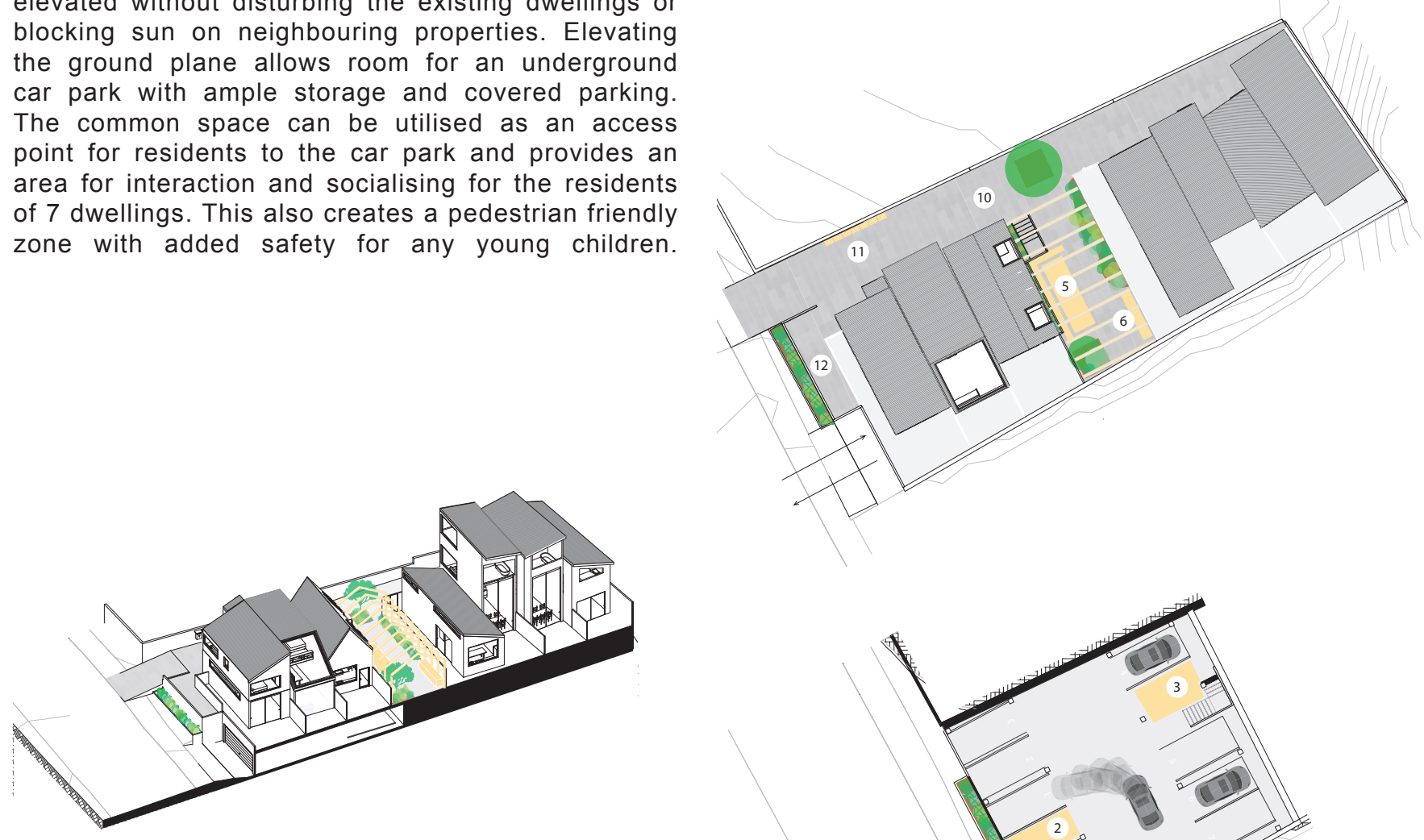
ITERATION 3: PARKING ON SITE

With consideration of affordability, onsite parking was reconsidered. By elevating the single storey house, more space for both parking and common could be developed. This provided covered parking below one dwelling and sufficient space to be utilised efficiently by all residents. An informal stacked parking could be used by the residents, allowing a larger area for shared amenities, gardens and storage.

1 Parking

2 Bike Storage

3 Garden Shed

4 Vegie Garden

5 Table

6 Barbeque

7 Playground

8 Sand Pit

9 Washing Line

10 Court - Area For Ball Games

11 Mail Collection

12 Rubbish/Recycling

13 Grass 


\section{INITIAL DESIGN}

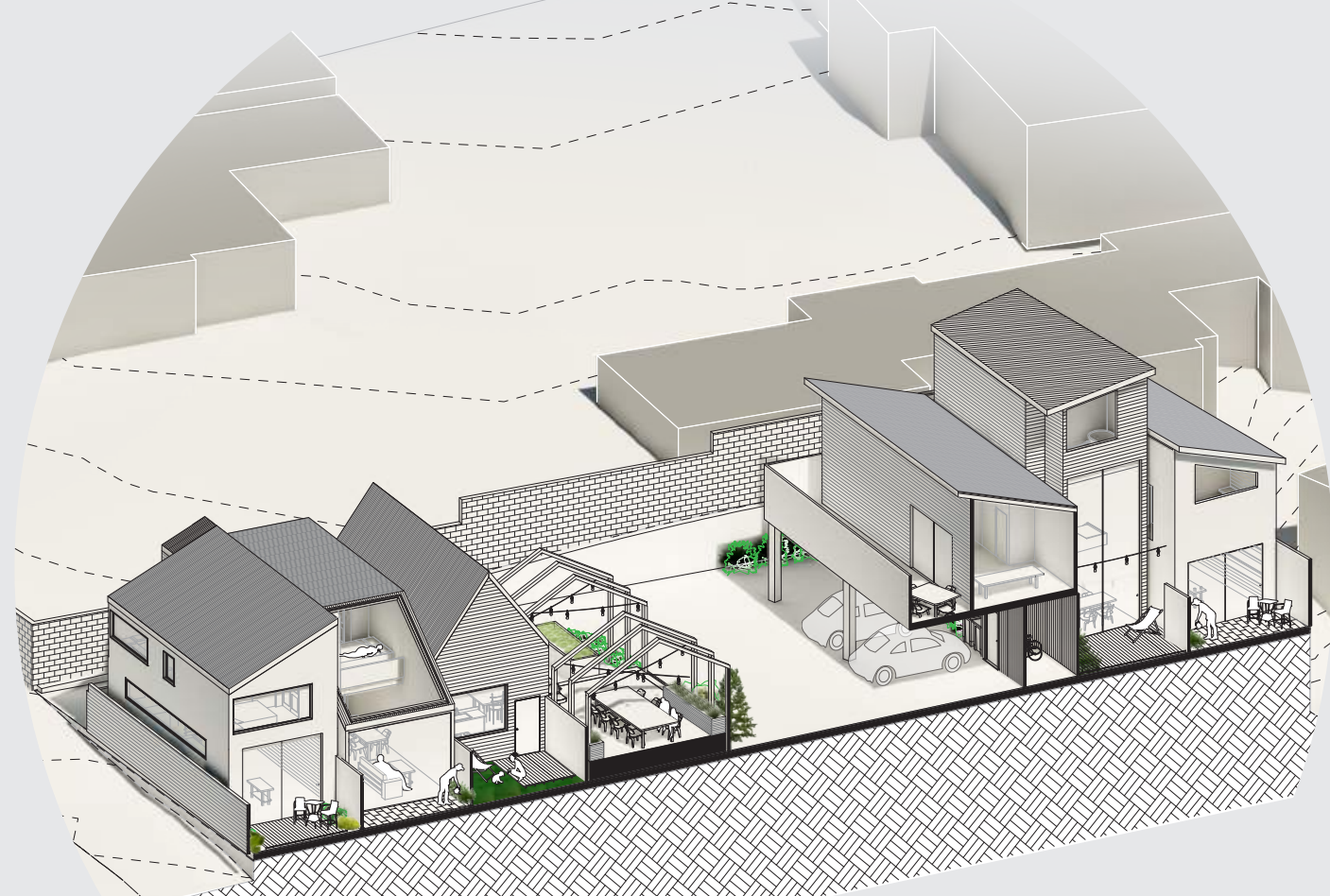

1 Site entrance

2 Mail collection

3 Informal parking

4 Garden/storage shed

5 Rubbish/recycling

6 Barbeque and seating

7 Vegetable garden

Fig 4.07.

* Ground floor site plan 


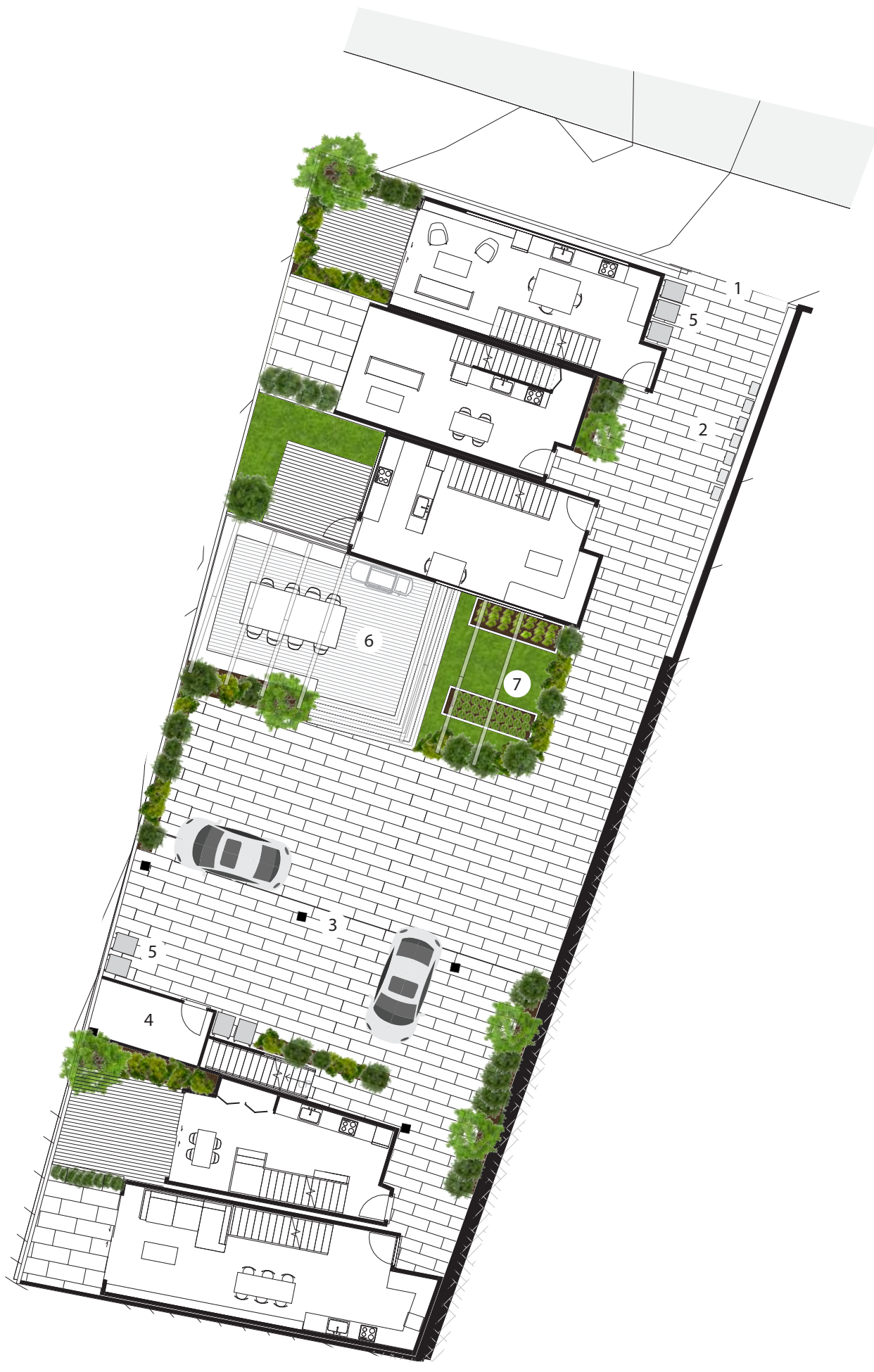

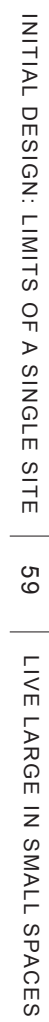




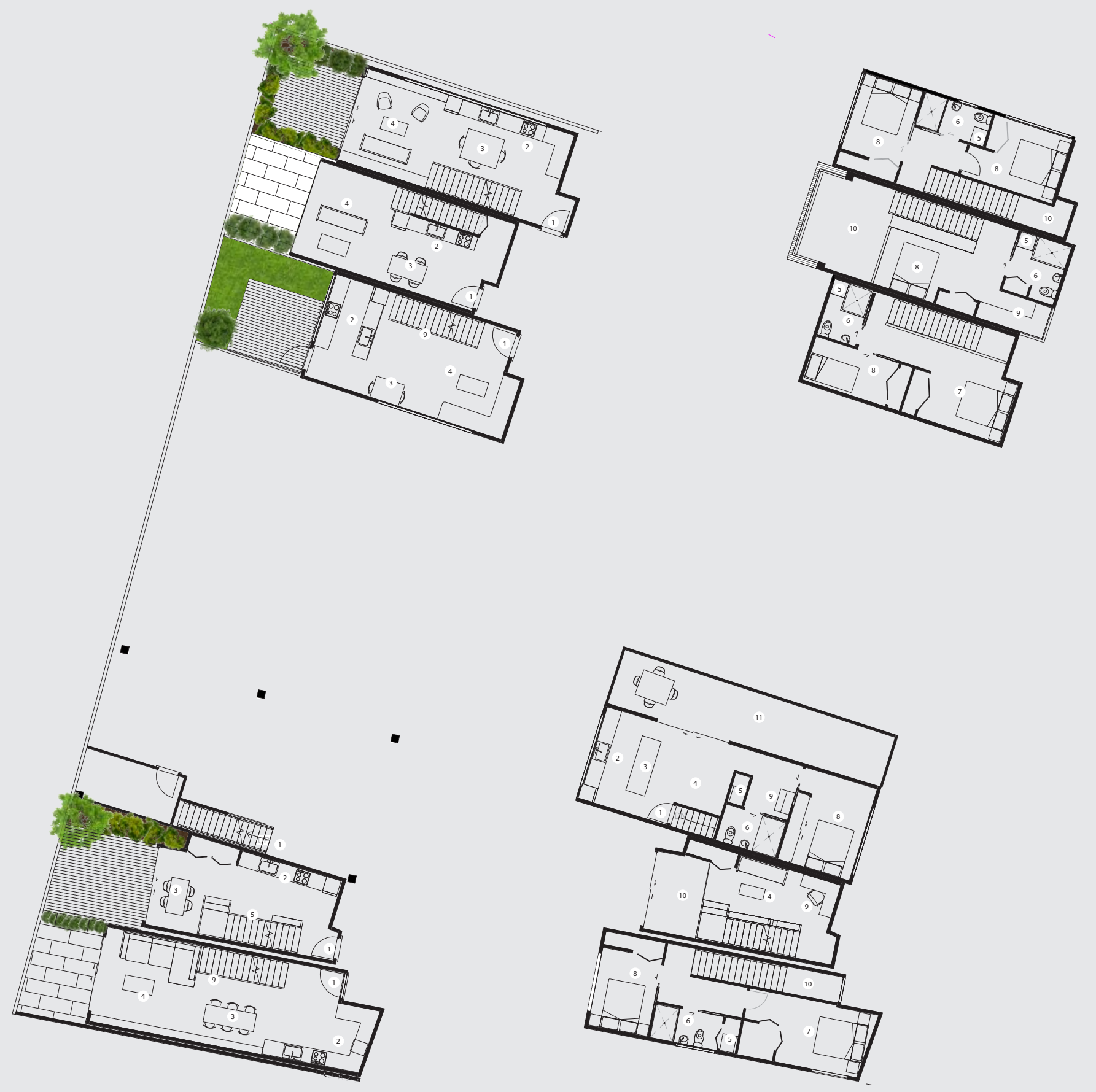




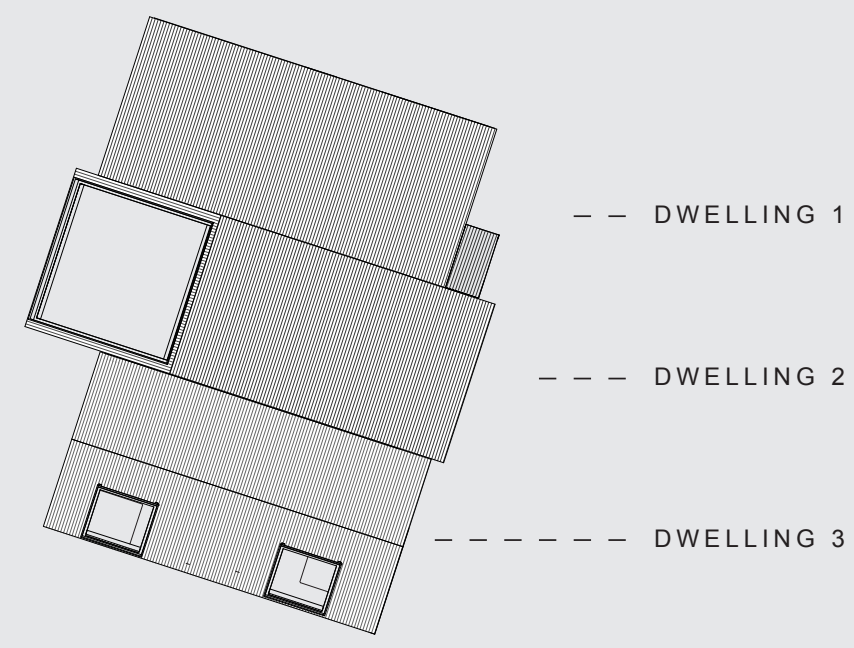

KEY

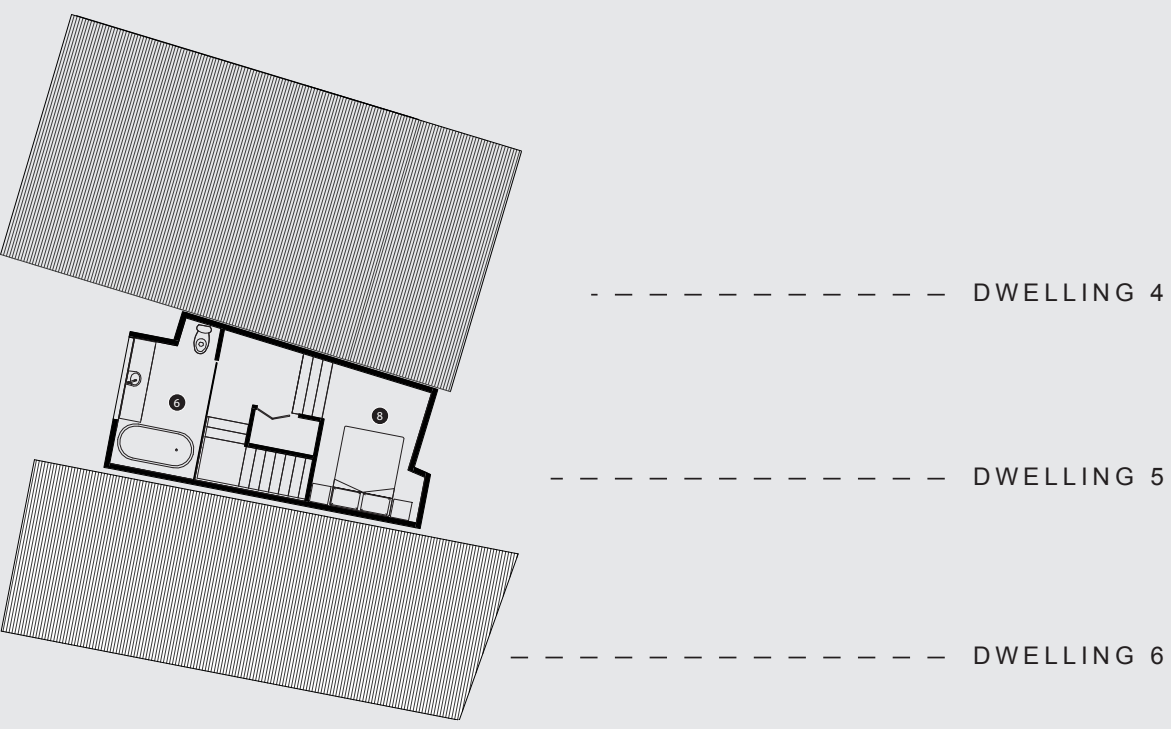
1 Entry
2 Kitchen
3 Dining
4 Living
5 Laundry
6 Bathroom/wc
7 Master bedroom
8 Bedroom
9 Study
10 Mezzanine
11 Balcony 


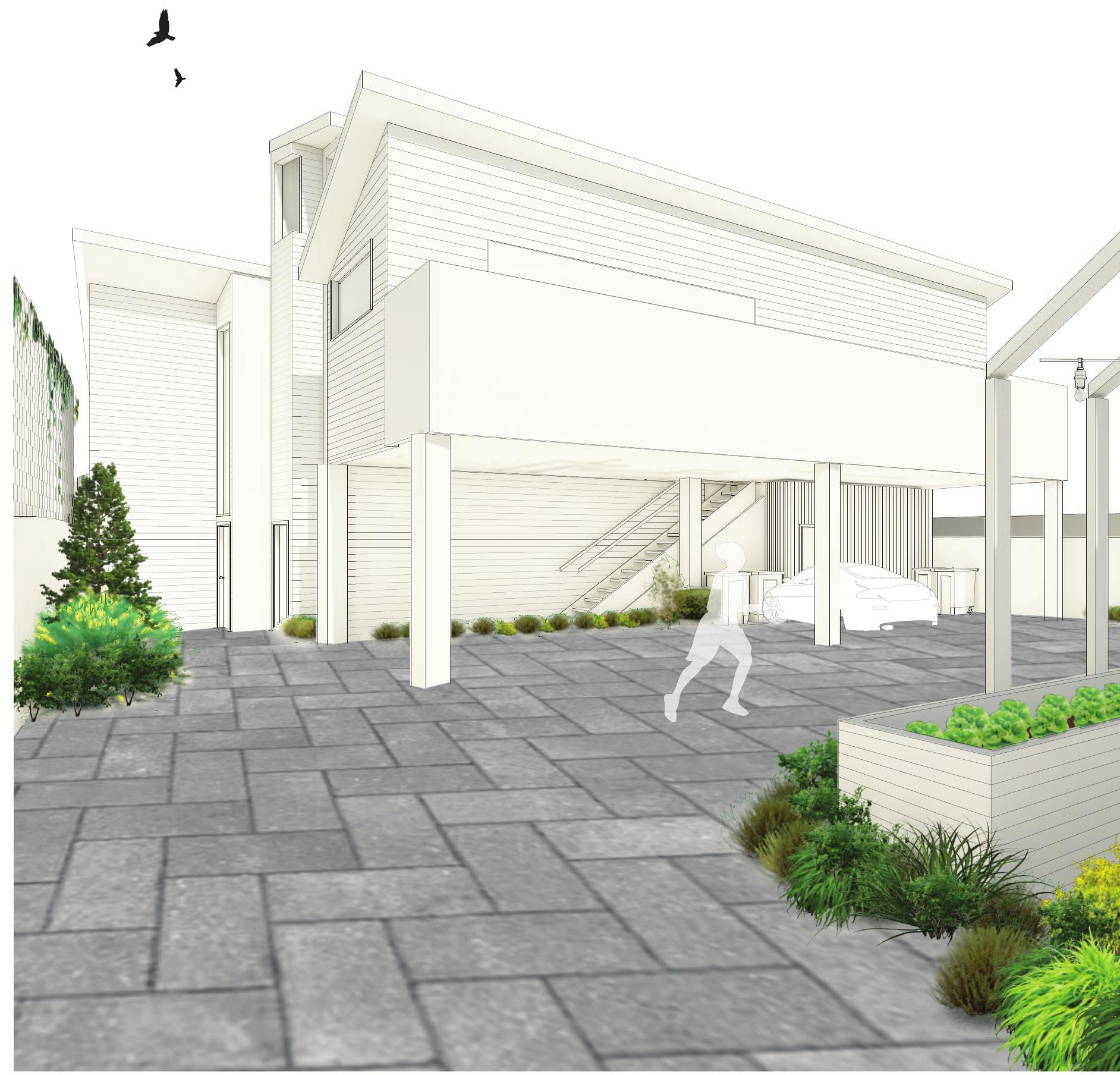

Fig 4.09

${ }^{*}$ An interactive common space of shared amenities 


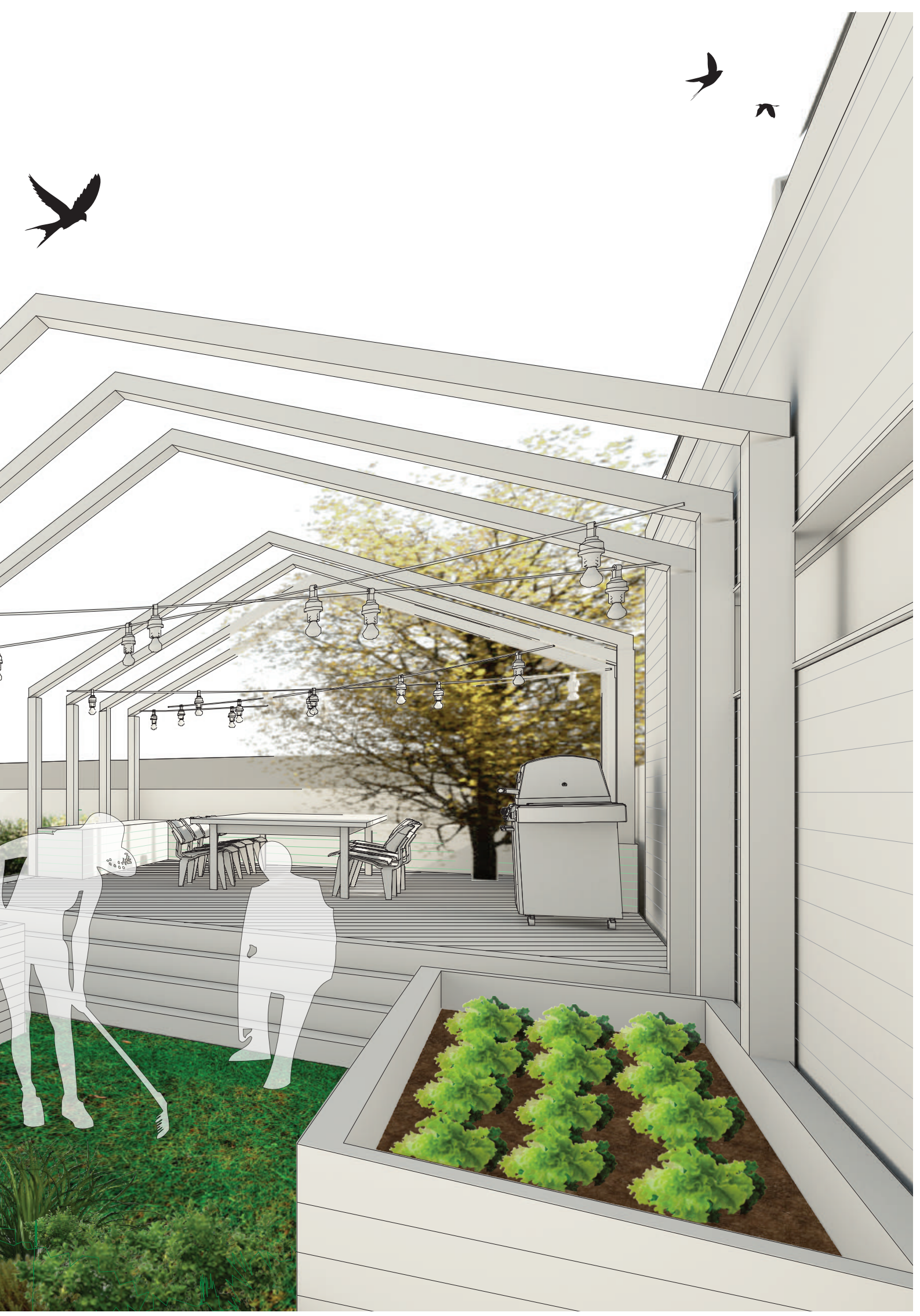

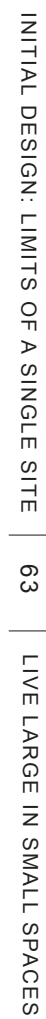




\section{WHERE TO NEXT FINDINGS + REFLECTION}

The 'Small Home' has been developed through 6 compact models, that are spacious and flexible, accommodating a level of individuality and diversity. They cater for the sense of place and security that homeownership provides in New Zealand, providing clear evidence that living large in small spaces can improve affordability of New Zealand housing.

The main objectives of this design-led research investigation is to develop a housing typology model for small dwellings within an Urban context. It should produce a set of guidelines and principles for designing successful small homes and work to develop a new mass gousing typology of small housing for New Zealand.

The first design phase has successfully explored development of small houses on a single site and issues related to 'downsizing' the average sized home. Integrating the balance between private and shared spaces, the design works to invoke a sense of community and relations between residents, but provides privacy and closure when needed.

Issues that need to be developed further should explore the wider context of the site, and the relationship of this intensification on neighbours. Taking into consideration the densification of the site, higher noise levels, more traffic and a mixing of social groups, the proposal will have a serious environmental impact, which brings forth the question, 'How can you accommodate density in a much less dense environment?' and 'How does intensifying a suburb affect the interrelationship between density and pattern of plot subdivisions?'

Close grain street buildings and townhouses activate the street, providing more entrances than other building typologies -

"Their proximity to each other facilitates the creation of more walkable and healthy neighbourhoods that are less dependant on car transport than those comprising other building types."

(Tarbatt, 2012)

Obstacles for such developments are the process of amalgamation (fig 4.10) -combining plots together to then re subdivide for close grain development (Tarbatt, 2012). Therefore, finding a way to redesign a suburb around the existing subdivided sites, at an appropriate increase in density, should be the next phase of design.

To develop small residential living, the scheme would work as a suburban intensification strategy, creating an argument for a change in the district plan. Medium density development within Khandallah is possible, and increasingthe suburban density while retaining similar site covergage will make housing

Fig 4.10. more affordable.

Plot amalgamation and subdivision options

Fig 4.11.

Principal block typologies 

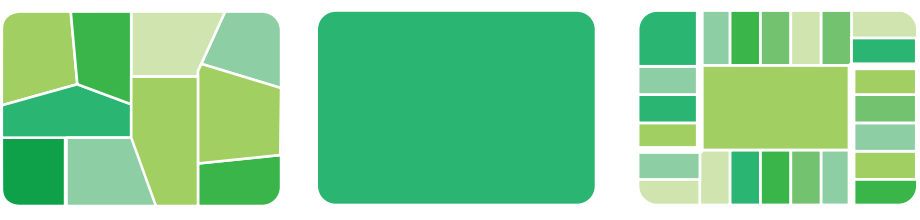

Amalgamating Plots as a means of achieving the desired plot Subdivision

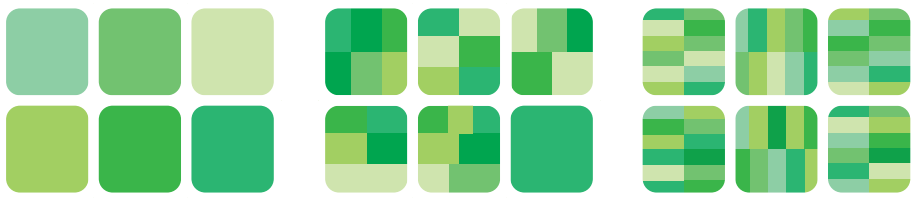

Strategic subdivision options

Principal Block Typologies relevant for medium density development
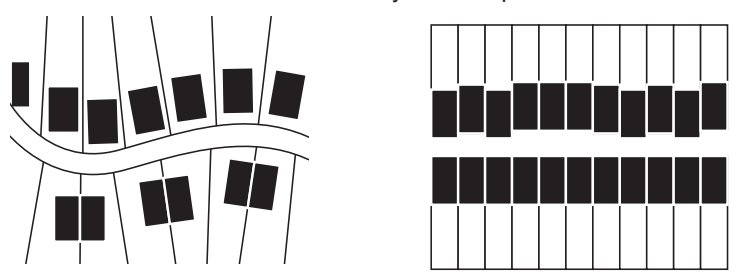

Open Row

Terrace

(Close Grain)

(Close Grain) 


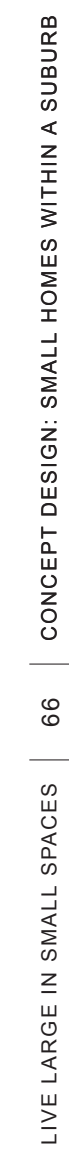




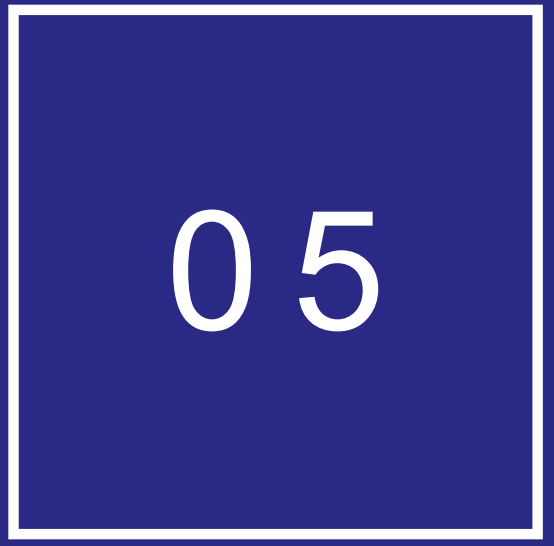

CONCEPT DESIGN

SMALL HOMES WITHIN A SUBURB 


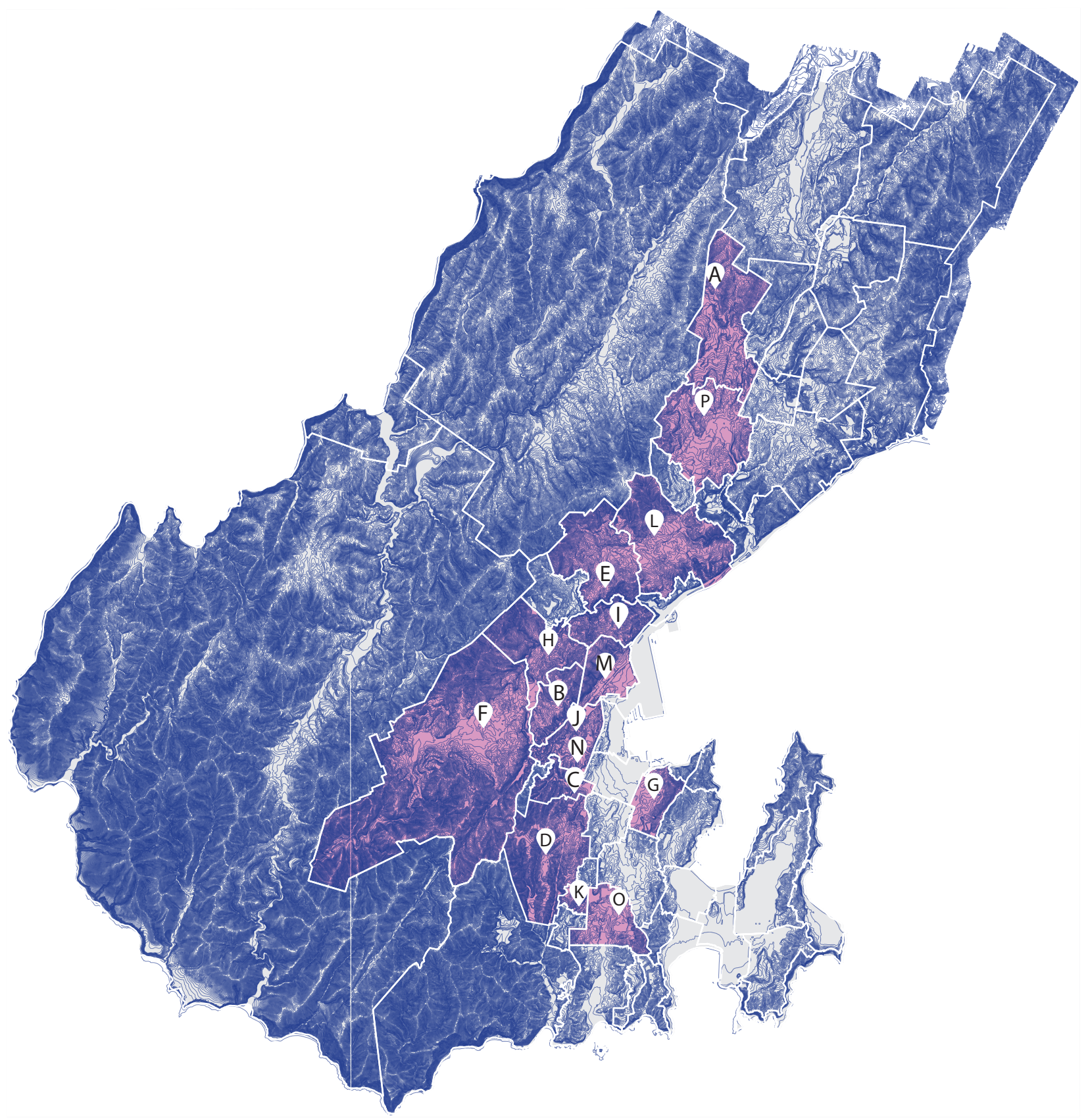

\section{WELLINGTON DPH DENSITY PER HECTARE}

The pattern of existing density around Wellington's suburbs was examined, to test the relation of the proposal against the wider context and feasibility of the intensification strategy.

Phase 3 design re-analysed the site and its potential for intensification. An understanding of the effects of phase 2 outcome on neighbouring sites and

Fig 5.01. (Above) the suburb as a whole.

Wellington suburbs map key

Fig 5.02 .

(Right)

Density per hectare analysis 
A AMESBURY DR, CHURTON PARK $7 \mathrm{DPH}$

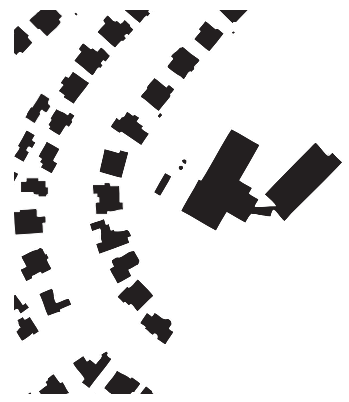

COCKAYNE RD, NGAIO

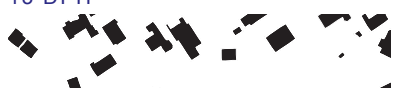

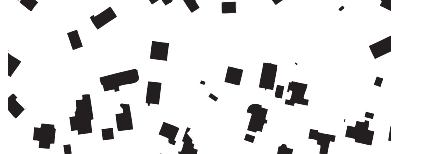

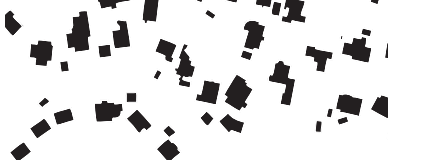
iv

I MAIRANGI RD, WADESTOWN

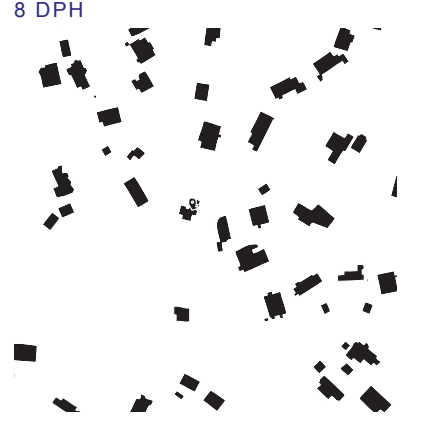

$M$ AORANGI TERRACE, THORNDON $20 \mathrm{DPH}$

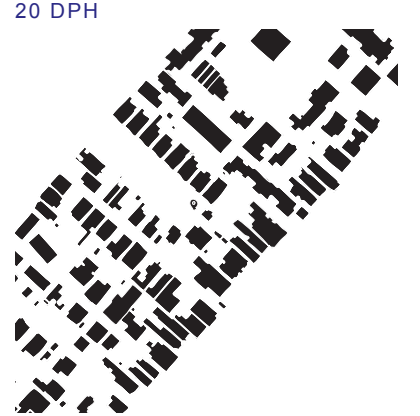

B $16 \mathrm{DPH}$

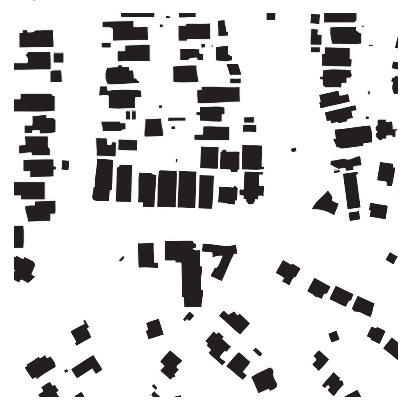

FIRTH TERRACE, KARORI $19 \mathrm{DPH}$

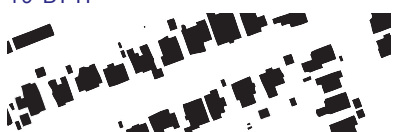

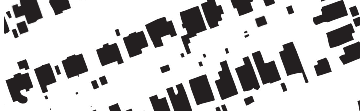

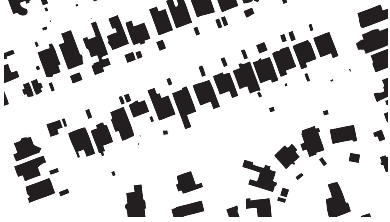

RIMU RD, KELBURN

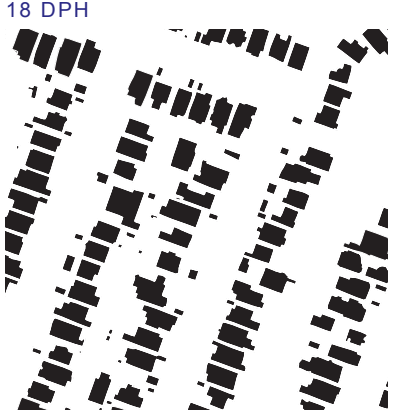
$18 \mathrm{DPH}$

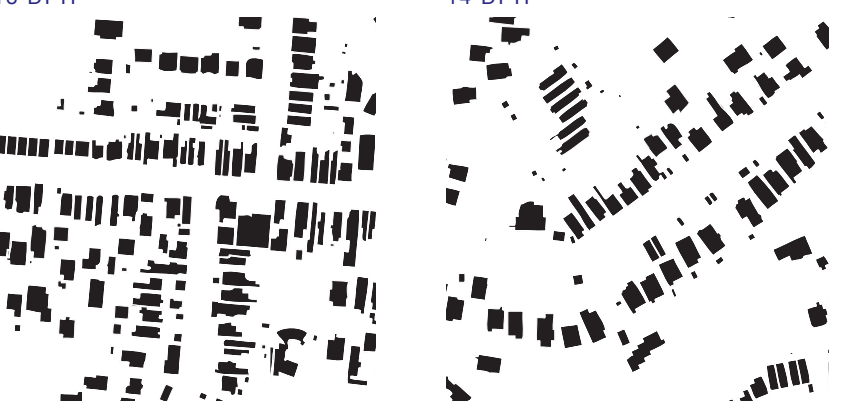

QUEEN ST, MOUNT VICTORIA

(3)

ROCHESTER ST, WILTON $11 \mathrm{DPH}$

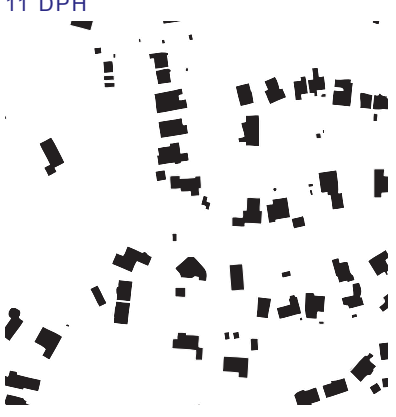

BALFOUR ST, MORNINGTON $9 \mathrm{DPH}$
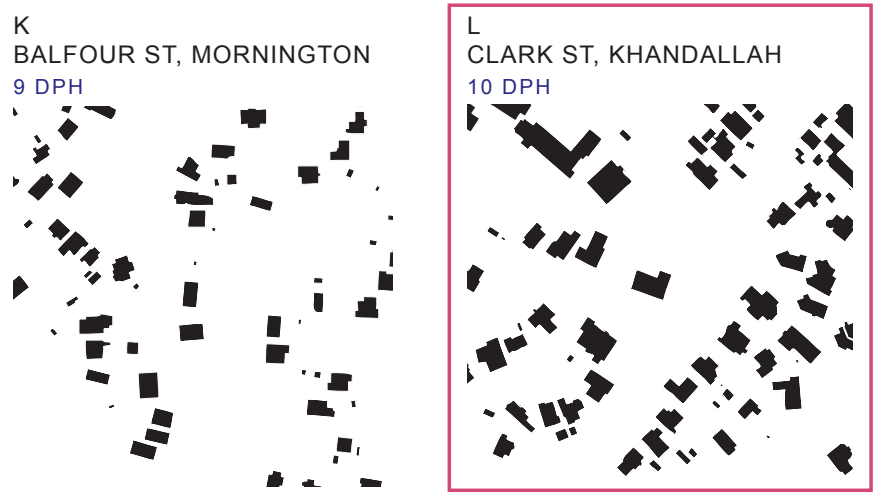

LUXFORD ST, BERHAMPORE $22 \mathrm{DPH}$

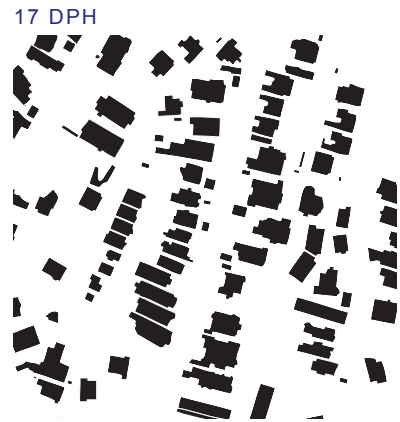

WOODLAND ROAD, JOHNSONVILLE (3PH 

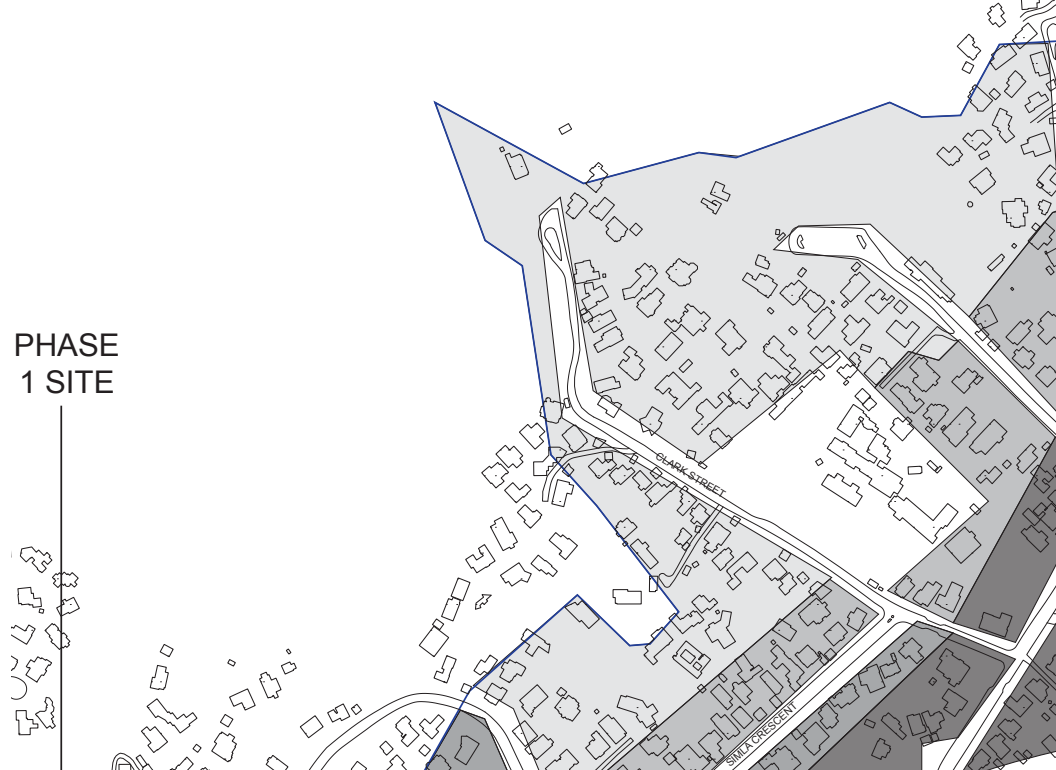

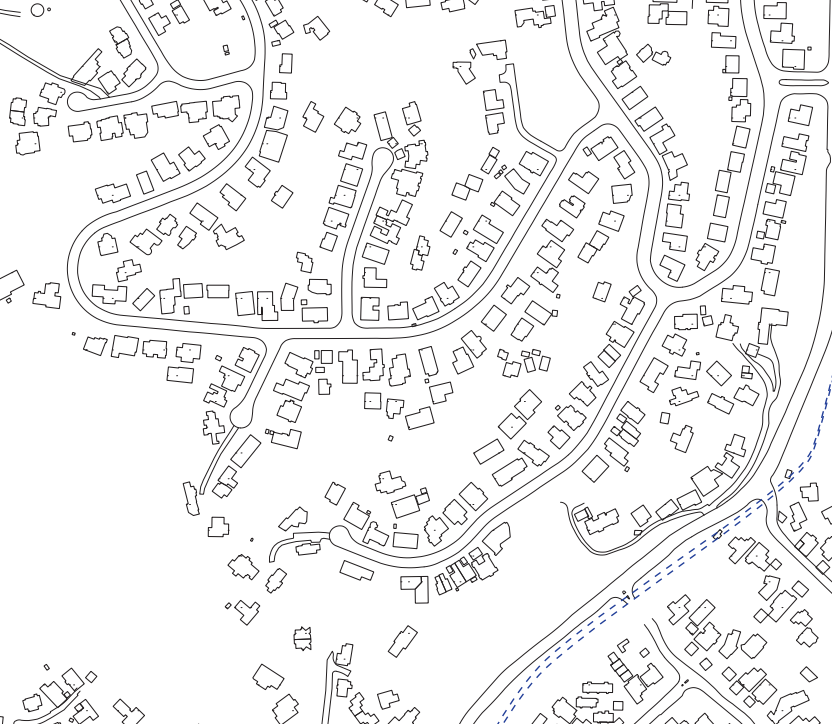

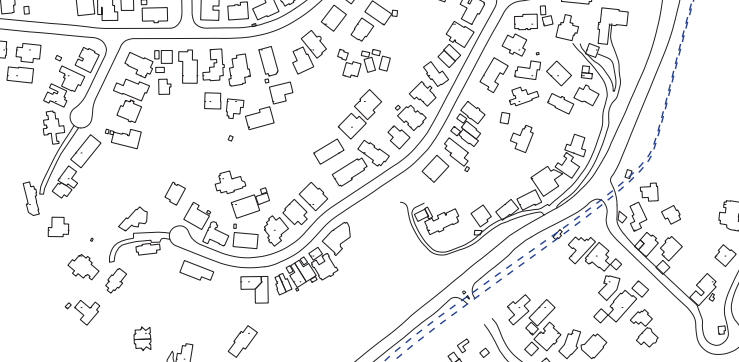

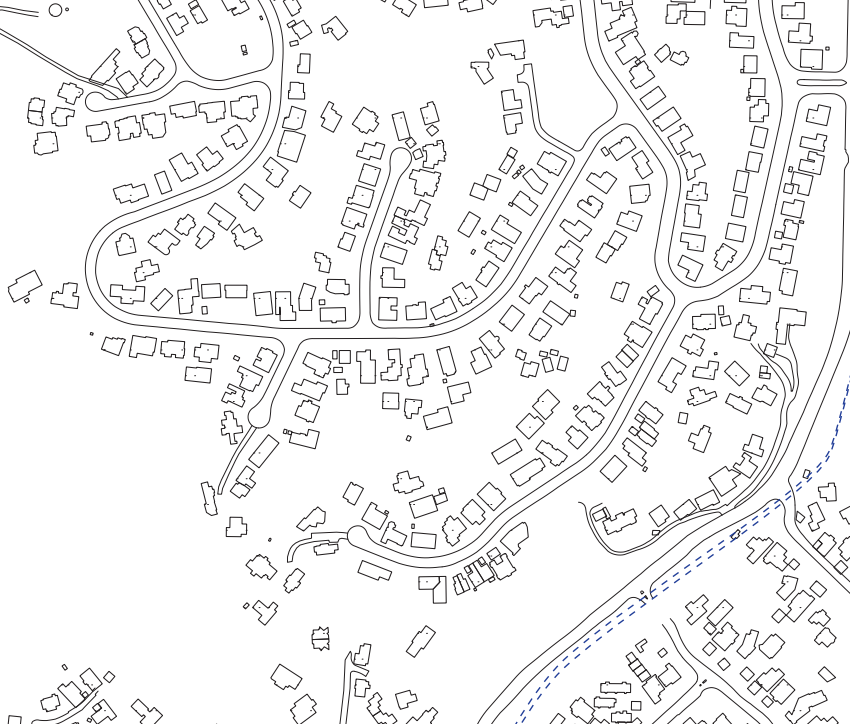

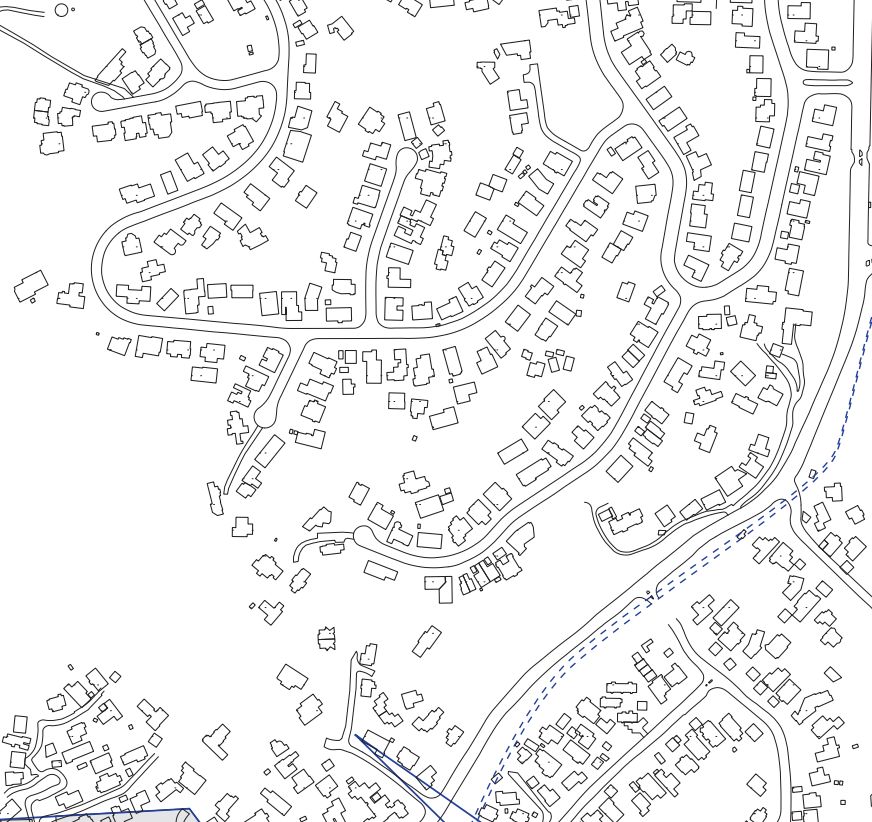

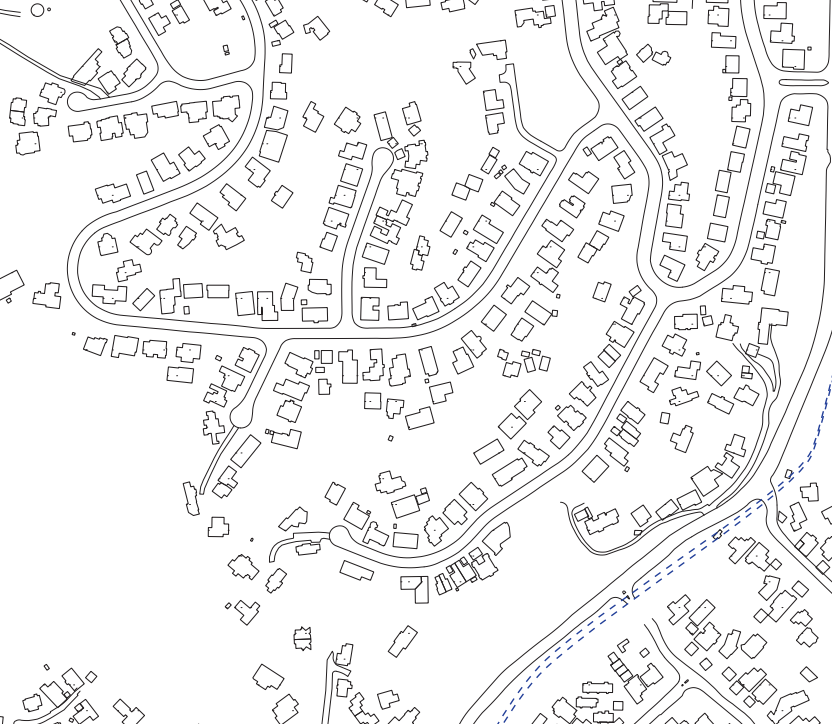

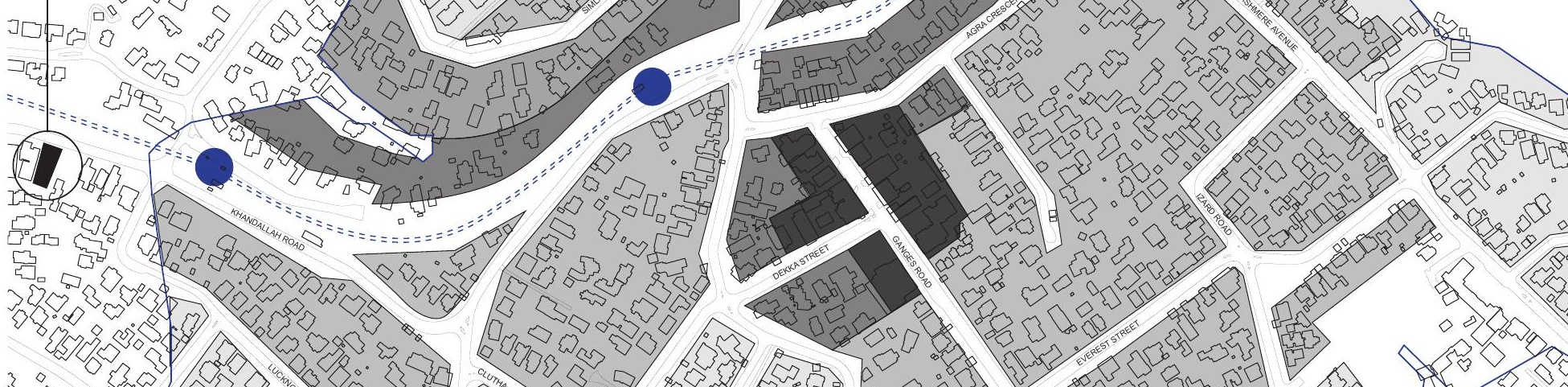

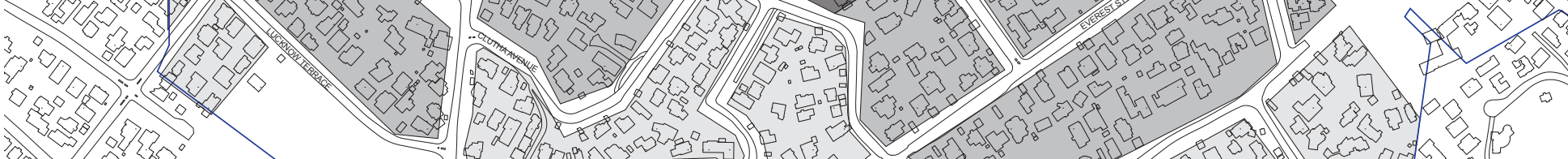

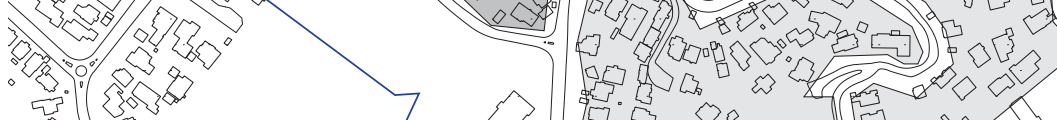

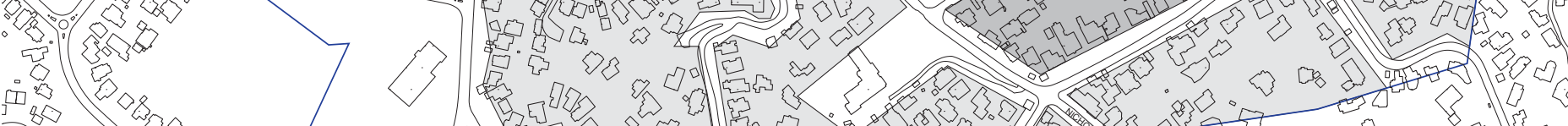

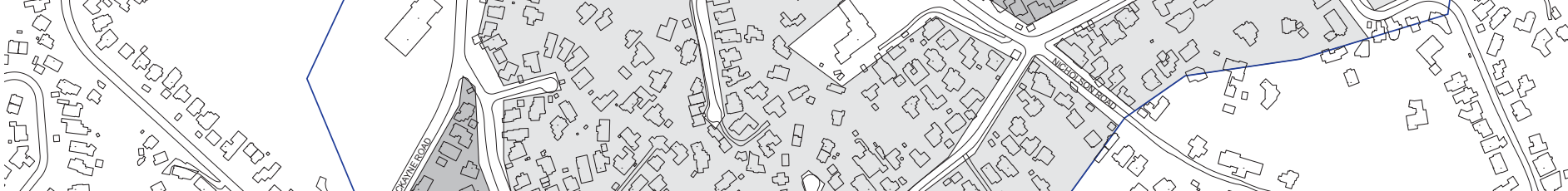

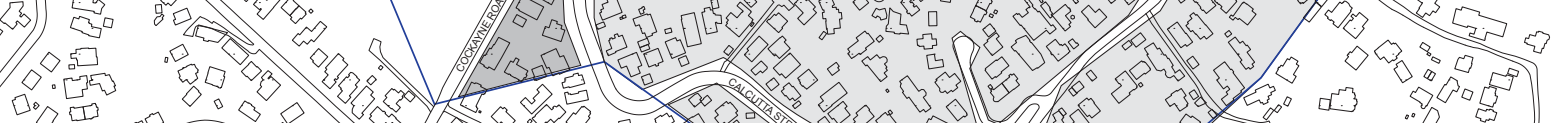
品地 क 00 .

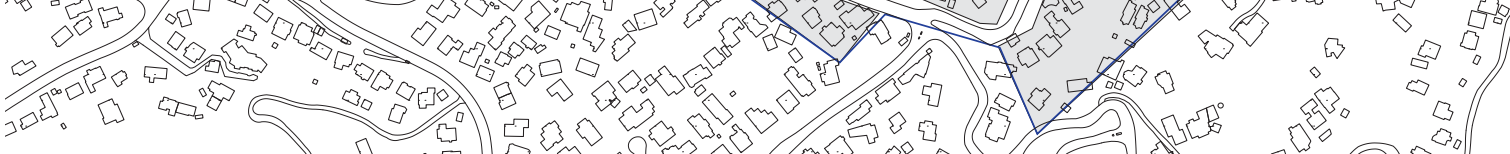
8,5

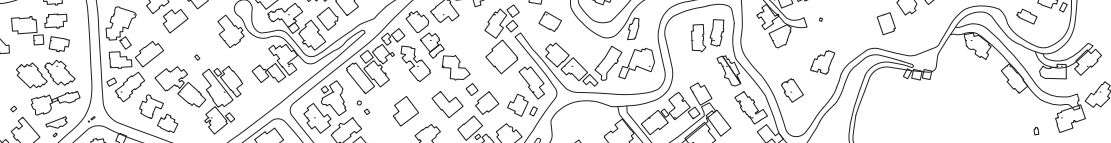

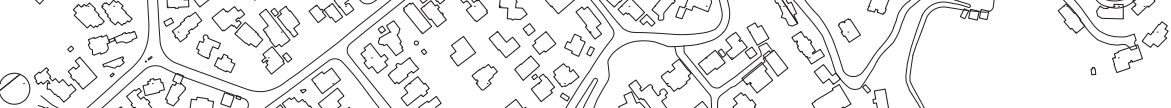




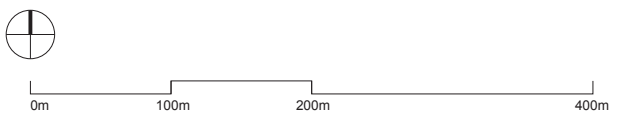

O KHANDALLAH STUDY AREA

O EXCLUDE FROM MEDIUM DENSITY AREA

O POTENTIAL AREAS FOR MEDIUM DENSITY HOUSING

O POTENTIAL AREAS FOR MEDIUM

DENSITY HOUSING (LOWER DENSITY)

- VILLAGE CENTRE

TRAIN STATIONS

\section{INTENSIFICATION ZONING}

Redevelopment of Wellington's suburbs should be driven by proximity to transport and activity centres. As one of Wellington's wealthiest suburbs, Khandallah has the potential to accommodate an increase in population. With high access to public amenity, transport and services, the suburb already has the infrastructure needed to accommodate intensification. It's comparatively low density housing holds great opportunity for medium density and infill development.

Investigating future development and rezoning of land around Khandallah's centre, Urban Perspectives Ltd completed a Character study on the suburb for the Wellington City Council (Urban Perspectives Ltd, 2016). The area studied was within 10 minutes walking distance to the village centre, shown by the following map (Fig 5.03). The purpose of the assessment was to indicate where new medium density development would be most appropriate and refine the District plans zoning rules to allow for this.

Landform/Landscape setting, spatial structure and built form are all elements that contribute to the character of the area. Khandallah is a low-density suburb with an undulating topography and open green character (Urban Perspectives Ltd, 2016). The introduction of medium density zoning will largely influence and change the suburbs character, in which the following map outlines where within the study area, medium density development could be considered.

It was found that areas of steep slopes, generally located on the periphery of the study boundary, would be unsuitable for intensification as these would need extensive earthworks (Urban Perspectives Ltd, 2016). Areas along the Railway corridor and centre would be most suitable for intensification, as medium density development would be easier to manage along these flatter sites, having the potential to accommodate a variety of housing needs.

The character study is a useful tool when assessing the wider context of site 1 , and the relationship the site has with neighbouring sites. The areas with potential for medium density will be investigated further, to explore consequences of intensification for the suburb, and to determine limits and recommended patterns of intensification. This will occur by testing the implications of the small housing typology on multiple sites. 
Case Study 01

64 Khandallah Road, Khandallah

$\begin{array}{ll}\text { Number of lots: } & \text { Single lot } \\ \text { Dwellings: } & \text { Single occupancy } \\ \text { Site area: } & 612 \mathrm{~m}^{2} \\ \text { Built Footprint: } & 155 \mathrm{~m}^{2}-25 \% \\ \text { Driveway: } & 22 \mathrm{~m}^{2}-3.5 \% \\ \text { Private open space: } & 435 \mathrm{~m}^{2} \\ \text { Dwelling Floor area: } & 155 \mathrm{~m}^{2}\end{array}$
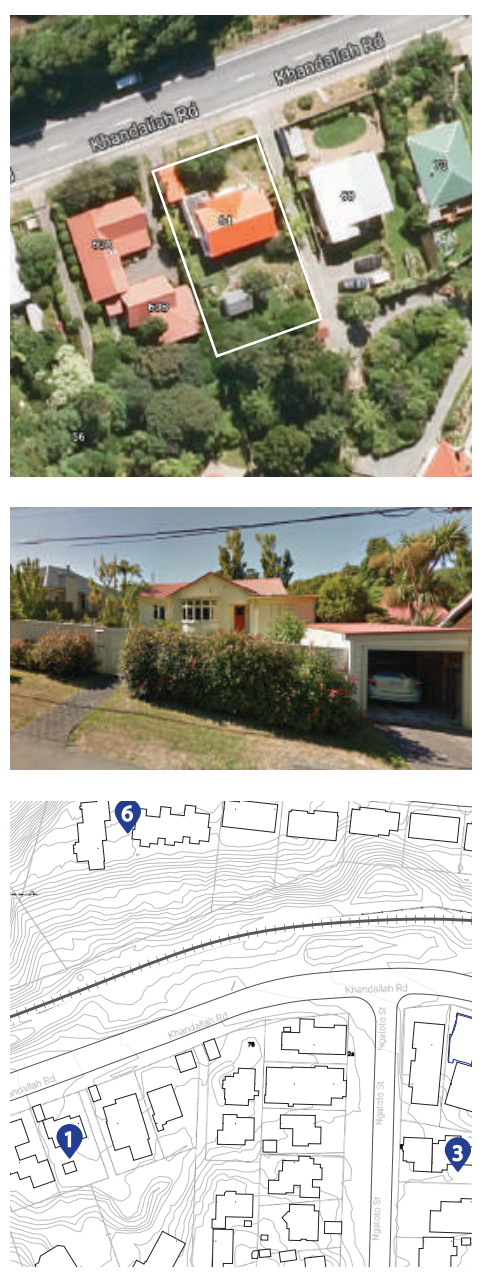

Case Study 02

3 Swansea Street, Khandallah

Number of lots: Single lot

Dwellings: Double occupancy

Site area: $\quad 400 \mathrm{~m}^{2}$

Built Footprint: $\quad 201 \mathrm{~m}^{2}-50 \%$

Driveway:

$55 m^{2}-13 \%$

Private open space: $72 \mathrm{~m}^{2}$

Dwelling Floor area: $100 \mathrm{~m}^{2}$
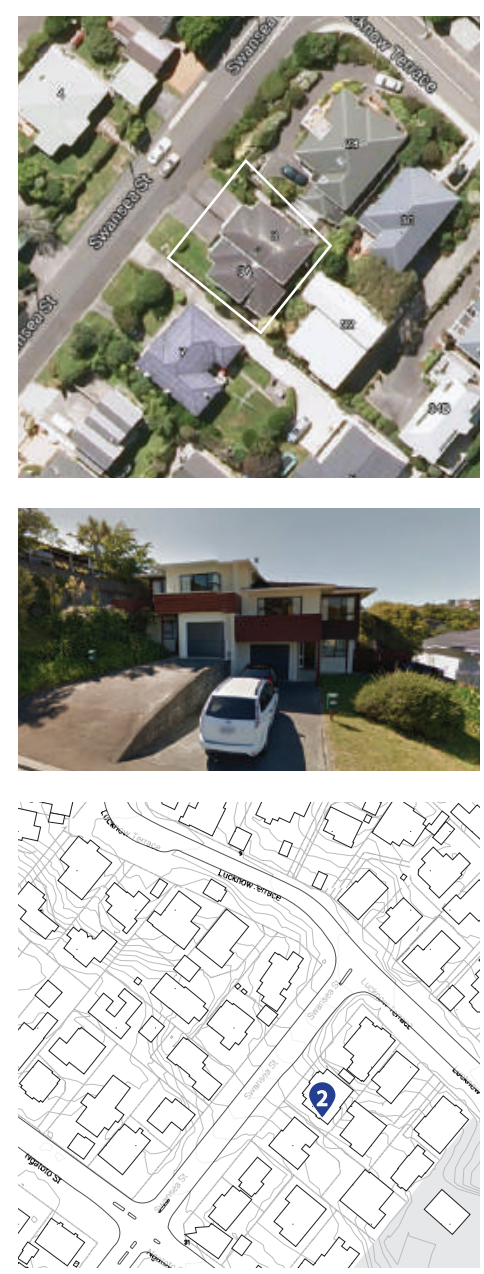

Case Study 03

5 Ngatoto Street, Khandallah

Number of lots: $\quad$ Single lot

Dwellings: Triple occupancy

Site area: $\quad 783 \mathrm{~m}^{2}$

Built Footprint: $\quad 330 \mathrm{~m}^{2}-42 \%$

Driveway:

$123 m^{2}-15 \%$

Private open space: $110 \mathrm{~m}^{2}$

Dwelling Floor area: $110 \mathrm{~m}^{2}$
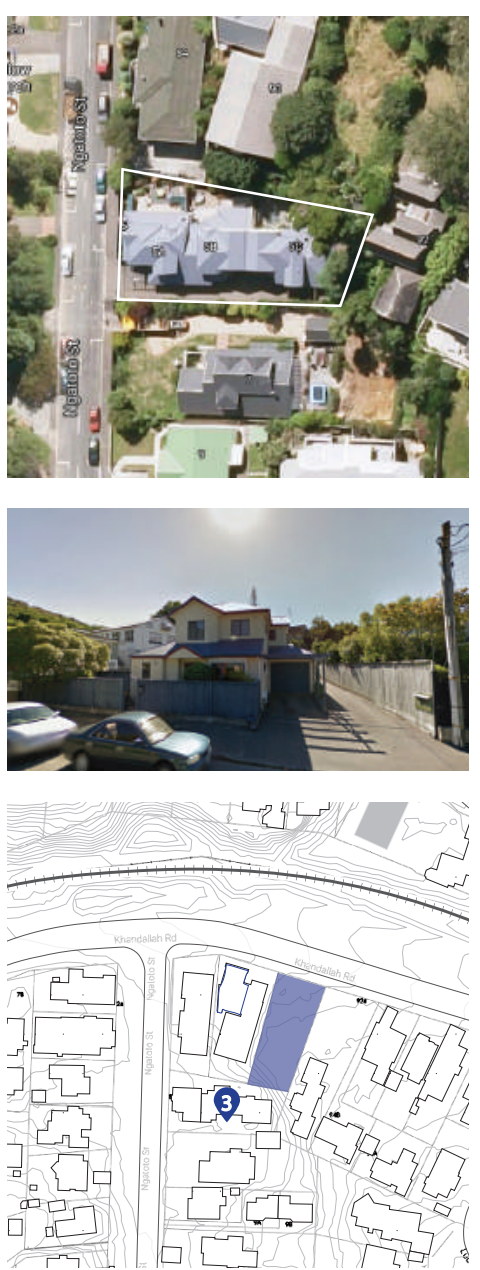

\section{KHANDALLAH HOUSING MODELS}

The analysis of housing models around Khandallah showed that developments of medium density scale were already existing within the suburb. Proving that the proposal for Site 1 fits within Khandallahs character. 
Case Study 04

57 Simla Cresent, Khandallah

Number of lots: Single lot

Dwellings: Quadruple occupancy

Site area:

Quadruple occupancy

Built Footprint:

$187 m^{2}-39 \%$

Driveway: $217 m^{2}-45 \%$

Private open space: $17.5 \mathrm{~m}^{2}$

Dwelling Floor area: $46 \mathrm{~m}^{2}$
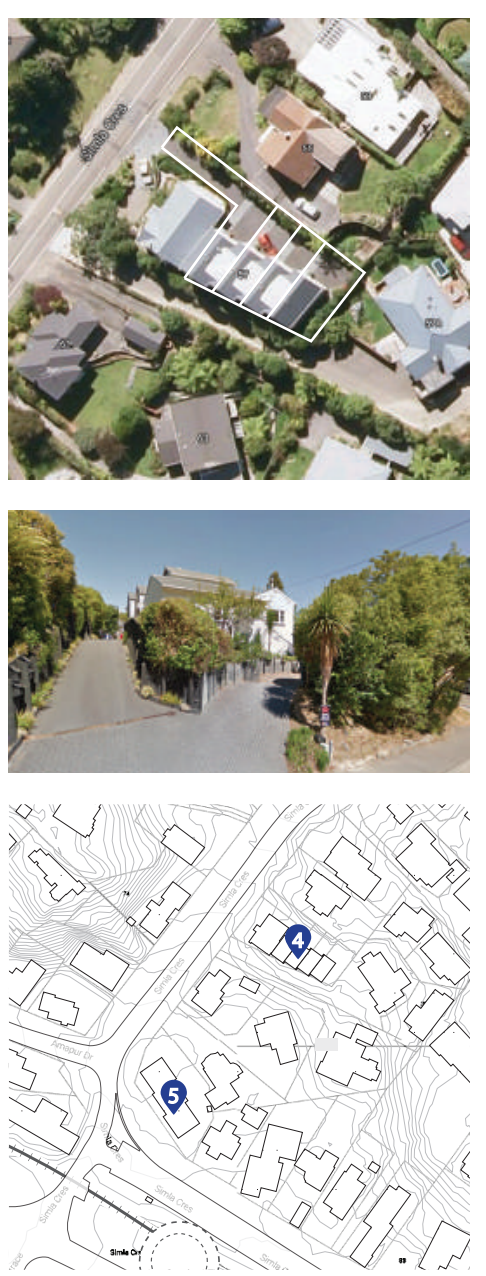

Case Study 05

69 Simla Cresent, Khandallah

Number of lots: Single lot

Dwellings: Triple occupancy

Site area: $\quad 744 \mathrm{~m}^{2}$

Built Footprint: $\quad 222 \mathrm{~m}^{2}-30 \%$

Driveway:

$130 m^{2}-17 \%$

Private open space: $130 \mathrm{~m}^{2}$

Dwelling Floor area: $74 \mathrm{~m}^{2}$
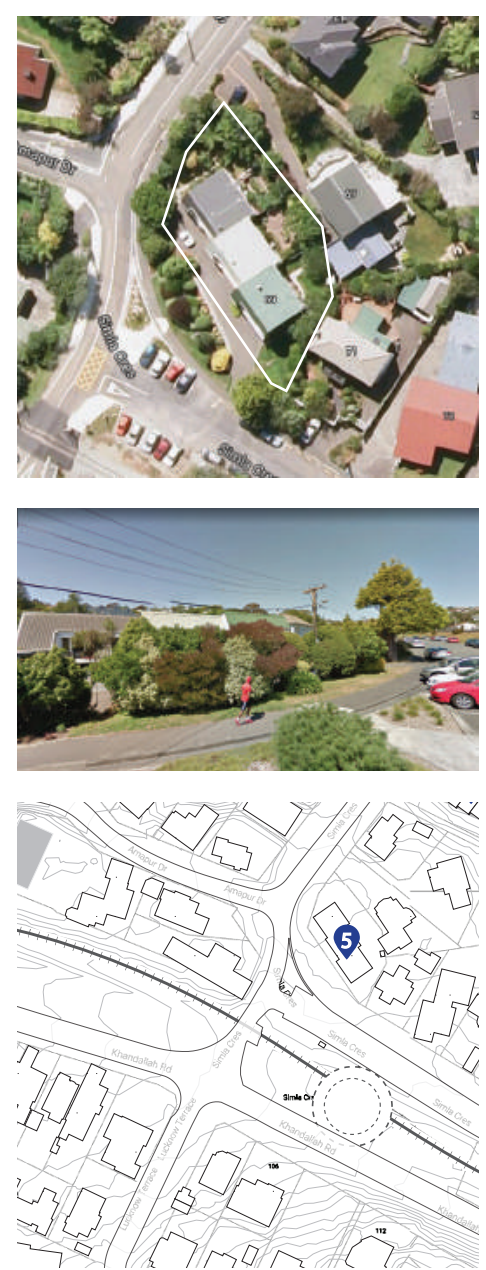

Case Study 06

57 Simla Cresent, Khandallah

Number of lots: $\quad$ Single lot

Dwellings: Ten occupancy

Site area: $\quad 4,700 \mathrm{~m}^{2}$

Built Footprint: $\quad 930 \mathrm{~m}^{2}-20 \%$

Driveway:

$462 m^{2}-10 \%$

Private open space: $330 \mathrm{~m}^{2}$

Dwelling Floor area: $70-90 \mathrm{~m}^{2}$
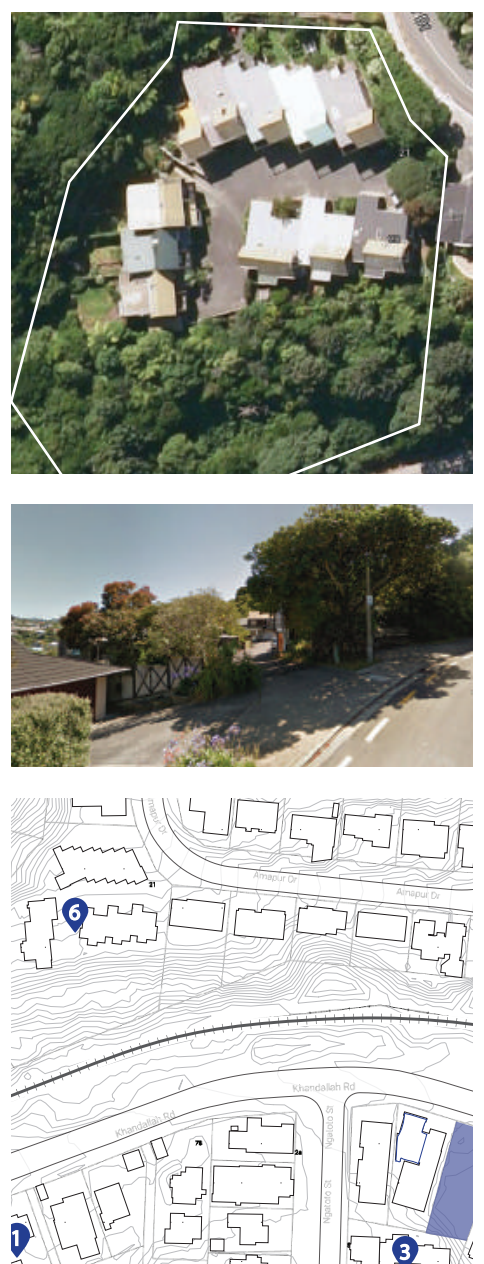
The next section of Design

Phase 3 investigated precedents

of infill and medium density

developments, particularly

looking at the integration of

common and outdoor spaces,

individuality and patterns for

intensification

SITE 1 REDEVELOPMENT 


\section{TRAUMHAUS EVOLUTION}
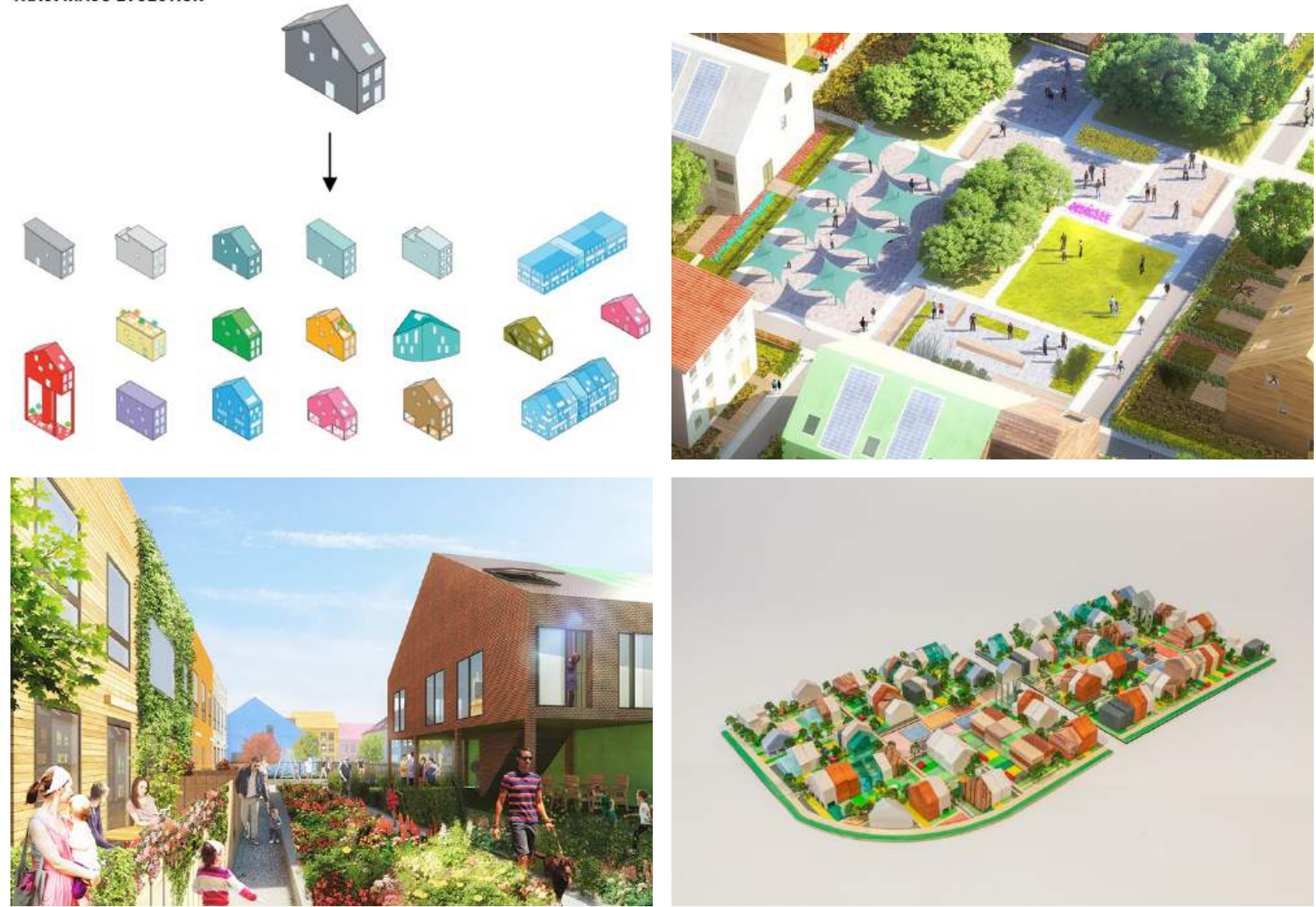

\section{TRAUMHAUS FUNARI MVRDV \\ MANNHEIM GERMANY}

Fig 5.05

A series of diagrams and renders by the architects. The Traumaus House was redesigned through several iterations to provide diversity and individuality per dwelling

The low-cost high quality homes, gardens and public spaces are located on a site of $27,000 \mathrm{~m} 2$. A set of variations on Traumhaus' original design, each dwelling is designed to cater for a varied demographic. By encouraging a diverse population of residents, MVRDV hoped to challenge the modern ideals of housing to facilitate community through individuality and a high quality of life.

The 'village' is fully pedestrianised, with parking located below ground allowing the ground level to become a safe, green, family friendly environment. The park is integrated throughout the development, providing public space and shared amenity for all residents through a network of paths that open out into sports parks and themed gardens (MVRDV, 2015+). 


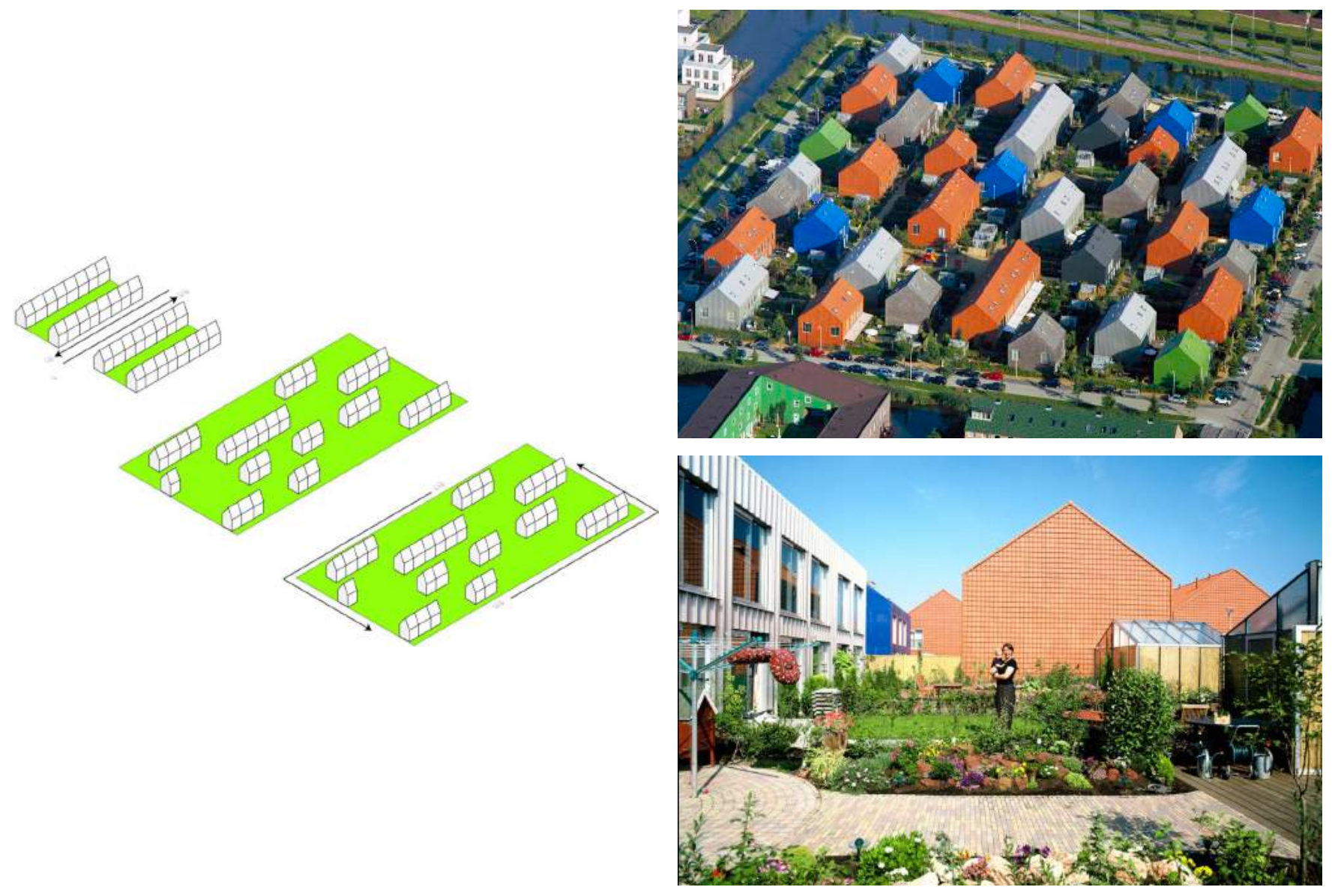

\section{HAGEN ISLAND}

MVRDV

THE HAGUE, NETHERLANDS

Hagen island is a social housing development, typically made of 12 to 20 rows of prefab units. By cutting and splitting the layout (fig 5.06), the architects were able to design a more open, garden like environment, increasing social diversity. The scheme involves single units and blocks of two, three, four or eight units. Each are positioned at various locations to provide a series of cross views that increase communication, provide social opportunities, shared outdoor spaces and allow the compact area to feel a lot more open.

A 'ring road' provides parking lots around the development and creates a pedestrian friendly environment. This provided a larger square meterage per dwelling, maximising outdoor space.(MVRDV, 2003).

Fig 5.06.

A series of diagrams and renders by the architects. The subdivision was developed by spliting two rows of housing and pushing these in and out for a more diverse layout 


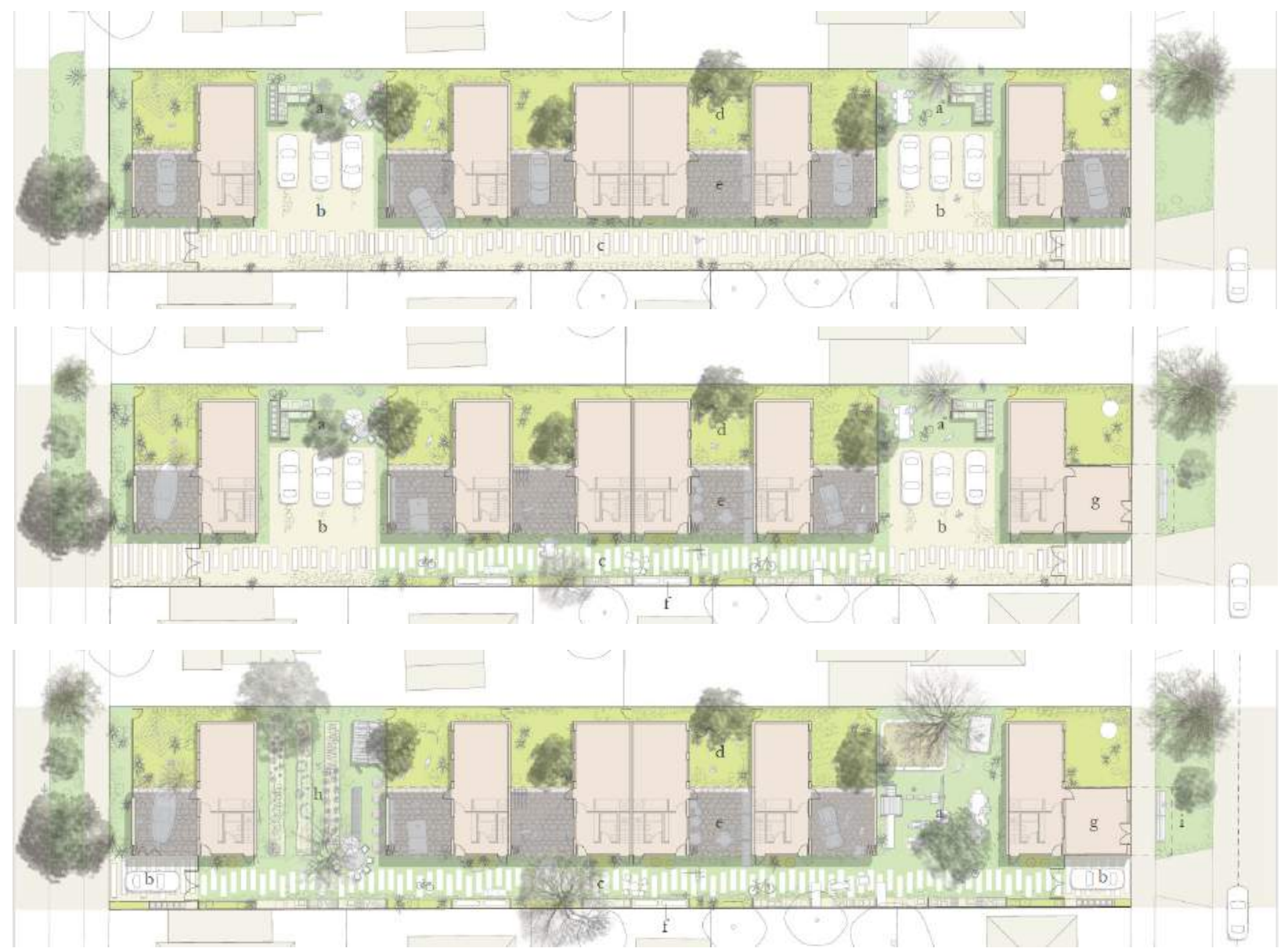

Double lot model:

3 for 1 dwelling replacement

site and dwellings accommodate future

change and growth

LEGEND

a - SHARED RECREATION SPACE

b - SHARED PARKING AREA "SHARED PARKING AREA (FLEX-CAR)

c - LANEWAY " GARDEN LANE

d - PRIVATE GARDEN

e - PRIVATE SHADED PATIO

f - STORAGE, WATER TANKS, GARDEN BEDS

g - POSSIBLE HOME OFFICE / NONRESIDENTIAL USE

h - COMMUNAL VEGETABLE GARDEN

i - BUS STOP

Fig 5.07.

(Top)

*Future change and growth for the development

Fig 5.08

(Right)

* Shared space splits the site at a proportion of 1 for every 3 dwellings

Fig 5.09.

(Far right)

*Perspective design of laneway use

\section{INFILL OPPORTUNITIES MONASH UNIVERSITY MELBOURNE}

The Infill opportunities report examines design strategies to enhance small scale infill redevelopment across established suburbs within Melbourne. The range of strategies explored demonstrate a potential solution for improving quality, density and performance of infill housing.

A significant purpose of their investigation was to maximise shared use and collective benefits. Shared amenity is necessary to support higher density living and their solution proposed using a ' 3 -for-1' dwelling replacement at a ratio of $1: 4$. This allowed an equally sized common open space for shared amenity, providing opportunities for interaction between residents and optimising collective benefits. The shared zone, as depicted in figure 5.08 can be situated at any point within a site, in response to its existing parameters and site conditions, i.e existing vegetation, orientation of site or solar access for neighbouring properties (Monash University, 2011).

The project is designed for both immediate and long term use, with more consideration for common and shared spaces developed over time. For example, the shared parking area could be transformed into shared vegetable gardens, garden shed and outdoor kitchen. While the laneway overgrows and becomes a garden lane, and less parking is necessary when car sharing becomes a more common and affordable option. 


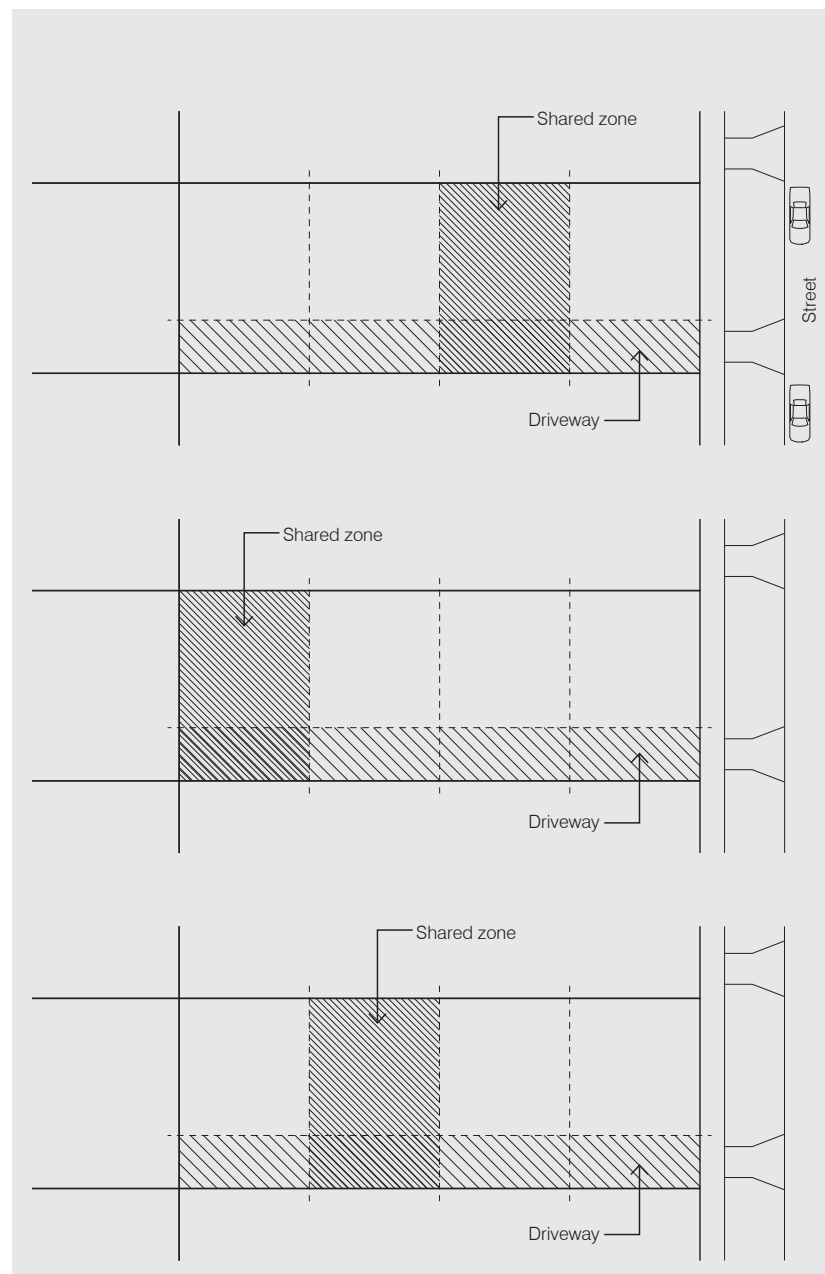

Shared space:

The subdivision of allotments comprises an allowance for shared space at a proportion 1:4

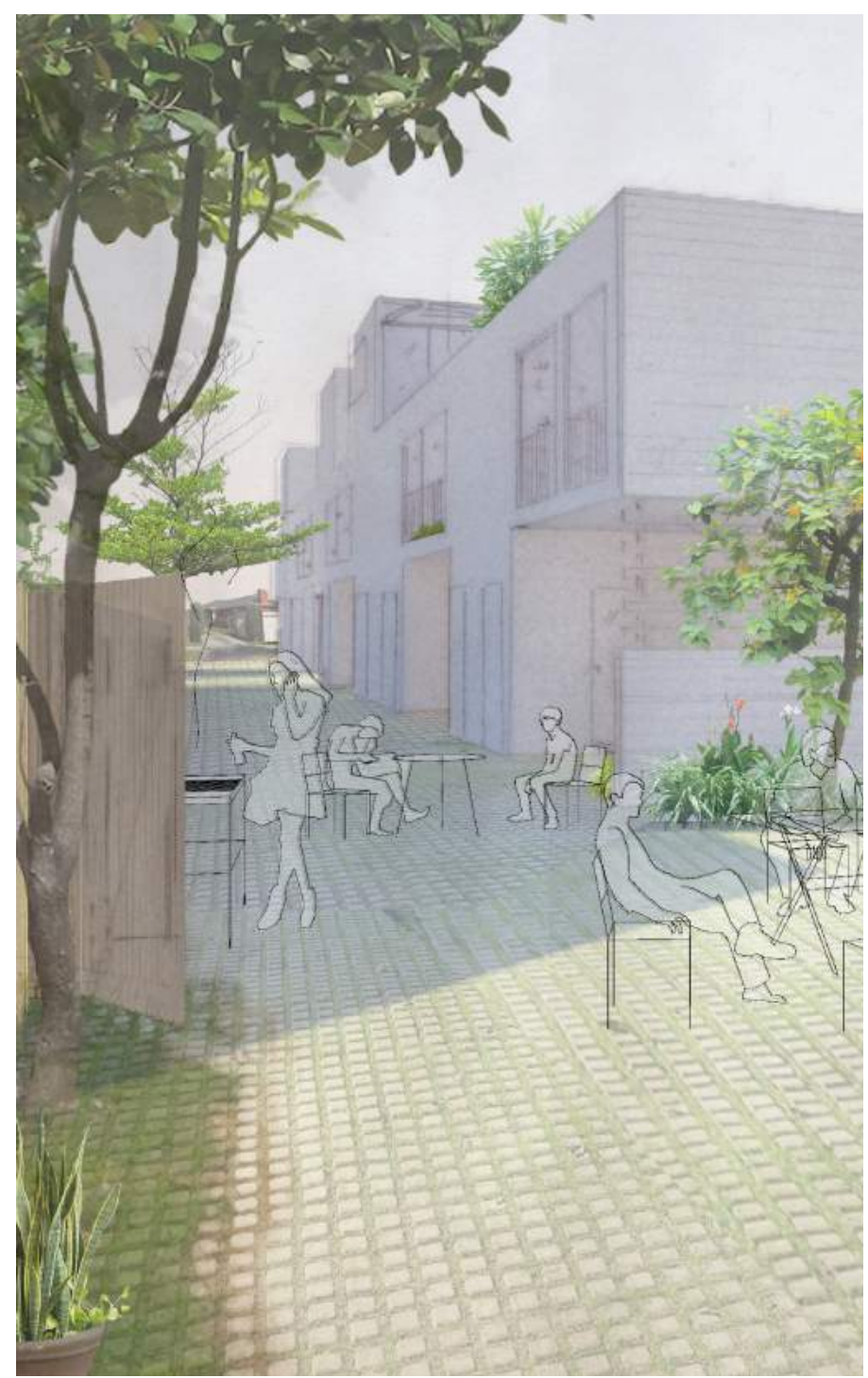




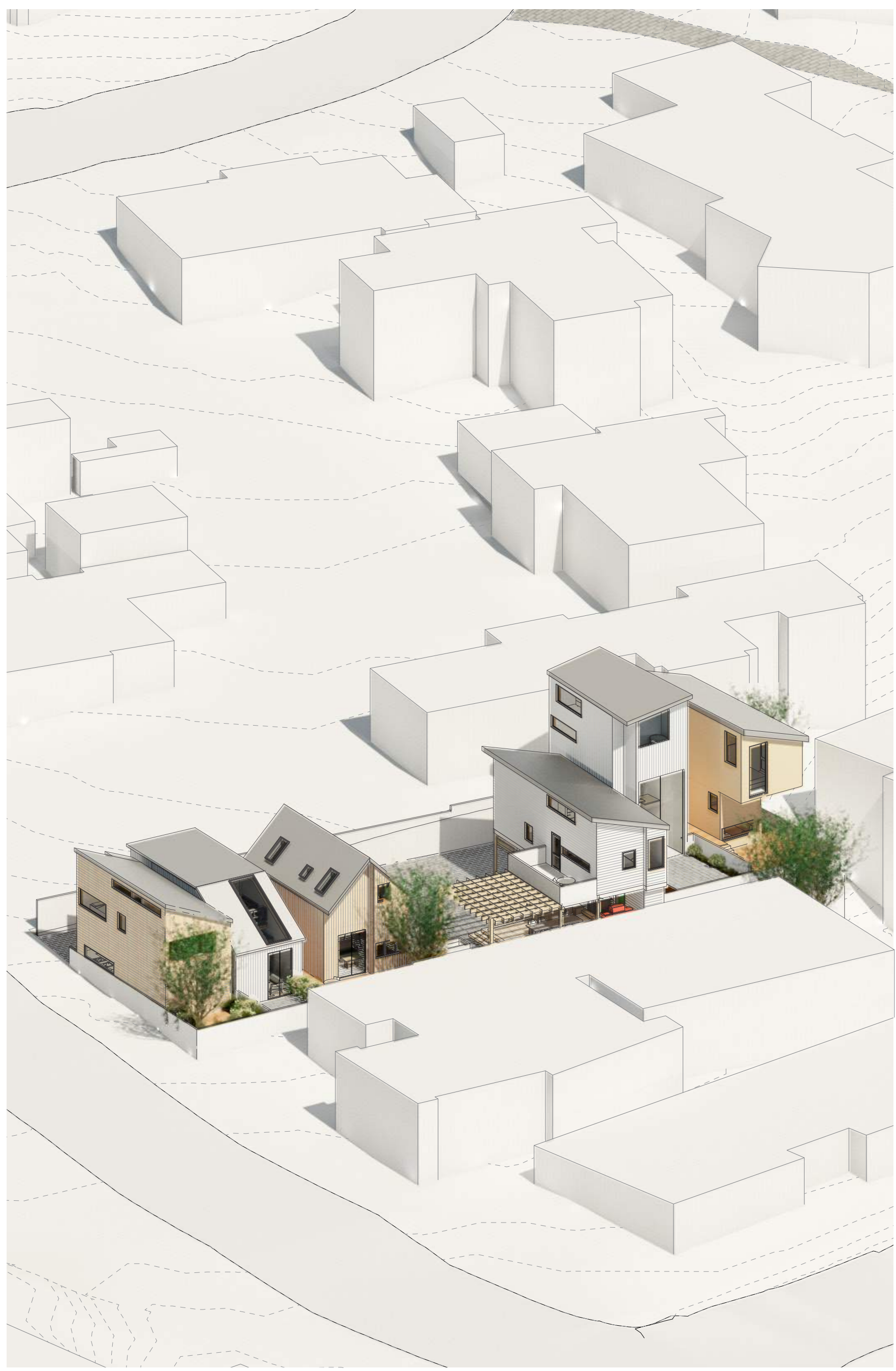




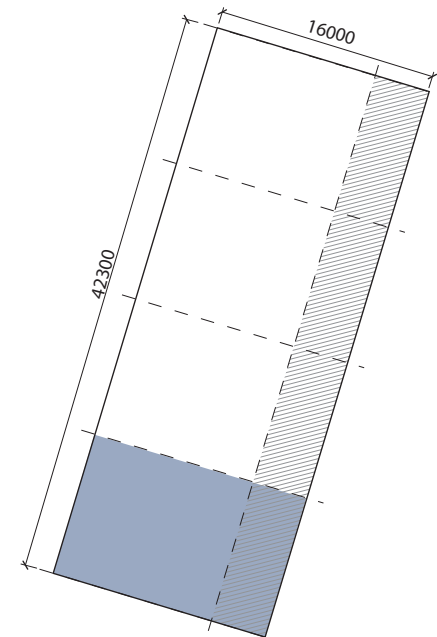

Melbourne infill site subdivision

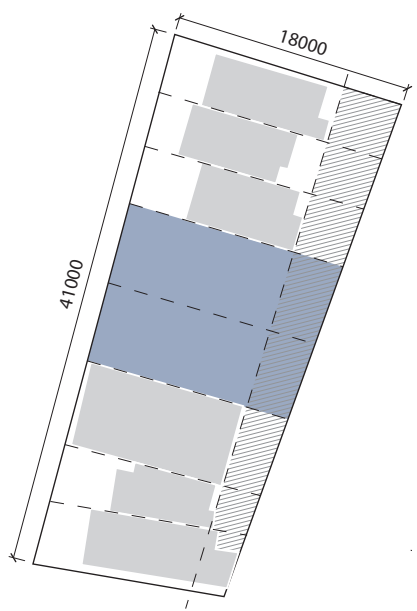

Test site: Applying a ratio twice the amount of Melbournes infill subdivision

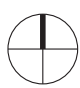

North/South Orientation

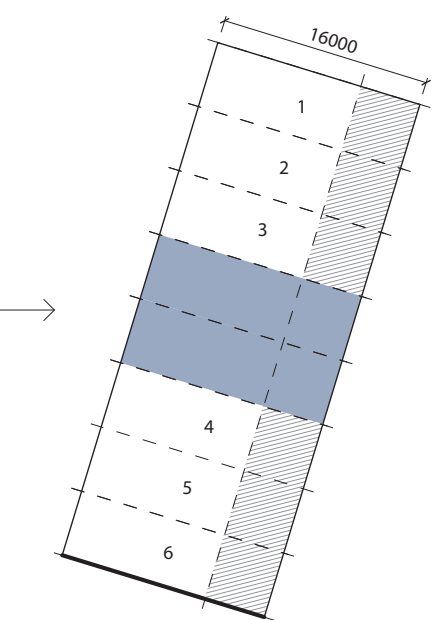

Typical subdivision for a site. For every 3 dwellings there is a shared space of equal size. For a typical site, the dwelling replacement is 6 -for- 1

\section{SITE 1: REDEVELOPMENT}

The design technique for Melbourne's infill redevelopment was applied and translated for the test site. The density is double the Melbourne scheme. A ratio of 6 -for- 1 dwelling replacement is applied for the target density, and a shared zone incorporated for every 3 dwellings gives an 8-to-1 subdivision ratio.

Using the site subdivision technique, a standard site area per dwelling was extracted, where this pattern could then be applied for various sites within Khandallah as a means to test the wider effects of this density on the suburb.

The typical site dimensions per dwelling is $5 \mathrm{~m} \times 11 \mathrm{~m}$ with a minimum lane width of $4 \mathrm{~m}$. Each site area could be modified dependant on the relationship between the proposed small dwellings and the site conditions. It would be recommended that these are the minimum site dimensions, in order to provide sufficient comfort and amenity for all dwellings.
Fig 5.10.

*SITE 1

Outcome of the redevelopment with the minimum subdivision

Fig 5.11.

*Translation of the Melbourne infill subdivision for Site 1 


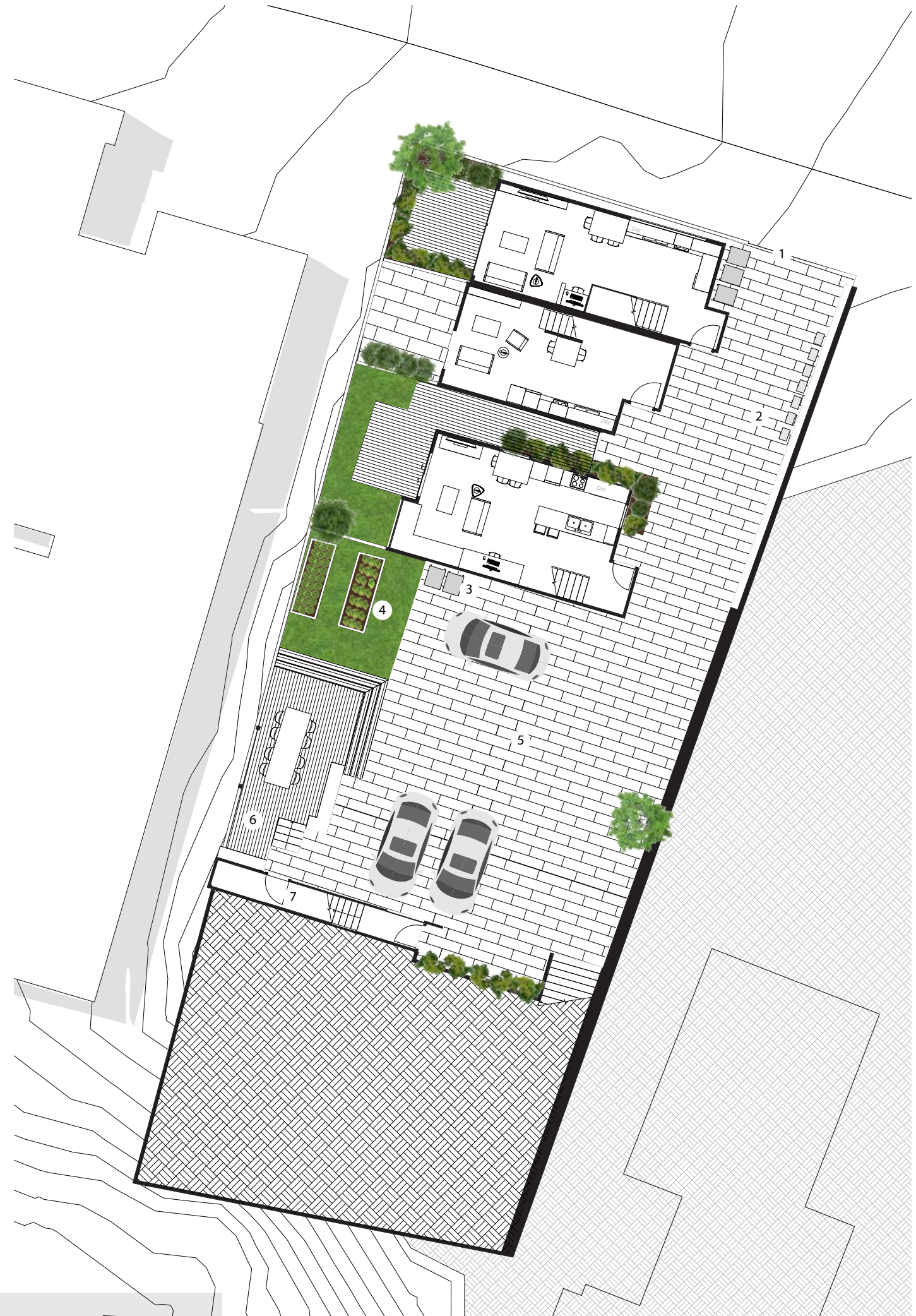

KEY
1 Site entrance
2 Mail collection
3 Rubbish/recycling
4 Vegetable garden
5 Informal parking
6 Barbeque and seating
7 Garden/storage shed

GROUND FLOOR SITE PLAN 


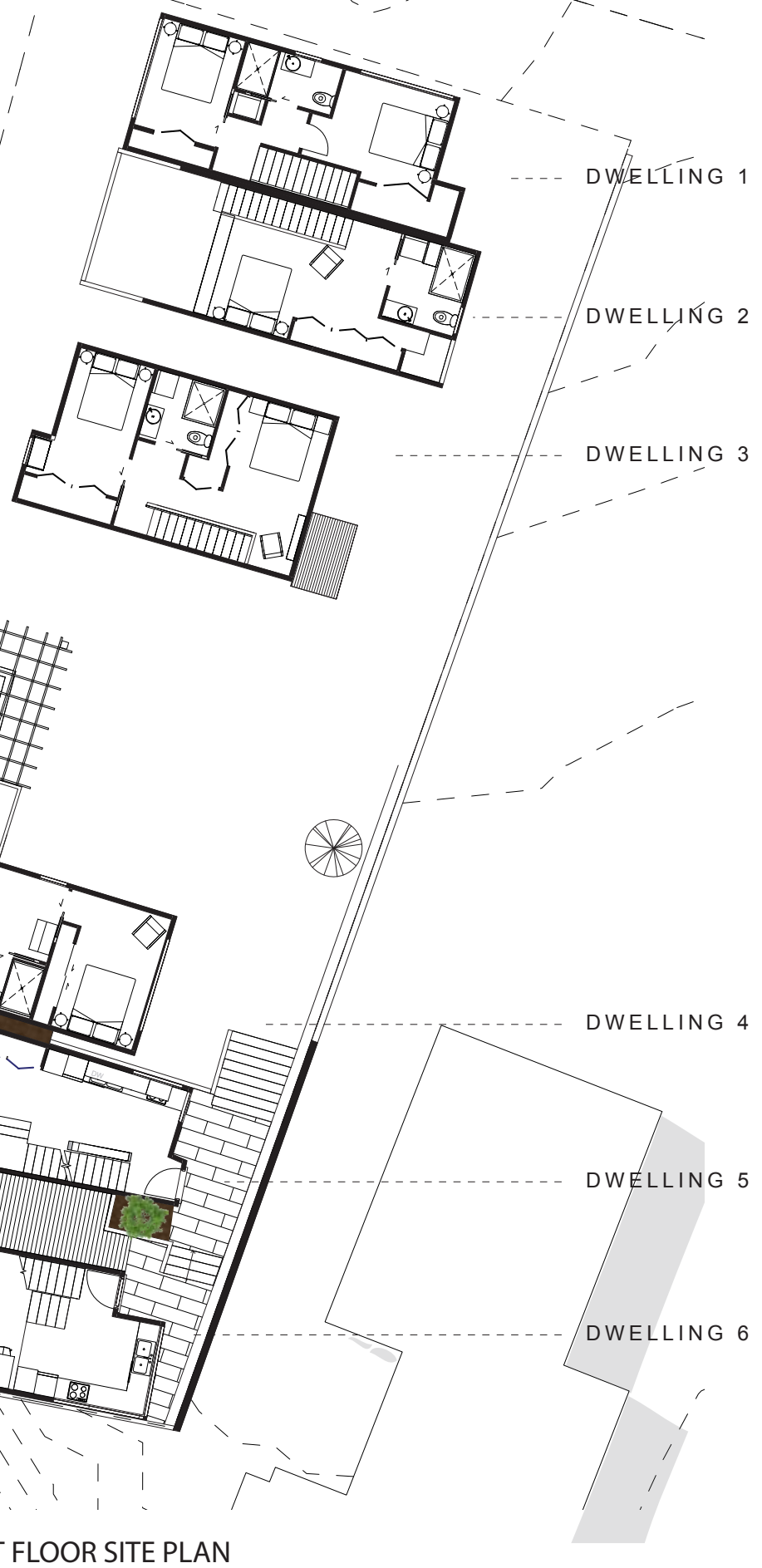

FIRST FLOOR SITE PLAN
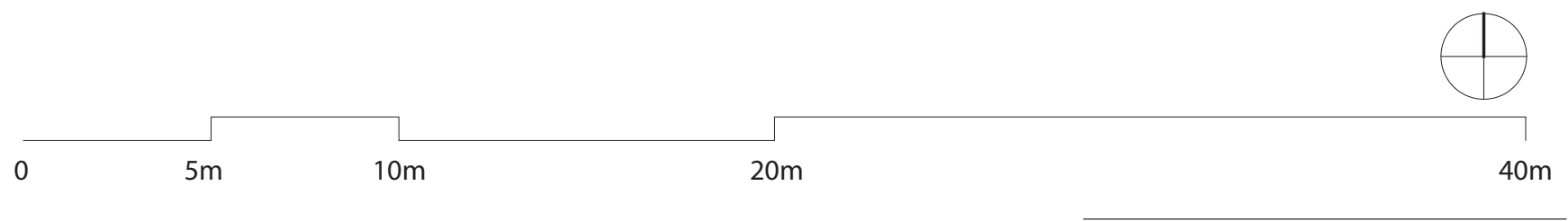

Fig 5.12. 


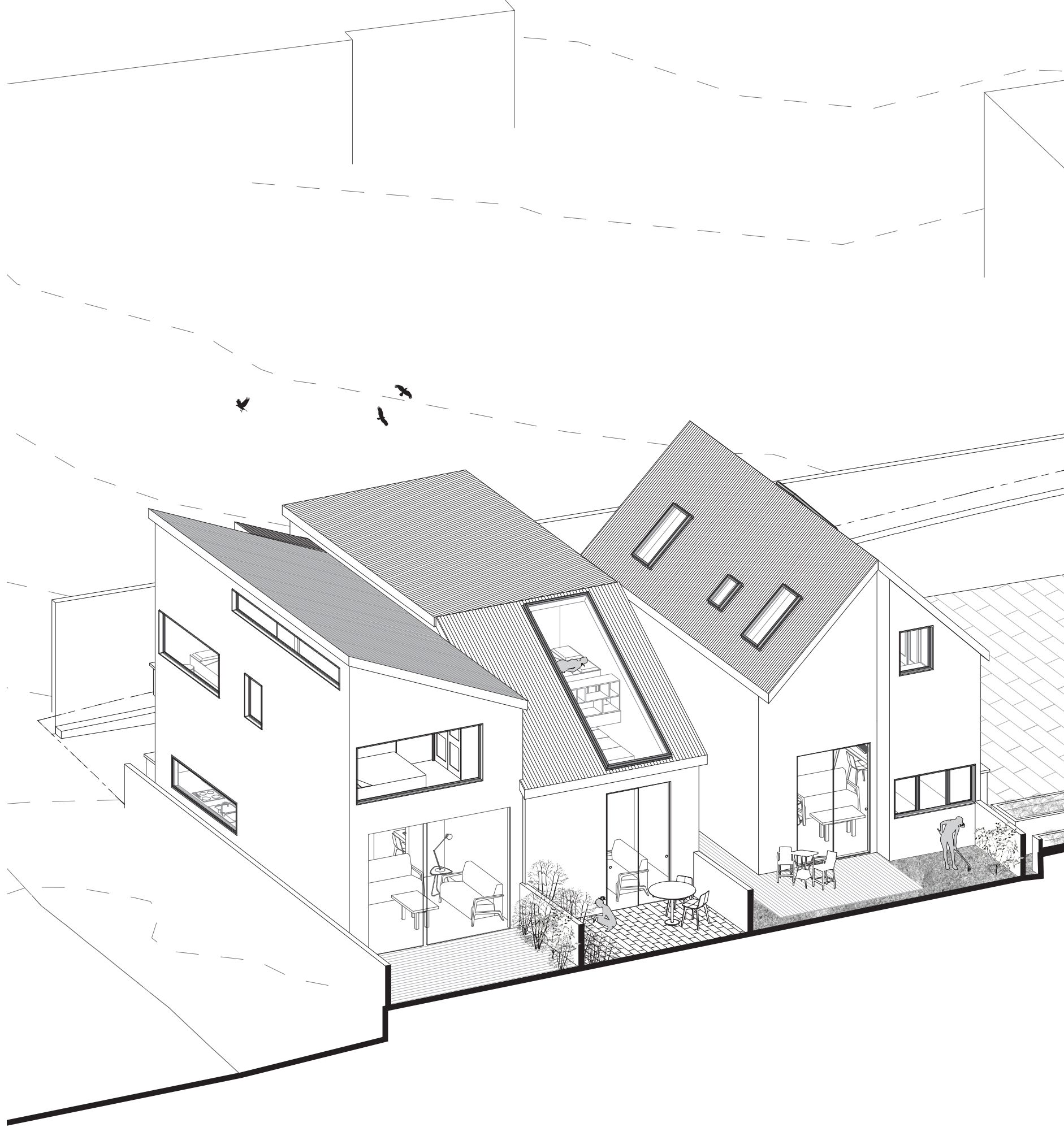

Fig 5.13.

*SITE 1, DEVELOPMENT 2

Relationship between houses, the

private space and the shared use of

amenities within the common 


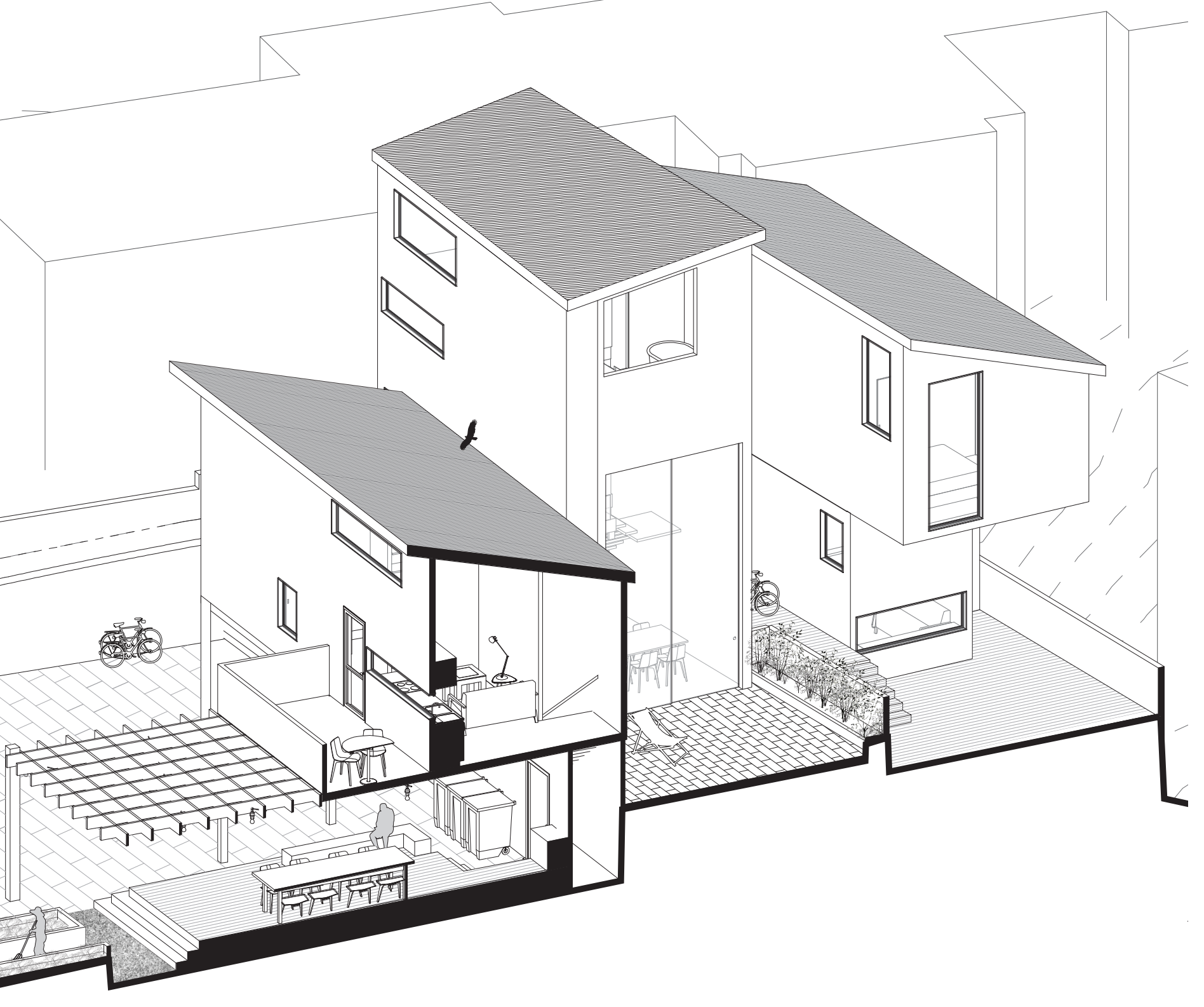




\section{DWELLING 1}

2 BEDROOM

$70 \mathrm{M} 2$

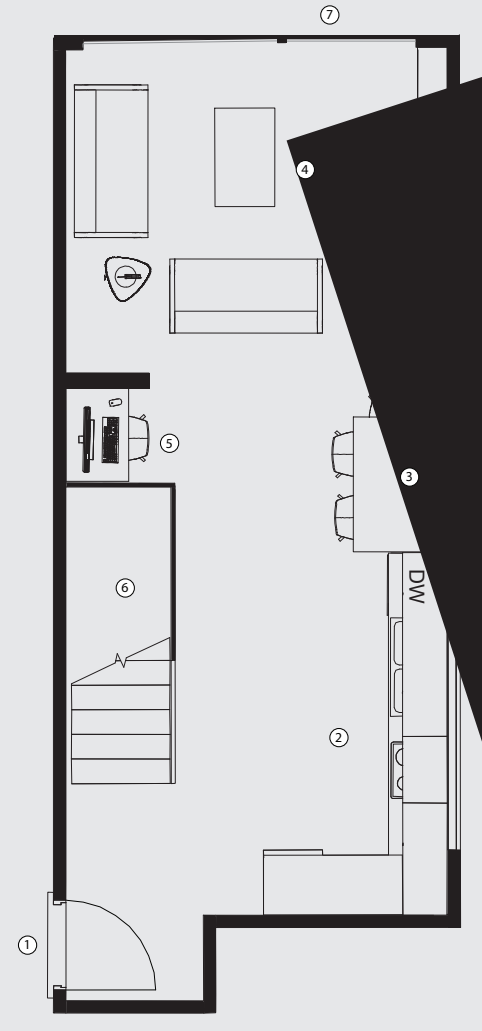

GROUND FLOOR
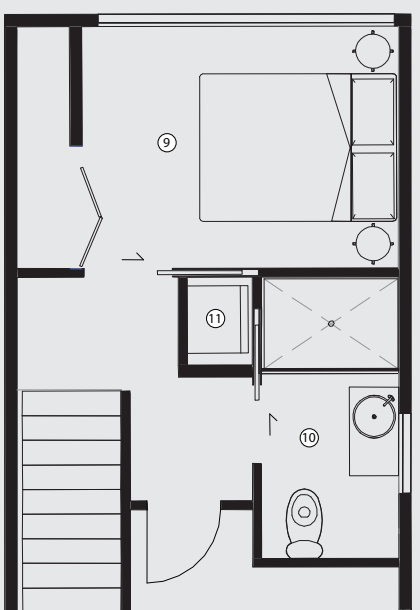

(8)

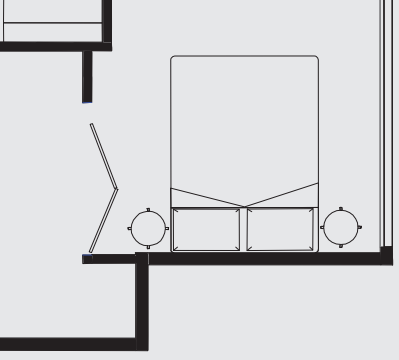

FIRST FLOOR

KEY

(1) Entry

(2) Kitchen

(3) Dining

(4) Living

(5) Study

6 Storage

(7) Outdoor space

(8) Master bedroom

(9) Second bedroom

(0) Bathroom

(11) Laundry

SCALE 1:100 
The redevelopment of Site 1 re-examined the design for each dwellings. The space efficient principles and guidelines extracted from the small house precedents were refined to address specific site conditions as the internal planning of each dwelling was influenced by experiments with site planning. The clusters of three dwellings affected placement of windows, location of circulation spaces and access to natural light.

The internal configuration for each dwelling tested multiple design efficient principles and allow the spaces to be altered for individual occupancy needs.

Dwelling 1

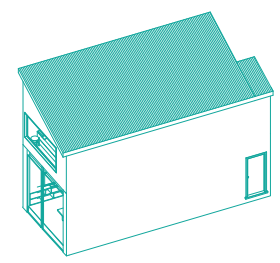

-The closed staircase provides space for storage, minimising clutter within the downstairs living spaces

-A study nook is located under the full height of the stair, providing an area for work at home without compromising the main lliving quarters

-Further storage space is utilised above the entrance, for the master bedrooms wardrobe

\section{Dwelling 2}

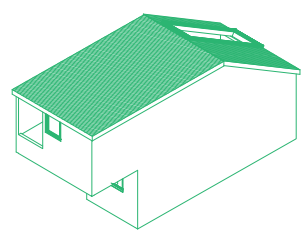

-The straight line kitchen is perfect for small builds, preventing wasted space and allows the dining table to act as further bench space when needed

-The large sliding doors and skylight align, filtering afternoon sun into the Iliving spaces. This, combined with the double height ceiling, work to enhance the illusion of space and optimise indoor outdoor flow

-A window seat on the first floor brings natural light into the bedroom during early hours of the morning

Fig 5.14.

*Dwelling 1 Plans

Fig 5.15.

*Dwelling 2 Plans 


\section{DWELLING 2}
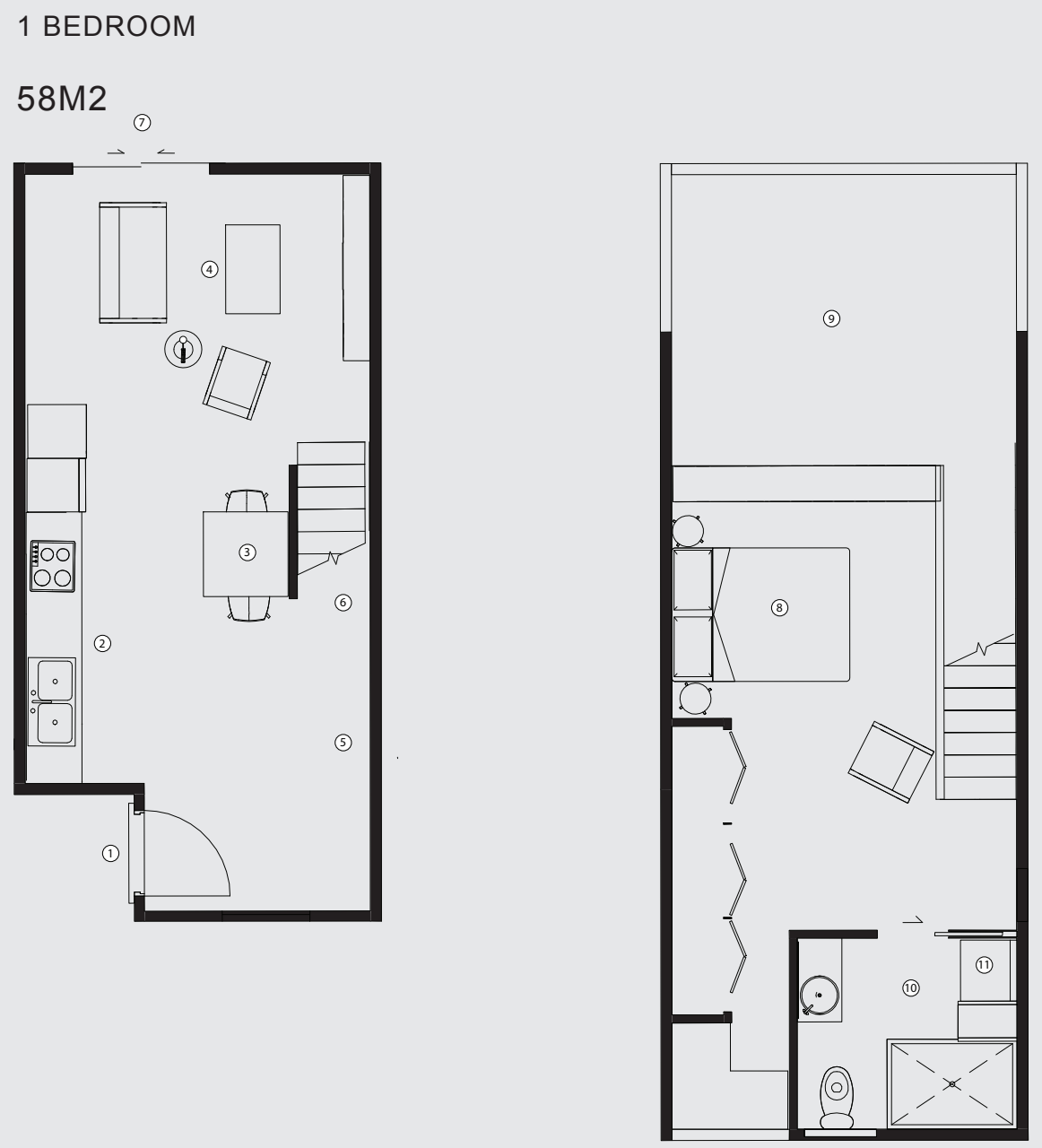

GROUND FLOOR

FIRST FLOOR

KEY

(1) Entry

(2) Kitchen

(3) Dining

(4) Living

(5) Study

6 Storage

(7) Outdoor space

(8) Master bedroom

(9) Second bedroom

(10) Bathroom

(11) Laundry

SCALE 1:100 


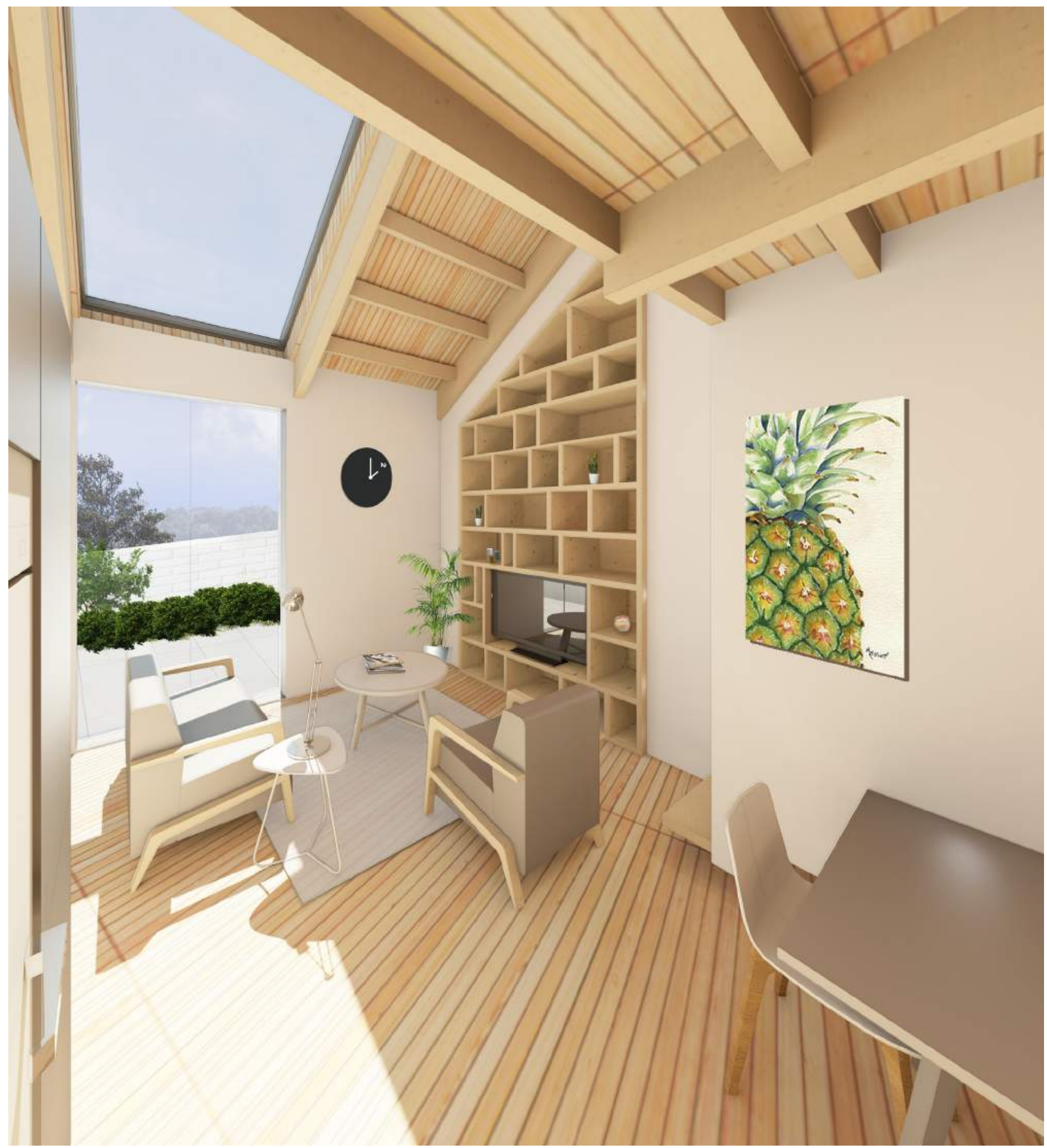

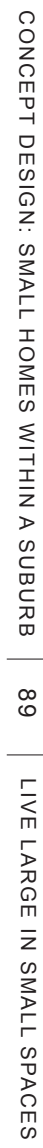

Fig 5.16.

*DWELLING 2

Early afternoon sun filters through

the double height space 


\section{DWELLING 3}

2 BEDROOM

$77 \mathrm{M} 2$

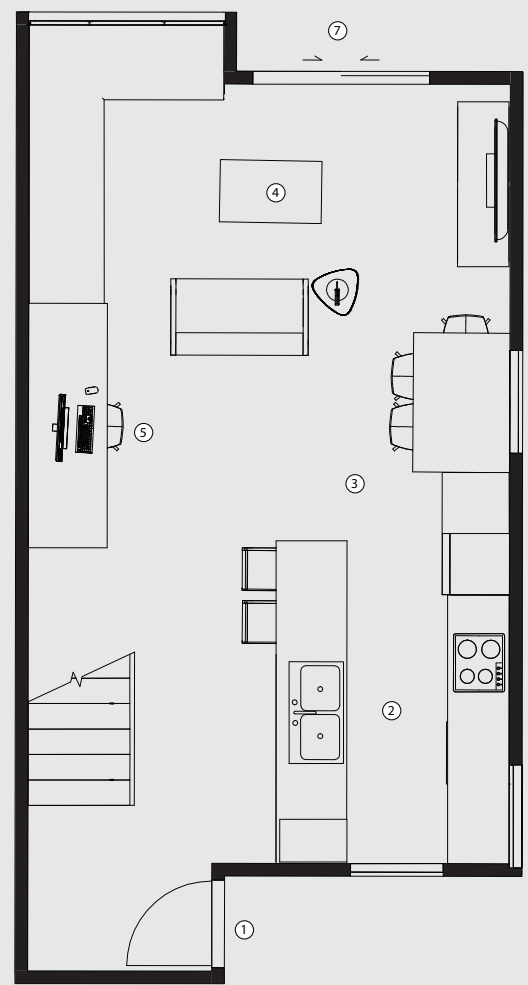

GROUND FLOOR

KEY

(1) Entry

(2) Kitchen

(3) Dining

(4) Living

(5) Study

6 Storage

(7) Outdoor space

(8) Master bedroom

(9) Second bedroom

(10) Bathroom

(1) Laundry

SCALE 1:100

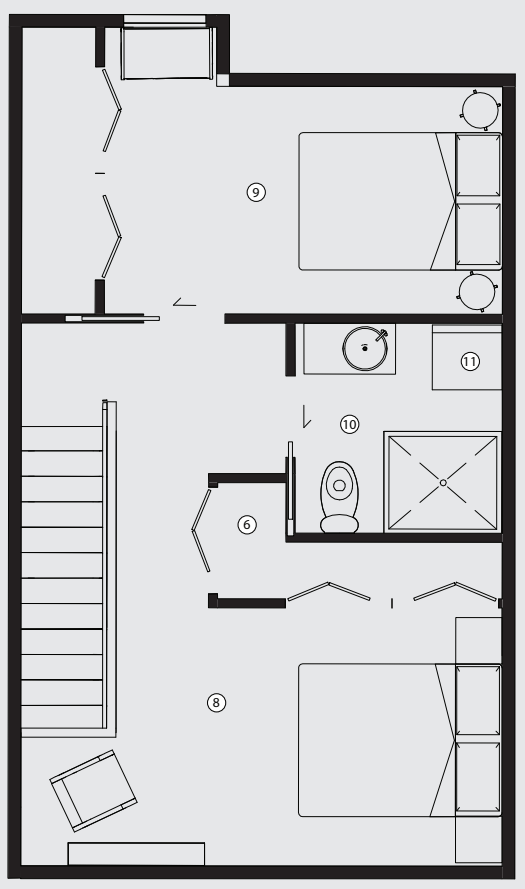

FIRST FLOOR 


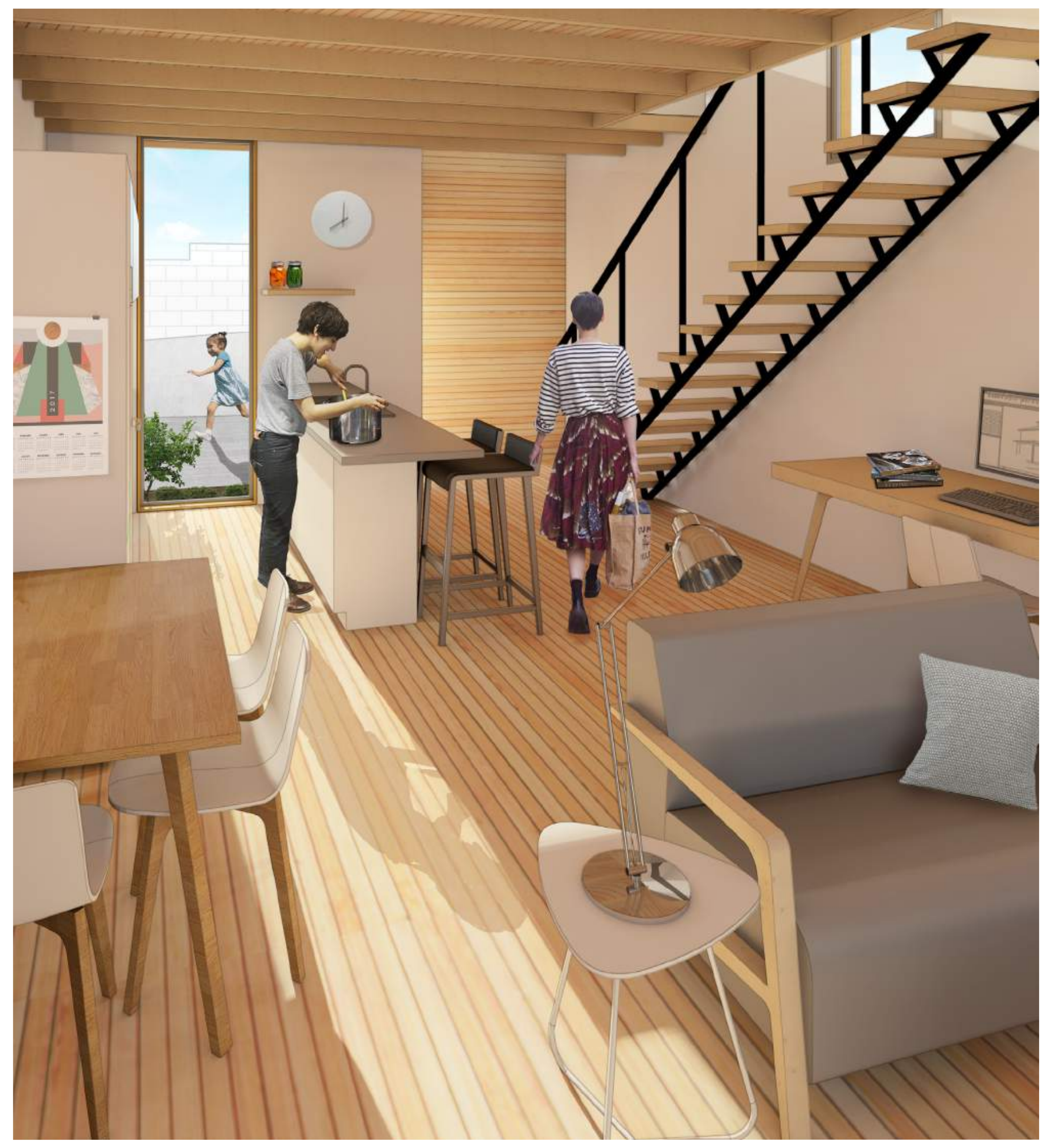

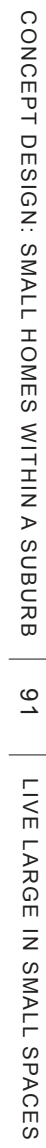

Fig 5.17.

*DWELLING 3

Tom prepares breakfast while Kayla and their daughter pop out to the markets 


\section{DWELLING 4}

1 BEDROOM

\section{$50 \mathrm{M} 2$}
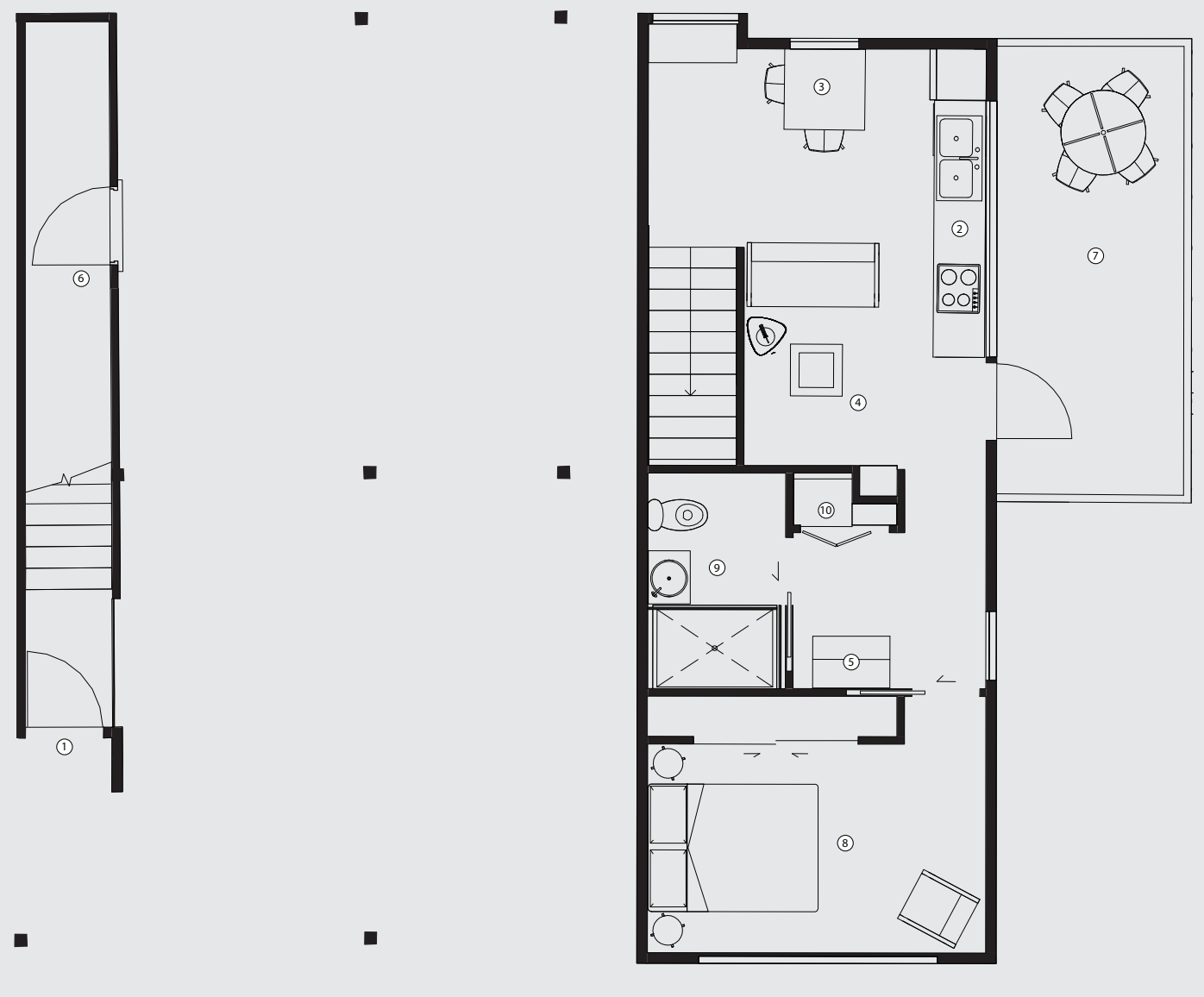

GROUND FLOOR

KEY

(1) Entry

(2) Kitchen

(3) Dining

(4) Living

(5) Study

6 Storage

(7) Outdoor space

8 Master bedroom

(9) Bathroom

(1) Laundry

SCALE 1:100 


\section{Dwelling 3}

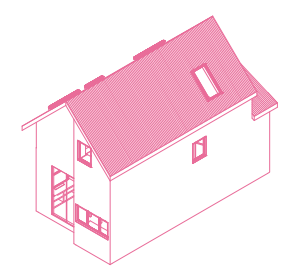

-An open stair case allows light to pass through, adding a textural and visual interest without making the space feel clutterd or too small

-A gally kitchen allows you to reach all work areas of the space with ease and provides an opprtunity for a window to fit between the two benches. This brings natural light in, easily making a tight space feel more generous

-The open staircase also allows the living space to freely position furniture how the occupant likes, with a windows seat designed to overlook the private outdoors

\section{Dwelling 4}

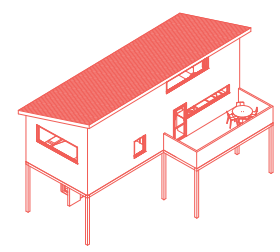

-The dwelling has been raised to provide covered car parking and extra outdoor space that can either be private or used to supplement the outdoor common zones

-The ground floor provides a space for storage

- The compact floor plan minimises sole circulation and a sloped roof catches allows high windows to catch the daytime sun without over heating the small space

-A window seat is positioned at the height of the stairs for visual interest and a place to sit and enjoy the late afternoon sun 


\section{DWELLING 5}

1 BEDROOM

$66 \mathrm{M} 2$
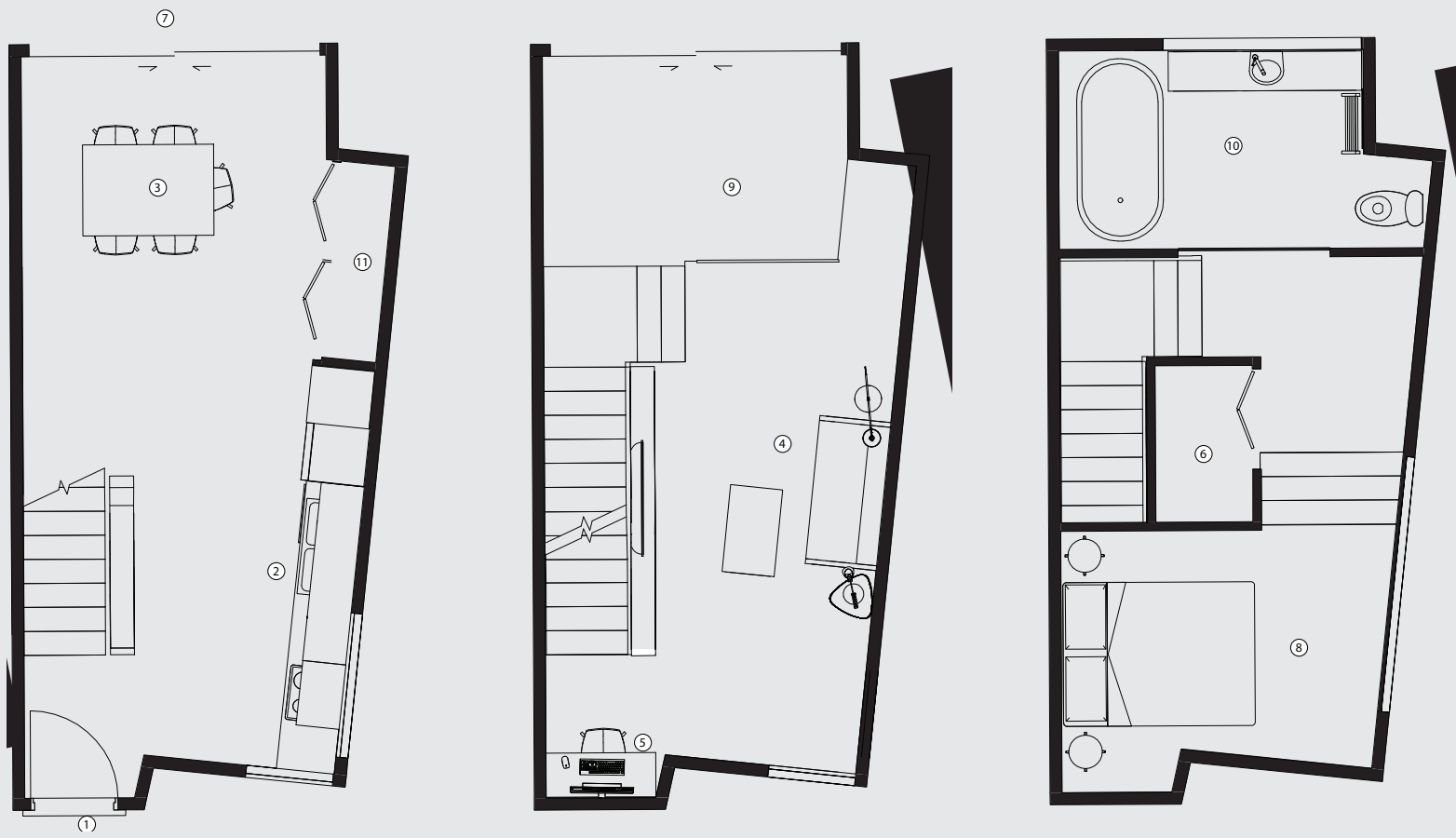

GROUND FLOOR

FIRST FLOOR

SECOND FLOOR

KEY

(1) Entry

(2) Kitchen

(3) Dining

(4) Living

(5) Study

6 Storage

(7) Outdoor space

8 Master bedroom

(9) Mezzanine

(10) Bathroom

(11) Laundry

SCALE 1:100 


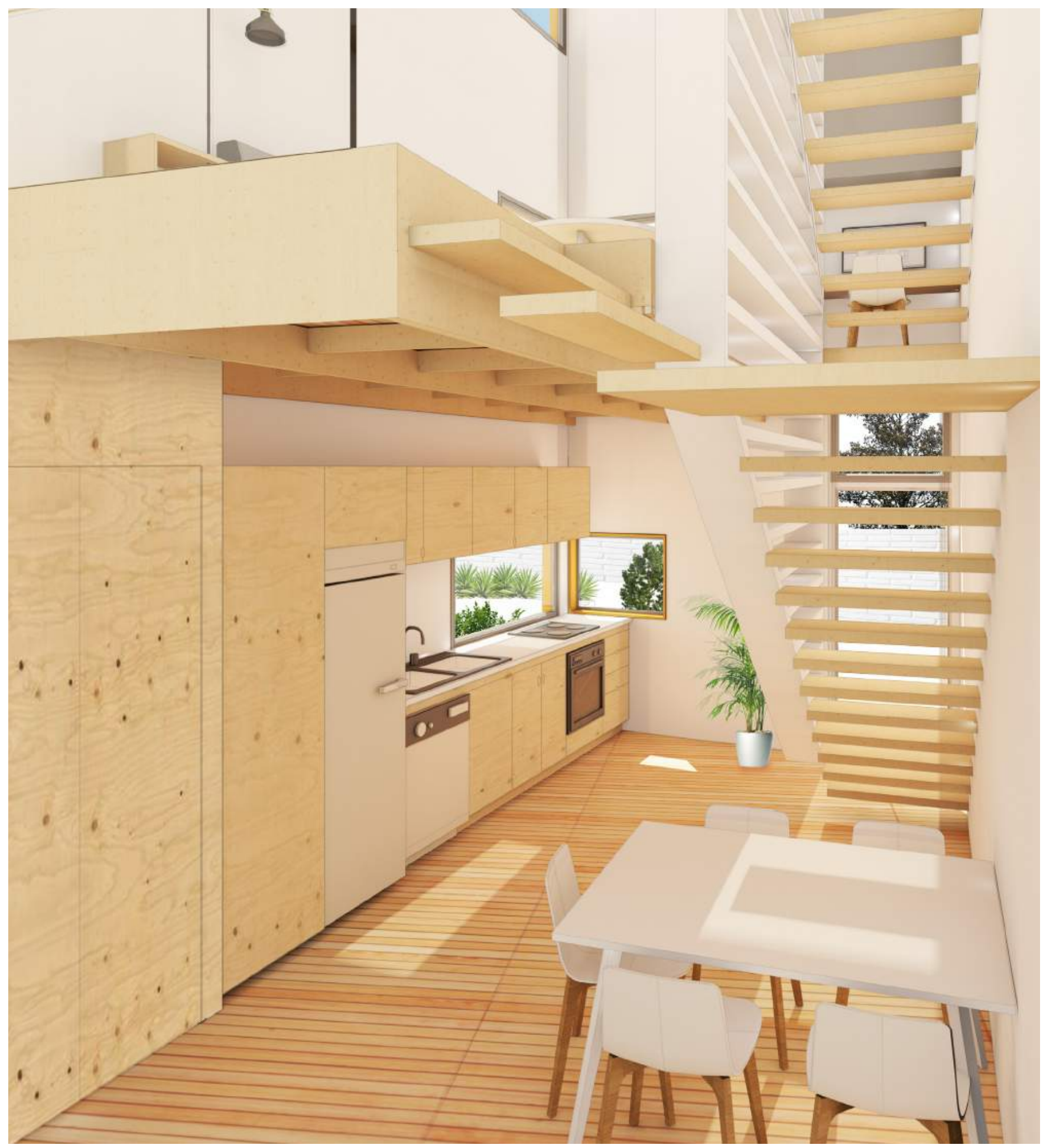

Fig 5.20.

*DWELLING 5

Morning sun filters into the kitchen and dining space 


\section{DWELLING 6}

\section{BEDROOM}

$60 \mathrm{M} 2$

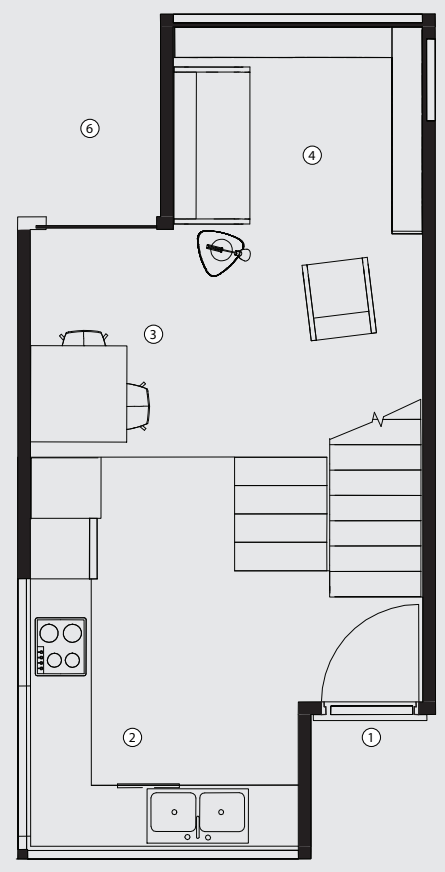

GROUND FLOOR

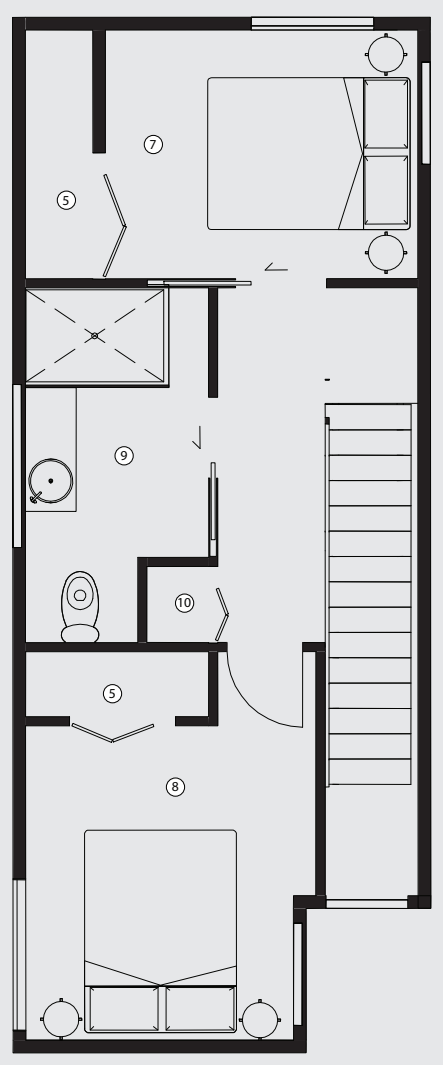

FIRST FLOOR

KEY

(1) Entry

(2) Kitchen

(3) Dining

(4) Living

(5) Storage

6 Outdoor space

(7) Master bedroom

8 Second bedroom

9 Bathroom

(10) Laundry

SCALE 1:100 
Dwelling 3

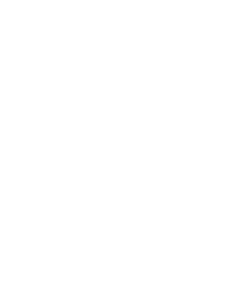

-This 3 storey compact dwelling has the smallest foot print, allowing more space for the private outdoors

-A mezzanine creates a large double height space for the dining area and large glass sliding doors to open out to the garden and outdoor living. The extra height make the space feel less enclosing while the indoor outdoor flow extends the footprint beyond the interior

-The bedroom is tucked away on the top floor, while the main living space is located on the middle floor with views down to the dining and private outdoors.

-A study area is tucked into the corner at the foot of the stairs, proving multifunctional use for the main living space

Dwelling 6

- The steppped level between the kitchen and living defines each zone without needing walls for separation

-The $L$ shaped kitchen is perfect for the open plan design, allowing occupants to move more freely

-The First floor is compactly designed, with uninterrupted flow between the bathroom and bedrooms

-A cantileavered upper floor optimises ground floor outdoor space while providing shelter where outdoor living will be situated

Fig 5.21. (Previous)

*Dwelling 5 Plans

Fig 5.22

*Dwelling 6 Plans 


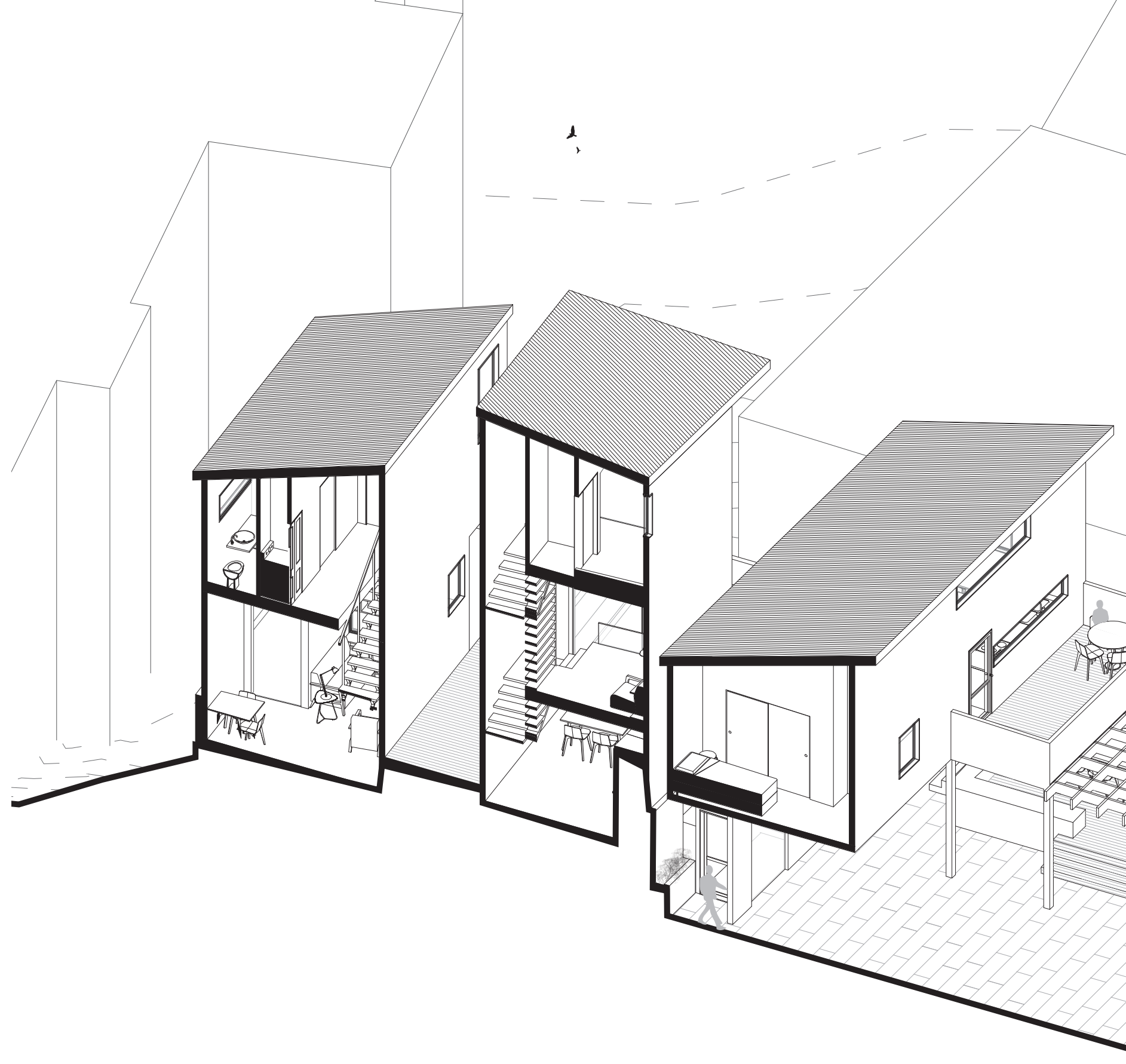

Fig 5.23.

SITE 1, DEVELOPMENT 2

Relationship between interior and

exterior forms, and the common

outdoor space 


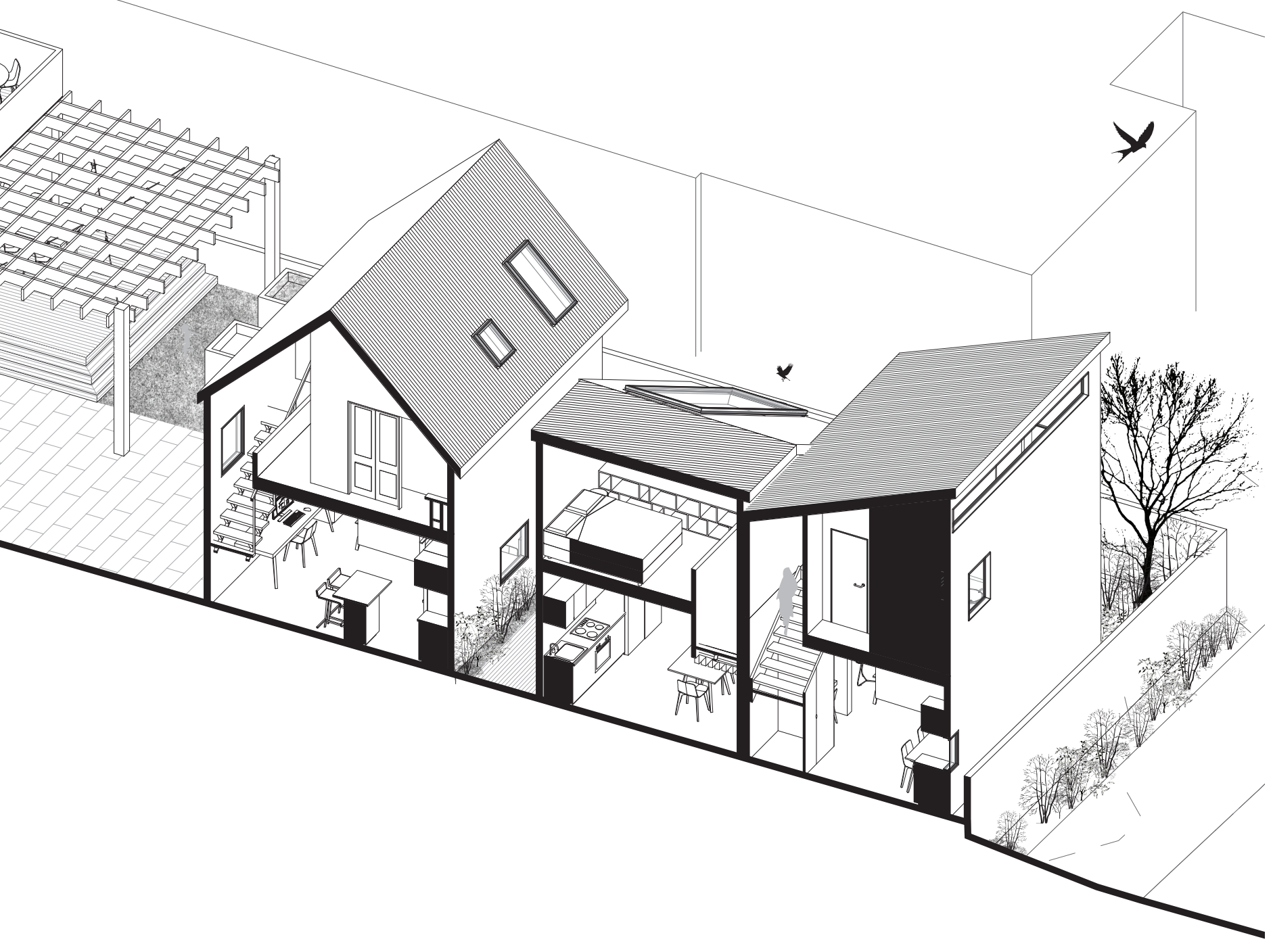




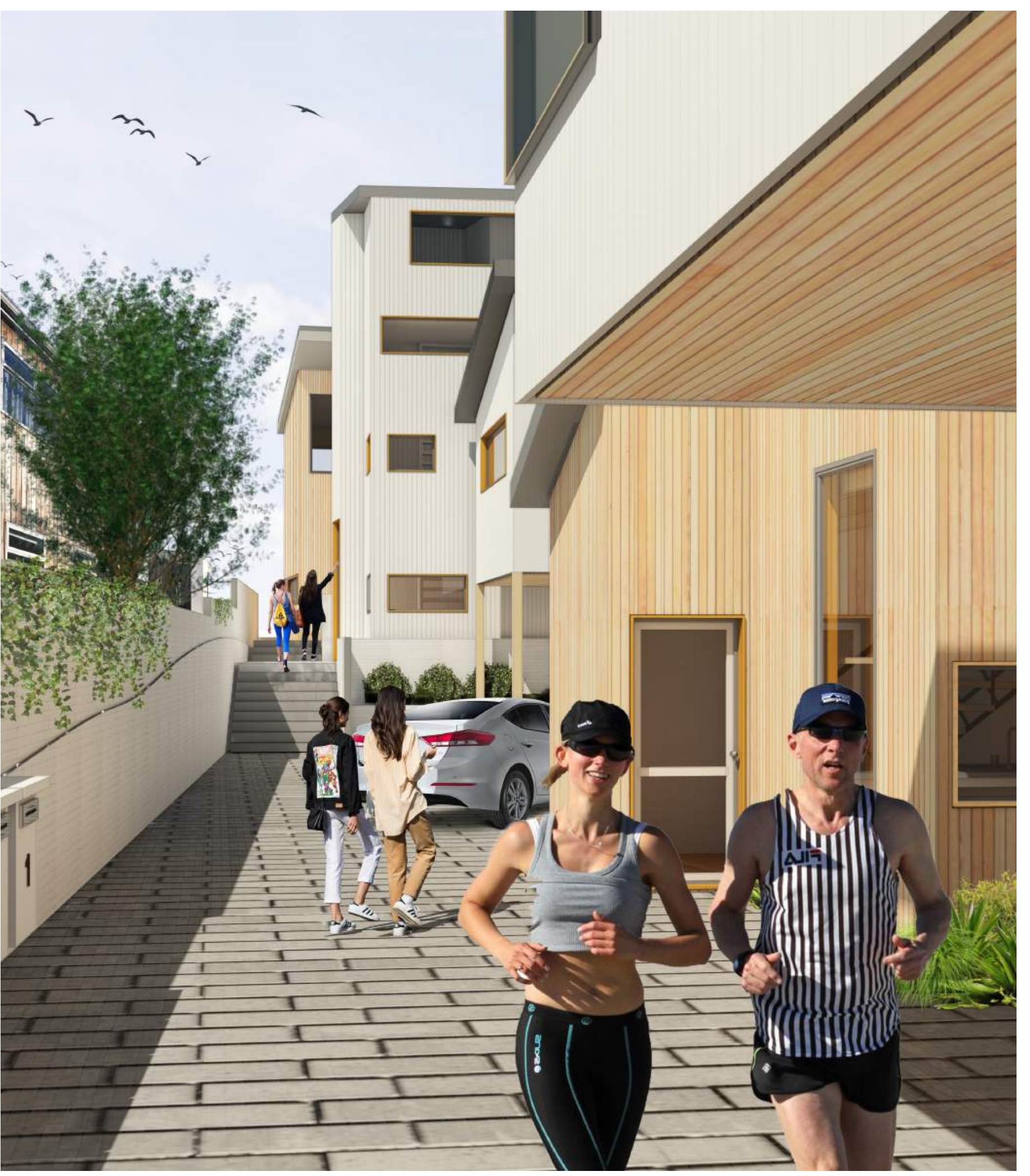

Fig 5.25

*SITE 1

Perspective entering site from

Khandallah Rd 


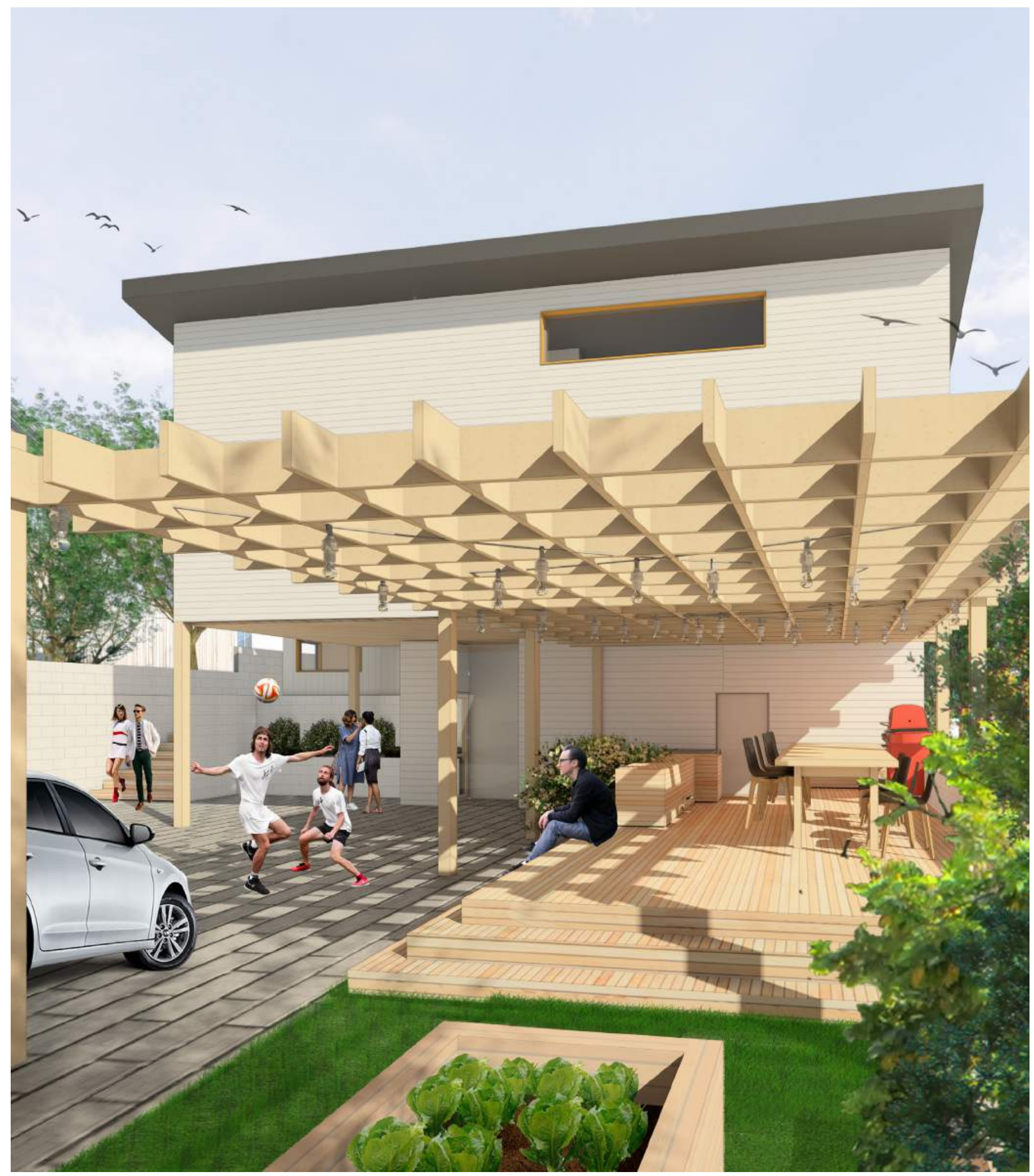

Fig 5.26

*SITE 1

An area for shared outdoor

entertainment, games and gardening 

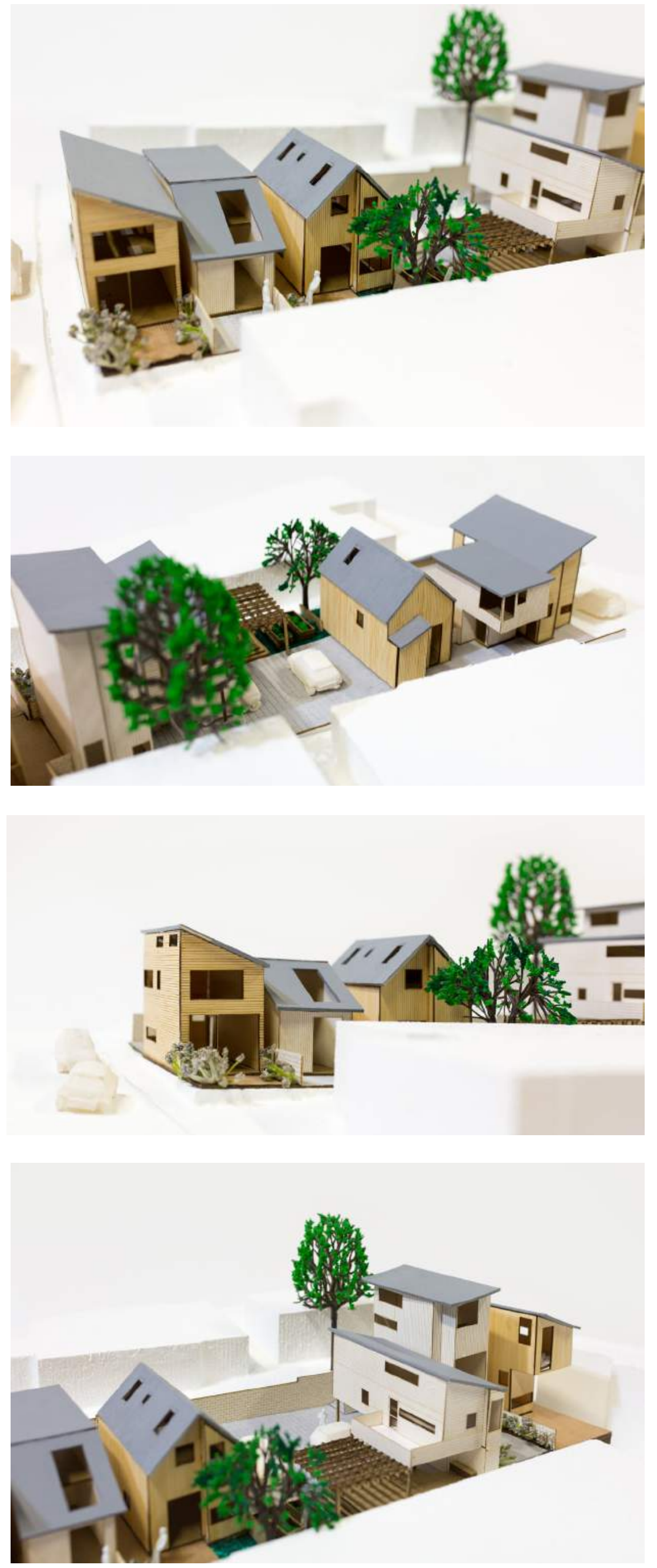


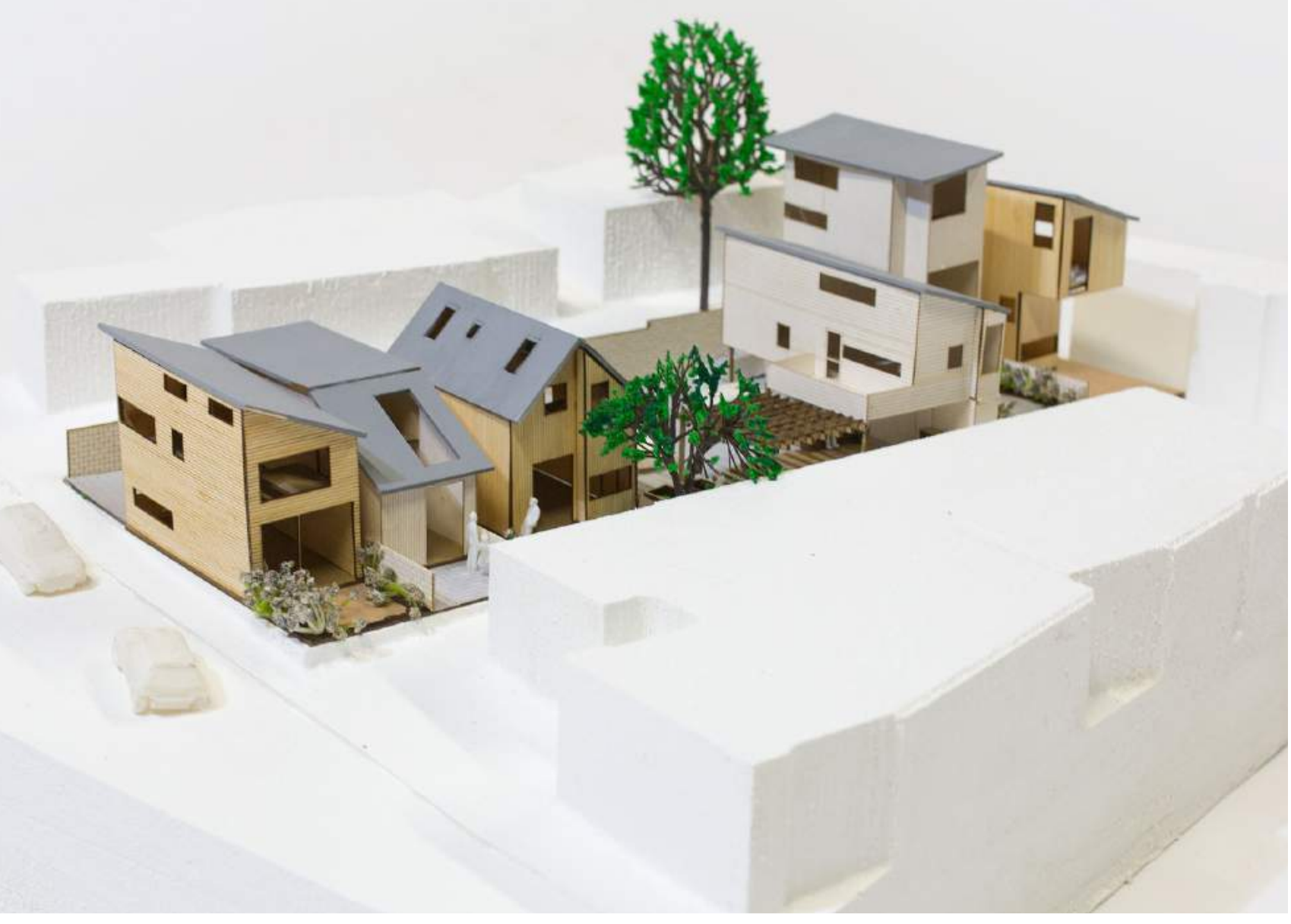

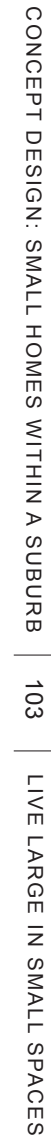




\section{WHERE TO NEXT FINDINGS + REFLECTION}

The analysis of Khandallah's density in relation to Wellingtons suburbs proved that the proposal for intensification is possible. Case studies of existing housing within the area showed that the suburb hosts similar housing at a density of this scale and therefore intensifying the suburb is possible and is already occuring to an extent.

The redevelopment of site 1 helped to ensure a reasonable minimum ratio between private outdoor spaces, augmented by some common external space, which was vital to ensure the intensification scheme provided high qualities of open space and shared amenity between residents. The introduction of a rule based subdivision allowed a more effective use of site, providing quality open space, beneficial for the residents.

The 6 houses were refined specific to site conditions with the intention of designing for diversity. As Tarbatt discusses, diversity manifests itself in different ways, but providing each place its own unique character and identity is important for the success of sustaining community, environment, economic and social liveability (Tarbatt, 2012). Each dwelling was developed for a sense of individualism and flexibility within a compact footprint, providing spaciousness while also accommodating a range of diverse first home buyers.

Adopting a minimum subdivision strategy defined threshold spaces between the common and private. A proposal at this scale of intensification, it is important to establish the relationships between private and public, the individual and collective and the building with the neighbourhood (Wietzorrek, 2010).

"Borders are the spatial expression of social relationships"

(Wietzorrek, 2010)

The private spaces, both interior and exterior are equally as important as the common spaces to ensure these relationships are fluid - they should work to envoke a sense of community between residents while satisfying contemporary housing demands. 
The redevelopment of site 1 has not yet addressed the problem of the side yard. Spaces between the clusters of housing needs to be refined further. Adopting the minimum subdivision strategy provided a rule for the houses to be positioned together, as clusters of three. The minimum dimensions provided spaces between the dwellings for access to private outdoors, however, these areas are often too narrow to be used effectively and become wasted space. Gaps between the dwellings do however, provide access to natural light and fresh air so the problem of the side yard and how this can be utilised effectively should be developed further.

The idea of living large in small spaces not only requires the design and critique of a small home, but how to cater for what is 'lost' when downsizing our homes. Adopting a rule based, minimum subdivision grid for existing sites, provides a pattern for potential intensification at a wider scale. The rule based subdivision allows the research to now investigate the implications of site, and how density can be accommodated in a low density environment.

"Naturally, this means working with smaller alotments and carefully considering the effects on privacy, community, environment, neighbours and the city as a whole."

-John Gray

(Badcock, 2014)

The next design phase should explore further the implications of the suburb, as John Gray discusses, the effects of this development on the wider community and its significance to Khandallah and Wellington.

The redevelopment of Site 1 proved that it is feasible to substantially reduce land costs through intensive use of already settled suburban land. It is socially acceptable to co-locate dwellings on sections that would typically house one dwelling, thus making efficient use of external space and minimising the internal footprint (Badcock, 2014). 


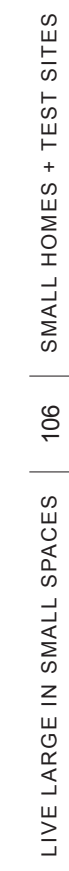




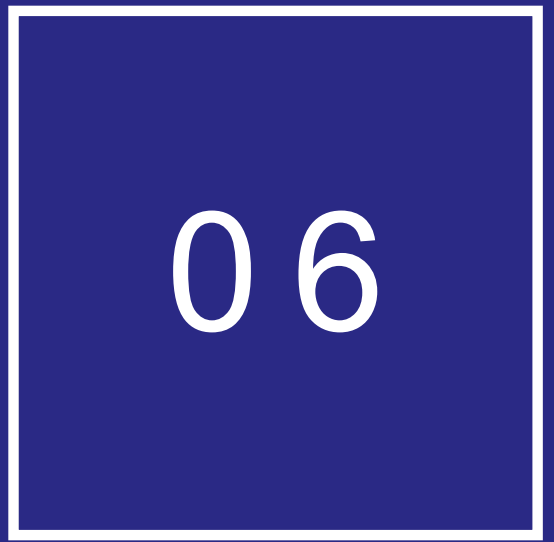

DEVELOPED DESIGN

SMALL HOMES + TEST

SITES 
Design phase 4 introduces

two more sites to investigate

issues related to site. I.e

slope, orientation, size,

shape and location. 
$3)$

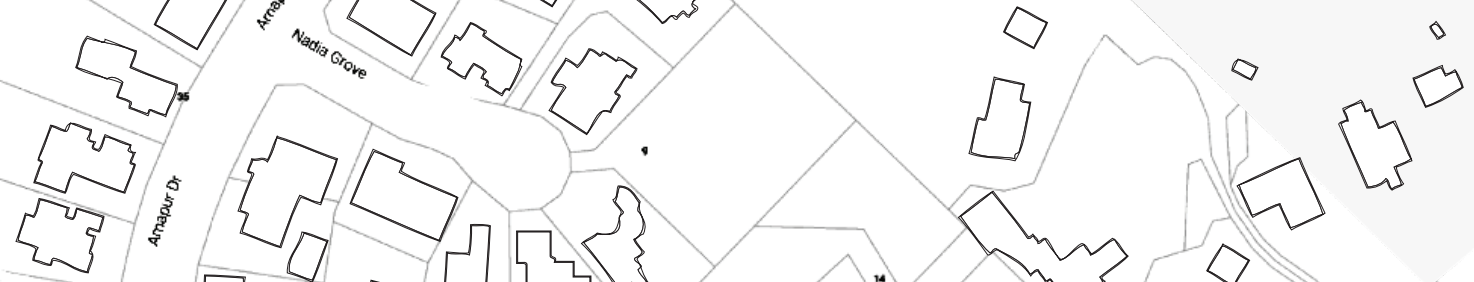

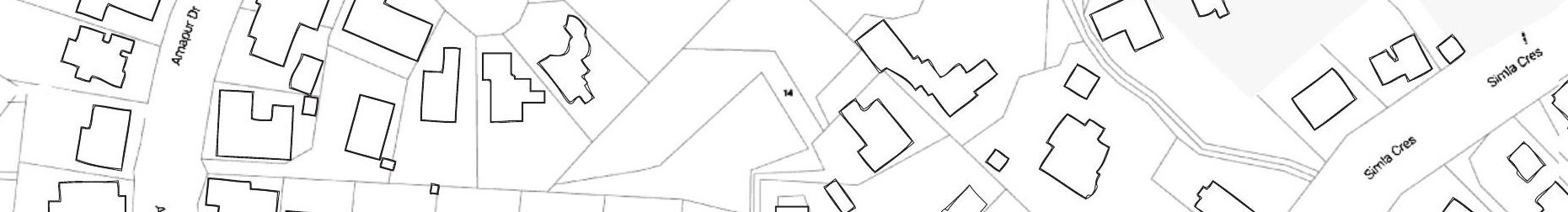

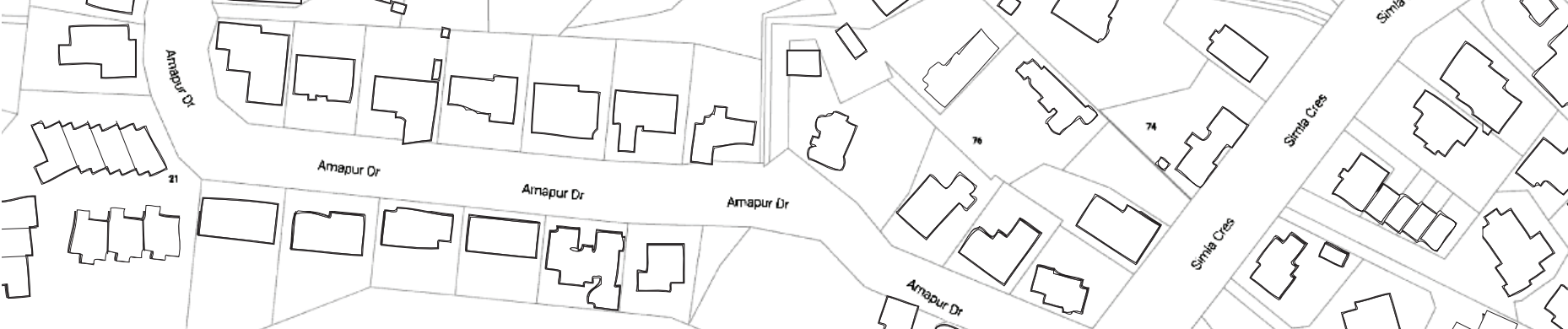

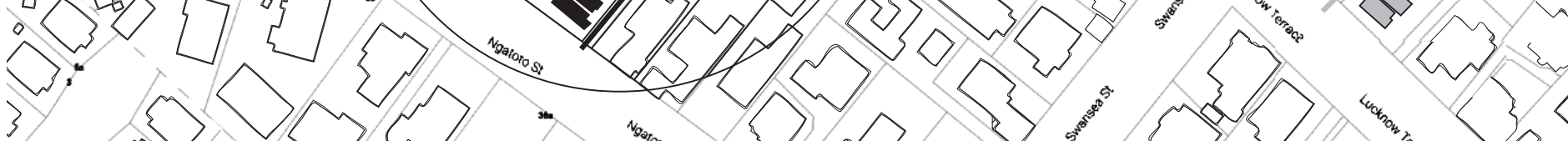
3.

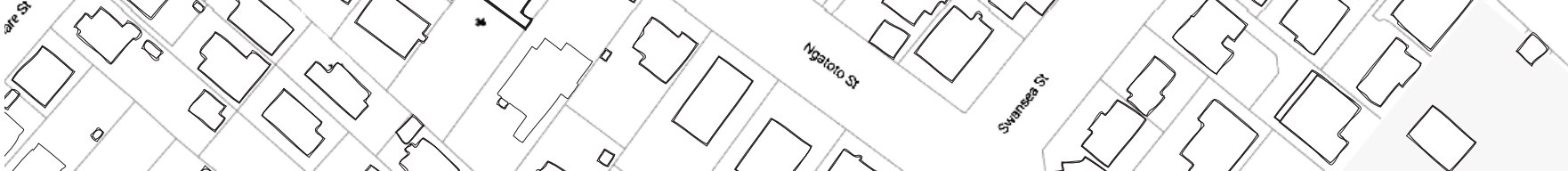

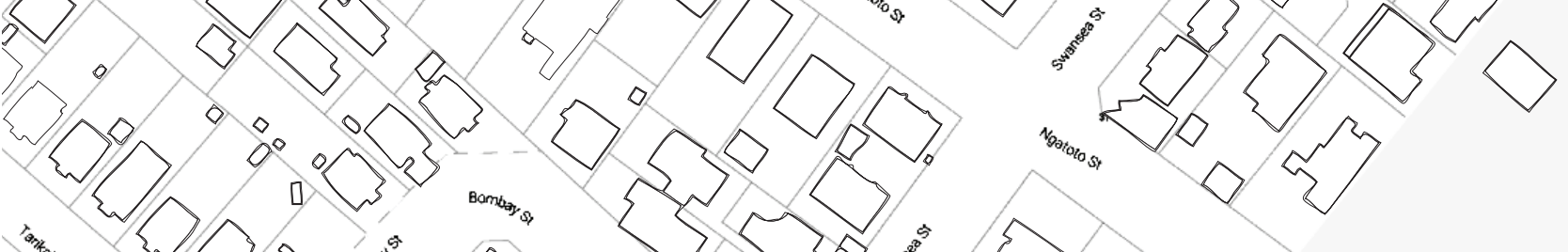
(3) 
(1)

तर

(a)

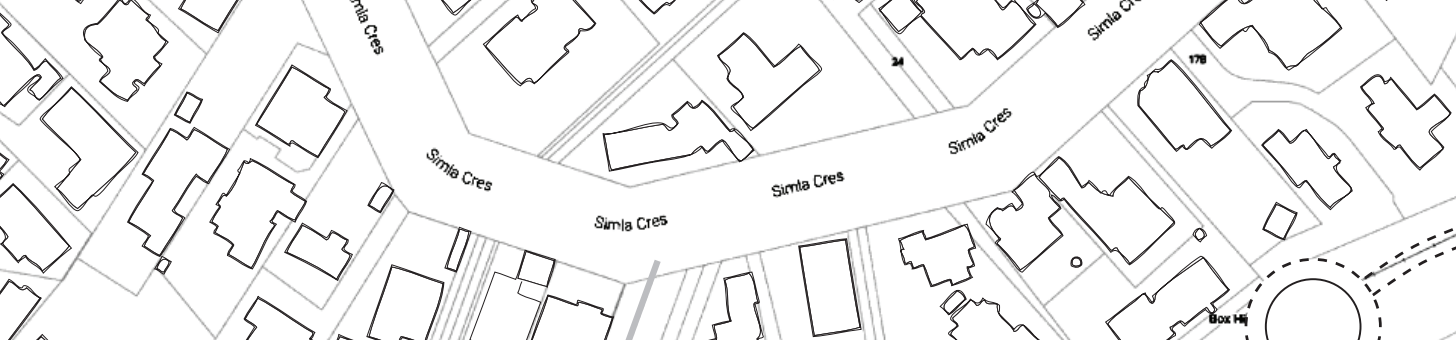

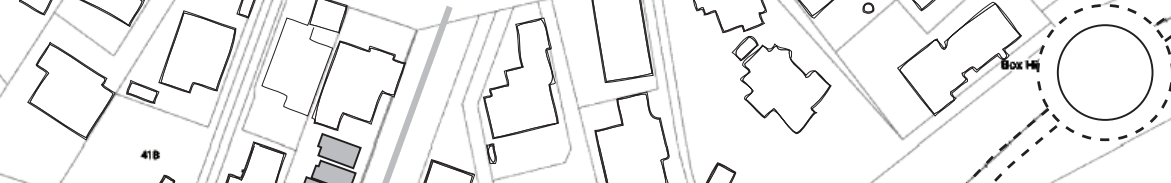

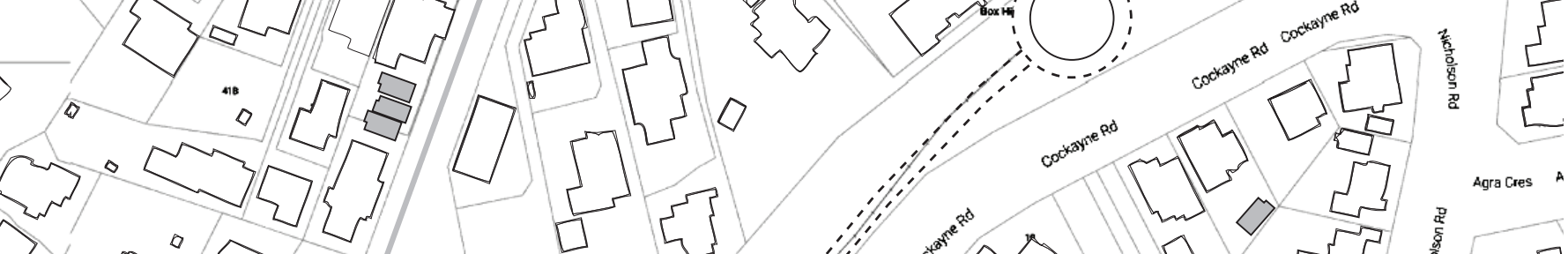

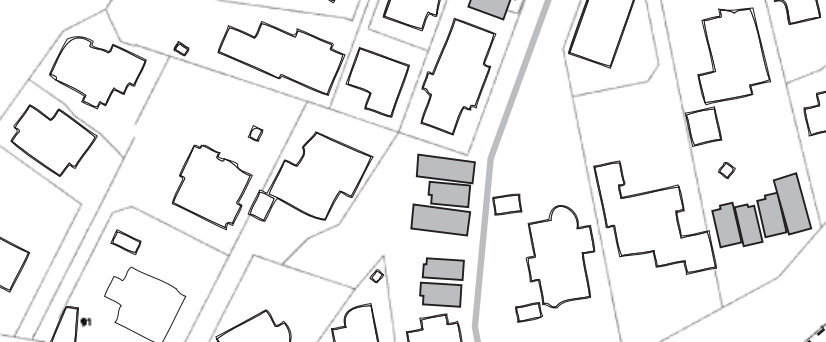
3 . 403 . $28 / 5$, H.

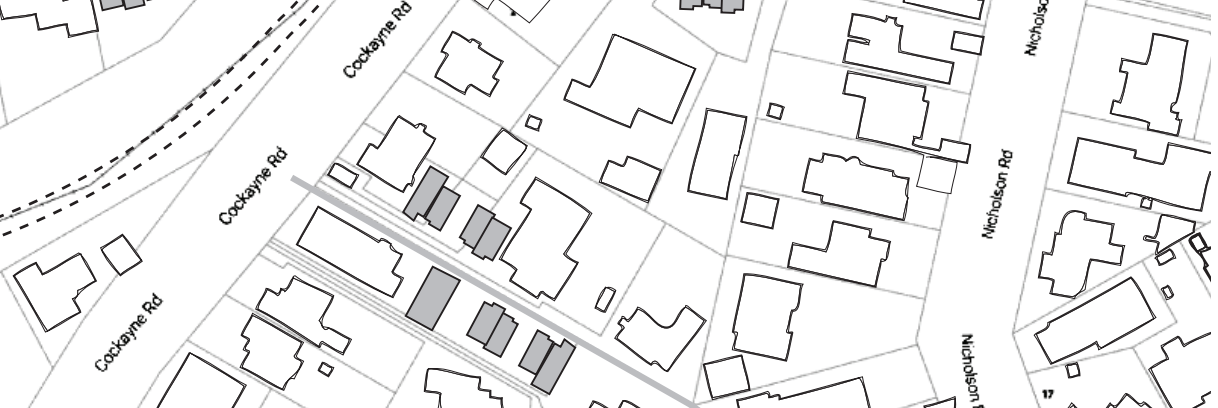
0 , s. bis.

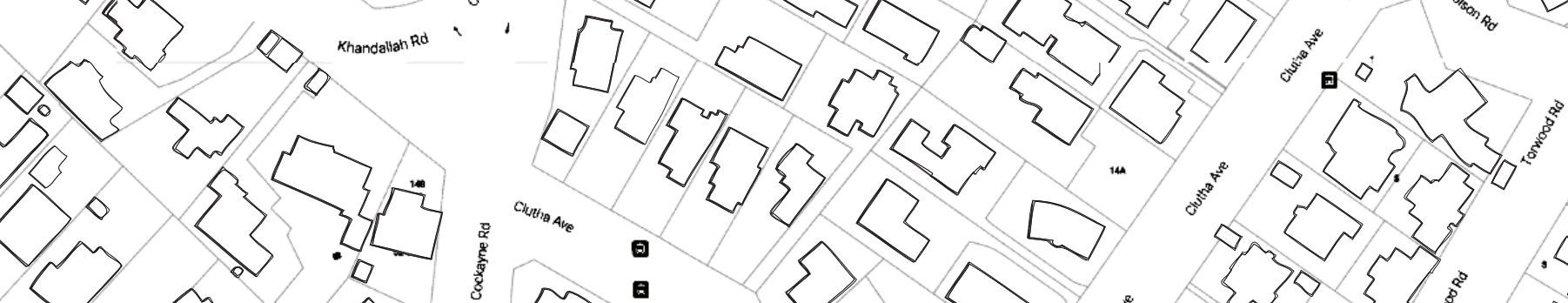
$\begin{array}{ccc} & \\ 1 & \end{array}$ 

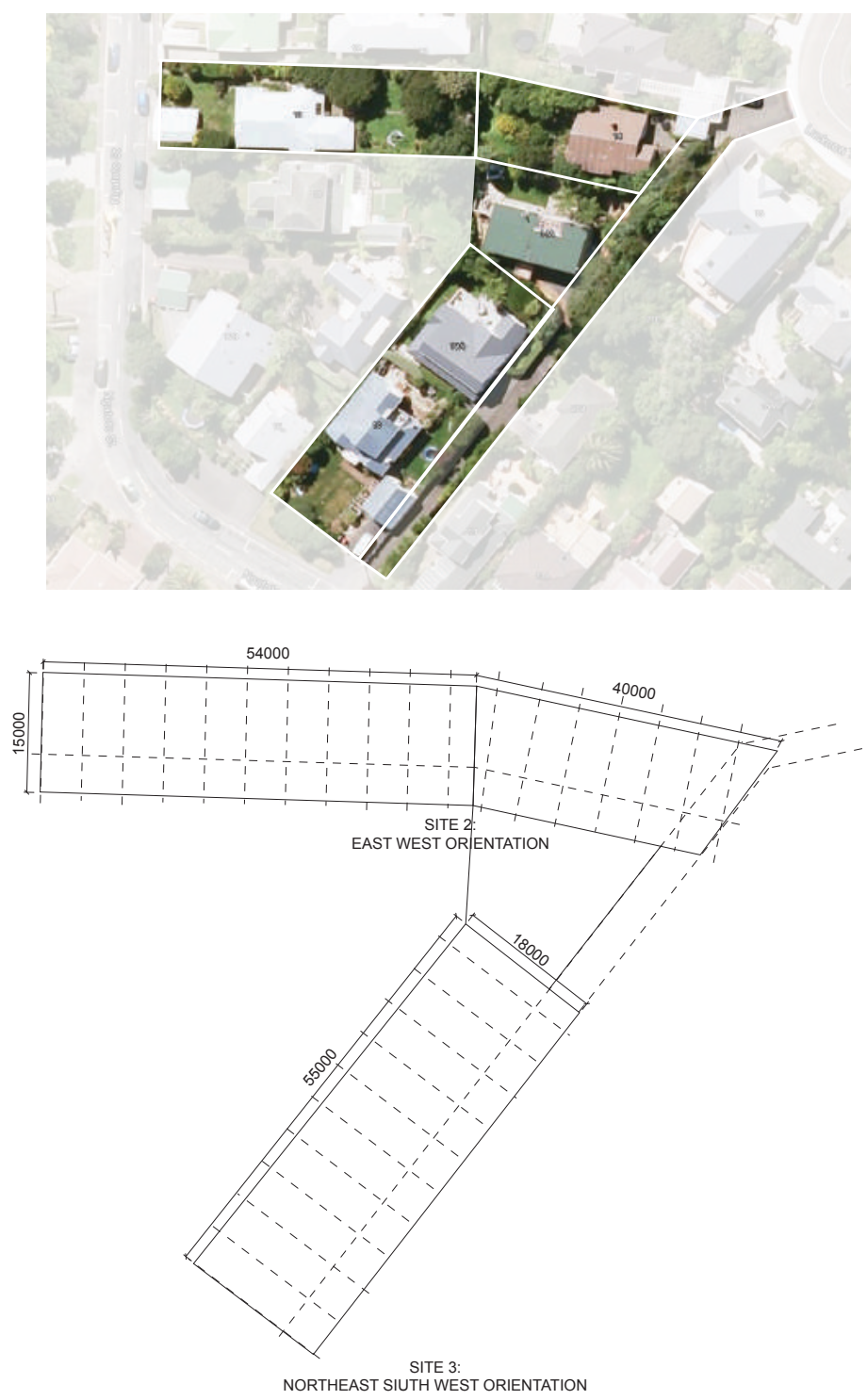

$\theta$

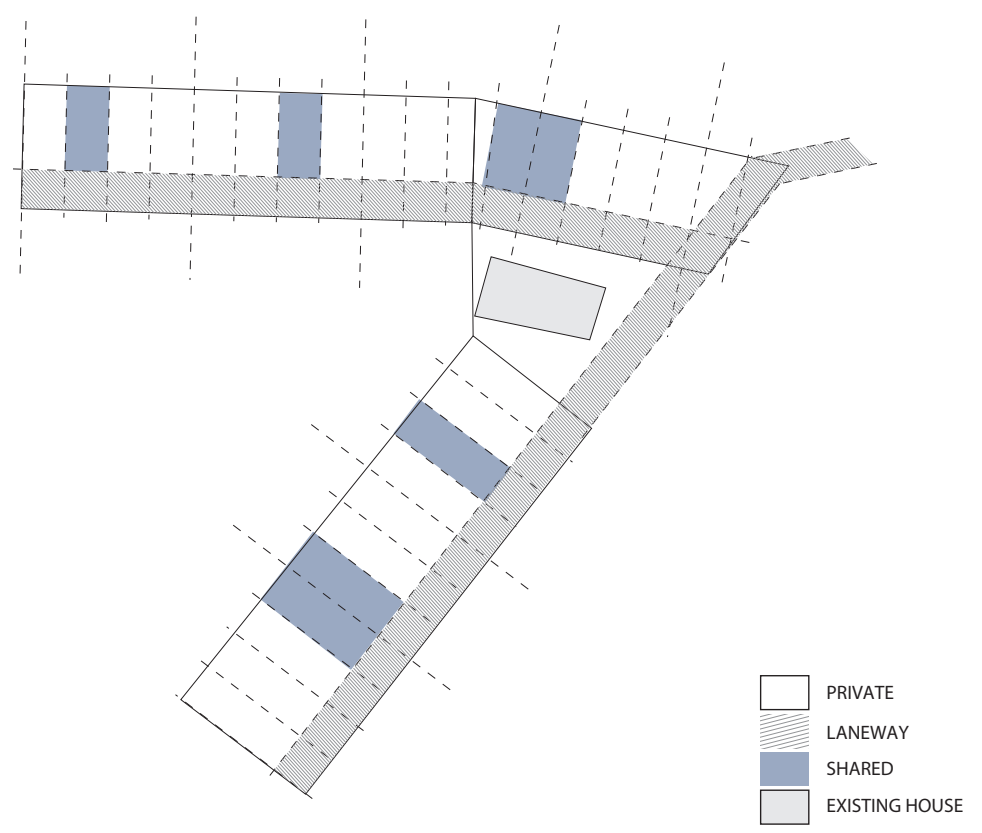




\section{SITE $2+3$ TEST}
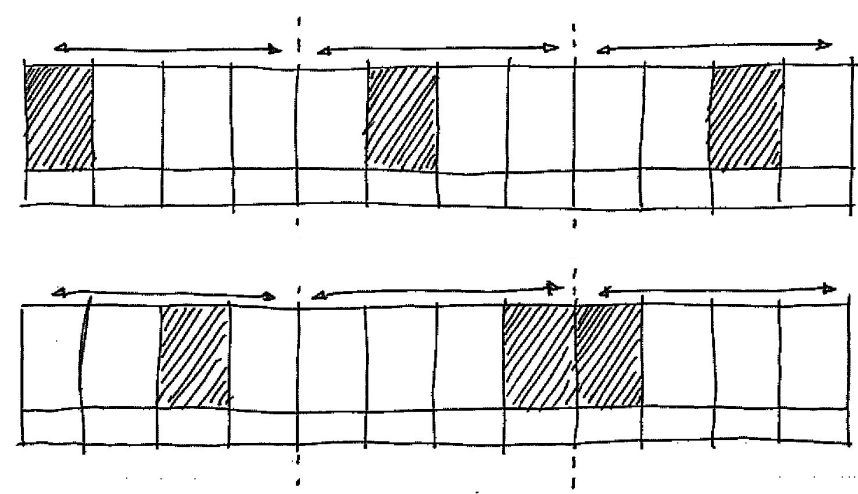

The introduction of two new sites was to test the effects of a sites orientation, size and gradient. The development of the scheme should explore the wider implications of densification for the suburb, and how a scale of this density may be implemented onto neighbouring sites, without becoming too dense or inappropriate for Khandallahs housing. A study of the area around site 1 located a series of sites that held potential for infill development. Site 2 and 3 were chosen as first tests.

The two sites were connected by an existing lane between Ngatoto street and Lucknow terrace. Site 2 is East-West oriented with a slope of approximately $8^{\circ}$, while site 3 is Northeast-Southwest oriented and relatively flat. The site design strategy using regular common spaces between houses, tested for site 1 was again applied to both sites. Areas intended for common space were examined in terms of existing vegetation and sunlight access. Location of the common zones was also tested, ensuring each would service 3 dwellings (fig 6.03 ). Site 3 has a width three metres wider than both site 1 and 2, allowing more flexibility of dwelling placement and private outdoors space.

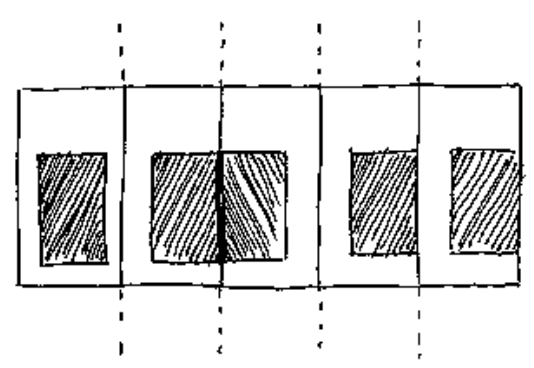

Consideration of how each dwelling was placed on site was explored through the arrangement of houses on the 'individual' sites, vs side yard sizing and shared walls. Introducing a common wall between dwellings provided a larger side yard for some dwellings that could then be used more efficiently. The problem with the common wall meant that access to natural light was reduced, this was addressed by adding skylights or high windows to allow natural light to filter inside. The larger side yard allowed windows to be located along the side of the dwellings, providing natural light and fresh air. Also providing a second access to the rear of the house and private outdoors. potential test sites

Fig 6.02. (Left)

${ }^{*}$ Aerial view of site $2+3$, site sectioning and infill redevelopment analysis of dwelling placement and shared lots on site

Fig 6.03. (Above) 


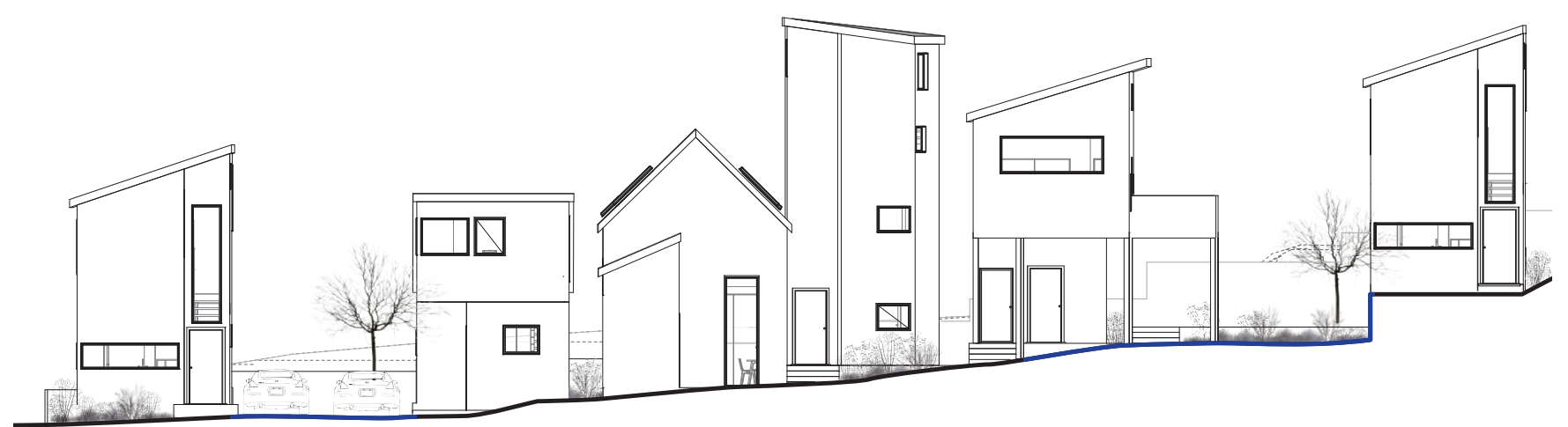




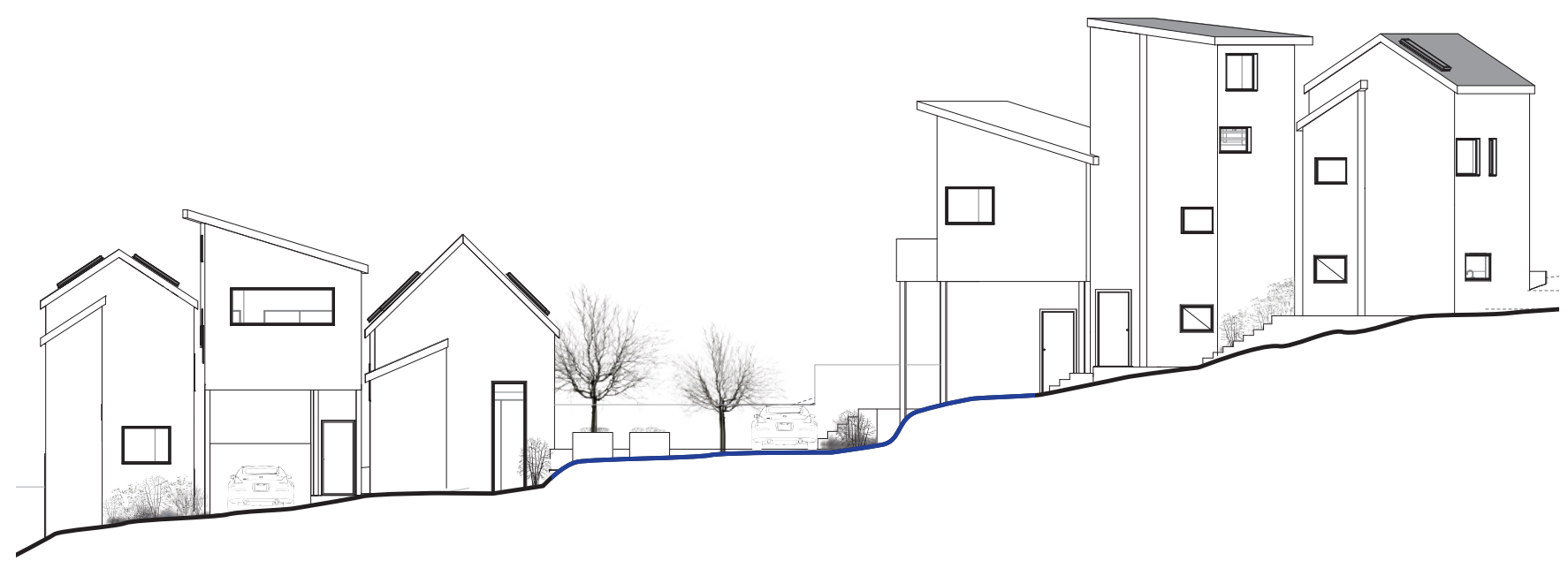

Fig 6.04.

Site 2 elevation in relation with the shared use and common amenities

which can be made larger where a stilted house faces onto the common 


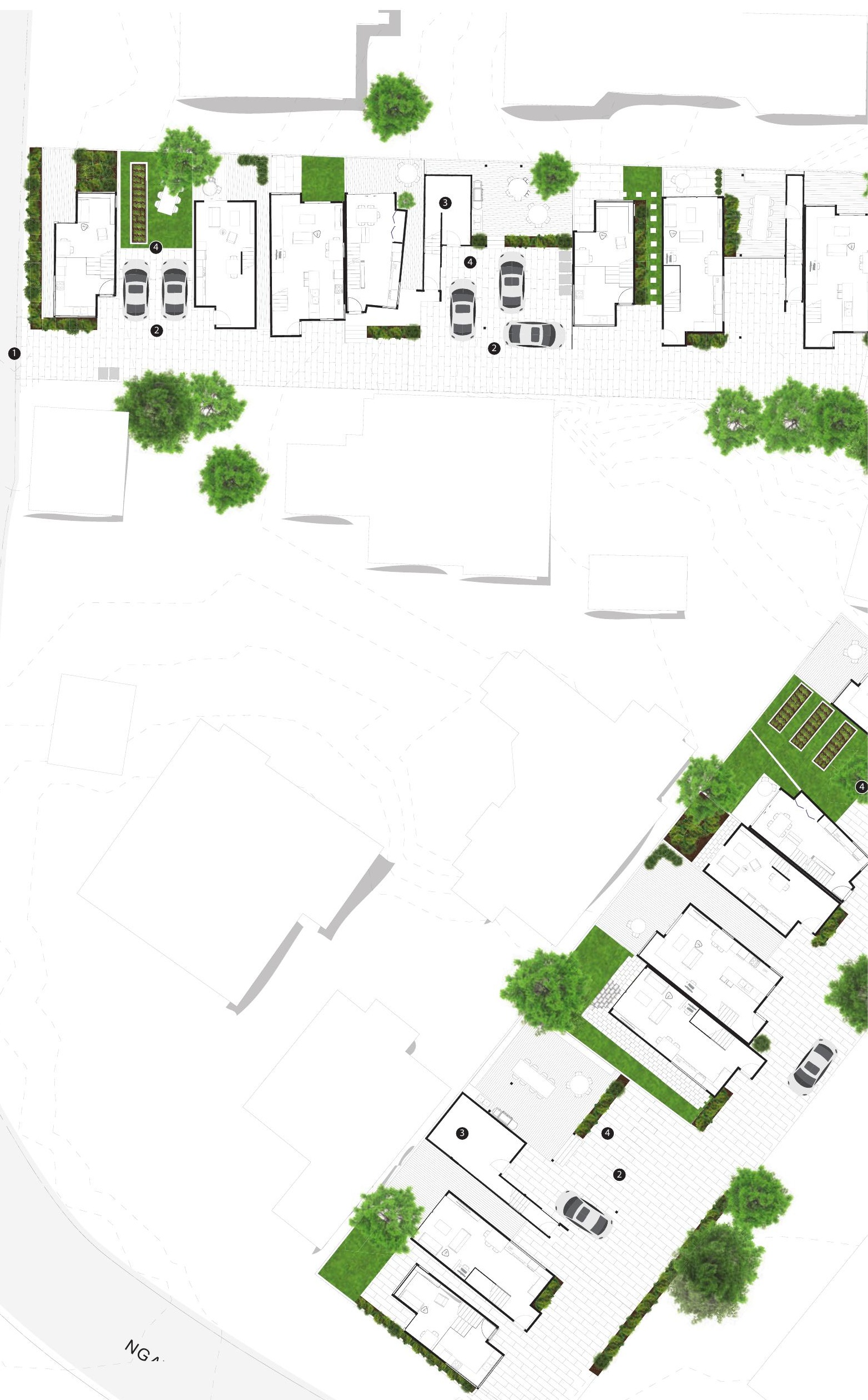




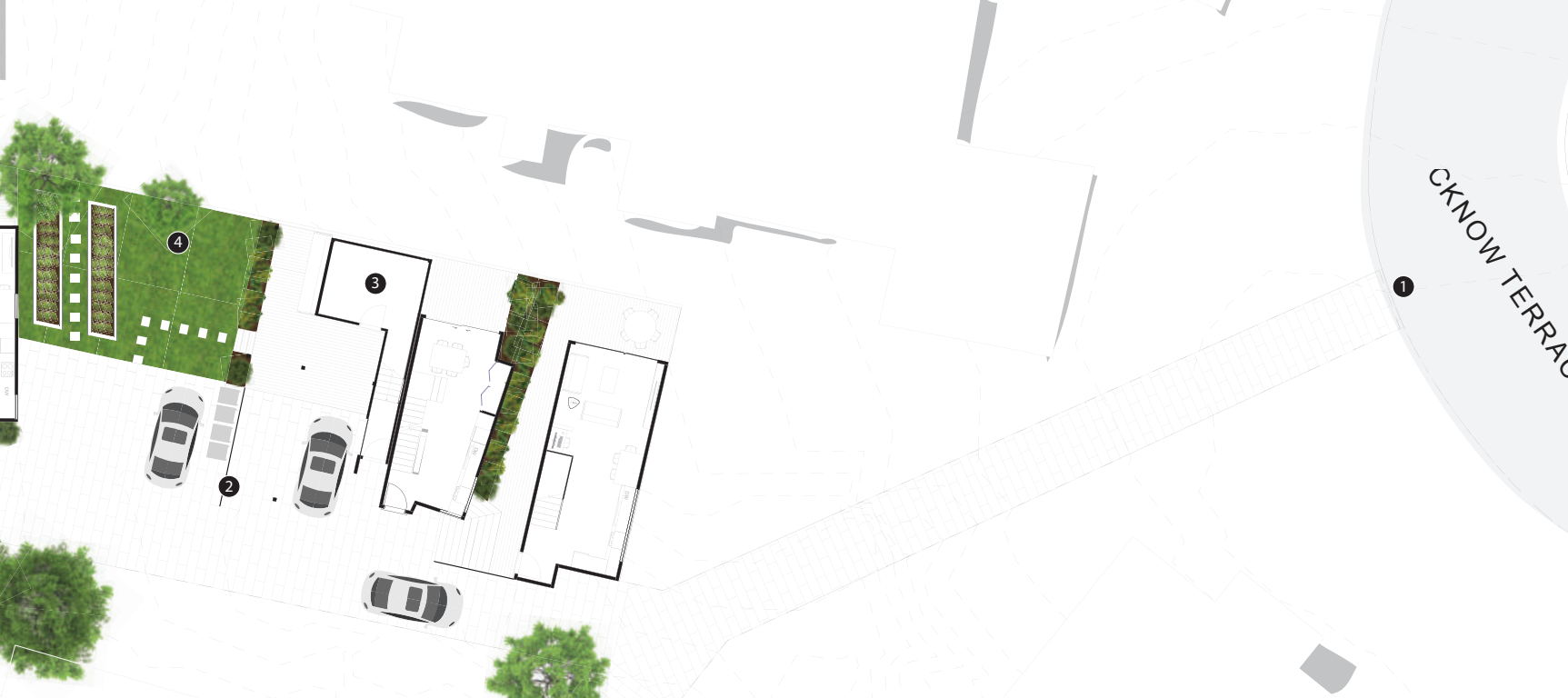

\section{c}
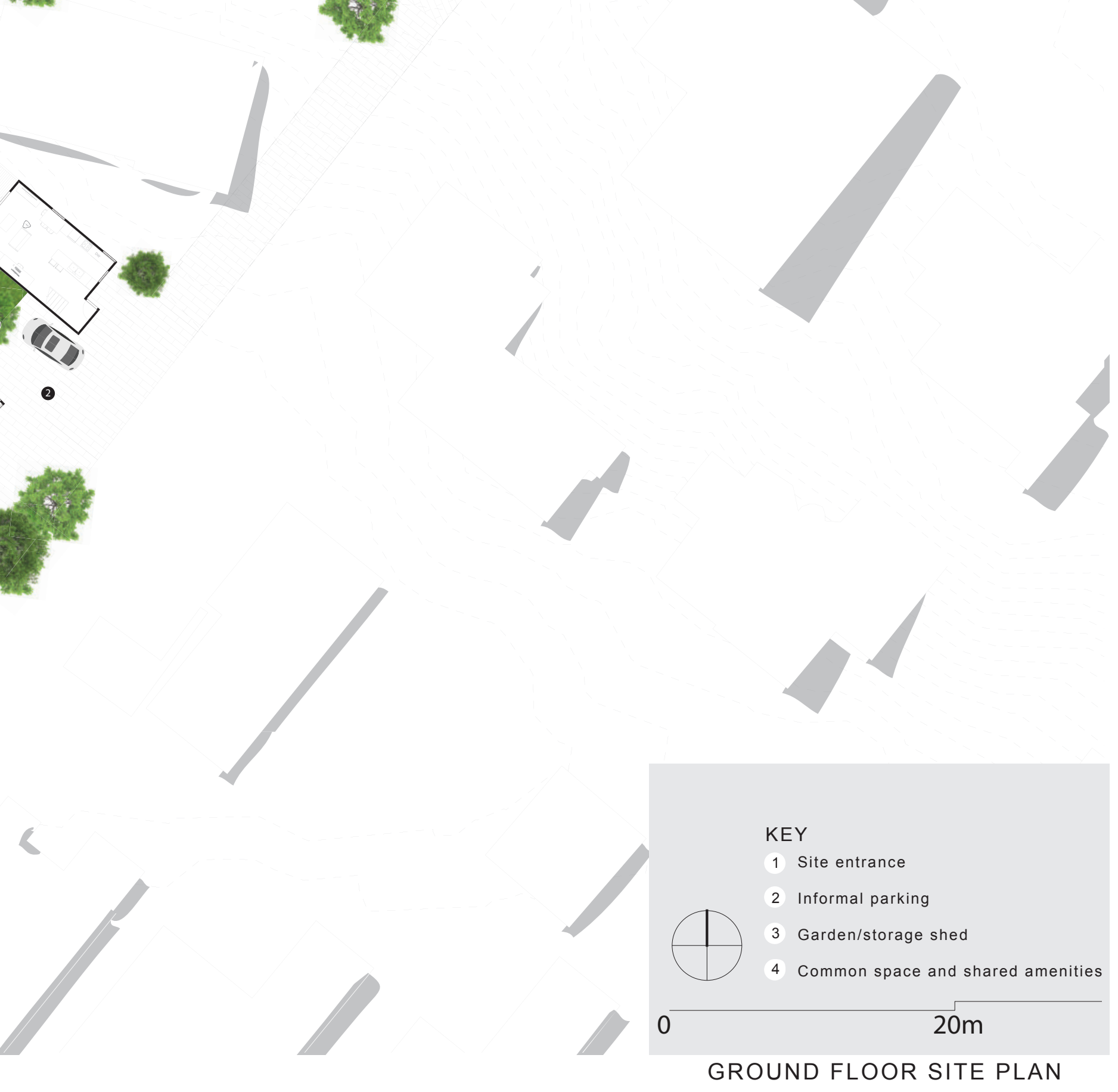


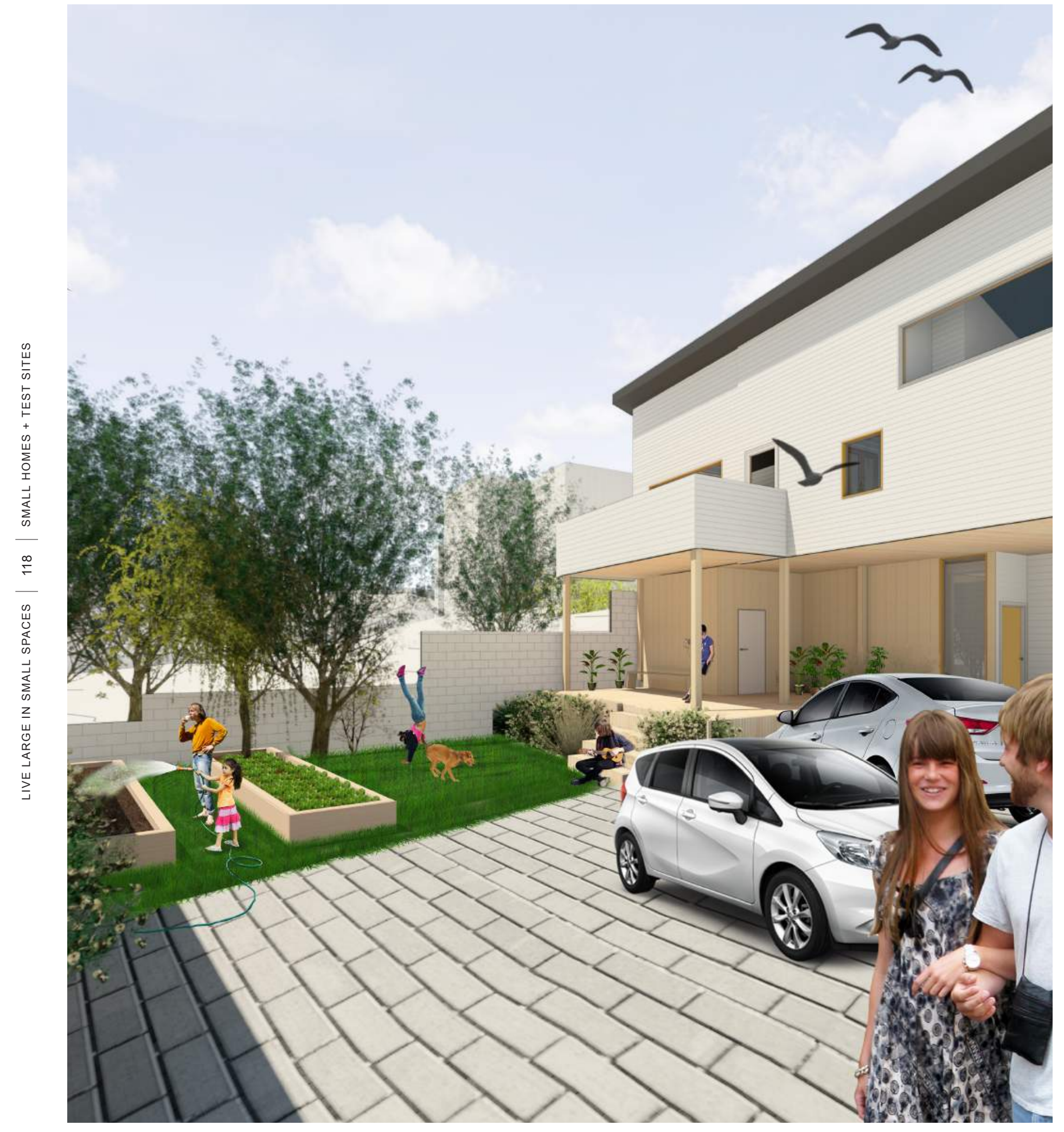

Fig 6.06

*SITE 2

An alternative design for the common

space, shows flexibility of the

scheme and alternative uses for the

residents 


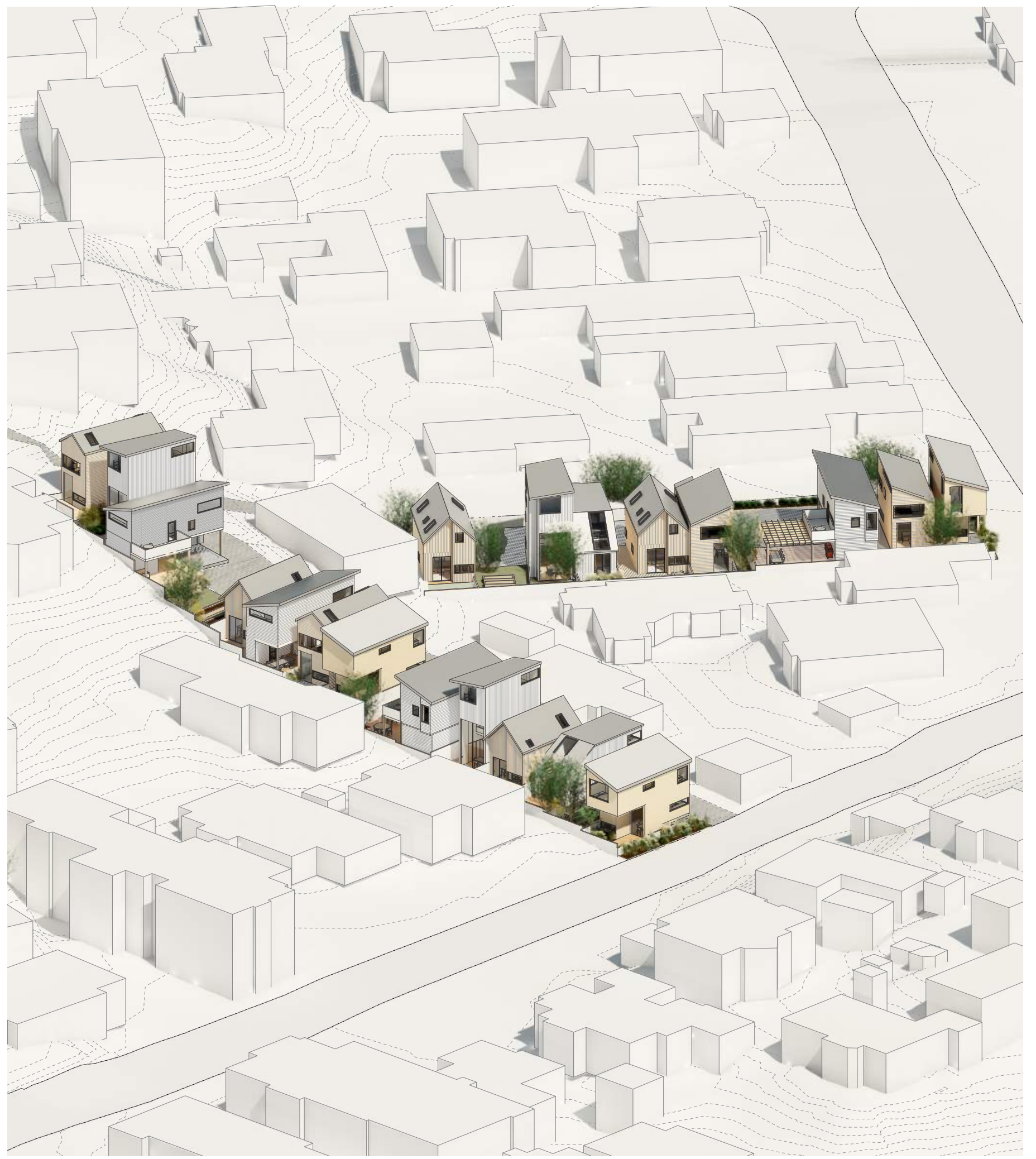

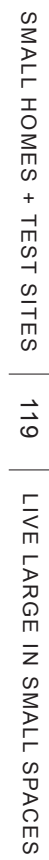

Fig 6.07.

SITE $2+3$

Overview 


\section{AFFORDABILITY REVISITED}

The affordability of dwelling 3 and 4 were revisited for an analysis of site 2 . The site, with an existing dwelling was valued at $\$ 1,110,000$ including the existing house value. Therefore the site cost per house is $\$ 92,000$.

-The largest house design came to $77 \mathrm{~m} 2$, with an estimated cost of $\$ 400,000$.

-The smallest house design came to $50 \mathrm{~m} 2$, with an estimated house cost of $\$ 295,000$.

This check on the original cost basis confirms that a range of affordable housing, significantly more affordable than the median Khandallah house, at $\$ 923,100$ can be provided.

**Target budget for deposit assumes occupants have saved for 4 years

Fig 6.08

${ }^{*}$ Affordability revisited for site 2

The affordability analysis for site 2 excludes demolition costs and assumes the existing house value would offset these costs. Detailed elemental costings were beyond the scope of the research at this stage. 


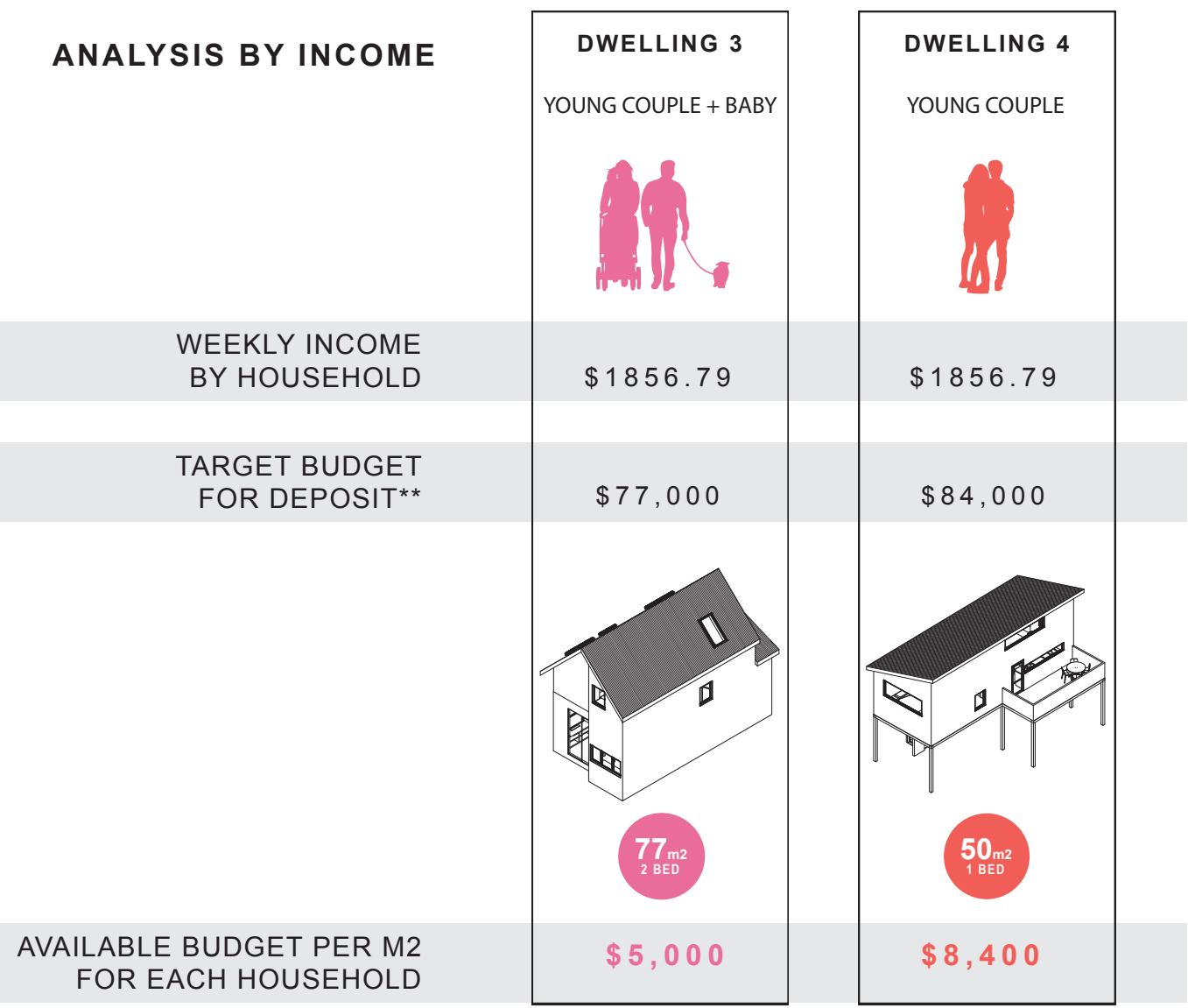

ANALYSIS BY HOUSE COST

HOUSE COST ASSUMING $\$ 4,000$ PER M2, INCLUDING $\$ 92,000$ LAND AND EXISTING HOUSE COST
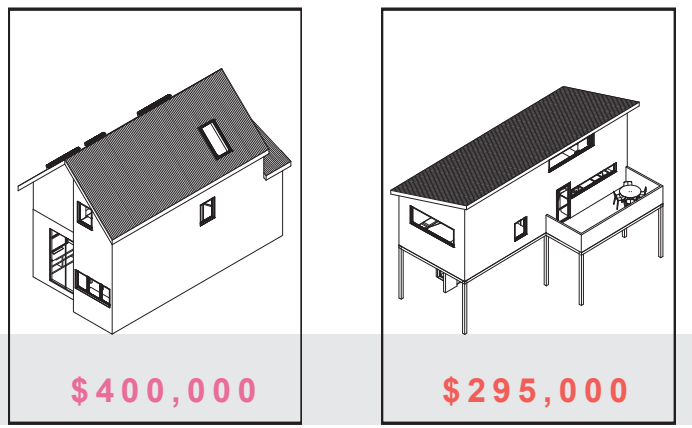

MEDIAN HOUSE PRICES IN WELLINGTON $\$ 583,700$

LOWER QUARTILE HOUSE PRICES IN WELLINGTON

$\$ 465,300$

MEDIAN HOUSE PRICE IN KHANDALLAH

$\$ 923,100$ 

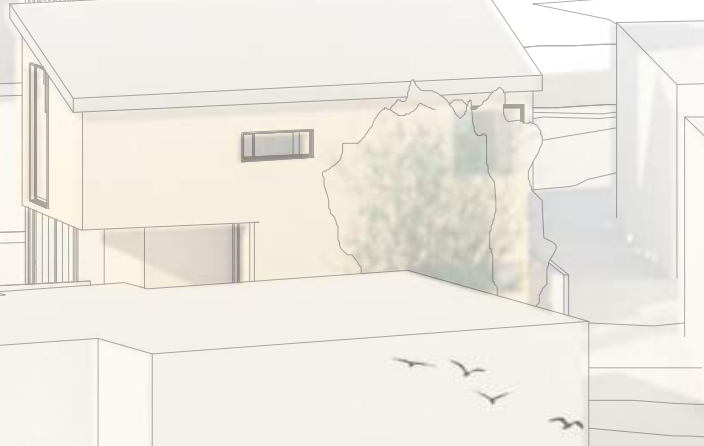

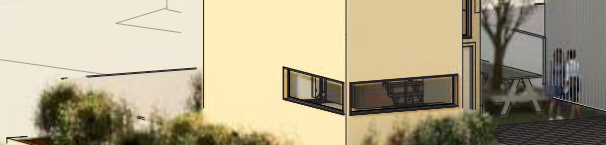




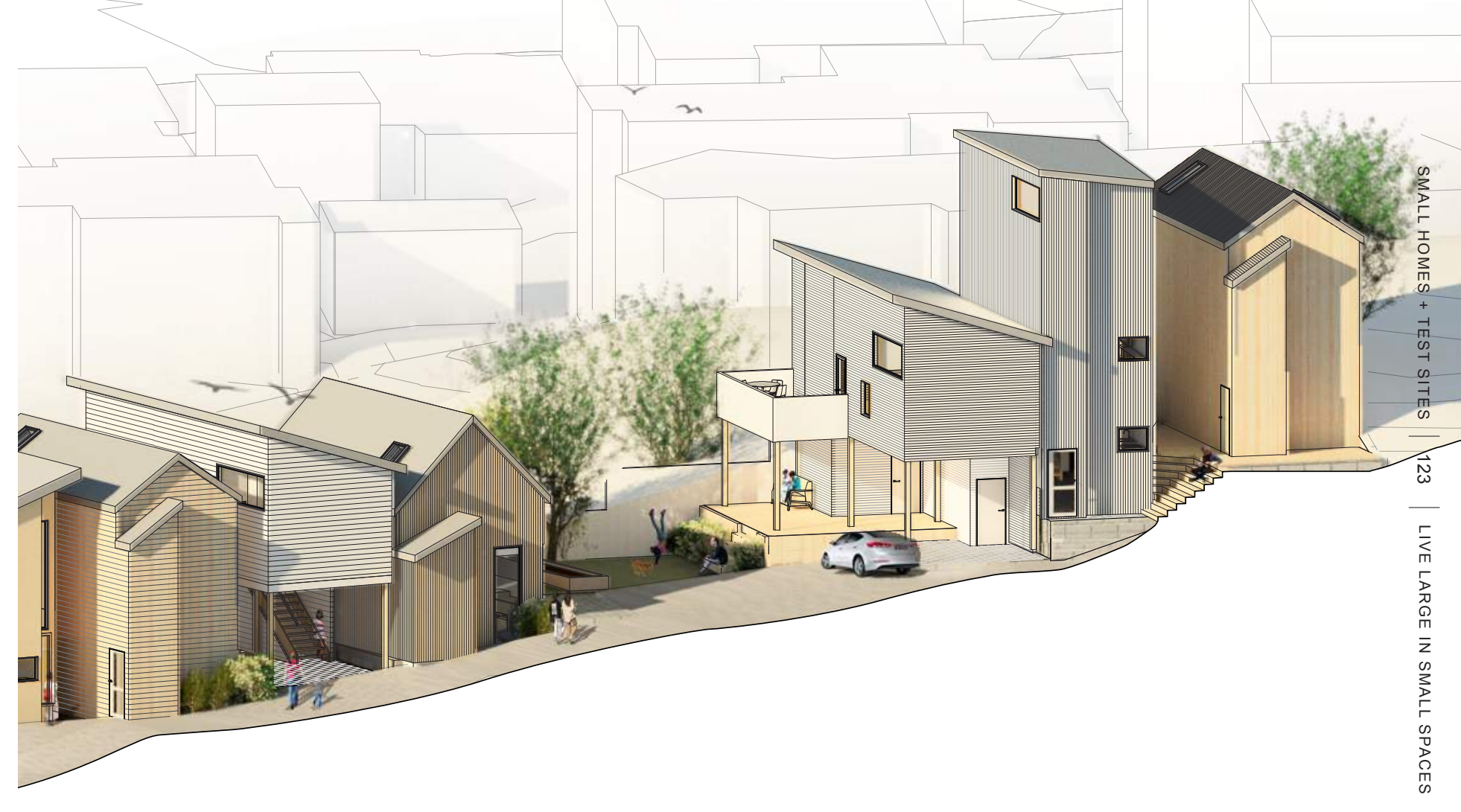

Fig 6.09.

*SITE 2

Perspective elevation of connections beween the laneway, common spaces and private entranceways 


\section{WHERE TO NEXT FINDINGS + REFLECTION}

The introduction of site 2 and 3 was to ensure the proposed density and site development was tested on a range of sites that would provide different site conditions and considerations that couldn't be solely explored within site 1 . These sites were chosen following a study of appropriate sites located close to transport facilities.

"I would argue that increasing the density of urban housing along transport corridors and at town centres would improve combined housing and transport affordability, and thus have a significant impact on households' two main expenses"

(Howden-Chapman, 2015)

This was important, as a way to understand how the intensification strategy could be implemented, to discover which sites were appropriate and should be developed first. The clusters of housing create neighbourhoods within each site which potentially adversely affect the neighbouring properties and existing amenities and infrastructure within the suburb. Developing a planning rule for eliminating unsuitable potential sites would allow a new pattern for the suburb to be integrated within the existing urban fabric.

The new cluster typology and common space rule allowed a pattern of density to be developed, with aims at improving the open space and shared amenity for the residents. The test design showed that its possible to provide a range of quality private open spaces per dwelling, and these enhance the common spaces and provide opportunities for interaction and shared use for the residents.

This site design strategy allowed a more effective use of the site, proving it could be replicated among multiple sites of similar dimensions and be adaptable to suit site conditions, size, orientation and gradient. 
The design is replicable among similar site sizes, however it has wider implications for the larger suburb. What is the appropriate density for expansion of neighbouring sites? and the question of, what are the implications for the whole suburb? are yet to be addressed. What are the limits of this subdivision strategy? Do these small houses position, isolate, or integrate themselves within the city?. Their integration becomes apparent through the relation to the existing suburb and the benefits of intensification:

- Land use is more sustainable, containing urban sprawl and better utilising outer land for recreation, food production and ecological regeneration.

- Greater social cohesion with cultural growth, and enhanced commerce, health and safety from more diverse compact neighbourhoods.

- Transport is more efficient and sustainable, and facilities are more accessible by walking or cycling.

John Gray (Badcock, 2014)

"The blocks or ensembles that form the architecture of collective living cannot be as easily swallowed up by their environment as, say, an individual small house can: They crucially influence their environment and are like small cities within the city."

(Dalziel, Cortale, \& Battle, 2012)

Small houses can postively contribute to the city through the clusters of dwellings that implement shared space and amenities within the design. 


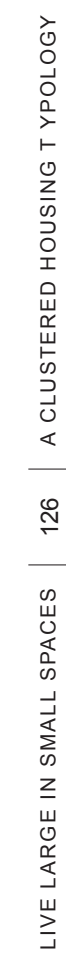




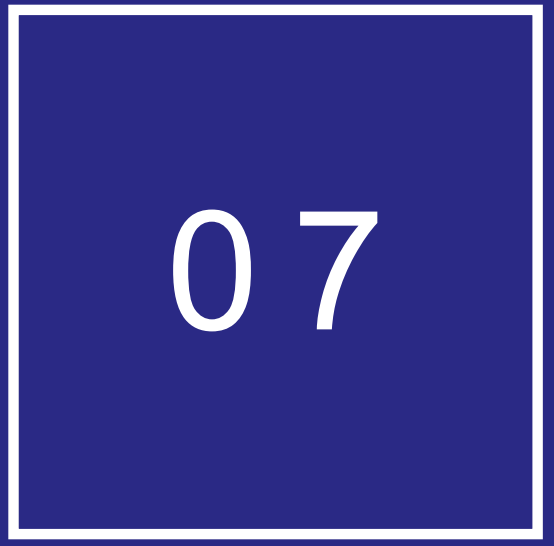

CONCLUSIONS

A CLUSTERED HOUSING TYPOLOGY 
The final phase of design

research worked as a

refinement and reflection

phase, drawing out

implications of the design

and conclusions. 


\section{REFINEMENT OF DESIGN}

House 2 and House 3 small home designs were refined and developed through working models at 1:20 scale. The process of modelling at a large scale allowed a 3 dimensional critique of the design and a closer understanding of how each space worked for its inhabitants. 


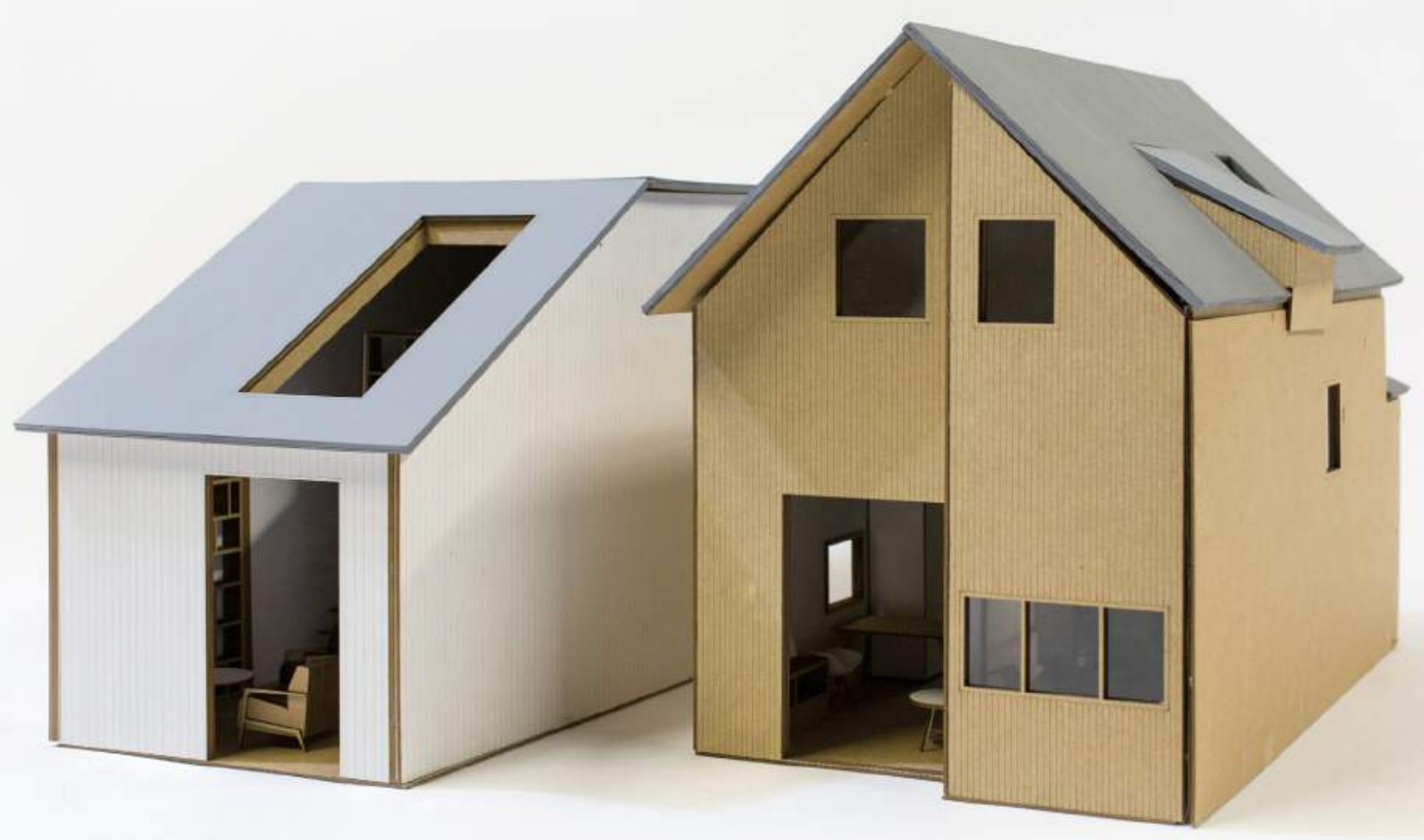

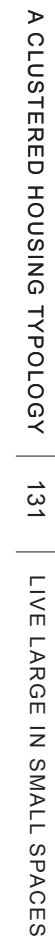



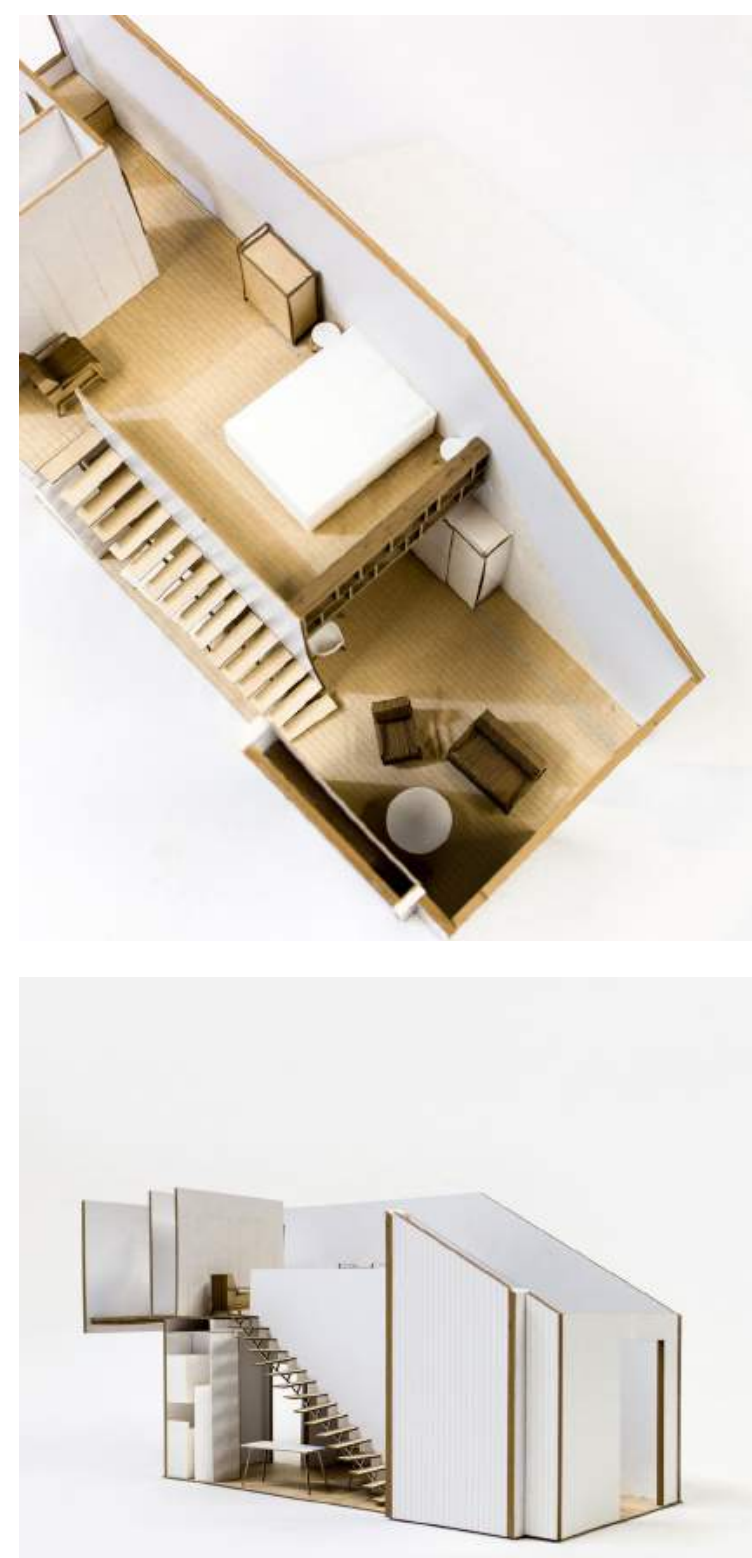

The laundry and hot water cylinder were relocated below the stairs. The open stair allowed ample room for storage space and an area for a desk/ study space
The first floor was redesigned to allow morning light to filter onto the bed, providing a window seat and better circulation into the bathroom.
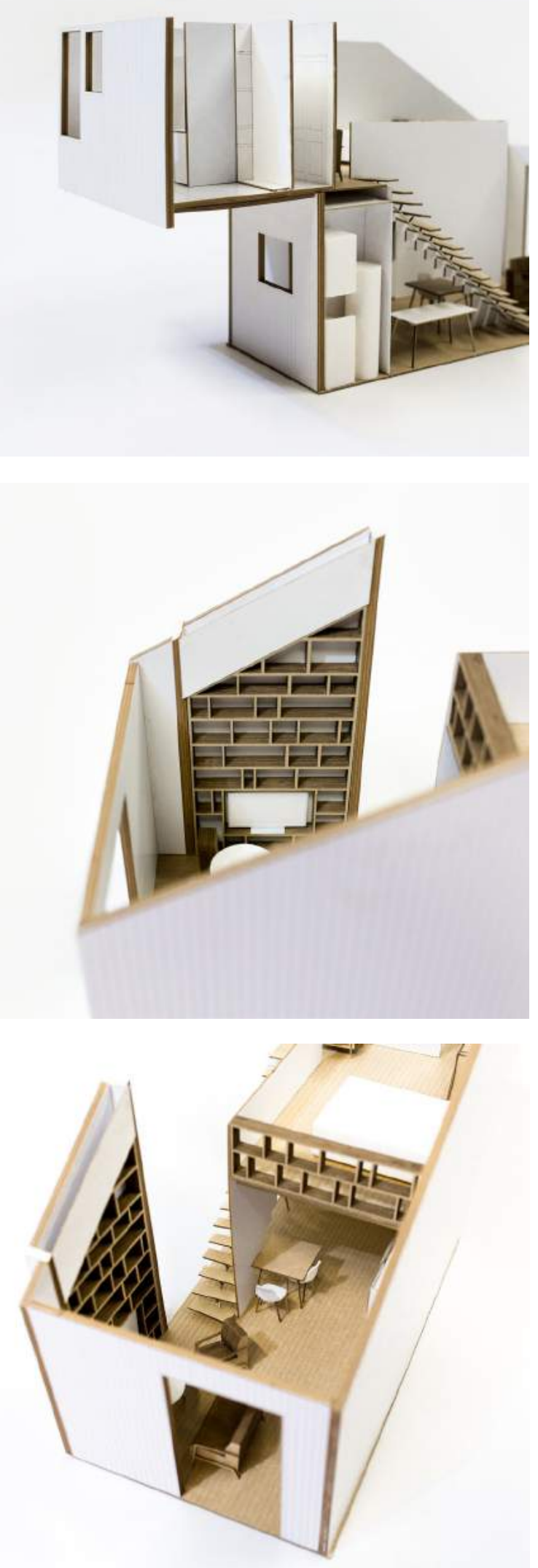

Fig 7.03. 


\section{HOUSE 2}

1 BEDROOM

$58 \mathrm{M} 2$

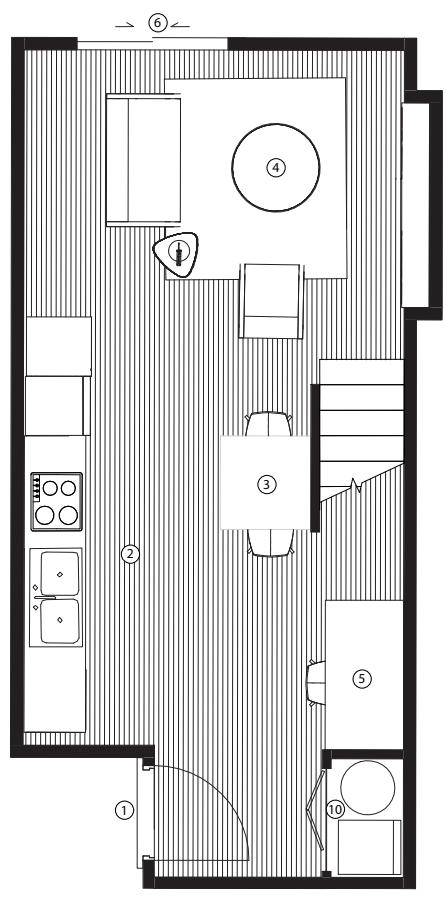

GROUND FLOOR

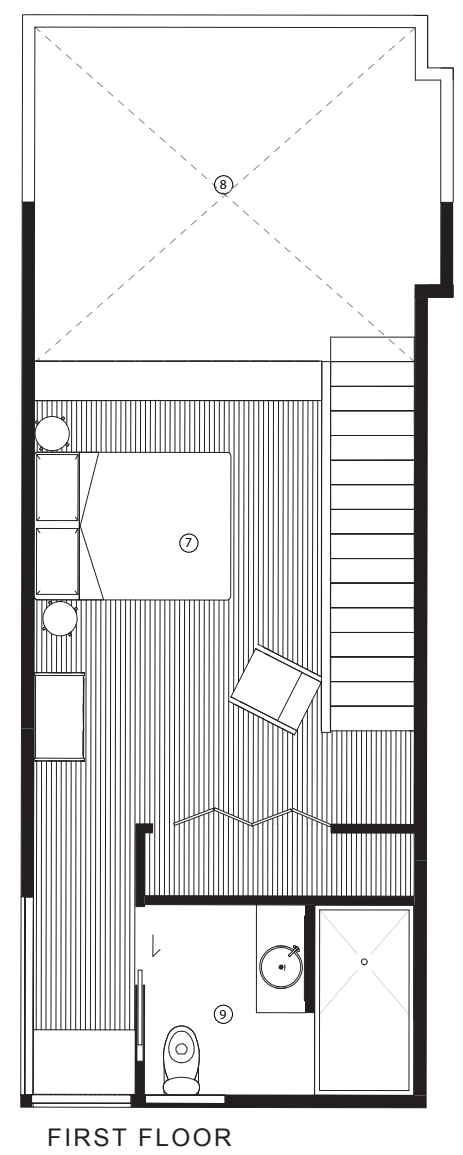

KEY

(1) Entry

(2) Kitchen

(3) Dining

(4) Living

(5) Study

6 Outdoor space

(7) Master bedroom

8 Second bedroom

(9) Bathroom

(10) Laundry

SCALE 1:100 
Window seat was made smaller to allow a desk or other furniture to occupy the space below the open staircase
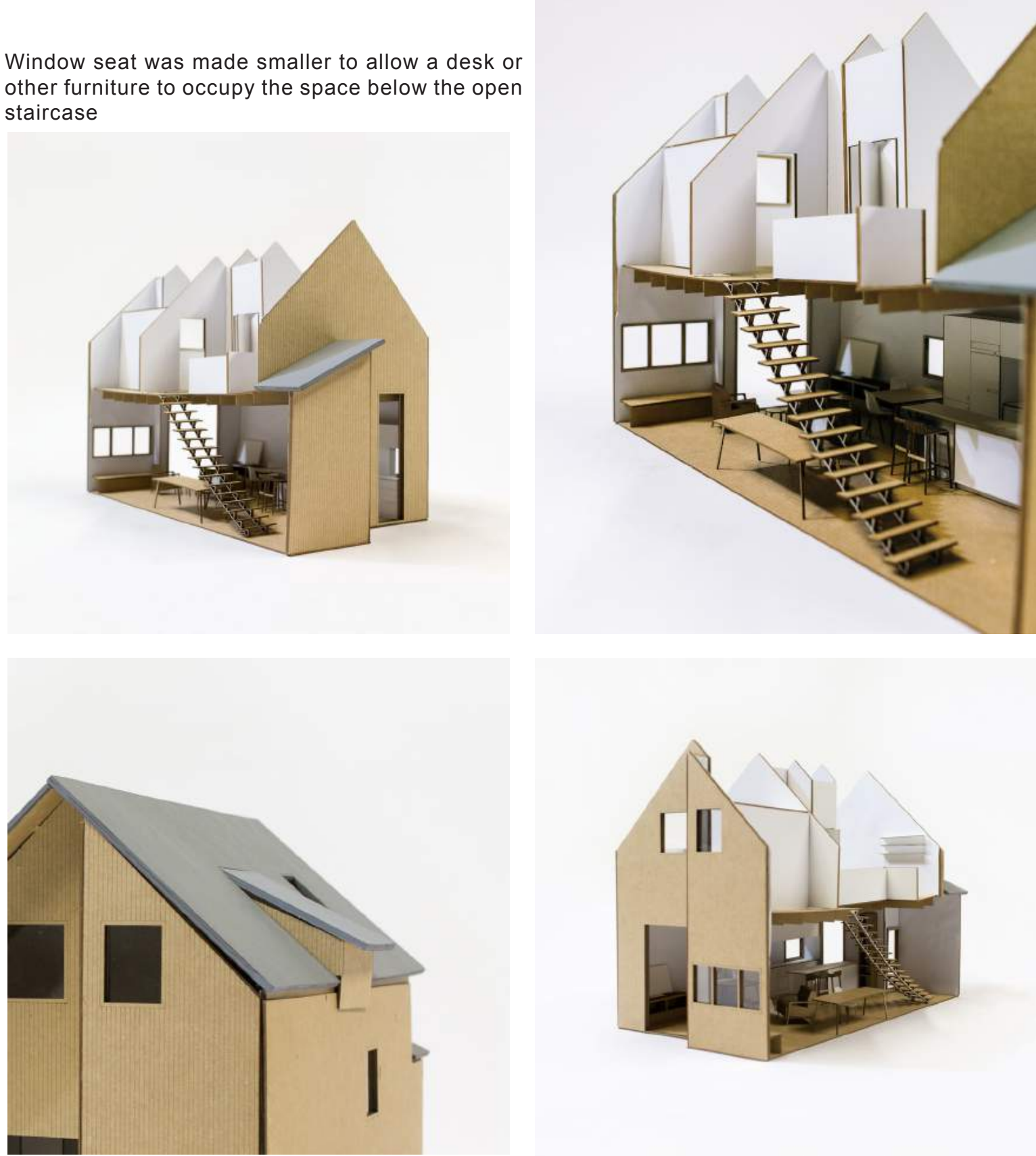

With the steep pitch of the roof, the ceiling came too low above the stair landing so a skylight was designed to jut out from the roof

The bathroom was altered to allow better flow within the small footprint, fitting the toilet beside the shower with an open corner for easy access

Fig 7.04.

(Above)

${ }^{*}$ House 3 physical model

Fig 7.05.

(Right)

House 3 Plans

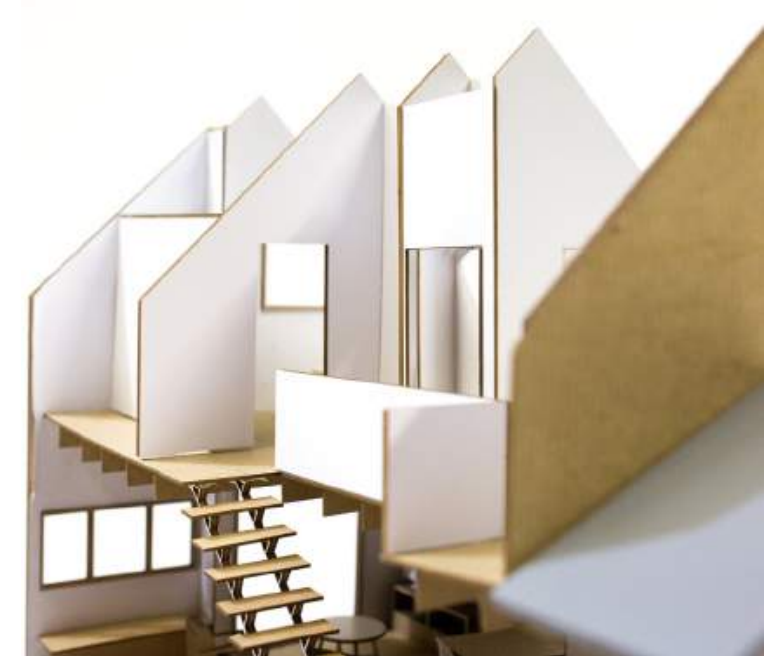




\section{HOUSE 3}

\section{BEDROOM}

\section{M2}
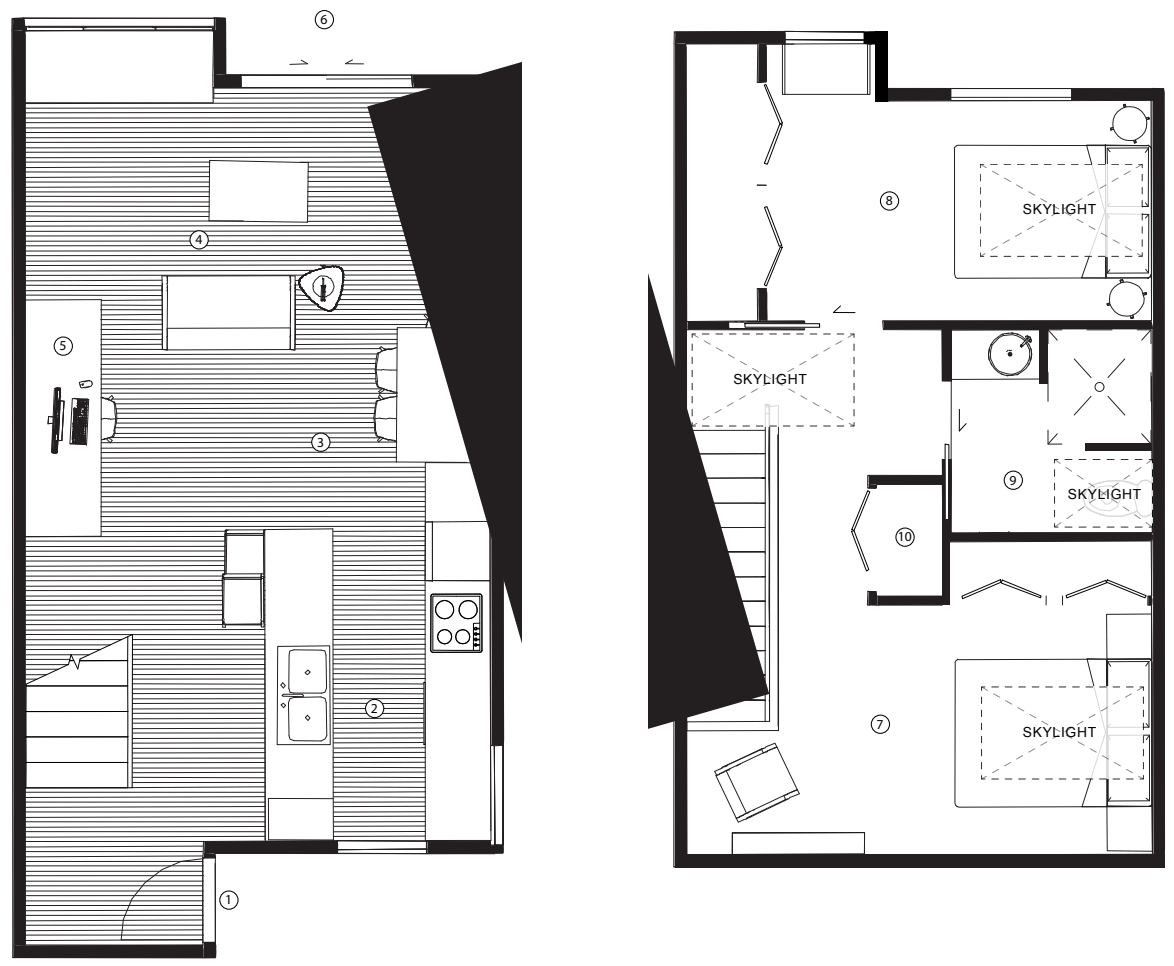

GROUND FLOOR

FIRST FLOOR

KEY

(1) Entry

(2) Kitchen

(3) Dining

(4) Living

(5) Study

6 Outdoor space

(7) Master bedroom

8 Second bedroom

(9) Bathroom

(10) Laundry

SCALE 1:100 


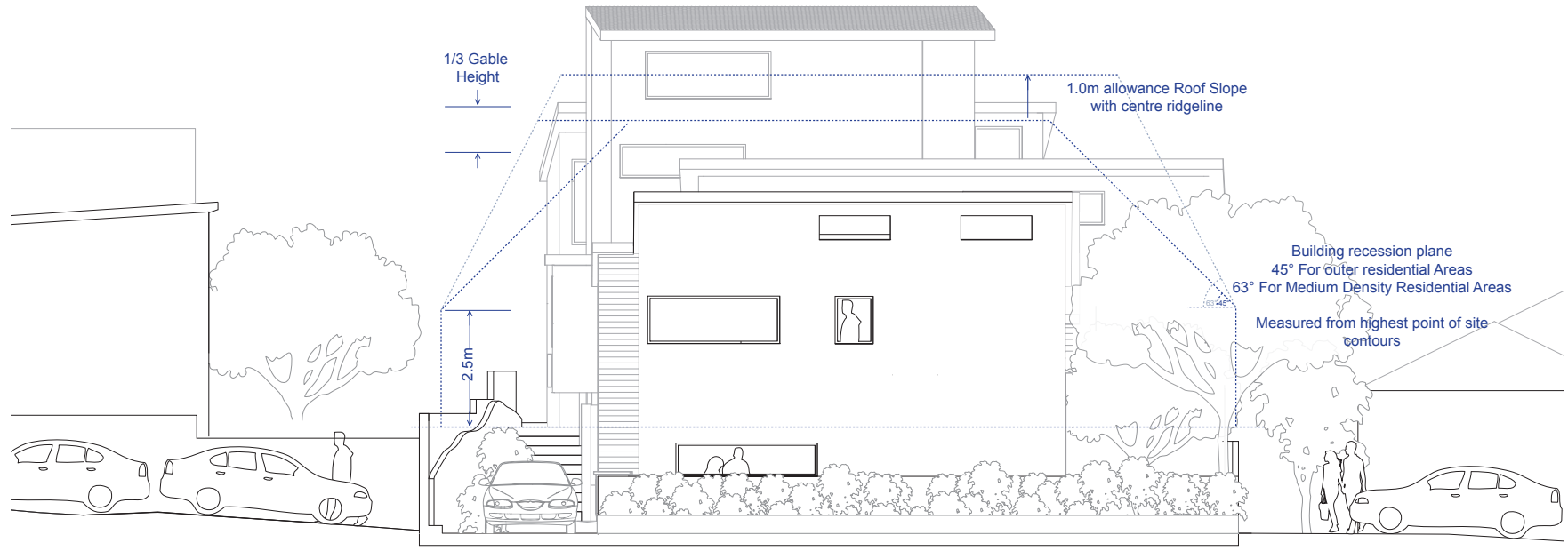

\section{DISTRICT PLAN} RULES + REGULATIONS

Khandallah is classified as an 'Outer Residential Zone'. For an increased level of intensification to be implemented, some areas of Khandallah will require a zone change to allow controlled medium density housing, to reflect Khandallahs location close to the city.

The design demonstrates that altering rules for building set backs, street frontages, site coverage and height restrictions will not adversely affect neighbouring properties and will benefit the existing amenity and comfort, better utilising existing infrastructure - specifically rail services and roading. The proposal aims to retain existing vegetation with the placement of common spaces around the site and relates to the existing pattern of building density through the clusters of housing which have similar building massing to the existing house volumes.

The opportunities to alter the current district plan provisions would promote public transport-oriented, higher density areas, of which benefits are numerous - specifically catering for affordable housing in Khandallah or adapted for specific site circumstances (Badcock, 2014).

The new cluster typology and common space rule requires a minimum $4 \mathrm{~m}$ width laneway, and aligns with the current regulations of 1 park per unit, but with some shared use/informal/stacked parking. The common spaces allow multiple uses. The informal parking also prevents the area becoming vehicle dominated, and can be adapted in future to give way to better recreation facilities, productive gardens and green open space. The proximity of the train stations allow occupants to not have cars or share cars through car clubs as car dependance diminishes over time.

Fig 7.06.

Site 1 Street Elevation
Current medium density requirements for shared open space is a minimum width of $3 \mathrm{~m}$. The new cluster typology and common space rule requires a higher minimum, of dimensions $5 \times 11 \mathrm{~m}$, for every three dwellings on site.

Fig 7.07

District plan rules and regulations proposal change for Khandallah suburb 


\section{KHANDALLAH: \\ OUTER RESIDENTIAL ZONE}

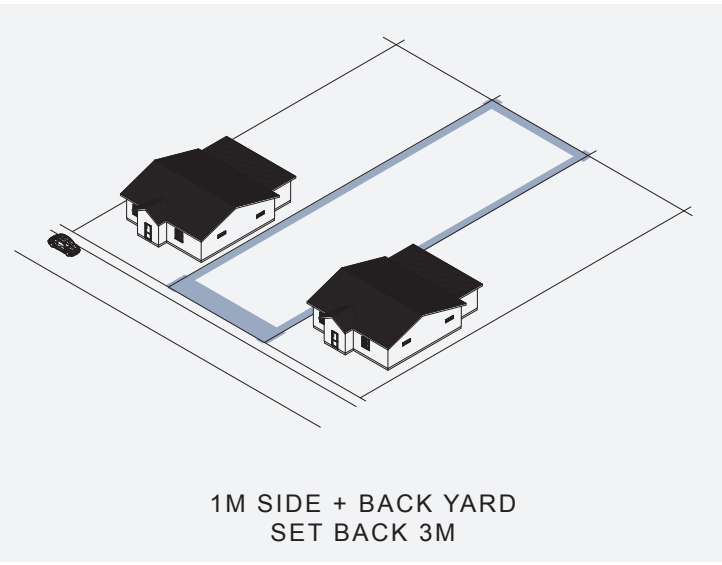

\section{CLUSTER HOUSING PROPOSAL: MINIMUM SITE WIDTH $16 \mathrm{M}$}

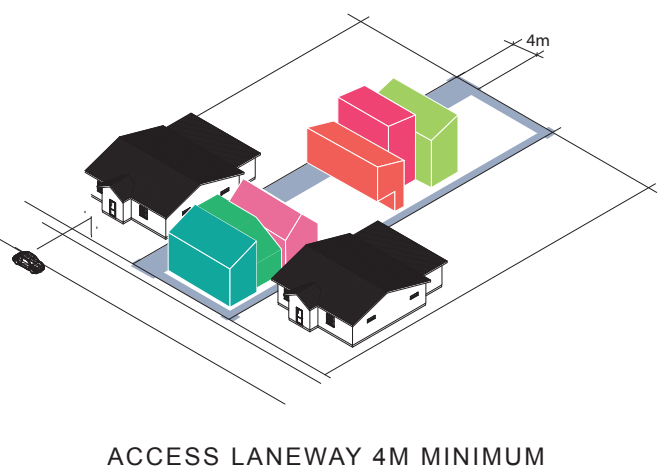

FRONT + SIDE + BACK YARD 2M MINIMUM

Proposed rule change 1 :

BUILDING SET BACKS \& STREET FRONTAGE

Street frontage should be sympathetic to the existing context, however a minimum $2 \mathrm{~m}$ setback allows the new cluster typology and coomon space rule to provide extra space for the common zone. There is no current minimum for medium density zones.
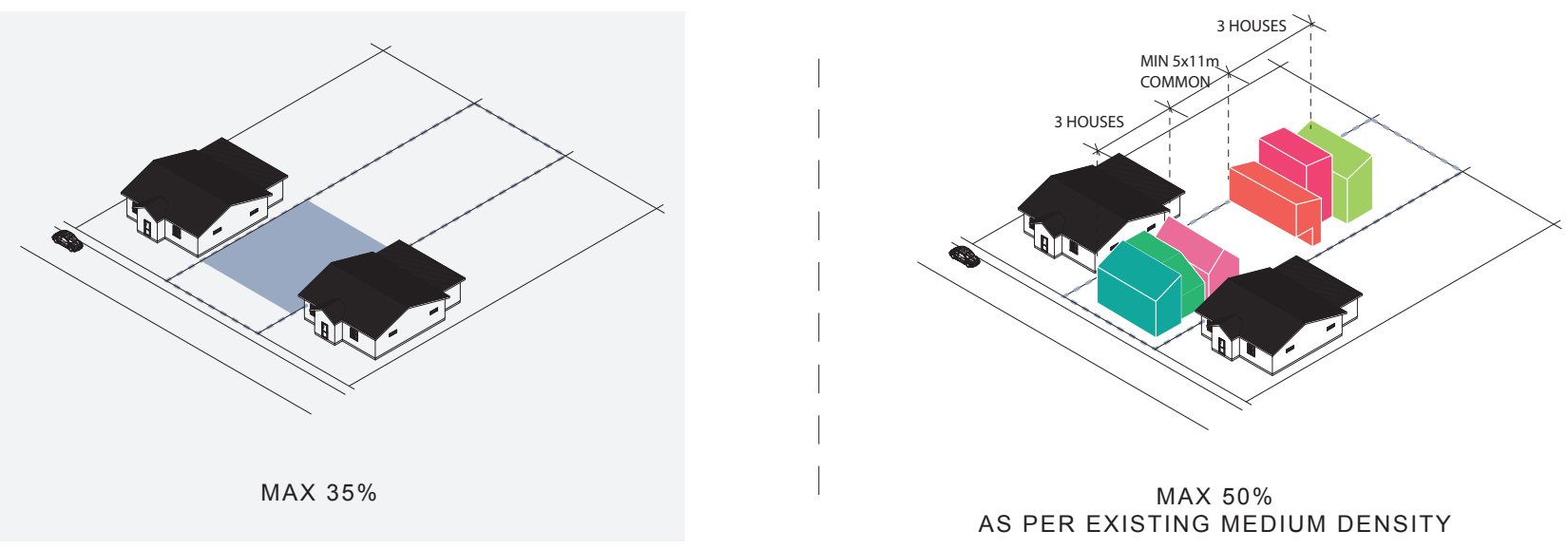

AS PER EXISTING MEDIUM DENSITY

Proposed rule change 2:

\section{SITE COVERAGE}

Khandallah sites are typically large, so increasing the maximum site coverage will better utilise the site. Shared open space will have a minum site coverage of $5 \mathrm{~m} \times 11 \mathrm{~m}$ for every 3 dwellings.
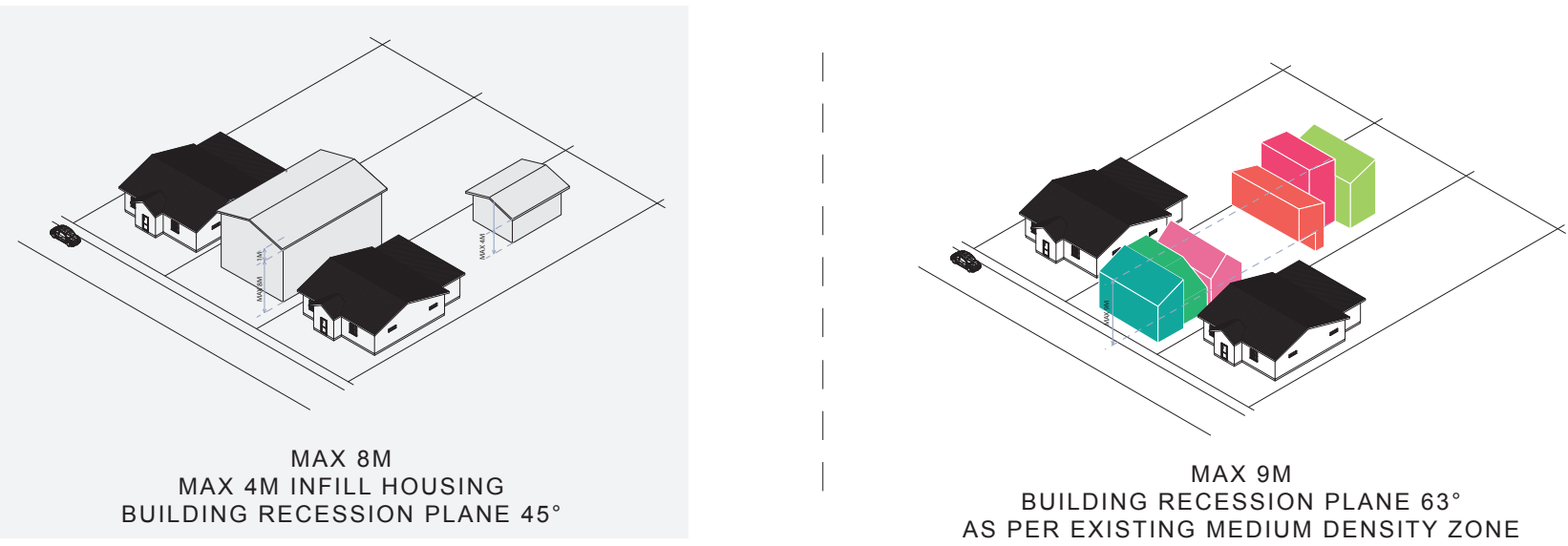

Proposed rule change 3:

\section{HEIGHT RESTRICTIONS}

Height too restrictive and prevents increased density at the same massing of the existing suburb, effectively reducing density for infill housing compared to subdivision. Increasing the maximum height to $9 \mathrm{~m}$ and a $63^{\circ}$ recession plane will be less restrictive 


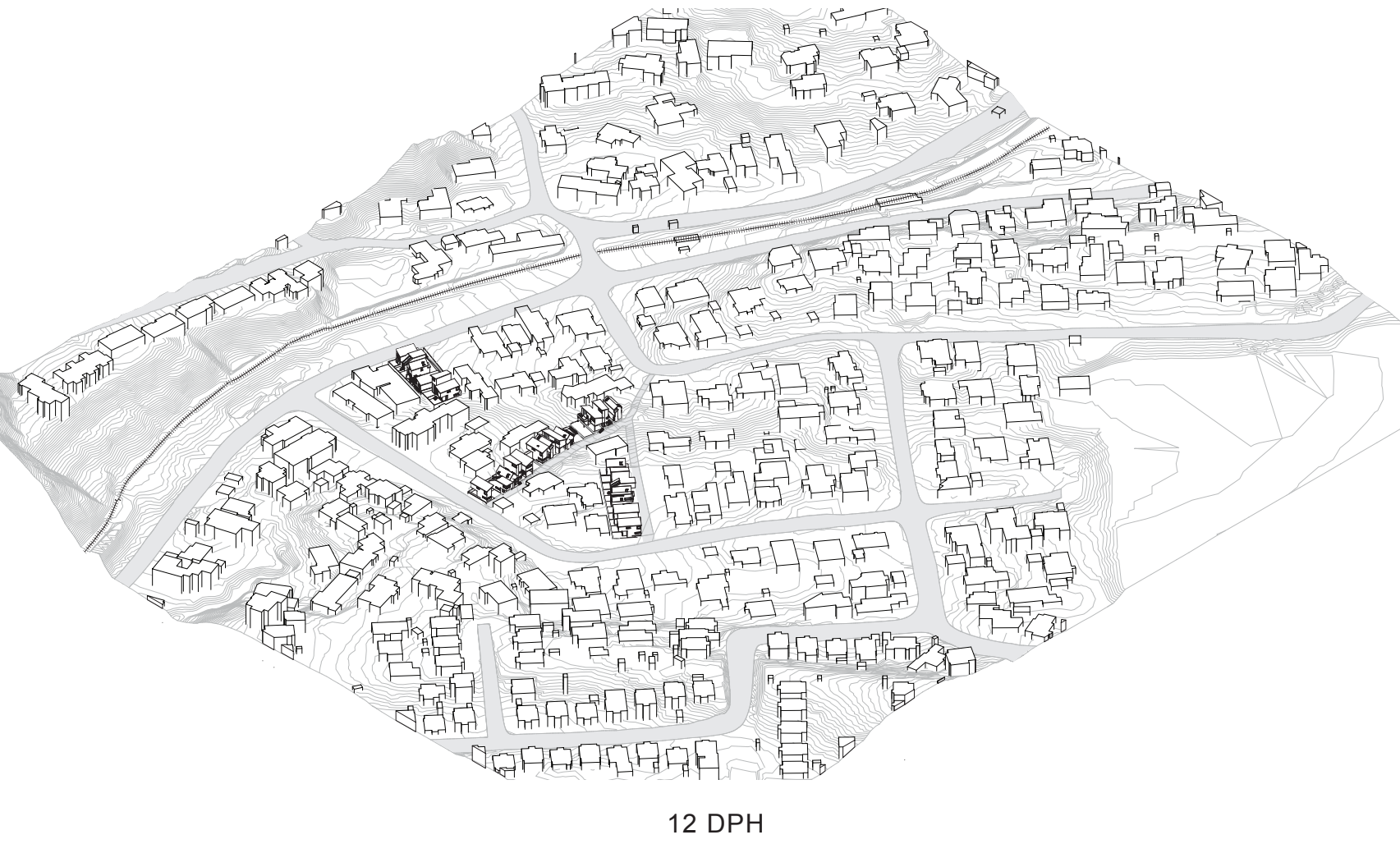

CURRENT SUBURBAN GRID WITH

SITE 1,2+3 INFILL DEVELOPMENT

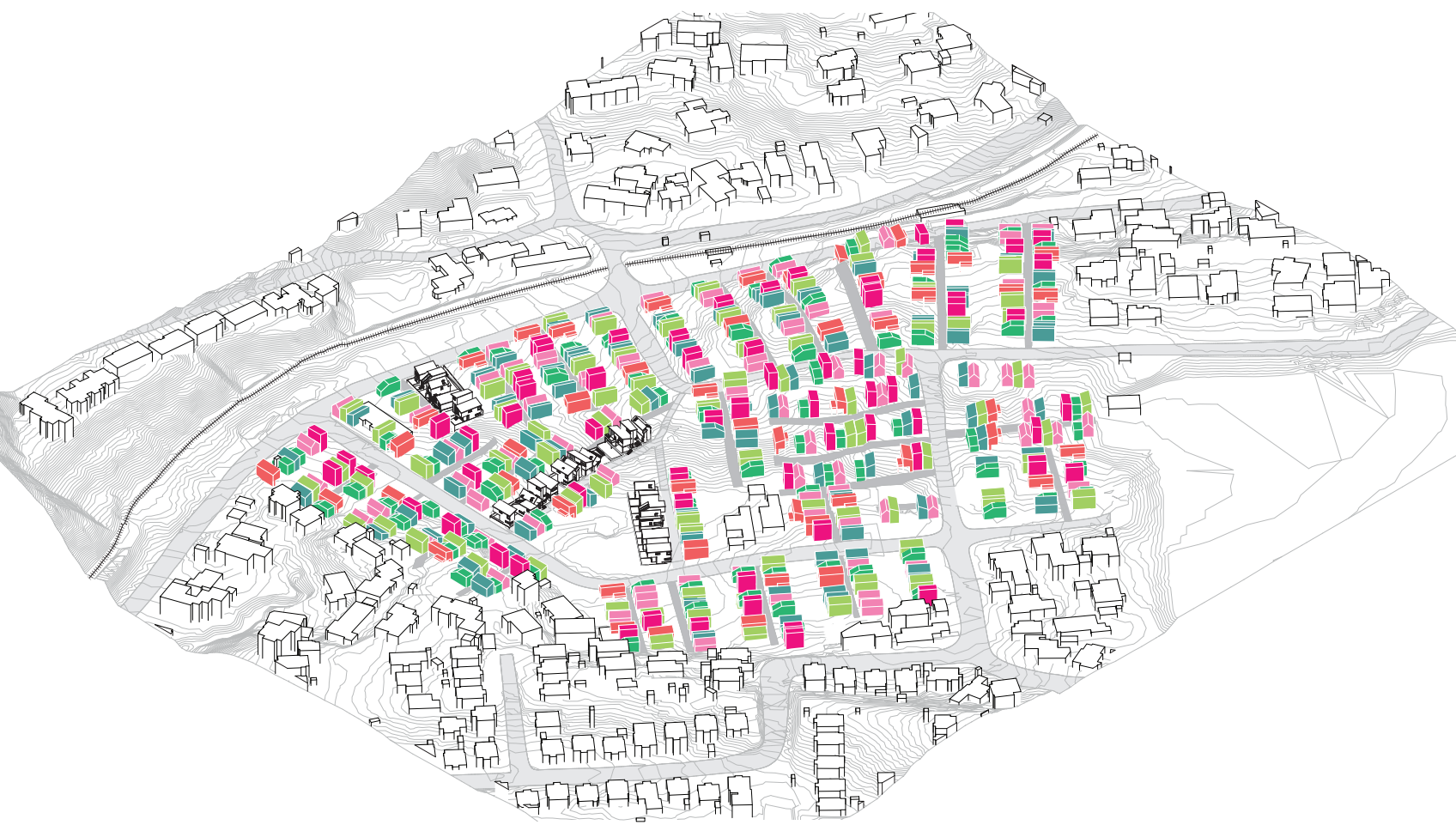




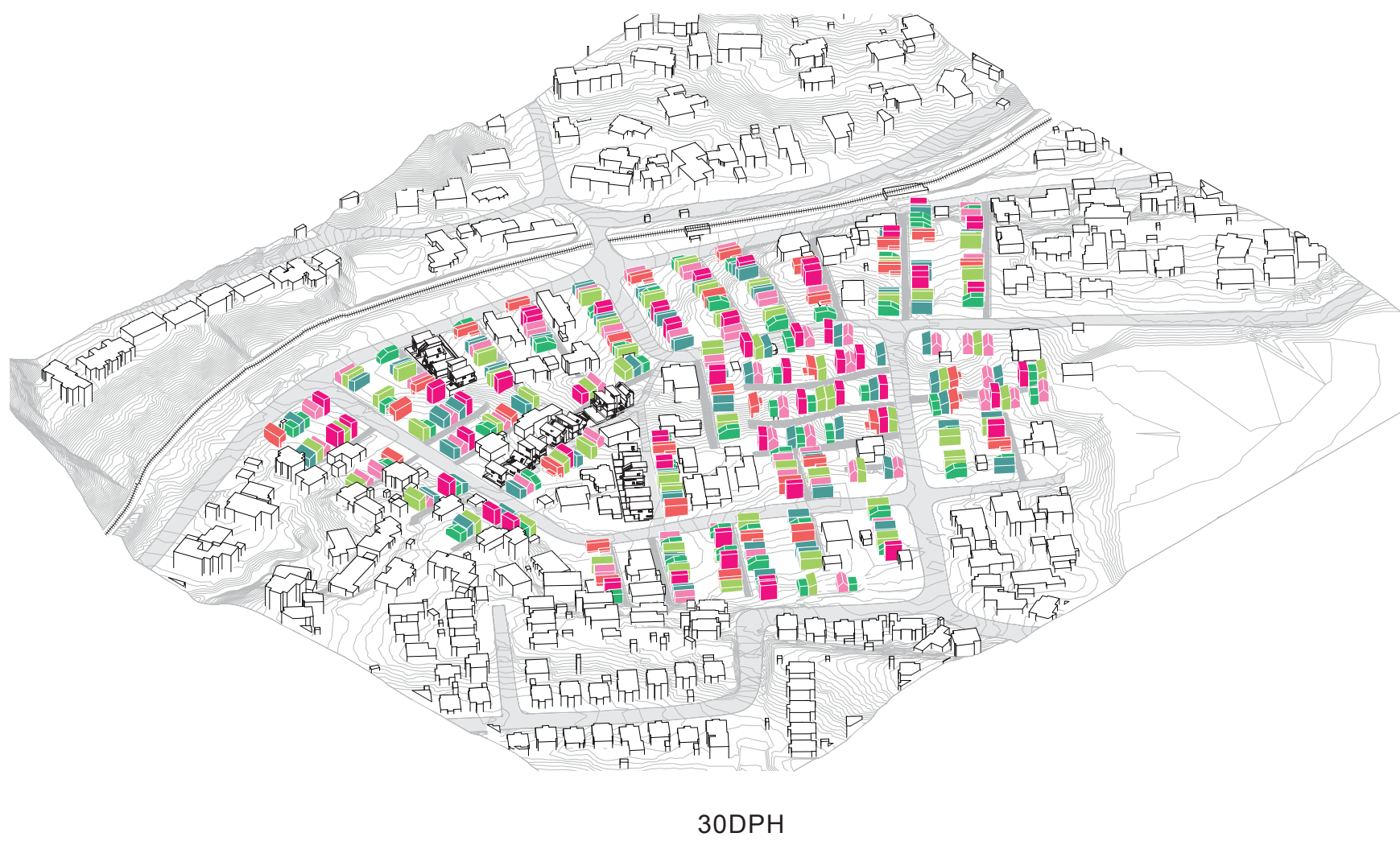

FIT BETWEEN SITE QUALITIES AND DESIGN DENSITY INCREASE

\section{IMPLICATIONS OF THE SUBURB}

The design research has resulted in a proposed new cluster housing typology for small dwellings within an existing suburban context. A set of modified district plan rules has also been produced to facilitate application of an intensification strategy for Khandallah.

Through massing studies of the area, a maximum infill density was tested at $40 \mathrm{DPH}$ or 4 times the current building density. This was to first understand the implications of the proposal and what an appropriate maximum density could be.

Then testing reduced density to fit between site qualities and an appropriate increase, a massing of $30 \mathrm{DPH}$ or 3 times the current building density. Sites less desirable for intensification were eliminated, these included qualities such as poor orientation, site access, steep gradient and small area.

Fig 7.08. 


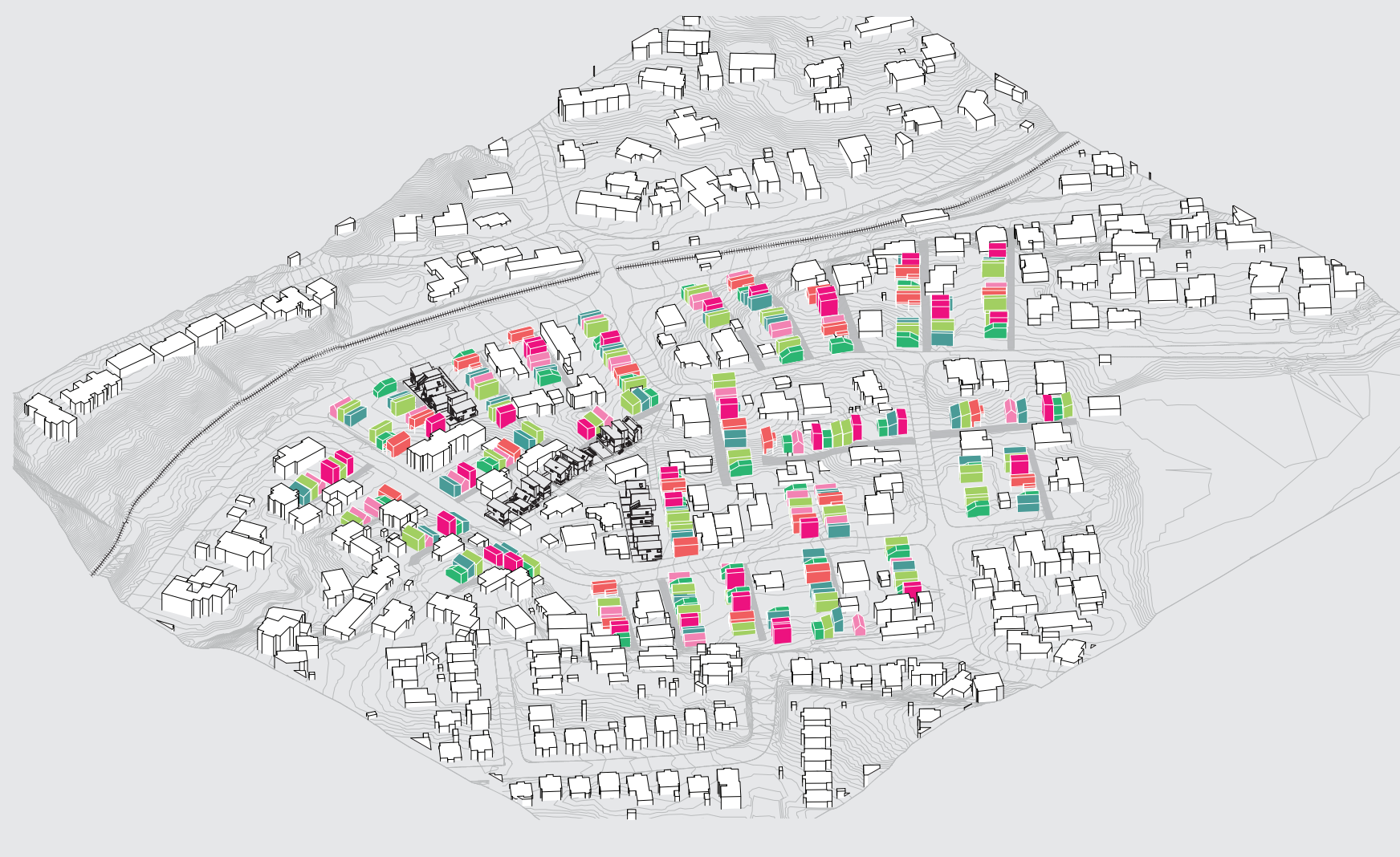

24DPH

FINDING A NEW HIGHER DENSITY RETAINING

A SENSE OF ORIGINAL CHARACTER 
The next design test reduced density further. It eliminated sites adjacent to an infilled site. Unless a lane created a through site thoroughfare, these would otherwise be too dense for one accessway. Sites of irregular shape were also eliminated. This produced a proposed density of 24 dwellings per hectare, double the existing suburb density while retaining a strong sense of the suburbs character for the existing affluent suburb.

This density would facilitate increased housing diversity and affordability within this desirable, near to the city, well serviced suburban environment.

The propsed new district plan rules would facilitate a mix of zones within a suburb. For Khandallah, an outer residential zone, sites that fit the below categories would classify for the zone change:

These sites must

- Have a width no less than $16 \mathrm{~m}$

- Have a slope no more than $8^{\circ}$

- Be located close to/have access to public transport nodes

Sites that classify for the zone change would have a new set of rules, set out as follows:

- Minimum subdivision dimensions $5 \times 11 \mathrm{~m}$

- Minimum $2 \mathrm{~m}$ setback from front, side and backyards

- Minimum $4 \mathrm{~m}$ accessway located South or East of the site

- A max of 3 clustered private dwellings for every outdoor common zone

- Max $9 \mathrm{~m}$ building height and recession plane at $63^{\circ}$

Fig 7.09.

*Massing analysis outcome 


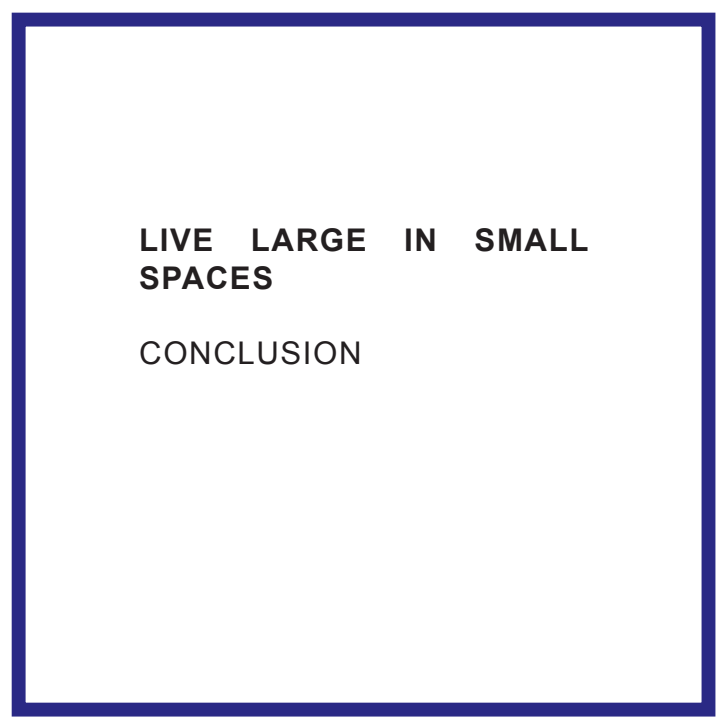




\section{A CLUSTERED HOUSING TYPOLOGY}

It is essential that the idea of 'small house living' is resolved through specific site based design, as multiple factors contribute to the success of a small space. Its efficiency and functionality can be measured through varying scales of intimacy and detail. The idea of living large in small spaces not only requires the design and critique of a small home, but also the relationship a house has with its nearby neighbouring houses and how to cater for what is 'lost' when downsizing our homes.

The dwellings were proven to be significantly more affordable than the current lower Quartile home in Wellington $(\$ 465,300)$ and Khandallah $(\$ 923,100)$ - The most expensive is calculated at a cost of $\$ 400,000$ and the most affordable came to $\$ 295,000$. This is two thirds the cost of the existing Wellington innercity suburban housing, and a third the cost of the typical Khandallah house. The affordability analysis was calculated from data retrieved from LINZ and conservative assumptions made for estimates of a cost per m2. Detailed costing analysis for the project was beyond the scope of the research at this stage. If the research were to advance further in future, an analysis of affordability would be calculated with a detailed elemental design in materials, construction and running costs (household costs, transport and utilities) - which would also allow a stronger aesthetic development through the visual potential of construction. The analysis is detailed enough to provide clear evidence that living large in small spaces can significantly improve affordability of New Zealand housing. It offers a solution to improve New Zealand's house crisis. It provides an opportunity for the younger generation such as myself, to realise the dream of homeownership, and gives opportunities for older Khandallah residents to downsize but remain in their community.

The design research proposes a new cluster housing typology for small dwellings within a suburban context. It also advocates a new set of strategies to apply an intensification strategy for Khandallah. The research was conducted through 5 scales of design resolution resulting in increased detail and rigour as the research unfolds.

A range of flexible, compact designs, the small home has tested and distilled a range of design principles and guidelines for efficient design that ensures a level of comfort, stability and quality of affordable housing that is missing in New Zealand's current market. The houses were resolved through an iterative process, with key factors considering storage, access to natural light, indoor outdoor flow, materials, colours and multi-use of space. The models, each on their own site, while compact, are spacious and flexible and accommodate a level of individuality and diversity catering for the sense of place and security that homeownership provides in New Zealand. 
The research found that adopting a revised rule based minimum subdivision grid for existing sites, helped to ensure a reasonable minimum ratio between houses private outdoor spaces. This was augmented by provision of some common external space. The common space was vital to ensure the intensification scheme provided high qualities of open space and shared amenity between residents.

The rule based subdivision can be replicable among various sites of size, orientation and gradient, sustaining an argument for compact cities and the numerous benfits of intensification - more sustainable use of land, higher transport efficiency and greater social cohesion - providing greater diversity of residential buildings and a range of housing typologies to support the needs of the growing population. The range of dwellings support adaptable living for a younger demographic who are wanting to get started on the property ladder.

Khandallah is situated in the Outer residential Zone. The research provides a convincing argument for a zone change in some areas of Khandallah, so that an increased level of intensification can be implemented. Current regulations for building setbacks, height restrictions, street frontage and site coverage are limiting the potential of site utilisation and could be reconsidered for the intensification strategy when linked with good design. The design demonstrates that altering these rules will not adversely affect neighbouring properties and will benefit the existing amenity and comfort and better utilise existing infrastructure. 


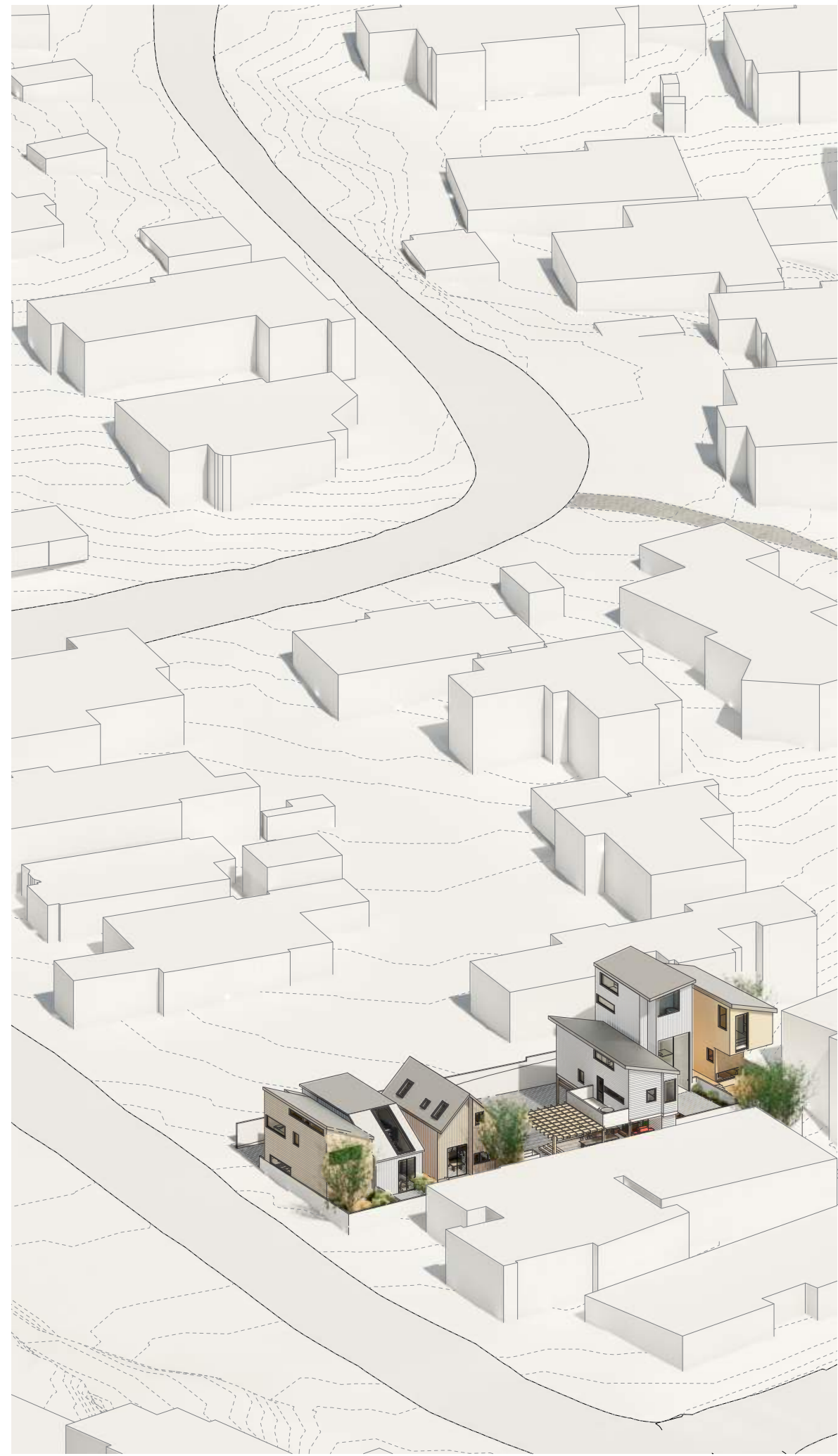




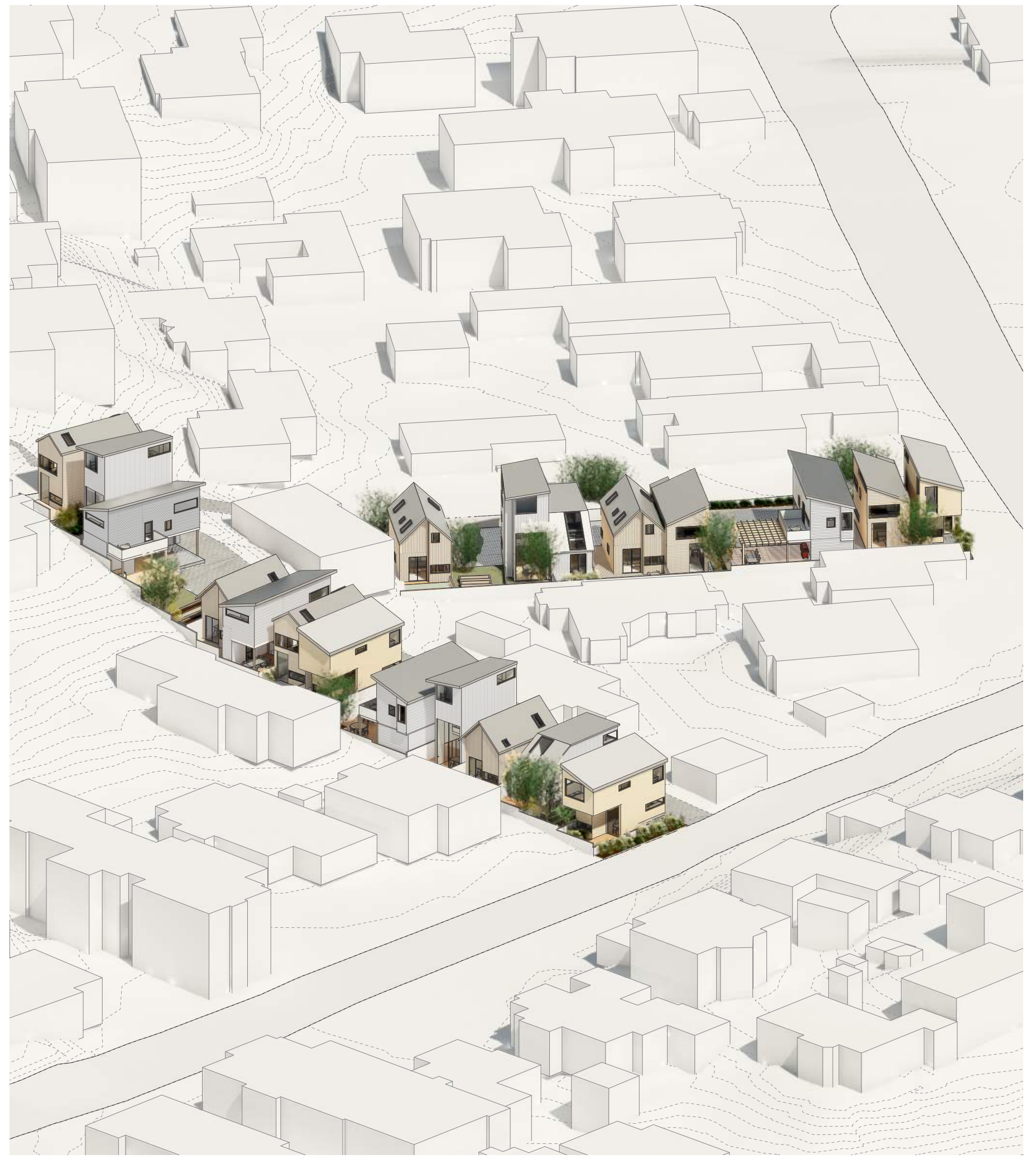




\section{BIBLIOGRAPHY}

.id. (2013). Kaiwharawhara - Khandallah - Broadmeadows

Population, households and dwellings. http://forecast.idnz.co.nz/ wellington/population-households-dwellings?WebID $=180$

.id. (2017). Newtown Dwelling type. http://profile.idnz.co.nz/wellington/ dwellings?WebID $=330$

Atorie, W. (2010). Behaviorology / Atelier Bow-Wow

Yoshiharu Tsukamoto + Momoyo Kaijima. New York: New York : Rizzoli.

Badcock, B. (2014). Sarah Bierre, Philippa Howden-Chapman \&amp Lisa Early (ed.)(2013) 'Homes people can afford. How to improve housing in New Zealand'. Steele Roberts Publishers. New Zealand sociology (Online), 29(1), 202-205.

Bakke, R. (2016). Which Suburb In Wellington Has The Highest Median House Price? https://blog.homes.co.nz/wellington-median-house-priceby-suburb/

Bruce, G. (2014). Our New Society. Retrieved from New Zealand Geographic website: https://www.nzgeo.com/stories/our-new-society/

Case, N. C., Dennis ; Donald, Sam; Kebbell, Sam; Southcombe, Mark (2015, 21/05/2015) Launch Pad 1: Affordable Housing/Interviewer: A. Centre.

Chaston, D. (2016). Home loan affordability for first-home buyers - New Zealand. Retrieved from https://www.interest.co.nz/property/first-homebuyer

Chaston, D. (2016). First home buyer affordability report Wellington the interest.co.nz Home Loan Affordability series.

Cocoro. (2008). Small house Tokyo : how the Japanese live well in small spaces. Tokyo, Japan]: Tokyo, Japan : Cocoro Books.

Wellington City Council. (2016). Khandallah as a medium-density housing area. Retrieved from https://wellington.govt.nz/your-council/projects/ housing-choice-and-supply/khandallah/khandallah-as-a-medium-densityhousing-area

Wellington City Council. District Plan - Volume 1: Objectives, Policies \& Rules, (2017). Retrieved from https://wellington.govt.nz/ /media/ your-council/plans-policies-and-bylaws/district-plan/volume01/files/ v1chap05standards.pdf?la=en

Dalziel, R., Cortale, S. Q., \& Battle, T. (2012). A house in the city : home truths in urban architecture / Robert Dalziel and Sheila Qureshi Cortale edited by Tim Battle. London: London : RIBA Publishing.

Eaqub, S., \& Eaqub, S. (2015). Generation rent: rethinking New Zealand's priorities / Shamubeel Eaqub and Selena Eaqub: Wellington, New Zealand : Bridget Williams Books.

Edwards, J. (2015). Heated debate at Khandallah housing meeting: The Dominion Post. 
Eriksen, A. (2013). Kiwis still crave slice of suburbia. Retrieved from http:// www.charactercoalition.org.nz/kiwis-still-crave-slice-of-suburbia/

excellence, R. R.-P. m. (2010). Wellington Suburb Profile. http://www. rentalresults.co.nz/Suburb-Profiles/wellington-suburb-profile.html

Foster, C. (2015). Small house living / Catherine Foster: Auckland Penguin Books.

Foster, C. (2017). Small house living Australia / Catherine Foster: Australia Penguin Books.

The Design Guide. (2016). The New Suburban Dream. Retrieved from http://www.designguide.co.nz/issue-06-out-now-the-new-suburbandream/

Harada, J. (2011). The lesson of Japanese architecture / Jiro Harada edited by C.G. Holme. Milton Keynes: Milton Keynes : Studio.

Harris, C. (2016). NZ tops IMF's housing unaffordability list Retrieved from http://www.stuff.co.nz/business/money/83750475/nz-topsimfs-housing-unaffordability-list

Hildner, C. (2014). Future living : collective housing in Japan / Claudia Hildner translation, Steven Lindberg: Basel : Birkhäuser.

Howden-Chapman, P. (2015). BOOK EXTRACT: Home Truths: Big ideas to tackle the housing crisis Home Truths: Big ideas to tackle the housing crisis: BWB Bridget Williams Books.

Howden-Chapman, P. (2015). Home truths : confronting New Zealand's housing crisis / Philippa Howden-Chapman (1st edition.. ed.). Wellington: Wellington, New Zealand: Bridget Williams Books Limited.

Infrastructure New Zealand. (2016). Old "pavlova paradise" thinking a hurdle to affordable housing target. Retrieved from https://www. infrastructure.org.nz/media-releases/3773505

Kenneth R. Tremblay, J. L. v. B. (1997). Small house designs / edited by Kenneth R. Tremblay, Jr. \& Lawrence von Bamford. Pownal, Vt.: Pownal, Vt. : Storey Communications.

Laxon, A. (2016). Home Truths: Big ideas to tackle the housing crisis.

Urban Perspectives Ltd. (2016). Khandallah Character Assessment. Retrieved from http://planningoursuburbs.org.nz/assets/images-and-files/ documents/files-documents/khandallah-character-assessment.pdf

Monash University. (2011). Infill Opportunities Design Research Report.

Ninnes, G. (2017). The interest.co.nz Home Loan Affordability series. Retrieved from http://www.interest.co.nz/sites/default/files/WellingtonCityMarch 17.pdf

NZIQS. (2016). QV Costbuilder Data Shows Building Costs Jumped $20.0 \%$ During The Christchurch Rebuild.

Page, I. (2008). Whats changing in housing needs. Build, no. 130, 31.

Page, I. (2009). Housing Affordability. Build, no. 114, 60. 
Page, I. (2012). Housing - Then and Now. Build, no. 130, 37.

Page, I. (2014). What's Behind Rising Prices? Build, no. 140, 41-55.

Page, I. (2015). Stats tell the story. Build, no. 150, 49,50.

Page, I. (2016). Growth in MDH. Build, no. 154, 48.

QV. (2017). Khandallah Statistics. https://www.qv.co.nz/suburb/ khandallah-wellington-686/sold

Rawlinsons. (2014). NZ Construction Handbook 2013/14.

Shelton, L. (2015). Medium-density housing planned for Khandallah, Newlands, Island Bay. Retrieved from http://wellington.scoop. co.nz/?p=81550

Sherwood, R. (1978). Modern housing prototypes / Roger Sherwood. Cambridge, Mass.: Cambridge, Mass. : Harvard University Press.

Statistics New Zealand. (2014). 2013 Census QuickStats about housing. Retrieved from www.stats.govt.nz

Stuart, K., Thompson-Fawcett, M., \& New Zealand Centre for Sustainable, C. (2010). Tāone tupu ora : indigenous knowledge and sustainable urban design / edited by Keriata Stuart \& Michelle Thompson-Fawcett. Wellington, N.Z.: Wellington, N.Z. : Steele Roberts.

Sullivan, P. (2016). Medium density residential areas - an 'all or nothing' vote. Retrieved from http://wellington.scoop.co.nz/?p=87183

Tarbatt, J. (2012). The plot: designing diversity in the built environment : a manual for architects and urban designers / Jonathan Tarbatt. London: London : RIBA Publishing.

MVRDV. (2015+). TRAUMHAUS FUNARI. https://www.mvrdv.nl/en/ projects/traumhaus-funari

MVRDV. (2003). HAGEN ISLAND. https://www.mvrdv.nl/projects/hagen

Westpac. Westpac affordability calculator. https://www.westpac. co.nz/home-loans/calculators/how-much-can-i-afford/? utm_ source=homesnz\&utm_medium=display\&utm_content=hnz_partnership_ homepage_tile_click\&utm_campaign=homesnż_homeloans_partnership

Wietzorrek, U. (2010). Housing+ : threshold, access and transparency in residential buildings / edited by Ulrike Wietzorrek. Basel : London: Basel : Birkhäuser London : Springer distributor. 


\section{LIST OF FIGURES \\ PREFACE}

Fig A

9tsubo House

Source: Authors collection

CH 01

Fig 1.01 .

Global house price to income ratio, Authors edit

Source: http://www.stuff.co.nz/business/money/83750475/nz-tops-imfshousing-unaffordability-list

Fig 1.02.

Typical suburban model of standalone houses

Source: Authors collection

Fig 1.03 .

Low density suburb Khandallah

Source: https://www.google.co.nz/maps/place/

Khandallah,+Wellington+6035/@-41.246394,174.774863,1925m/data=!3

$\mathrm{m} 1$ ! $1 \mathrm{e} 3$ ! $4 \mathrm{~m} 5$ ! $3 \mathrm{~m} 4$ ! $1 \mathrm{~s} 0 \times 6 \mathrm{~d} 38 \mathrm{ada} 46 \mathrm{a} 60 \mathrm{~b} 693: 0 \times 500$ ef6143a2d530!8m2!3d41.2442571!4d174.7911353. (Accessed 21/11/17)

Fig 1.04 .

Medium density suburb Newtown

Source: https://www.google.co.nz/maps/place/

Newtown,+Wellington+6021/@-41.313347,174.7759702,2277m/data=!3 $\mathrm{m} 1$ ! 1 e3!4m5!3m4!1s0x6d38afe72ecf2605:0x500ef6143a2ea30!8m2!3d41.3109306!4d174.7790121. (Accessed 21/11/17)

Fig 1.05 .

Research Methodology

Source: Authors collection

\section{$\mathrm{CH} 02$}

Fig 2.01 .

Combination of The Bachelor Pad photos and Authors diagrams

Source: http://colabarch.co.nz/project/armagh. (Accessed 6/03/17)

Fig 2.02.

Combination of The Nine Tsubo House photos and Authors diagrams Source: https://www.wiredogarchitecture.co.nz/island-bay-house. (Accessed 6/03/17)

Fig 2.03.

Combination of The Office Rd Hut photos and Authors diagrams Source: http://blackhut.co.nz/the-hut-designs/the-office-rd-hut/. (Accessed 6/03/17)

Fig 2.04 .

Combination of The Warrander Studio photos and Authors diagrams Source: http://www.makersofarchitecture.co.nz/warrander-studio/. (Accessed 6/03/17) 
Fig 2.05.

Combination of The City Bach photos and Authors

diagrams and floor plans

Source: http://melling-architects.co.nz/portfolio-

item/citybach/ (Accessed 6/03/17)

Fig 2.06.

Floor plan diagrams

Source: Authors collection

Fig 2.07.

Matrix diagrams for space efficient design

principles

Source: Authors collection

\section{$\mathrm{CH} 03$}

Fig 3.01 .

Small House iterations

Source: Authors collection

Fig 3.02.

a Khandallah Rd looking towards site

b Site view from street

Source: Authors collection

Fig 3.03.

Khandallah Rd

Source: Authors collection

Fig 3.04.

Wellington house prices by suburb. Authors own edit.

Source: https://blog.homes.co.nz/wellington-median-house-price-bysuburb/. (Accessed 29/03/17)

Fig 3.05.

Khandallah town centre walking catchments

Source: Authors collection

Fig 3.06.

Aerial view of site

Source: Authors collection

Fig 3.07.

Aerial view of site

Source: Authors collection

Fig 3.08.

Site context

Source: Authors collection 
Fig 3.09.

Design massing iterations

Source: Authors collection

Fig 3.10.

Experimental design overview

Source: Authors collection

Fig 3.11.

Experimental design ground plan

Source: Authors collection

Fig 3.12.

Proposal for an affordable project

Source: Authors collection

Fig 3.13.

Graph - Housing affordability index, Authors edit

Source: Page, I. (2015). Stats tell the story. Build, no. 150, 49,50.

Fig 3.14.

Graph - New house cost components, Authors edit

Source: Page, I. (2014). What's Behind Rising Prices? Build, no. 140, 41-55.

Fig 3.15.

Graph - House price index, Authors edit

Source: Page, I. (2009). Housing Affordability. Build, no. 114, 60.

Fig 3.16.

Concept design house sizing

Source: Authors collection

Fig 3.17.

Demographic diagram

Source: Authors collection

Fig 3.18.

Affordability analysis by income and house cost

Source: Authors collection

\section{CH 04}

Fig 4.01 .

Sketches for development

Source: Authors collection

Fig 4.02.

Exploration between private and common space

Source: Authors collection

Fig 4.03.

How the common space might be utilised

Source: Authors collection 
Fig 4.04.

Parking options

Source: Authors collection

Fig 4.05.

Phase 2 development iterations

Source: Authors collection

Fig 4.06.

Initial design

Source: Authors collection

Fig 4.07.

Ground floor site plan

Source: Authors collection

Fig 4.08.

Floor plans

Source: Authors collection

Fig 4.09.

Initial design, Site 1, Exterior perspective

Source: Authors collection

Fig 4.10.

Plot amalgamation and subdivision options, Authors edit.

Source: Tarbatt, J. (2012). The plot: designing diversity in the built environment : a manual for architects and urban designers / Jonathan Tarbatt. London: London : RIBA Publishing.

Fig 4.11.

Principal block typologies, Authors edit.

Source: Tarbatt, J. (2012). The plot : designing diversity in the built environment : a manual for architects and urban designers / Jonathan Tarbatt. London: London : RIBA Publishing.

\section{CH 05}

Fig 5.01.

Wellington suburbs map key

Source: Authors collection

Fig 5.02 .

Density per hectare analysis

Source: Authors collection

Fig 5.03 .

Urban Perspectives Khandallah study zone, Authors edit

Source: Ltd, U. P. (2016). Khandallah Character Assessment. Retrieved

from http://planningoursuburbs.org.nz/assets/images-and-files/

documents/files-documents/khandallah-character-assessment.pdf 
Fig 5.04 .

Existing housing Khandallah, Authors edit

Source: https://www.google.co.nz/maps/@-

41.2433437,174.7916423,639m/data=!3m1!1e3. (Accessed 9/06/17)

Fig 5.05 .

Traumhaus Funari, renders and diagrams by the architects MVRDV Source: https://www.mvrdv.nl/en/projects/traumhaus-funari (Acessed 2/07/17)

Fig 5.06.

Hagen Island, renders and diagrams by the architects MVRDV.

Source: https://www.mvrdv.nl/projects/hagen (Acessed 2/07/17)

Fig 5.07 .

Growth development - Infill Opportunities

Source: Monash University. (2011). Infill Opportunities Design Research Report.

Fig 5.08.

Shared zoning - Infill Opportunities, Authors edit

Source: Monash University. (2011). Infill Opportunities Design Research Report.

Fig 5.09.

Perspective - Infill Opportunities

Source: Monash University. (2011). Infill Opportunities Design Research Report.

Fig 5.10 .

Site 1 redevelopment perspective overview

Source: Authors collection

Fig 5.11.

Translation of the Melbourne infill subdivision for Site 1

Source: Authors collection

Fig 5.12.

Site 1, site Plan

Source: Authors collection

Fig 5.13.

Site 1, Section 1

Source: Authors collection

Fig 5.14.

Dwelling 1 Plans

Source: Authors collection

Fig 5.15.

Dwelling 2 Plans

Source: Authors collection 
Fig 5.16.

Dwelling 2 interior render

Source: Authors collection

Fig 5.17.

Dwelling 3 interior render

Source: Authors collection

Fig 5.18.

Dwelling 3 Plans

Source: Authors collection

Fig 5.19.

Dwelling 4 Plans

Source: Authors collection

Fig 5.20.

Dwelling 5 interior render

Source: Authors collection

Fig 5.21.

Dwelling 5 Plans

Source: Authors collection

Fig 5.22.

Dwelling 6 Plans

Source: Authors collection

Fig 5.23.

Site 1, Section 2

Source: Authors collection

Fig 5.24.

Site 1, Perspective entering site

Source: Authors collection

Fig 5.25.

Site 1, Perspective of common space

Source: Authors collection

Fig 5.26.

Site 1, Physical model

Source: Authors collection

\section{CH 06}

Fig 6.01.

Map of potential test sites and surrounding context

Source: Authors collection

Fig 6.02.

Aerial view of site 2 and $3 /$ Site subdivision and dwelling placement

Source: Authors collection 
Fig 6.03.

Diagrams for analysis and development of site 2 and 3 Source: Authors collection

Fig 6.04.

Site 2, Elevation

Source: Authors collection

Fig 6.05.

Site 2 and 3 , Site plan

Source: Authors collection

Fig 6.06.

Site 2, Perspective of common space

Source: Authors collection

Fig 6.07 .

Site $2+3$, Perspective overview

Source: Authors collection

Fig 6.08 .

Site 2, Affordability analysis

Source: Authors collection

Fig 6.09.

Site 2, Perspective elevation overview

Source: Authors collection

\section{CH 07}

Fig 7.01.

Models at 1.20 scale

Source: Authors collection

Fig 7.02 .

House 2 physical model

Source: Authors collection

Fig 7.03.

House 2 Plans

Source: Authors collection

Fig 7.04.

House 3 physical model

Source: Authors collection

Fig 7.05.

House 3 Plans

Source: Authors collection

Fig 7.06.

Site 1 Street Elevation

Source: Authors collection 
Fig 7.07.

District plan rules and regulations proposal change for Khandallah suburb

Source: Authors collection

Fig 7.08 .

Massing analysis of the suburb

Source: Authors collection

Fig 7.09.

Massing analysis outcome

Source: Authors collection

Fig 7.10.

Final Design overview

Source: Authors collection 